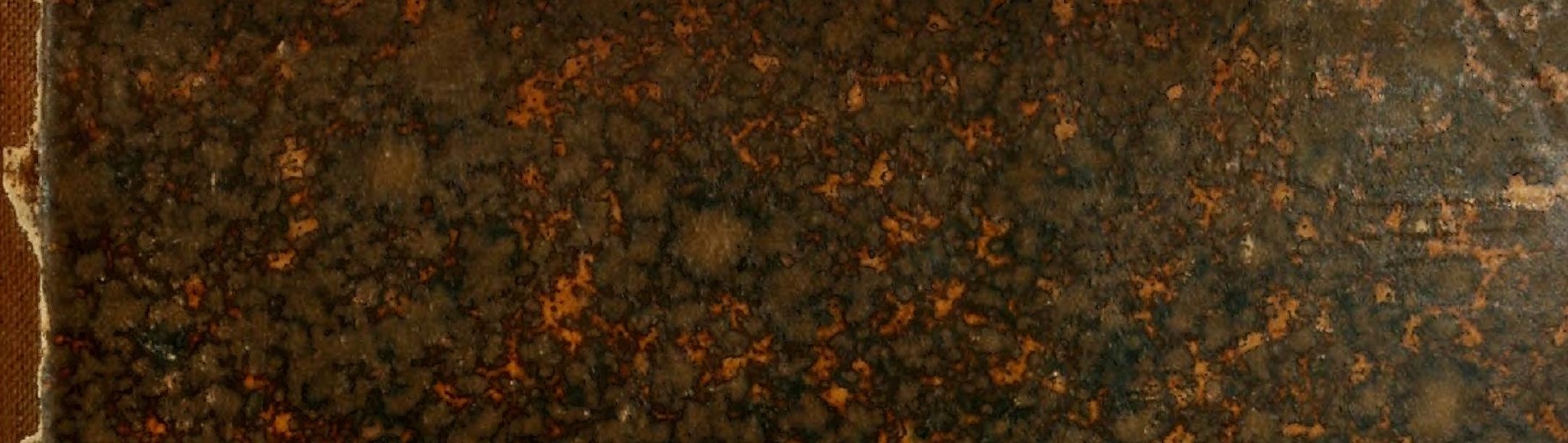

(i)

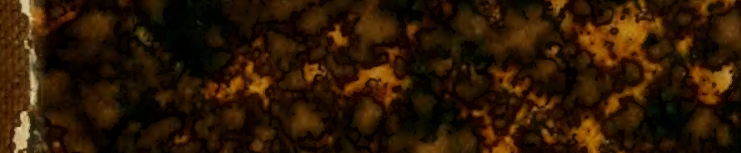

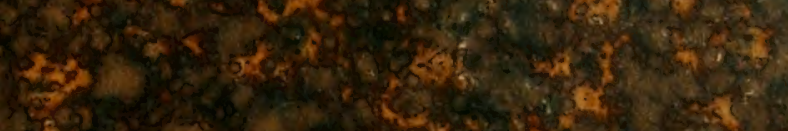

tes

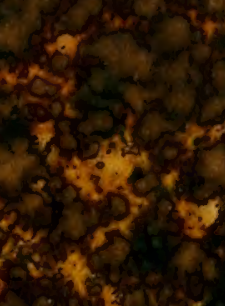

1. 1.5.

if.

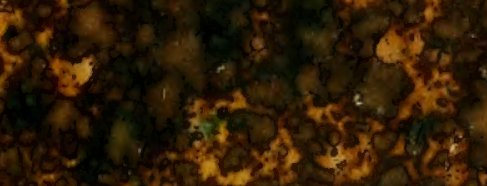

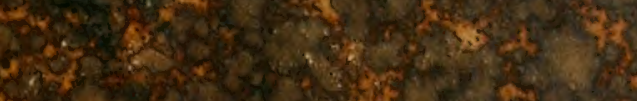

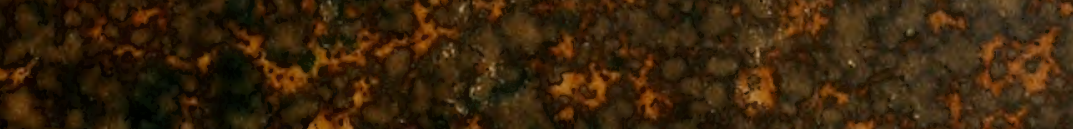

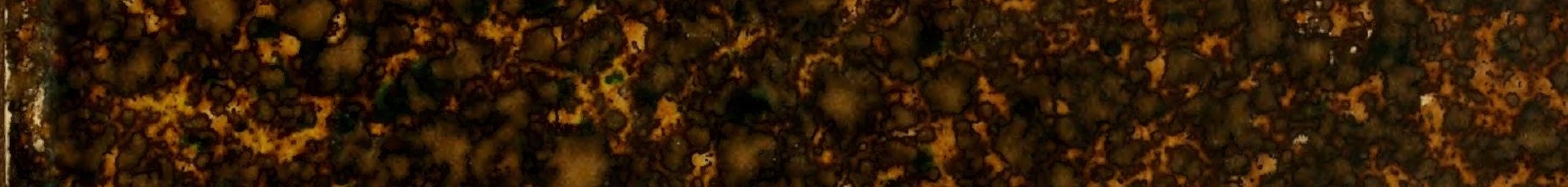

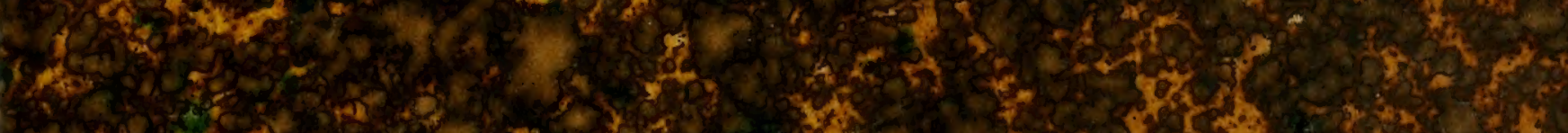

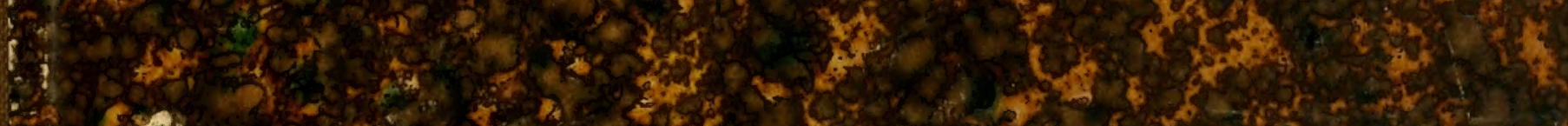

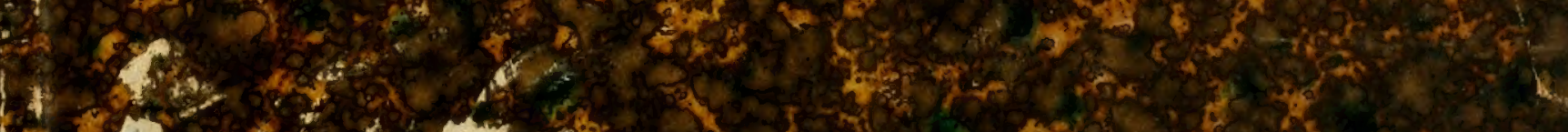

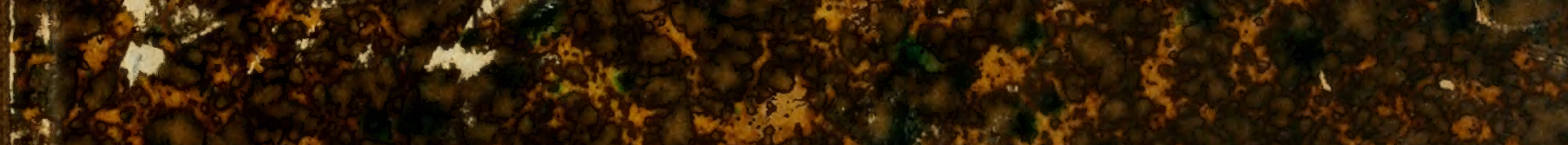

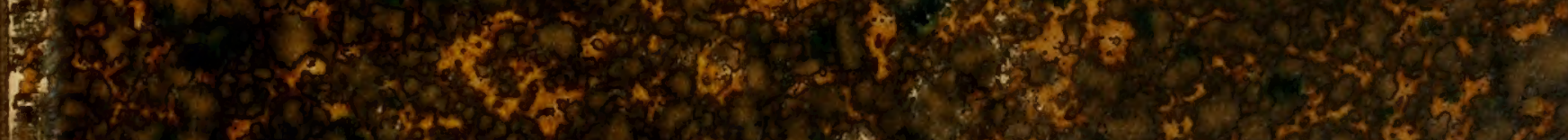

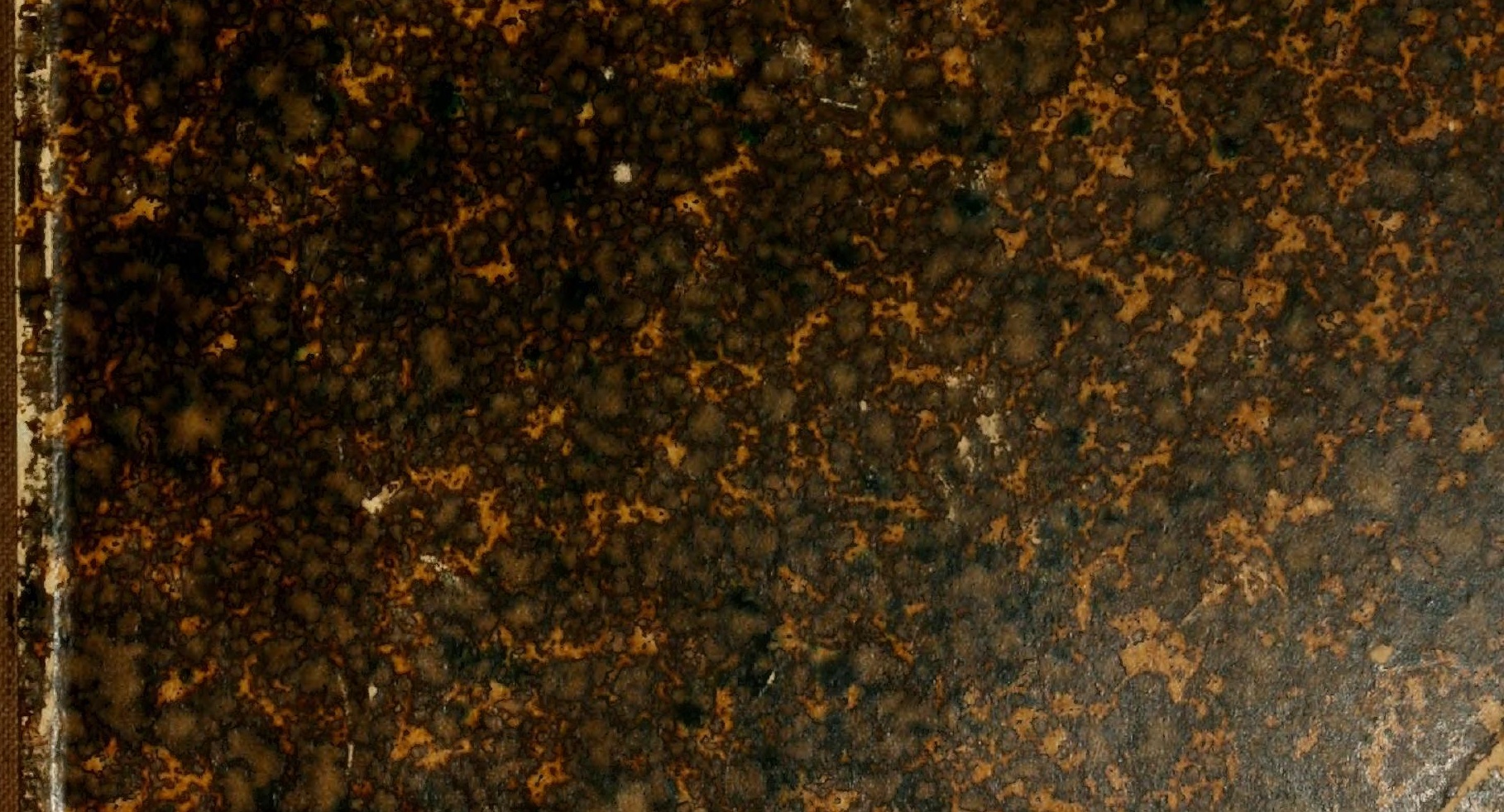




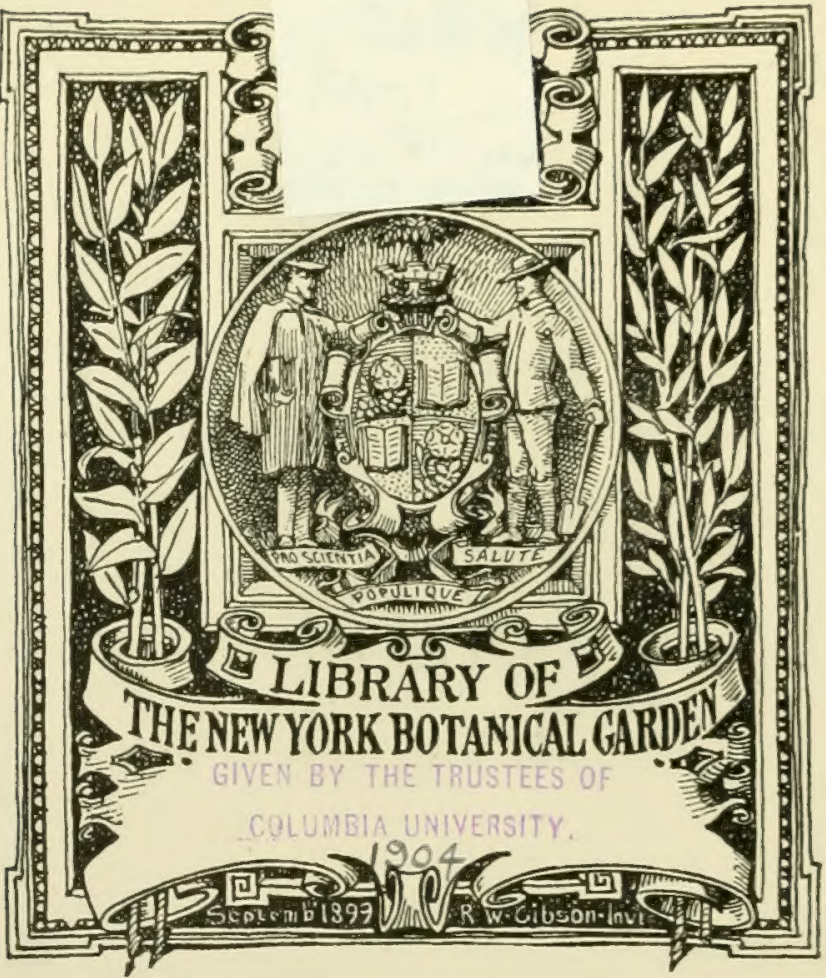








\section{TH E SOURCE $\mathrm{S}$ F}

THE

\section{N I T R OGEN OF VEGETA TION;}

WITH SPECIAL REFERENCE TO THE QUESTION WHETHER PLANTS ASSIMILA'TE FREE OR UNCOMBINED NITROGEN.

BY

JOHN BENNET LAWES, F.R.S., F.C.S., JOSEPH HENRY GILBERT, PH.D., F.R.S., F.C.S., AND EVAN PUGH, Ph.D., F.C.S.

From the PHILOSOPHICAL TRANSAC'TIONS.-PART II. 1861.

\section{LONDON :}

PRINTED BY TAYLOR AND FRANCIS, RED LION COURT, FLEET STREEI: 1862. 
ON

\section{T H E S 0 U R C E S O F}

THE

\section{N I T R OGE O F VEGETA T ION;}

WITH SPECIAL REFERENCE TO THE QUESTION WHETHER PLANTS ASSIMILATE FREE OR UNCOMBINED NITROGEN.

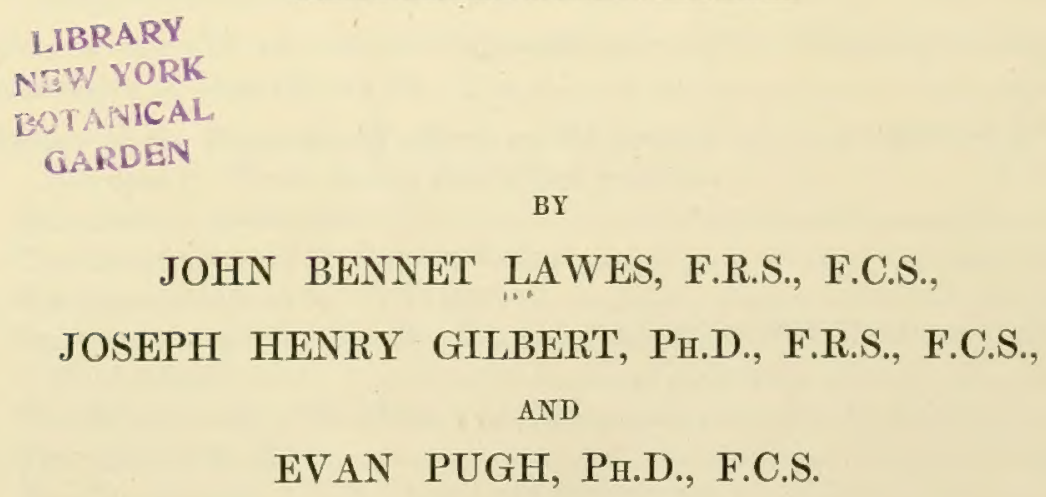

From the PHILOSOPHICAI TRANSACTIONS.-PART II. 1861.

\section{LONDON:}

PRINTED BY TAYLOR AND FRANCIS, RED LION COURT, FLEET STREET. 1862. 
. 435

1862 


\section{[ 431 ]}

XXIII. On the Sources of the Nitrogen of Vegetation; with special reference to the Question whether Plants assimilate Free or uncombined Nitrogen. By Joнr Bexset Lawes, F.R.S., F.C.S., Josepu Henry Gilbert, Ph.D., F.R.S., F.C.S., and Evali Pugir, Ph.D., F.C.S.

Receired June 21,--Read June 21, 1860.

Contents.

PART FIRST.

GENERAL IISTORY, AND STATEMENT OF THE QUESTION.

SEorrox I.-Introduction, and carly History .................................................. Pago $433-135$

Bectiox II.-Annual yicld of Nitrogen per acre, in different Crops:-

A. Yield of Nitrogen per acre when the same crop is grown year after year, on the same land ...............................................................

B. Yield of Nitrogen per acre when Wheat is grown in alternation with Beans, or with Fallow

$435-435$

C. Field of Nitrogen per acre when crops are grown in an actual course of Rotation $439-110$

D. Relation of the increased yield of Nitrogen in the produce, to the amount supplied, when nitrogenous manures are employed ................................

$410-412$

Sectios III.-General view of the various actual or possible sources of the Nitrogen of our crops :-

Enumeratiou of, observations, \&c.

$442-417$

SEOTIOs IV.-Review of the Researches of others, on the question of the assimilation of Free Nitrogen by Plants, and on some allied points:-

Intruductory observations :

447

A. The Experiments of M. BoustixGaUdT .....................................

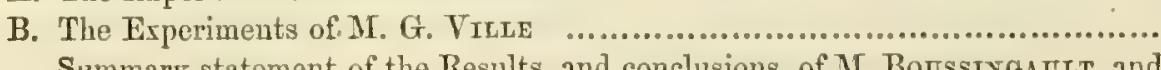

Summary statement of the Results, and conclusions, of M. Boussiva $\Delta$ ULT, and M. G. VILLE

$448-455$

$455-463$

C. The Experiments of M. Mìne

$463-464$

D. The views of $M$. Ror

E. The Esperiments of MM. Clozz and Gratrolet

464

$461-465$

F. The Experiments of M. De.LuCA.

465

1. Whe Expen

$465-460$

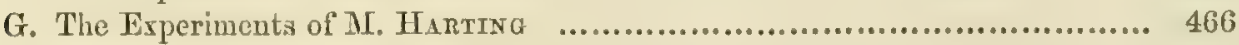

II. Experiments recorded by MI. A. Petziroldt .................................. 467

Concluding observations

$467-468$

\section{PART SECOND.}

\section{EXPERIMENTAL RESULTS OBTAINED AT ROTHAMSTED, DURING TIIE FEARS 1S氵7,} 1858, AND 1859.

Introductory observations

Sectiox I.-Conditions required, and Plan adopted, in Experiments on the Question of the assimilation of Fice Nitrogen by Plants:-

A. Preparation of the soil, or Matrix, for the reception of the Plant, and of the nutriment to be supplied to it 
B. The Mineral Constituents added to the prepared soil

C. The Distilled Water .......................................................

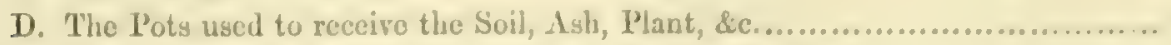

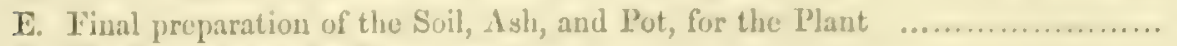

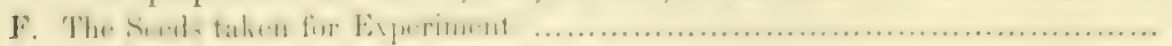

G. Tho Atmosplicre supplied to the Plants

II. The A pparatus used to enclose the Plants, and to supply them with $\mathrm{Air}$, Water, Carbonic acid, se.

I. Use of the Apparatus

J. The supply of Carbonic acid to the Plants

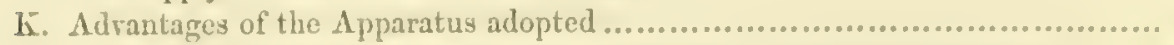

L. Adaptation for healthy growth of the conditions of experiment adopted .....

SEOTIOx II.-Other Conditions of Experiment requiring collateral Investigation:Einumeratiun of

A. General considerations in regard to the possible influence of Ozone on the

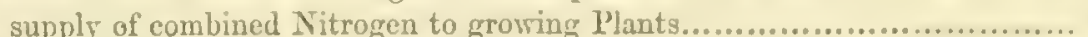

B. Composition of the Gas in Plants...

C. Experiments on the action of Ozonized air on decomposing Organic Matter, and porous and alkaline substances ...........................................

D. Evolution of free Nitrogen in the decomposition of Nitrogenous organic matter

E: Experiments on the action of the oxidizing and reducing forces, as manifested in the decomposition of Nitrogenous organic matter ...........................

F. The mutual relations of Gaseous Nitrogen, and the Nascent Hydrogen erolred during the decomposition of organic matter.................................

Summary Statement of the Results of the consideration of the conditions required, or involved, in

Experiments on the question of the assimilation of free Nitrogen by Plants ....................

SECTIOs III.-Conditions of grouth under which assimilation of Free Nitrogen by Plants is most likely to take place. Direct Experiments upon the Question under various circumstances of growth :-

A. General consideration of conditions of growth

B. Direct experiments on the question of the assimilation of free Nitrogen by plants I. Experiments in which the plants had no other supply of combined Nitrogen than that contained in the seed sown

$151-156$

$156-19.5$

$495-197$

$197-505$

$509-515$

$515-516$

$516-51 \%$

II. Experiments in which the plants had a known supply of combined Nitrogen, bejond that contained in the original seed

Relations of the plants grown with an extraneous supply of combined nitrogen, to those gromn without it .............................................

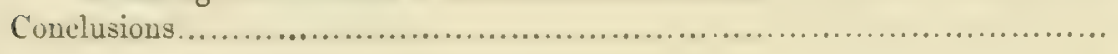

$517-520$

$520-540$

$521-529$

$529-535$

$533-539$

$539-540$

Summary of the Results of the whole Inquiry

$5 \pm 0-511$

\section{APPENDIX.}

A. Preparation of solutions for manuring the plants, dates of application, and quantities applied

B. Taking up the plants, preparation for analysis, methods of analysis, \&c........

C. Abstract of the Records of Growth of the Plants.

I. Plants grown in $\mathbf{1 8 5 7}$ 


\section{PART FIRST.}

\section{GENERAL HISTORT, AND STATEMENT OF THE QUESTION.}

\section{SECTION I.-INTRODUCTION, AND EARLT HISTORY.}

THE facts at the present time generally accepted regarding the ultimate composition, and the sources of the constituents, of plants, hare, for the most part, received their preponderating weight of proof within the limits of the present century. But it is to the century preceding it that we must look for the establishment of much that was essential as the foundation of those adrances which have since been made.

Whatever may be the value at present attached to the particular views of HALEs regarding the composition and the sources of regetable matter, we must accord to his labours, in the carly part of the eighteenth century, the merit of having been guided by a proper spirit of experimental inquiry. Nor did he fail in applying to good account, and even in extending, the then existing knowledge of the material things around him which were apparently involved in the mysterious processes of vegetable growth.

With our present knowledge, howerer, of the general composition of plants, and of the sources of their constituents, it is easy to see how essential was a proper understanding of the chemistry of the air, and of water, to any true conceptions of the material changes involved in the regetative process. It can, indeed, hardly excite surprise, that what may be called the gerns of our present knowledge of the chemistry of plantgrowth came forth almost simultaneously with the now adopted views of the composition of those universal, though not exclusire, media of vegetation-air, and water.

Accordingly, it is between the dates of 1770 and 1800 that we find BuAch, ScHeELe, Priestlex, Luroisier, Catexdisir, and Tratt establishing for us the facts that common air consists chiefly of nitrogen and oxygen, with a little carbonic acid, that carbonic acid itself is composed of carbon and oxygen; and that water is composed of hydrogen and oxygen; and it is within the same period that Priestley and Irgexhocsz, SenveBIER and WOODHOCSE, laboured to show the mutual relations of these bodies and regetable growth.

But the observers last mentioned seem to have had more prominently in view the question of the influence of plants upon the media with which they were surrounded, than that of the influence of these media in contributing materially to the increased substance of plants themselves. Following closely on their footsteps, both in point of time and in general plan of research, came De Sicssure. His labours were conducted towards the end of the last century and in the beginning of the present one; and their results, and the arguments he founded upon them, published by him in 180t, may be said to have indicated, if not indeed established, many of the most important facts with which we are yet acquainted regarding the sources of the constituents stored up by the growing plant. To DE SAdssure we owe the experimental, and even quantitative, illustration of the fact, that plants in sunlight increase in their amounts of carbon, hydrogen, and oxygen, at the expense of carbonic acid and of water. It is remarkable, too, that, in the case of the main experiment he cites on the point, he, with his very imper- 
fect metlods, found the increase in carton and in the elements of water to be almost identically in the proportion in which these are known to exist in the sodenomi-

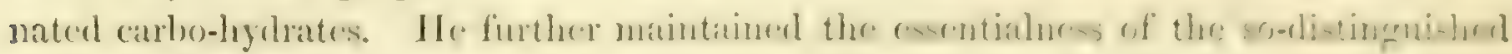
"mineral" constituents of plants; and he pointed out, in opposition to previous viers, that they were derived from the soil, and were not the result of a creative power exercised by the living plant. IIe also called attention to the probability that the incom. bustible or mineral constituents derived lyy plants from the soril, were the enoure of these found in the animals which are fed upon them.

Besides carbon, hychogen, oxygen, and the more peruliarly mineral constiturnte. plants had already been shown to contain nitrogen. PRIESTLEY and INGexnotsz thought they had observed that plants absorbed the free nitrogen of the confined atmontheres in which

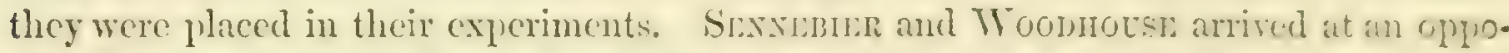
site conclusion. Drs Susstrir, again, did not find that plants took up appreciable chuantities of the nitrogen supplied to them in the free and gaseous form. On the other hand, he thought that his experiments indicated rather an erolution of that clement at the expense of the substance of the plant, than any assimilation of it from gaseous media. On this point he further concluded that the source of the nitrogen of plants was, more probably, the nitrogenous compounds in the soil, and the small amount of ammonia which he demonstrated to exist in the atmosphere.

From his results, as a whole, De Surssere concluded that air and water contributed a much larger proportion of the dry substance of plants, than did the soils in which they grew. In his riew, the fertile soil was the one which yielded liberally to the plant nitrogenous compounds and the incombustible or mineral constituents; whilst he attributed to air and water, at least the main part of the carbon, hydrogen, and oxygen of which the greater portion of the dry substance of the plant was made up.

$\mathrm{Up}$ to the present time, carbonic acid and water are admitted to be the chief sources of the carbon, hydrogen, and oxygen which constitute the great proportion of recretable produce. Nor is it questioned that ammonia, and especially ammonia provided within the soil, is at least an important source of the nitrogen of such produce. But the experiments of DE S.russtre-howerer sagacious his conclusions-were less satisfactory as to the source of the nitrogen, than as to that of the carbon, hydrogen, and oxrgen, of regetable matter.

It will not be supposed, from what has just been said, that there remain no questions, of rast scientific as well as of practical interest, to be yet solred, regarding the conditions under which our different crops take up their carbon, hydrogen, and oxygen. At the same time, those who derote themselves to the subject of Agricultural Chemistry soon find that the explanation of the chemical phenomena of agriculturul production amaits much more for a further elucidation of the sources, and of the modes of assimilation, of the nitrogen than of the other, so-called, organic elements of our crops-carbon, hydrogen, and oxygen.

In 1837, Borssixgalle took up the subject of the sources of the Nitrogen of plants, where De Sutssure had left it more than thirty years before. To the inrestigations 
and conclusions of Boussivgatut, and others, in connexion with this question, from the date above mentioned up to the present time, we shall have to refer pretty fully further on. It may here be mentioned, however, that already at that early period BousSING_ULt had so far advanced in his inquiries into the chemical statistics of certain agricultural practices on the large scale, as to be apparently led by them to see the importance of inrestigating much more closely the sources of the Nitrogen periodically yielded by a given area of land, over and above that which was artificially supplied to it.

We fully admit the pertinence of the considerations, and the sagacity of the observations adduced on this head, more than twenty years ago, by Boussingault. It will, nevertheless, be well to preface the discussion of our own experimental evidence regarding the sources of the nitrogen of plants, by the statement of a few prominent and striking facts, established by investigations conducted here, at Rothamsted, illustrative of the amounts of nitrogen yielded by different crops over a given area of land, and of the relation of these amounts to certain measured, or known, sources of it. Of these points, however, we profess to speak only in a very brief and summary manner on the present occasion. The discussion in detail, of the evidence relating to them, would indeed itself exhaust the limits of our Paper. Moreover, we have already treated of this subject in a separate form, elsewhere*; and it is our intention to consider it much more fully at some future opportunity.

\section{Section II.-ANNUAL YIELD OF NITROGEN PER ACRE, IN DIFFERENT CROPS†.}

\section{A.- Yield of Nitrogen per acre when the same Crop is grown year after year on the same Land.}

The following Summary Table shows the arerage annual amounts of nitrogen yielded per acre, in the crops enumerated, when each was grown for a number of years consecutively on the same land, without manure.

TABLE T.

\begin{tabular}{|c|c|c|c|}
\hline Description of Crop. & $\begin{array}{l}\text { Dates of the Experi- } \\
\text { menis. }\end{array}$ & Number of Years. & $\begin{array}{l}\text { Arerage Annual yield of } \\
\text { Nitrogen per acre, } \\
\text { without Mfanure. }\end{array}$ \\
\hline $\begin{array}{l}\text { Wheat } \quad \ldots \ldots \ldots \ldots \ldots . . . \\
\text { Barley }\end{array}$ & $\begin{array}{l}1844-1859 \text { inclusive } \\
1852-1859 \text { inclusive }\end{array}$ & $\begin{array}{r}16 \\
8\end{array}$ & $\begin{array}{l}\text { lbs. } \\
24 \cdot 4 \\
24 \cdot 7\end{array}$ \\
\hline Meadow Hay........ & $1856-1859$ inclusive & 4 & $39 \cdot 4$ \\
\hline Beans................. & $1847-1858$ inclusive & 12 & $47 \cdot 8$ \\
\hline
\end{tabular}

There were obtained, then, in each of the Cereal crops (wheat and barley) about $24 \frac{1}{2}$ lbs. of Nitrogen per acre, per annum, without manure. In the case of each of the crops the land was, in an agricultural sense, exhausted at the commencement of the

British Association for the Advancement of Science, Ireeds Mreeting (1858), Section B.

+ The results given in this Section have been revised, and in some cases the periods over which the estimates are taken extended, since the reading of the Paper. 
experiment; that is to say, it had been brought to such a condition by previons orepping, that, in the ordinary course of pactice, it would be deemed nece-ary to supply manure to it before growing another comp-crop). It may be further remarked thint in the case of the wheat there is as yet little, but in that of the barley more obvious indication of progressive decline in the annual yield.

The meadow-land yielded nearly $40 \mathrm{lbs}$. of Nitrogen per acre, per annum, or above onc-half more tham the exclusively Girminaceous crope, what and barle... The hrotere.

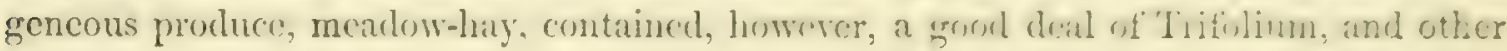
Leguminous plants, intermixed with the Grasses. To this fact is to be attributed, at

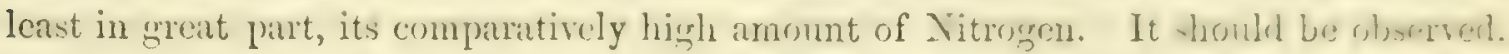
too, that the arerage is as yet taken orer only four years.

The Leguminous crop (beans) has given, over a period of twelve years, an average of nearly $48 \mathrm{lbs}$. of Nitrogen per acre, per annum. The yield of Nitrogen in this Leguminous crop was, therefore, nearly twice as great as in the Graminaceous corn-crops. 'The bean and allied crops are, however, very subject to disease, especially when grown too frequently on the same land. It is, at least in part, owing to this circumstance, that the average annual yield orer the twelve years was so much less than mould be the yield of the crop when grown in suitable alternation with others in a season of arerage adaptation for its bealthy development. In fact, so great was the deterioration in the character and amount of produce in the experiments in question, due to the continuous cropping, that whilst the arerage annual jicld of Xitrogen over the first sis of the twelve years was $70 \mathrm{lbs}$., that over the concluding six years was only $26 \mathrm{lbs}$. Nor did the addition of nitrogenous manure in the form of ammonia-salts, tegether with liberal mineral manuring, obriate this deterioration in any material degree more than did mineral manures alone.

In further illustration of the larger amount of Nitrogen obtained orer a given area of land in Leguminous crops than in Graminaccous ones, some remarkable results with clover may be cited. Red clover was grown in three out of four consecutire years, the intermediate crop being wheat-all without manure. The following amounts of Nitrogen were obtained per acre:-

TABLE II.

\begin{tabular}{|l|l|c|}
\hline \multicolumn{1}{|c|}{ Season. } & Crop. & Nitrogen per acre. \\
\hline & & $1 \mathrm{bs}$ \\
1st Year, 1849 ...... & Clover. & $206 \cdot 8$ \\
(2nd Year, 1850 ... & Wheat. & $\left.45^{\circ} .2\right)$ \\
3rd Year, 1851 ..... & Clover. & $29 \cdot 3$ \\
4th Year, 1852..... & Clover. & 111.9 \\
\hline Average of the three years Cluver .......... & 116.0 \\
\hline
\end{tabular}

All further attempts to grow clover year after ycar, on this land, hare, howerer, failed. Neither ammonia-salts, nor organic mattcr rich in carbon as well as other constituents, nor mineral manures, nor a mixture of all has arailed to restore the 
clover-yiclding capabilities of the land. On the other hand, it should be particularly observed that, after taking $206.8 \mathrm{lbs}$. of Nitrogen from an acre of land in the clovercrop of the first ycar, the wheat-crop of the second or succeeding year, compared with that of the same season in the adjoining experimental wheat-field where the crop is grom year after year on the same land, was about double that obtained from the plot which had there been unmanured for a series of consecutive years, and fully equal to that from a plot which had for the same period received annually a dressing of farm-yard manure. It should be added that, after failing to get any crop of clorer at all in 1853 and in 1854, and getting a rery poor one in 1855 , the land was allowed to lie fallow for two years; that after this, in 1858, there was obtained an over-luxuriant and laid crop of barley, more than twice as great as the arerage annual produce of eight years of the successive growth of the crop without manure in the same field; yet, after resowing with clorer in the spring of 1859 , and getting a small cutting in the autumn of the same year, the plant has again died off during the winter of 1859-60. This was the case notwithstanding that it was a perennial variety that was last sown.

Again, eight consecutive crops of turnips (four "White Globe" and four "Swedish") gave an arerage annual yield, per acre, of about $40 \mathrm{lbs}$. of Nitrogen, without the supply of any in the manure. In the case of these turnips, howerer, the land receired annually certain "mineral" manures. In fact, turnips grown year after year without manure of any kind, yielded, after a few years, only a few hundred-weights of produce per acre; but the percentage of Nitrogen in these diminutive unmanured turnips was tery unusually high. It will be observed that the arerage annual yield of Nitrogen per acre, in the turnips grown by mineral manures (containing no Nitrogen), was considerably more than that in the unmanured Cereal grain-crops. And, in connexion with this point, it is worthy of remark, that, on barley, without manure, succeeding on the land from which these eight mineral-manured turnip-crops had been taken, the produce was only about three-fourths as much as that obtained, in the same season, where barley was grown for the second year in succession without manure, in another field; and it was only about three-fifths as much as that obtained, also in the same season, where barley was grown as the second crop of the second course, in a series of entirely unmanured four-course Rotation-crops.

It may be mentioned that, in the case of the purely Graminaceous crops, there has been but very little gain in the annual yield of Nitrogen per acre by the use of mineral or non-nitrogenous manures. But in the case of the Leguminous crops, as in that of the root-crops just referred to, there has been much more Nitrogen harrested orer a giren area, within a given time, when mineral manures were employed, than when no manure at all was used.

It has thus far been seen, then, that the Leguminous crops yield much more Nitrogen over a given area than the Graminaceous ones, and, further, that the amount of Nitrogen harvested in the former is increased considerably by the use of "mineral " manures, whilst that in the latter is so in a very limited degree. It is, nevertheless, a well-known agricultural fact, that the growth of the Leguminous crops, which carry off such a com- 


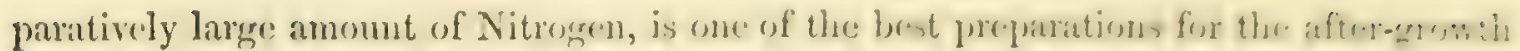
of wheat. On the other hand, it is equally true that fallow-one important effect of which is to accumulate within the soil the available Nitrogen of two or more years for the growth of one-and adding nitrogenous manures, have cach much the same cffect in increasing the produce of the Cereal crops.

\section{B. - Yield of Nitrogen per acre when Wheat is grown in alternation with Beans, or with liallow.}

The striking and interesting fact, that the growth (and removal from the land) of a highly nitrogenized I, eguminous crop, and fallow, have each the reffect of increa-ing the nmount of produce, and with it the yield of Nitrogen per acre, of a sucereding Cereal crop, is briefly illustrated by the summary of direct experinental results griven in the following 'lable:-

\section{Table III.}

Showing the Amount of Nitrogen obtained per acre, in Wheat grown consecutively. in Wheat alternated with Beans, and in Wheat altemated with Fallow:

Period of Experiment ten years, 1850-1859 inclusive.

\begin{tabular}{|c|c|c|c|}
\hline & & \multicolumn{2}{|c|}{ Nitrogen per acre, lbs. } \\
\hline & & Total. & Arerage annual. \\
\hline Beans - 10 crops consecutively & 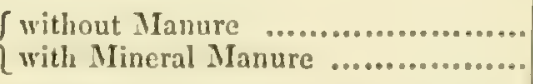 & $\begin{array}{l}346 \cdot 9 \\
510 \cdot 6\end{array}$ & $\begin{array}{l}34 \cdot 7 \\
51 \cdot 1\end{array}$ \\
\hline Wheat-without Manure & $\left\{\begin{array}{r}10 \text { Crops consecutively.................... } \\
5 \text { Crops alternated with Fallow ...... }\end{array}\right.$ & $\begin{array}{l}234 \cdot 0 \\
219 \cdot 3\end{array}$ & $\begin{array}{l}23 \cdot 4 \\
43 \cdot 9 \text { (1r } 21 \cdot 9\end{array}$ \\
\hline $\left.\begin{array}{l}\text { Wheat } \\
\text { Beans }\end{array}\right\}$ without Manure & $\left\{\begin{array}{l}5 \text { Crops alternated with Beans ...... } \\
5 \text { Crops alternated with Wheat ..... }\end{array}\right.$ & $\begin{array}{l}225 \cdot 8 \\
244 \cdot 5\end{array}$ & $\begin{array}{l}45 \cdot 2 \text { or } 2.3 \cdot 6 \\
45 \cdot 9 \text { or } 24 \cdot 5\end{array}$ \\
\hline $\left.\begin{array}{l}\text { Wheat } \\
\text { Beans }\end{array}\right\}$ with Mineral Manure & $\left\{\begin{array}{l}5 \text { Crops alternated with Beans ....... } \\
5 \text { Crops alternated with Wheat ..... }\end{array}\right.$ & $\underset{207 \cdot 0}{207}$ & $\begin{array}{l}41 \cdot 4 \text { or } 20 \cdot \% \\
45 \cdot 4 \text { or } 2: 3\end{array}$ \\
\hline
\end{tabular}

It is seen, then, that ten consecutive crops of beans, without manure of any kind, gave an average annual yield of Nitrogen, per acre, of $34.7 \mathrm{lbs}$; and ten consecutire crops with "mineral" but without nitrogenous manure gave an arerage annual yield, per acre, of $51 \cdot 1 \mathrm{lbs}$.

During the same period, ten consecutive crops of wheat without manure of any kind gave annually 23.4 lbs. of Nitrogen, or less than half as much as the beans with mineral but without nitrogenous manure. Again, extending orer the same series of years, five crops of whent altemated with fullow gare, taking the average of the five years under crop, $43.9 \mathrm{lbs}$, and on the arerage of the ten years, $21.9 \mathrm{lbs}$. per acre, per annum, of Nitrogen. . That is to say, the wheat alternated with fallow gare, taking the average of the five years of its growth, nearly twice as much Nitrogen annually as the wheat grown after wheat in the same seasons. The total Nitrogen cbtained, per acre, orer the ten years, was, howerel, pretty much the same in the tro 
cases,-namely, 234 lbs. in the ten crops of wheat grown consecutively, and $219 \cdot 3 \mathrm{lbs}$. in the five crops of wheat alternated with fallow.

Again, five crops of wheat alternated with beans gave $45.2 \mathrm{lbs}$. of Nitrogen per acre, per annum, over the five years-equal half that amount, or $22.6 \mathrm{lbs}$, averaged over the ten years. 'The total amount of Nitrogen obtained during the ten years was, in the ten crops of wheat grown consecutively, $234 \mathrm{lbs}$, in the five crops of wheat alternated with fallow, $219.3 \mathrm{lbs}$, and in the five crops of wheat alternated with beans, $225 \cdot 8 \mathrm{lbs}$. -or not very materially different in the three cases. But, notwithstanding that the land has thus yielded in wheat, over ten years, almost as much total Nitrogen in five crops alternated with beans, as in ten crops grown consecutively, and rather more than in five crops alternated with fallow, the five intermediate crops of beans have, in addition to this, themselves carried off more than the same amount of Nitrogen as the wheatnamely, $244 \cdot 5 \mathrm{lbs}$.

The general result is, then, that pretty nearly the same amount of Nitrogen was taken from a given area of land in wheat, in ten years, whether ten crops were grown consecutively, five crops in alternation with fallow, or five crops in alternation with beans. In fact, the crop of wheat was increased fully as much when it succeeded beans, which carried off a large amount of Nitrogen, and of mineral matters also, as when it succeeded fallow, which conserved the stores both of Nitrogen and of mineral matter.

It will be seen, by the illustrations given in the next sub-section (C.), that the experimental results thus far adcluced are perfectly consistent in character with those obtained under circumstances more nearly allied to those of ordinary farm practice.

\section{C.- Field of Nitrogen per acre when crops are grown in an actual course of rotation.}

In Boussingault's experiments, he obtained, taking the results of six separate courses of rotation, an average of between one-third and one-half more Nitrogen in the produce than had been supplied in the manure. He found, moreover, that the largest yields of Nitrogen were in the Leguminous crops, and, further, that the Cereal crops were the larger when they next succeeded upon the removal of the highly nitrogenized Leguminous crops.

For our own experiments at Rothamsted upon an actual course of rotation, a piece of land was sclected which was, in an agricultural sense, exhausted; that is to say, it had grown a course of crops since the application of manure, and would, under ordinary 


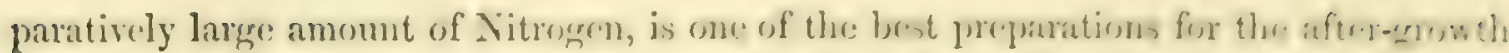
of wheat. On the other hand, it is equally true that fallow-one important effect of which is to accumulate within the soil the available Nitrogen of two or more years for the growth of one-and adding nitrogenous manures, have cach much the same effect in increasing the produce of the Cereal crops.

\section{B. - Field of Nitrogen per acre when Wheat is grown in altemation with Beans, or with Fallow.}

The striking and interesting fact, that the growth (and remosil form the land) of a

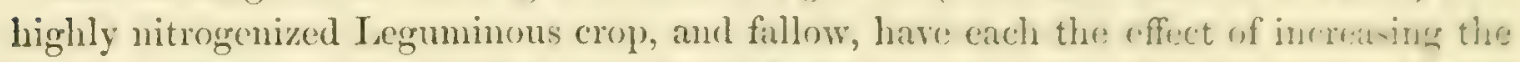
nmount of produce, and with it the yicld of Nitrogen pere acre, of a sureereding (ineal crop, is briefly illustrated by the summary of direct experimental results friven in the following 'lable:-

\section{TABLE III.}

Showing the Amount of Nitrogen obtained per acre, in Wheat wrown conecutively in Wheat alternated with Beans, and in Wheat alternated with Fallow.

Period of Experiment ten years, 1850-1859 inclusire.

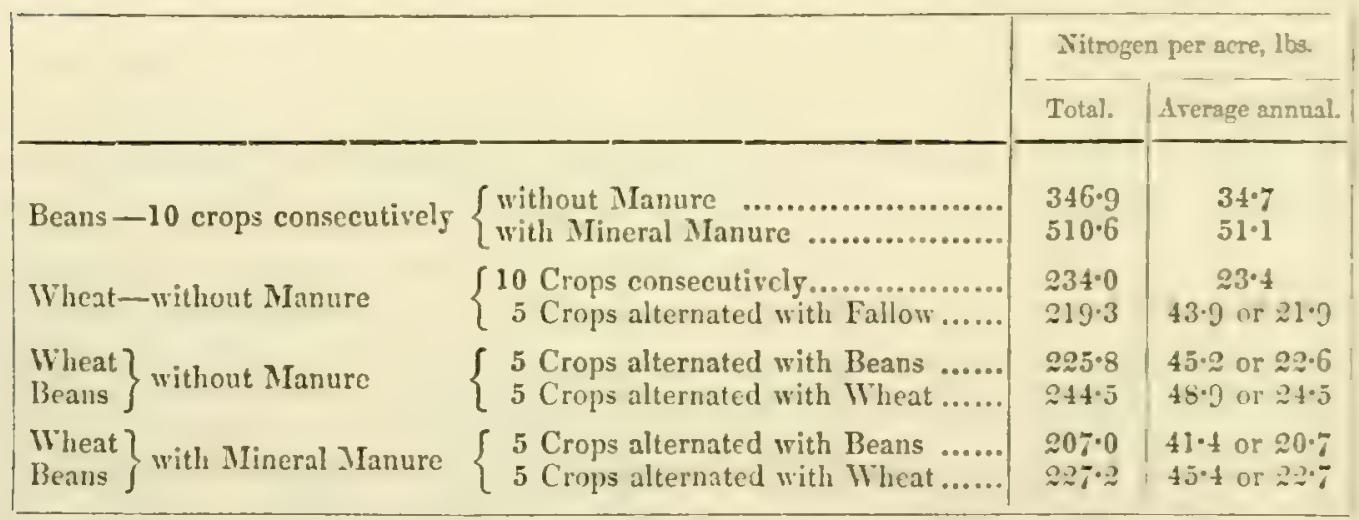

It is seen, then, that ten consecutive crops of beans, without manure of any kind, gave an average anmual yield of Nitrogen, per acre, of $34.7 \mathrm{lbs}$; ; and ten consecutive crops with "mineral" but without nitrogenous manure gave an arerage annual yield, per acre, of $51 \cdot 1 \mathrm{lbs}$.

Note-At page 439, line 3 from bottom, after "... average annual amount, per acre, of 42.6 lbs." insert The second and third courses gave, howerer, much less than the first, and hence a less arerage per annum than that stated for the twelre jears. 
cases,-namely, 234 lbs. in the ten crops of wheat grom consecutively, and $219.31 \mathrm{lbs}$. in the five crops of wheat alternated with fallow.

Again, five crops of wheat alterinated with beans gave $45.2 \mathrm{lbs}$. of Nitrogen per acre, per annum, orer the five years-equal half that amount, or $22 \cdot 6 \mathrm{lbs}$, averaged over the ten years. The total amount of Nitrogen obtained during the ten years was, in the ten crops of wheat grown consecutively, 234 lbs., in the five crops of wheat alternated with fallow, $219 \cdot 3 \mathrm{lbs}$, and in the five crops of wheat alternated with beans, $225.8 \mathrm{lbs}$. -or not rery materially different in the three cases. But, notwithstanding that the land has thus yielded in wheat, over ten years, almost as much total Nitrogen in five crops alternated with beans, as in ten crops grown consecutively, and rather more than in five crops alternated with fallow, the five intermediate crops of beans have, in addition to this, themselves carried off more than the same amount of Nitrogen as the wheatnamely, $244.5 \mathrm{lbs}$.

The general result is, then, that pretty nearly the same amount of Nitrogen was taken from a given area of land in wheat, in ten years, whether ten crops were grown consecutively, five crops in alternation with fallow, or five crops in alternation with beans. In fact, the crop of wheat was increased fully as much when it succeeded beans, which carried off a large amount of Nitrogen, and of mineral matters also, as when it succeeded fallow, which conserved the stores both of Nitrogen and of mineral matter.

It will be seen, by the illustrations given in the next sub-section (C.), that the experimental results thus far adduced are perfectly consistent in character with those obtained under circumstances more nearly allied to those of ordinary farm practice.

\section{C.-Yield of Nitrogen per acre when crops are grown in an actual course of rotation.}

In BoussingaulT's experiments, he obtained, taking the results of six separate courses of rotation, an average of between one-third and one-half more Nitrogen in the produce than had been supplied in the manure. He found, moreover, that the largest yields of Nitrogen were in the Leguminous crops, and, further, that the Cereal crops were the larger when they next succeeded upon the remoral of the highly nitrogenized Leguminous crops.

For our own experiments at Rothamsted upon an actual course of rotation, a piece of land was sclected which was, in an agricultural sense, exhausted; that is to say, it had grown a course of crops since the application of manure, and would, under ordinary practice, have received a new supply before growing another crop. On this land the four-course rotation of Turnips, Barley, Leguminous crop (or Fallow), and Wheat, in the order of succession here enumerated, and without manure, has now been followed for twelve years - that is, through three separate courses. The yield of Nitrogen during these twelve years, or three courses, has been determined; and the result shows an arerage annual amount, per acre, of $42.6 \mathrm{lbs}$. This, it will be remembered, is nearly trice as much as was obtained in either wheat or barley when these crops were, respectively, grown year after year on the same land. The greatest yicld of Nitrogen obtained MIDCCLII. 
in the Rotation experiment was in the case of a clover-crop, grown once during the twelve years, and which constituted the Leguminous crop of the first conrse. After both this clover-crop (in which was removed such a large amount of Nitrogen) and beans which replaced it in the second and third courses (but which gave a very small yichld of Nitrogen), the wheat-crop was about double as much as the average where wheat has been grown succeding wheat, and it was about equal to the average per crop when wheat was grown after fallow, or after beans, in the experiments already referred to.

It has been seen, then:-that even Cereal crops grown, year after year, on the same land, gave an arerage of about $24 \frac{1}{2} \mathrm{lbs}$. of Nitrogen per acre, per annum; that, under similar circumstances, Leguminous crops gave much more; that, nerertheless, the produce of the Cereal crop was nearly doubled when it was preceded by the more highly nitrogenized Leguminous crop; that the produce of the Cereal crop was also nearly doubled when it was preceded by fallow; and lastly, that in an actual rotation of crops, though entirely without manure, there was also an avcrage annual yield of Nitrogen nearly twice as great as that obtained in the continuously grown Cereal.

It has been incidentally mentioned, too, that the highly nitrogenous Leguminous crops are companatively little benefited by the direct application of nitresenoms manne lammonia-salts). It has also further been stated, on the other hand, that, notwithstanding the comparatively small amount of Nitrogen harvested in a Cereal crop, and that both the crop and its Nitrogen are very much increased when succeeding upon the growth and remoral of a highly nitrogenous Leguminous crop, yet the application of nitrogenous manures is also one of the surest means of increasing the produce, and the yield of Nitrogen, of a Cereal crop.

\section{D.-Relation of the increased yield of Nitrogen in the produce, to the amount supplied, when nitrogenous manures are cmployed.}

Not only do we harrest in our crops (particularly the Leguminous ones) a large amount of Nitrogen, the source of which, it will afterwards be seen, is by no means fully explained, but, when we increase their growth (particularly that of the Cereals) by the direct application of nitrogenous manures, it is found that, over a series of years, a considerable proportion of the so-supplied Nitrogen is not recovered in the increase of crop.

Thus, when a certain amount of ammonia-salts (in addition to a complex mineral manure) was applied, year after year, for the growth of wheat, the result, taken orer a period of six years, was, that the increased yield of Nitrogen in the crop was only equal to about 43 per cent. of the Nitrogen which had been supplied in the manure. Then double the amount of ammonia-salts was employed, by which the crop was still further increased, the proportion of the supplied Nitrogen which was recorered as increase was almost identically the same; but with more still, the proportion was less.

Again, when the smaller amount of ammonia-salts was applied amnually, for six years. to barley; the increased yield of Nitrogen corresponded to only about 42 per cent. of the 
Nitrogen supplied in the manure; and when the double amount of the manure was employed for barley, over the same series of years, only about 43 per cent. of the supplied Nitrogen were recovered as increased yield.

To the statement of these facts it should be added that the Nitrogen (equal in amount to, say 60 per cent. of that supplied in the manure) which is not obtained as increased yield in the immediate crop does not appear to exist in the soil availably for an immediately succeeding crop. Thus, when by the use of nitrogenous manures an increased yield of Nitrogen has been obtained in the first succeeding wheat-crop, equal in amount to about 40 per cent. of the Nitrogen supplied in the manure, the increased yield obtained in the second crop, without any further supply, is equal to little more than one-tenth of the remainder.

In connexion with this subject it may be mentioned that, so far as our experiments with meadow-grasses at present show, it does not appear that the increased yield of Nitrogen in the crop on the use of nitrogenous manures bears a much higher proportion to the amount supplied in their case than in that of either wheat or barley. In the case of the Leguminous corn-crops, the proportion of the increased yield to the amount supplied appears to be even less than in that of the Cereal grains. Root-crops, on the other hand, would seem to gather up an increase of Nitrogen bearing a larger proportion to the quantity directly supplied in the manure.

On the assumption that the relation of the immediately increased yield of Nitrogen to the amount supplied in manure represents really or approximately the proportion of the directly supplied Nitrogen which is actually recovered in the immediate crop, the following questions seem to suggest themselves:-

Is the unrecovered amount of supplied Nitrogen, or at any rate a considerable proportion of it, drained away and lost?

Are the nitrogenous compounds transformed within the soil, and their Nitrogen, in some form, evaporated?

Does the missing amount for the most part remain in some fixed combination in the soil, only to be yielded up, if ever, in the course of a long series of years?

Is ammonia itself, or Nitrogen in the free state, or in some other form of combination than ammonia, given off from the surface of the growing plant? Or, lastly,

When Nitrogen is supplied within the soil for the increased growth of the Graminaceous crop, is there simply an unfarourable distribution of it, considered in relation to the distribution of the underground feeders of the crop? - the Leguminous crop, which alternates with it, gathering from a more extended range of soil, and leaving a residue of assimilable Nitrogen within the range of collection of a next succeeding Cereal one?

But other and wider questions than those just enumerated present themselves on a careful reriew, as a whole, of the Nitrogen-statistics of field-produce to which attention has briefly been directed. For the moment, all may be asked in one-namely, What

$$
3 \text { Р } 2
$$


are the sources of all the Nitrogen of our crops beyond that which is directly sunplied to the soil by artificial means? 'This brings us to a consideration of the next section of our subject.

SECTIOX III.-GLNEIRAL VIFW OF THI VARIOUS ACTUAL OR POSSIBLE SOLRCES OF THE NITROGLA OF OUR CROPS.

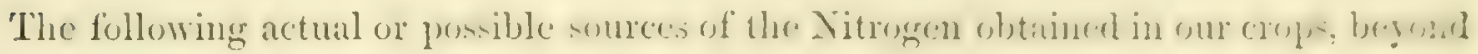
that supplied in manure, may be enumerated:-

1. 'The Nitrogen in certain constituent minerals of the soil, especially the ferruginous and aluminous; and certain nitrides.

2. 'The combined Nitrogen ammully coming down in the aqueous depositions from the atmosphere:-

(a) As ammonia.

(b) As nitric acid.

(c) As organic corpuscles, \&c.

3. 'The accumulation by the soil of combined Nitrogen from the atmosphere:-

(a) By surface absorption aided by moisture.

(b) By the chemical action of certain mineral constituents of the soil.

(c) By the chemical action of certain organic compounds in the soil.

4. The formation of ammonia in the soil, from free Nitrogen, and nascent Hydrogen (the so-formed ammonia either remaining as such, or being oxidated into nitric acid).

5. The formation of nitric acid from fiee Nitrogen:-

(a) By electric action.

(b) With common Oxtgen, in contact with porous and alkaline substances.

(c) Under the influence of Ozone, or nascent Oxygen.

6. The direct absorption of combined Nitregen from the atmosphere, by plants themselves.

7. The assimilation of free Nitrogen by plants.

A careful consideration of the abore actual or possible sources of the Nitrogen of the regetation which covers the earth's surface will show, in regard to some of them, that they at least are quantitatively inadequate to supply the amounts of Nitrogen mhich direct experiment has shown to be remorable in various crops from a given area of land.

(1) The combined Nitrogen that may be due to certain of the constituent minerals of the débris of which our soils are made up cannot be supposed to be an adequate source of the nitrogen annually carried off in the regetable produce of the land.

(2) The combined Nitrogen which comes down from the atmosphere in the rarious aqueous deposits of rain, hail, snow, mists, fog, and dew-whether it be merely the return from previously existing generations of plants or animals elsewhere, or whether in part the product of a new formation-undoubtedly does contribute materially to the 
annual yicld of Nitrogen in our crops. The amount of Nitrogen derivable from these sources is, moreorer, perhaps more readily quantitatively estimated than that from any of the other sources enumerated. Accordingly, much labour has, of late years, been bestowed in determining the amounts of ammonia and nitric acid in these sereral aqueous deposits. Extensire series of observations hare been made on these points by BotssixGAULT, BARRAL, WAT, and two of ourselves; and others have experimented on a more limited scale. It may be stated, generally, that the rain of the open country has indicated an average of very nearly the same amounts of ammonia in the hands of BotssixF.ACLT in Alsace, and of Wir and ourselves in England. The most numerous and reliable determinations of the amount of nitric acid in rain-water are probably those of $\mathrm{Mr}$. WAX.

By the aid of numerous determinations of the ammonia by ourselves, and of both the ammonia and nitric acid by $\mathrm{Mr}$. WAY, we are enabled to form an estimate of the total amount of Nitrogen coming down as ammonia and nitric acid in the total rain, hail, and snow, and in some of the minor aqueous deposits, during the years 1853, 1855, and 1856 , here at Rothamsted, where the experiments relating to the acreage yield of Nitrogen in the different crops were made. The result was, that in neither of the three years did the Nitrogen so coming down as ammonia and nitric acid amount to $10 \mathrm{lbs}$. per acre.

Supposing the combined Nitrogen coming down in the direct aqueous deposits were to be estimated, in round numbers, at $10 \mathrm{lbs}$. per acre, per annum, this amount would supply less than half as much Nitrogen as was annually remored in the continuously grown wheat and barley crops. It would amount to only about one-fourth of that which was obtained in the hay, and in the turnips; to a less proportion of that obtained in beans; and to a still less proportion of that obtained in the clover. . Lastly, it would amount to only about one-fourth as much as was obtained per annum, over twelve years of ordinary Rotation, but without manure of any kind either during that period or for some years previously.

We are driven, then, to seek for other sources of the Nitrogen of our crops, than that which comes down as ammonia and nitric acid in the more direct and more easily measurable aqueous deposits from the atmosphere. Nor does it appear, so far as can be judged from the results of Boussingault on this point, that the amounts of combined Nitrogen deposited by dew are such as to lead to the supposition that our approximate estimate would require any material modification, were as large a proportion of dew included in our collected and analysed aqueous deposits as is probably receired by the soil itself or the regetation which may cover it.

(3) With regard to the amounts of combined Nitrogen accumulated by the soil from the atmosphere by virtue of surface absorption, or chemical action, it is probable that they constitute no inconsiderable proportion of that which is annually arailable for regetation orer a given area of land. Numerous investigations have indecd been undertaken during the last few years, both by ourselves and others, to determine the actual or relative capacitics for absorption of different soils, or constituents of soils. Unfortu- 
nately, however, even quantitative results established by laboratory methods do not

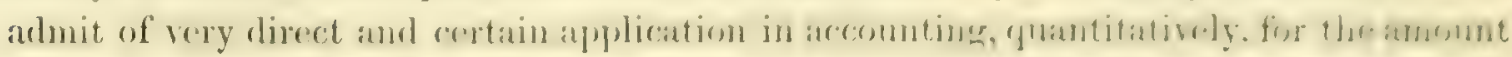
of combined nitrogen that may be so fixed, to a given depth, over a given area of land, within a given time. We hope, however, to treat of this subject in some detail on some future occasion.

$(4 \& 5)$ 'The circumstances of the formation of ammonia, or nitric acid, from gaseous, dissolved, or nascent Nitrogen, are at present involved in too much obscurity, and are the subject of too much conflicting statement for their consideration to serve us much in our present inquiry. 'The rarious assumed actions are, as yet, by no means all clearly established in a merely qualitative way; and still less, quantitatively. Moreover, as in the case of absorption, so in that of the formation of ammonia, or of nitric acid, there would be considerable difficulty and uncertainty in applying the results of laboratory experiments to the estimation of the probable amount of the Nitrogen of vegetation due to such sources. 'To some of the questions involved, we shall, horrever, have to refer more or less in detail in discussing the conditions of the experiments which will form the subject of the second part of the present Paper.

(6) With regard to the dixect absorption of ammonia or nitric acid from the air by plants themselves, we have little of either qualitative or quantitatire eridence of any kind to guide us. Still, a few observations may be usefully hazarded, in passing, which may bear more or less directly upon the point.

In our ripened Cereal crops, we find 1 part of Nitrogen to somewhere about 30 parts of carbon; and in our Leguminous crops, 1 part of Nitrogen to about 15 or fewer parts of carbon. It is supposed that the atmosphere, on the arerage, contains 1 part (or ratlier more) of carbon in the form of carbonic acid to 10,000 parts of air. We mar. perhaps assume, as an extreme amount, that the atmosphere contains only 1 part of Nitrogen in the form of ammonia to about $12,000,000$ parts of air. Adopting these assumptions, there would obriously be, instead of only 30 or 15 times less Nitrogen than carbon (as in the respective crops), 1200 times less Nitrogen in the ambient air in the form of ammonia, than of carbon in the form of carbonic acid in the same medium.

If, however, we were to adopt as more nearly the amount of ammonia in the air that found by M. G. VILLE (namely, only about one-fifth as much as we hare assumed abore), it would then appear that there were 6000 times less of Nitrogen in the air in the form of ammonia, than of carbon in that of carbonic acid.

Taking the former or more farourable assumption of the tro, the result rrould be, that the ambient atmosphere contained Nitrogen as ammonia, to carbon as carbonic acid, in a proportion 40 times less than that of Nitrogen to carbon in the Cereal produce, and 80 times (or more) less than that of Nitrogen to carbon in the Leguminous produce. Adopting M. G. VilLE's estimates, on the other hand, the proportion of the so-combined Nitrogen to the so-combined carbon, in the air, would be 200 times less than that of the Nitrogen to the carbon in the Cereal crops, and about 400 times less than that of the Nitrogen to the carbon in the Leguminous crops. 
Looking, therefore, at the subject from the point of view of actual quantity merely, the ammonia in the atmosphere would appear very inadequate to yield Nitrogen in a degree at all corresponding to the yield of carbon by carbonic acid. It would appear too, from the observations hitherto recorded bearing upon the point, that the amount of Nitrogen existing in the atmosphere as nitric acid is very much less than that existing as ammonia. Hence, the inclusion, in the estimate of the combined Nitrogen in the atmosphere, of the amount existing as nitric acid would, in point of quantity, by no means materially affect the question.

But it is worthy of remark, in reference to the question of the proportion of Nitrogen as ammonia to carbon as carbonic acid, that may be available to vegetation from atmospheric sources, that, although the actual amount of Nitrogen as ammonia in the atmosphere is very small compared with that of the carbon as carbonic acid, yet, a given amount of water would absorb very much more Nitrogen as ammonia, or dissolve very much more Nitrogen as carbonate of ammonia, than it would absorb of carbon in the form of carbonic acid under equal circumstances. In illustration, it may be mentioned that water at $60^{\circ} \mathrm{F}$. (about $15^{\circ} .5 \mathrm{C}$.) would at the normal pressure absorb about 850 times as much Nitrogen in the form of ammonia as it would of carbon in the form of carbonic acid; and, under equal circumstances, very many times more Nitrogen as carbonate or even as bicarbonate of ammonia would be dissolved, than there would be of carbon as carbonic acid absorbed. There would appear to be, then, a compensating quality for the small actual amount of Nitrogen as ammonia in proportion to carbon as carbonic acid in the atmosphere, in the greater absorbability or solubility of the compounds in which Nitrogen exists than of the carbonic acid in which the carbon is presented. How far, however, the compensating quality here suggested may really influence the proportion of the Nitrogen to the carbon available from the atmosphere, in the combined form, under the actual conditions involved in vegetation, is a question the numerous and intricate bearings of which we do not profess here to enter upon.

Before passing from this question of the direct absorption of Nitrogen in the combined form from the atmosphere by plants themselves, one or two further observations may yet be made which are suggested by the actual facts of agricultural production. It is undoubtedly the case that the Graminaceous crops depend very materially upon combined Nitrogen within the soil, to determine the amount of their produce. They seem, however, to be comparatively independent of carbonic acid yielded by manure within the soil. The Leguminous crops, on the other hand, appear to be much less benefited by direct supplies of characteristically nitrogenous manures. It would hence seem that they are more able to avail themselves of Nitrogen supplied in some way by the atmosphere, possibly by the aid of their green parts. But it can hardly be to a greater mere extent of surface above ground that the property which the Leguminous plants possess of acquiring a greater amount of Nitrogen than the Graminaceous ones, over a given area of land, and under otherwise equal circumstances, is to be attributed. 


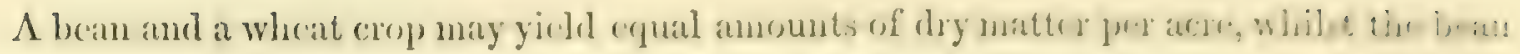
produce would contain from two to three times as much Nitrogen as the wheat. Devertheless some attempts at alphesimate measurement hate indicater that the wheat-phat offers a greater external superficies in relation to a given weight of dry substance, than does the bean. 'The wheat-plant would, of course, show a still higher relation of superficies to a given amount of Nitrogen fixed. If, therefore, the larger amount of Vitrogen yielded per acre by a bean than by a wheat crop be due to a larger assumption of it directly from atmospheric sources in some form, it is obvious that the result must be due to character, and function, and not to mere extent of surface above ground. In comnexion with this point it may be observed, more particularly with reference to the crops that are grown for their ripened seed, that the Leguminous ones generally maintain their green and succulent surface in relation to a more extended period of the season of active growth and accumulation than do the Graminaceous ones.

(7) Assimilation of free or uncombined Nitrogen by Plants. - It has been seen, in the course of the foregoing brief review of the various sources of combined Nitrogen to plants, that those of them which have as yet been quartitatively estimated are inadequate to account for the amounts of Nitrogen obtained in the annual produce of a given area of land beyond that which may be attributable to the supplies by previous nanuring. It must be admitted, too, that the sourees of combined Nitrogen which have been alluded to as not yet even approximately estimated in a quantitatire sense (if indeed they are all fully established qualitatively) offer many practical difficulties in the way of any such investigation of them as would afford results directly applicable to our present purjere. It appeared, therefore, that it would be desirable to settle the question, whether or not that vast storehouse of Nitrogen, the atmosphere, in which the vegetation which corers the Earth's surface is seen to live and flourish, be of any measurable arail to the growing plant, so far as its free or uncombined Nitrogen is concerned.

The settlement of this question (whether affirmatively or negatively) would at any rate indicate the degree of importance to be attached to the remaining open points of inquiry. Indeed, were it found that plants generally, or some of those we cultivate more than others, were able to fix Nitrogen from that presented to them in the free or uncombined form, we should, in this fact, have a clue to the explanation of much that is yet clouded in obscurity in connexion with the chemical phenomena of Agricultural production. We should establish for regetation, the attribute of effecting chemical combinations with an element at once the most reluctant to associate itself with other bodics in obedience to laboratory processes and at the same time apt to rid itself of connexions once formed in the most violent manner-as the explosire character of many Nitrogen compounds forcibly illustrates. We should further be able, much more satisfactorily than we are at present, to account-by processes established to be going on under our own obserration-for the actually large total amount of combined Nitrogen which we know to exist and to circulate, in land and water, in animal and regetable life, and in the atmosphere. 
But another and potent reason for investigating the relation of plants to the free or uncombined Nitrogen of the atmosphere is to be found in the fact, that the question has, of late years, been submitted to an immense amount of research by numerous experimenters, and from the results obtained very opposite conclusions have been arrived at. Thus, M. Boussingault concludes that plants do not assimilate the free or uncombined Nitrogen of the atmosphere. M. G. VILLE maintains, on the contrary, that the assimilation of free Nitrogen does take place, and further, that, under favourable circumstances, a considerable proportion of the Nitrogen of a plant may be derived from this source. Others have experimented in connexion with the subject on a more limited scale; and various explanations have been offered of the discrepant results and conclusions of M. Boussixgault and M. G. Vilie.

Before entering upon the discussion of our own experimental evidence in regard to the question of the assimilation of free or uncombined Nitrogen by plants, it will be desirable to pass in review the methods, results, and conclusions of M. Boussingault and M. G. ViLLE; and also of some other experimenters, who seem to have been led to take up the subject by a consideration of the contrary opinions arrived at by Botssixa.1ULT and VILLE.

SECTION IT.-REVIEW OF TIIE RESEARCHES OF OTHERS, ON THE QUESTION OF THE ASSIMILATION OF FREE NITROGEN BY PLANTS, AND ON SOME ALLIED POINTS.

It has already been mentioned that, in 1837, Boussingault took up the question of the sources of the Nitrogen of Plants where De Saussure had left it more than thirty years before. De Sausscre and his predecessors had sought to solve the question, among others, whether plants assimilated the free or uncombined Nitrogen of the atmosphere, by determining the changes undergone in the composition of limited volumes of air by the regetation of plants within them. Boussingault pointed out that the methods which had been adopted were not sufficiently accurate for the determination of the point in question. The general plan instituted by himself, and adopted with more or less modification in most subsequent researches, was:-

To set seeds or plants, the amount of Nitrogen in which was estimated by the analysis of carefully chosen similar specimens.

To employ soils and water containing either no combined Nitrogen, or only known quantities of it.

To allow the access, either of free air (protecting the plants from rain and dust), of a current of air freed by washing from all combined Nitrogen, or of a fixed and limited quantity of air, too small to be of any arail so far as its compounds of Nitrogen were concerned. And finally-

To determine the amount of combined Nitrogen in the plants produced, and in the soil, pot, \&c., and, so, to provide the means of estimating the gain or loss of Nitrogen during the course of the experiment.

MDCCCLII. 


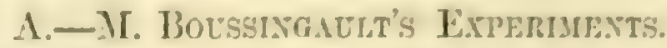

1. M. Boussivgault's experiments in 1837 and 1838, in which the plants were alloved fice access of air, but were protected from rain and dust.

In 1837 * BoussixGaltut grew; in bumt soil, watered with distilled water, and with the aceres of free air, a pot of 'Trifolium for two months, and another for them month-; also a pot of Wheat for two months, and another for three months.

The total Vitrogen in the seeds sown in the two experiments with Tirifilime annement to 0.224 gramme. The Nitrogen in the produce, soil, pot, \&e., amounted to 0.270 gramme. There was a gain, therefore, of 0.052 gramme of Nitrogen $=$ nearly 20 per cent. of the total Nitrogen of the products. 'The derelopment of regetable matter, implying, of course, the assimilation of carbon, hydrogen, and oxygen, was, howerer, in a much greater proportion; the dry matter of the produce in the two experiments amounting to nearly three times that of the seed sown.

In the two experiments with Wheat, the total Nitrogen in the seed ras estimated at 0.100 gramme. The Nitrogen in the products was exactly the same amount. In the case of the Wheat, there was, therefore, no gain of Nitrogen indicated. Nerertheless the dry matter of the produce amounted to nearly double that of the seed.

In 1838t, Boussixatut, in a similar manner, sowed Peas containing 0.046 gramme Nitrogen. The plants obtained; yielded flowers and ripe seed, and their dry matter was more than four times as much as that of the seed sown. The Nitrogen of the total products amounted to 0.101 gramme. Here again, therefore, the Leguminous plants seemed to gain Nitrogen from some undetermined source.

Botssixgault made experiments in the same year (1838), with Trifolium, and with Onts. In these cases, he commenced with carefully selected plants instead of with seeds. The Trifolium nearly trebled its total regetable matter during growth; and it gained 0.023 gramme of Nitrogen out of 0.056 gramme in the total products. The Oat, on the other hand, indicated only 0.053 gramme Nitrogen in the total products, whilst it was estimated that there was 0.059 gramme contained in the plants taken for the experiment. The total vegetable matter was, howerer, doubled.

The substance of M. Botssixgdult's conclusions from the abore experimental results, may be stated as follows:-That under sereral conditions, certain plants seem adapted to take up the Nitrogen in the atmosphere; but that it ras still a question, under what circumstances, and in what state, the Nitrogen was fixed in the plants. He submitted - that the Nitrogen might enter directly into the organism of the plant, provided its green parts were adapted to fix it; that it might be conreyed into the plant in the ac̈rated water taken up by its roots; that, as some phrsicists suppose, there may exist in the atmosphere an infinitely small amount of ammoniacal rapour. He further suggested that the gain of Nitrogen beyond that supplied in manure, which he had observed in agricultural production on the large scale, and which he thought eridently

* Ann. de Chim. et de Phys. sér. 2. tome lrrii. Is38.

t. Ibid tome lrir. 
came from the atmosphere, might be partly due to Nitrate of Ammonia produced by electrical action and brought down by rain.

2. MI. Botssurgaulr's experiments in 1851, 1852, and 1853, in which the plants were confined in limited rolumes of air**

BotsSLNGAULT resumed the subject of the sources of the Nitrogen of regetation in 1851. His object was, apparently, to settle more definitely, whether plints assimilated Nitrogen from any other source than the combined forms of it.

In his experiments in 1851 and 1852, Borssixgatut confined his experimental plants under a glass shade of about 35 litres capacity, which shut off the free access of external air by resting in a lute of sulphuric acid. Tubes passed under the shade for the supply of carbonic acid, and water, as they might be needed. Pumice-stone, coarsely powdered, washed, ignited, and cooled orer sulphuric acid, served as soil. To this, at the commencement, some of the ash.from farm-yard manure, and also from seed of the kind to be sown, was added.

In 1851, a Haricot was grown under these conditions, the seed of which, when sown, was estimated to contain 0.0349 gramme of Nitrogen. After two months of growth, flowers being formed, the dry substance of the plant was more than double that of the seed sorm; and the total products yielded only 0.0340 gramme of Nitrogen. There was, therefore, apparently a slight loss of Nitrogen, which amounted, howerer, to less than a milligramme. In 1852, two Haricots, sown respectively in separate pots, contained, together, 0.0455 gramme Nitrogen. They were each allowed to grow for three months, during which time the dry substance was nearly doubled; and in one instance cpen flowers were formed. The products of both experiments taken together yielded to analysis only 0.0415 gramme of Nitrogen. 'There was an apparent loss, therefore, in the two experiments, of 4 milligrammes of Nitrogen. It is seen, then, that in these new experiments with Leguminous plants, in which the free circulation of atmospheric air was not permitted, there was not the apparent gain of Nitrogen that had been met with in Botssingault's early experiments (in 1837 and 1838), in which free access of air into the enclosing apparatus was allomed.

In 1851, ten seeds of Oats, and in 1852 four, were experimented upon in a similar manner. In both cases there was an apparent very slight loss of Nitrogen. In the first case the Oats vegetated for two months, and in the second for $2 \frac{1}{2}$ months; and in the latter, the plant arrived at the point of shooting forth the ear.

In 1853, the apparatus adopted by Borssixg.17Lt consisted of a large globe, or carboy; of white glass, having a capacity of 70 or 80 litres. At the bottom of this ressel, a matrix of pumice-stone (or bunt brick) and ashes, prepared as in the last series, was placed to serve as soil. This was watered with distilled water, and then the seeds mero sown. The neck of the vessel was then closed with a cork, through a perforation in which, a flask of carbonic acid was inverted, whose aperture, opening into the globe, was

* Ann. de Chim. et de Phys. sér. 3. tome ìli. 1851.

3 Q 2 
somewhat contracted. Finally, access of air from without was excluded by bandages of cnoutchone, which were so secured as to render the whole apparatus air-tight.

In such an apparatus, Boussivanule made five separate experiments with White Lupins. In all he sowed thirteen seeds, which were estimated to contain, together, 0.2710 gramme of Nitrogen. The experiments extended over prerionls sary ine form ix to eight wecks. In one instance, burnt brick instead of pumice-stone was used as the soil; and in this case, as well as in one where pumice was used, bone-phosphate as well as ashes was added as manure. 'The dry matter of the produce was about three times as much as was contained in the thirteen secds sown. The Nitrogen in the total products of the five experiments amounted to 0.2669 gramme. There was, therefore, a loss, in the five experiments taken together, of about 4 milligrammes of Nitrogen. In two of the cases there was a slight gain of Nitrogen, but in neither instance did it amount to 1 milligramme.

In a similar apparatus, two experiments were made with Dwarf Haricuts, a sinerle weet only being sown in each case. One of the experiments extended orer two months, and the other over two and a half months. In both instances flowers were formed, and in one of them seed. 'The dry matter of the produce was three to four times as much as that of the seed sown. Taking the two experiments together, the Nitrogen contained in the seed was estimated at 0.0652 gramme; and that found in the products amomiterl to 0.0637 gramme. There was a loss, therefore, of $1 \frac{1}{2}$ milligramme of Nitrogen.

There was, then, in this third series of experiments with Leguminous plants, again rather a loss than a gain of Nitrogen,- the supplies of it in this case being confined to the combined Nitrogen contained in the seeds sown, and to the free or uncombined Nitrogen in the fixed and limited volume of air within the apparatus.

Still in the same apparatus, Boossivanult sowed Garden Cress. Thirteen seeds were sown, all of which germinated, but three plants only surrived. The growth of these extended orer three and a half months; and flowers and seed were produced. The Nitrogen in the products amounted to precisely as much as was estimated to be contained in the thirteen seeds sown.

The last experiment in this closed globular apparatus was as follows: Tro White Lupins were sown to grow ; and eight others were applied as manure, after treatment with boiling water to destroy their powers of germination. The experiment continned for a period of between four and five months. The dry matter of the produce was nearly twice as much as would be contained in the ten seeds involved in the experiment. The whole ten seeds were estimated to contain 0.1827 gramme of Nitrogen; whilst the total products yielded only 0.1697 gramme. The loss of Nitrogen was here, therefore, $1: 3$ milligrammes; or about one-fourteenth of the whole amount inrolred in the experiment. Botssixgutut considered that the loss was probably due to free Nitrogen being given off in the process of decomposition of the organic matter employed as manure.

In order to ascertain whether the limitation of growth in the foregoing experiments was due to the limitation in the amount of air, or to a deficiency of arailable Nitrogen in the matters used as soil, Borssixg.sult sowed Cress in a good soil, placed the ressel 
in a limited atmosphere, and supplied carbonic acid. The result was, that the plants thus grown, in a limited atmosphere, but in a good soil, were even more luxuriant than a parallel set, grown in a similar soil, in the open air. In both cases a large quantity of seed was produced.

\section{M. Bocssingault's experiments in 1854 , with a current of washed air*}

In this series of experiments, Borssixgatut supplied his plants with a current of air, previously washed by passing first through ressels containing pumicc-stone saturated with sulphuric acid, and then through water. He also supplicd carbonic acid from bicarbonate of soda acted upon by sulphuric acid,-the gas evolved being passed first orer chalk, then through a solution of carbonate of soda, and lastly over pumice-stone saturated with a solution of carbonate of soda. The enclosing apparatus cousisted of a metal-framed glass case of 124 litres capacity, which was cemented down upon a polished iron plate, upon which the experimental pots were placed. Across one side of the case was a metallic joint-bar, in which were apertures for the insertion of tubes for the admission of the washed air, and for the supply of water and carbonic acid. On the opposite side was a similar joint-bar, to an aperture in which, a tube was attached connecting the case with an aspirator of 500 litres capacity. By this apparatus, therefore, the plants could be supplied with a current of air freed from ammonia, with water, and with carbonic acid, at pleasure. During the experiment, the atmosphere in the Case generally contained from 2 to 3 per cent. of carbonic acid. Lastly, by means of one of the apertures any withered leaves were removed as they fell from the plants; and they were then dried and preserved for analysis with the remainder of the products.

One of the experiments made in this apparatus was with a single Lupin, which was allowed to grow for two and a half months. The dry matter of the produce was more than six times that of the seed. The Lupin sown was estimated to contain 0.0196 gramme of Nitrogen. The Nitrogen found in the products amounted to 0.0187 gramme. There was a loss, therefore, of nine-tenths of a milligramme of nitrogen.

Four experiments were made with Dwarf Haricots, in three of which single seeds, and in the fourth two seeds, were sown. One experiment lasted over two and a half months, and the plant flowered; one over three months, and the plant seeded; one orer three and a half months, in which case also the plant seeded; and another over three and a quarter months. The dry substance of the produced plants was firom three to four times as much as that of the sced sown. The total Nitrogen in the five seeds employed in the four experiments was estimated at 0.1672 ; the Nitrogen found in the total products amounted to $0 \cdot 1661$ gramme. There was therefore, upon the whole, a loss of 0.0011 gramme of Nitrogen. In two of the experiments there was a loss of 1 milligramme each of Nitrogen; and in the other two a gain, amounting to less than 1 milligramme in each case.

In the next experiment, one Lupin seed was sown to grow, and another was steeped in hot water and applied as manure. The dry matter of the produce from the one sced amounted to nearly three times that of the two seeds employed in the experiment. The 


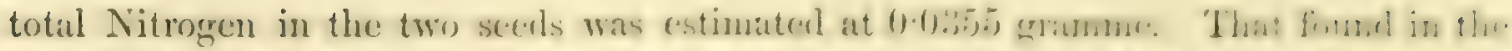

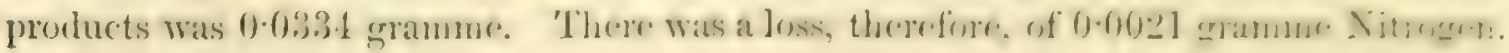

Lastly, forty-two seeds of Cress were sown, twelve of which served as manure. Many of the plants seeded. 'The dry matter of the produce was more than five times that of the seed. 'The Nitrogen in the forty-two seeds was estimated at $0 \cdot 0040$ gramme. 'I'hat found in the products amounted to 0.0052 gramme. 'There was a gain, thercfore, of 0.0006 gramme, or little more than half a milligramme of Jitrogen.

The whole of these experiments in 1854, in which a current of air was supplied to the plants, taken together, indicated a slight loss of Nitrogen. 'This was the case, notwithstanding that all the plants, excepting the Cress, were of the Leyuminous family.

\section{1I. Boussingaulit's experiments in 1851, 1852, 1853, and 1854, in which the I'lants} were allowed free access of air, but were protected from rain and dust".

Contemporaneously with the sereral series of experiments abore described, BotsSINGAULT grew plants simply corered with a case, in such a manner as to exclude any material amount of dust, but so as to allow of the fiee access of the extemal air.

Single Haricots were grown in the manner here described, in the seasons of 1551 , 1852, 1853, and 1854, respectirely. All four plants flowered; one podded; and one seeded. The Nitrogen in the seed of the four experiments amounted to 0.1173 gramme. 'That found in the regetable produce, soil, \&c., was $0.123 \mathrm{~S}$ gramme. There was a total gain of Nitrogen, therefore, under these circumstances, of 0.0065 gramme. In one case there was an apparent loss of Nitrogen of a little more than 2 milligrammes; in the three others the gain was about equal. The dry matter in the produce amounted to from three to four times as much as that in the seeds sorrn.

In the seasons of 1853 and 1854 , three experiments of the same kind were made with White Lupins. 'The dry matter of the produce was from three to four or more times as much as that in the seed. 'The Nitrogen in the seed of the three experiments taken together amounted to 0.0780 gramme. 'That in the total products was 0.0873 gramme. Here again, therefore, there was a gain of Nitrogen-amounting in this case, in all, to between 9 and 10 milligrammes.

Under similar conditions, Oats were grown in 1852 which yielded seed. The Nitrogen sown was 0.0031 gramme. That in the products was 0.0011 gramme. There ras a gain, therefore, of 1 milligramme of Nitrogen.

In like manner, five seeds of Wheat were sorn in 1853. The dry matter of the produce was more than three times that of the seed. 'The Nitrogen in the seed was estimated at 0.0064 gramme. That in the products was 0.0075 gramme. The gain was, therefore, 0.0011 gramme.

Lastly, 210 seeds of Cress were sorm in 1854. Many of the plants seeded; and there was, of course, a considerable gain of dry matter. The Nitrogen in the seed was 0.0259 gramme. That in the products amounted to 0.0272 gramme. There mas a gain, therefore, of 0.001 .3 gramme.

..* Ann. de Chim. et đe Pliys, sér. 3. tome sliii. 1555. 
Taking all these experiments together, in which the plants were shaded from rain and dust, but still allowed free access of air, the total gain of Nitrogen was 0.0192 gramme upon 0.2307 gramme supplied in the seed sown. 'There was a gain of Nitrogen, therefore, equal to about one-twrelfth of that. som in the seed. BoussingaulT considered that part of the gain was due to organic corpuscles, and part to the ammonia in the atmosphere. He also considered that, bearing in mind the circumstances of the experiment, the gain was not sufficiently great to justify the conclusion that there had been any assimilation of the free or uncombined Nitrogen of the air.

\section{M. Boussixgault's collateral experiments to control and explain his results*.}

In order to ascertain the amount of Nitrogen that might be introduced into the materials under experiment when the matter used as soil, \&c. was not excluded from the air whilst cooling after ignition, or when free access of air was allowed during the whole period of vegetation, Bousslygauli instituted the following experiments.

Sand, powdered brick, powdered bone-ash, and wood-charcoal were each exposed to the air for two or three days after being ignited, and then the Nitrogen determined in them. 'The result was that, after this exposure, a kilogramme of sand gave 0.5 milligramme, a lilogramme of powdered brick 0.5 milligramme, a hilogramme of pordered bone-ash 0.84 milligramme, and a kilogramme of wood-charcoal 2.9 milligrammes of ammonia.

In orcter to test the influence of the organic corpuscles of the atmosphere, a pot of burnt sand, with ashes, the whole moistened with water, was so arranged under a shade as nevertheless to allow free access of air, and it was so exposed for two and a half months. At the end of this period small spots of cryptogamic regetation were visible on the surface of the sand; but the whole yielded only 0.74 milligramme of Nitrogen.

Again, Boussingault found that unless the ashes used as manure were burnt until nearly all apparent traces of carbon were destroyed, they were liable to retain more or less and sometimes material amounts of Nitrogen. In some imperfectly burnt ashes cyanides, and in some, ferrocyanides were found; in others the Nitrogen seemed to exist in neither of these conditions.

With regard to the much larger gain of Nitrogen indicated in his early experiments in free air (1837 and 1838) than in those made more recently, BoussivguUlt remarks that the result may be partly due to the comparatively defective methods of analysis at the early date, and partly also to the distilled water used for watering the plants containing some ammonia. For, at the time of his first experiments, he was not aware of the fact, since learned in his analyses of rain and other waters, that water distilled from that which contained minute quantities of ammonia did not come over free from it until about two-fifths of the whole had been drawn off.

It will be observed that, in most of the experiments of BoussisG.ault thus far passed in review, he limited the supply of Nitrogen to the plants to that contained in the seed sown, and to that which they could obtain from the atmosphere, either washed or un-

\footnotetext{
Ann. de Chim. et de Physo sér. 3. tome sliii. 1855.
} 
washed, in which they grew. In no case among those experiments in which the modern refinements of analysis were had recourse to did he find, either with Leguminous or with other plants, surh a gain of Nitrogren beyomd that supplind in the ared. as conld lead to the conclusion that the free or uncombined Nitrogen of the atmongherse

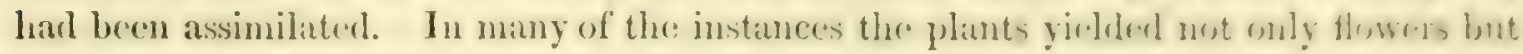
seed; and hence it might be concluded that the comditions prosided were anderinate for the performance, by the plant, of the complete conrese of its natural functions of wrom th. Still it might be objected that the vigour of growth was somewhat linuited, and that, under these circumstances, the plant might well refuse to perform the, prerhap, difficult office of assimilating a very refractory elementary body. In a few instances, secels where: germinating power had been destroyed were supplied as manure. In these cases the amount of Nitrogen assimilated by the plants was much greater than that contained in the living seed sown; and the luxuriance of growth was consequently comparutively ereat. Nevertheless, instead of a gain, there was generally a loss in the total amount of combined Nitrogen, which was considered to be due to the evolution of free Nitrogen ly the decomposing manurial matter. 'To get increased rigour of growth-to avoid, if posible, a loss of Nitrogen such as is above supposed-and, at the same time, to determine whether or not the Nitrogen of Nitrates were really assimilable by plants-Bocssirgatiot has latterly made some experiments in which Nitrates were employed as manure, a brief notice of the results of which should be here given.

\section{M. Boussixgadut's experiments in which he supplied combined Aitrogen in the form of Nitrate of Potash, or Soda*.}

In 1855 Borssixgatut made one experiment with IIelianthus in which he supplied no nitrate to the soil, and another in which a small known quantity of Nitrate of Potan was employed. In a third experiment Cress was grown in a manured soil, in a fourth in a soil destitute of combined Nitrogen, and in a fifth in a soil to which a known quantity of Nitrate of Soda was added. In the case of the manured soil, and in the two cases where Nitrate was employed, there was a very considerable increase in the assimilation of carbon; and there was also much more Nitrogen assimilated than was supplied in the seeds sown. The increased assimilation of Nitrogen where Nitrate was used, did not, however, exceed that supplied in the manure. Borssragaver concluded that the gain of Nitrogen was to be attributed to the Nitrogen of the Nitrate.

Lastly in regard to Borssixgallit's experiments: In 1858 the resumed the question of the action of Nitrates upon vegetation. He grew two separate pots of Ielianthus, two seeds being sown in each pot. The soils were composed of sand and quartz well washed from saline matter and ignited. To one pot Nitrate of Potash containing 0.0111 gramme of Nitrogen, and to the other Nitrate containing 0.0222 gramme Nitrogen, was added. In the first case, he did not get back, in the plant, soil, and pot, the Nitrogen of the seed and Nitrate by 0.0014 gramme. In the second experiment the loss of Nitrogen amounted to just 1 milligramme. BorssLyciclt found, however, that there remained

- Ann. de Chima. et de Phys. sér. 3. tome slri. 1550.

+ Compt: Rend. tome Ilrii. $155 \mathrm{~s}$. 
in the soil an amount of carbonate of potash very nearly corresponding in potash to the amount of nitrate of potash which would represent the observed loss of Nitrogen. He concluded that nitrate had been decomposed in the soil, by the organic matter of the débris of the seeds and of the roots, and that Nitrogen had been evolved. If we clearly understand this explanation of the loss of Nitrogen of the nitrate, we would suggest that it would seem to require for its validity that the plant should have assimilated potash from the nitrate exactly corresponding in amount to the Nitrogen it fixed from the same source.

From the results of these experiments with nitrate, Boussingauli drew the following conclusions :-

1. That there was no assimilation of free Nitrogen.

2. That there was a loss of supplied Nitrogen, either from the soil, or by the plant.

3. That, in the two cases, the amount of carbon assimilated bore a close relation to that of the Nitrogen taken up by the plant.

It is seen, then, that the results of the laborious inrestigations of Boussixgault, extending at intervals over a period of more than twenty years, have led him to conclude that, neither Leguminous plants, nor the others experimented upon, were able, either when their supplies of combined Nitrogen were limited to that contained in the seed sown, or when their vigour of growth was stimulated by artificial supplies of combined Nitrogen, to assimilate the free or uncombined Nitrogen of the atmosphere.

\section{B.-M. G. Ville's Experinietst.}

\section{M. G. VILLE's determinations of the Ammonia in the atmosphere.}

M. G. VILLe, of Paris, commenced his investigations, on the subject of the assimilation of Nitrogen by plants, in 1849. He first sought to determine the proportion of Ammonia in the atmosphere. 'To this end, he aspired kmown quantities of air through acid, and determined the amount of ammonia absorbed. He operated upon very much larger volumes than previous experimenters had done. His results show, moreover, a much smaller proportion of ammonia in the air than those of others.

The air of Paris, during part of 1849 and part of 1850 , gare a mean of only 0.0237 part by weight of ammonia, to $1,000,000$ parts by weight, of air; and that of the saburbs of Paris, during some period of 1852 , gave 0.0211 parts of ammonia, to $1,000,000$ parts of air.

2. M. G. VILLE's general plan of experimenting on the question of the assimilation of Nitrogen by plants.

MI. G. Ville employed specially-made porous flower-pots, and used, as soil, washed

* Recherches Expérimentales sur la Végétation, par M. Georass Ville. Paris, 1853. MDCCCLXI. 


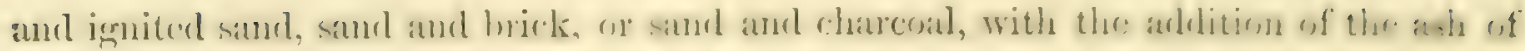
the plant to be grown. IIe planted seeds or plants, the composition of which was estimated by the analysis of parallel specimens. Several pots were for the most part

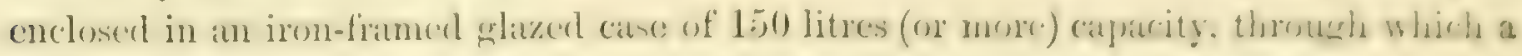
current of air equal in amount to several times the volume of the ressel was aspired daily. Carbonic acid and distilled water were supplied as needed. In some cases the aix admitted into the apparatus was only previously freed from dust; and then the amomit of atmospheric ammonia that would be brought in was calculated according to the determination of the proportion of ammonia in the air, above alluded to. In other cases the aspired air was previously freed from ammonia by washing. In some experiments, ammoniacal gas was passed, in known quantities, into the air of the apparatus. Lastly, others were made, in which combined Nitrogen was added to the soil in the firm of nitrate, or of ammonia salts; and in these cases the plants were allowed to grow in free air, only shaded from xain and dust.

\section{M. G. VILLE's experiments in 1849 and 1850, in which the plants were supplied with a current of unwashed air.}

In 1849, sand was used as soil; three pots of plants were grown for two months; namely, one of Cress, one of large Lupins, and one of small Lupins. The air admitted into the apparatus was not previously deprived of its natural ammonia. 'The dry substance of the produced Cless plants amounted to more than sixteen times that of the seed sown. The Nitrogen in the Cress seeds amounted to 0.026 gramme; that in the products to 0.147 gramme. The Nitrogen in the products ras, therefore, betreen fire and six times as much as that in the seed; and the actual gain of it amounted to 0.121 gramme. In the case of the large Lupins, the dry matter of the produce was about $3 \frac{1}{2}$ times as great as that of the seeds sown; but there was neither gain nor loss of Nitrogen. 'The small Lupins gave $2 \frac{1}{2}$ times as much dry substance in the produce as was supplied in the seeds; and of the Nitrogen of the seeds sown, there was an apparent loss of rather more than one-fourth, during the experiment.

The total gain of combined Nitrogen in the apparatus, taking the three experiments together, was 0.103 gramme. The Nitrogen in the ammonia of the current of unwahed air, was, howerer, estimated at only 0.001 gramme. M. G. VILLE concluded, therefore, that the Cress had appropriated a cousiderable quantity of the free or uncombined Nitrogen of the atmosphere.

. The plants experimented upon in 1850 , rrere Colzn, Wheat, Rye, and Maize. In the case of the Colza, the experiment commenced with young plants, but in the other cases with seed. The four pots were placed in an apparatus similar to that used before, and the conditions supplied were also the same as in 1849 .

The dry matter of the produced Colza plants amounted to between forty and fifty times as much as that of the young plants when taken for experiment. The Nitrogen was also increased more than forty-fold. The dry matter of the Whent plants was about 
four times that of the seed sown; and the Nitrogen in the total products was nearly double that in the seed. The dry substance of the produced Rye plants was fire times, and their Nitrogen nearly three times that of the seed. In the experiment with Maize, the dry matter increased only about three times, but the Nitrogen nearly $4 \frac{1}{2}$ times.

The actual gain of Nitrogen in the total products of the four experiments, was 1.1803 gramme. The whole admitted in the form of atmospheric ammonia was estimated at 0.0017 gramme, or less than 2 milligrammes. M. Ville remarks, moreover, that an examination of the distilled water before being used to water the plants, and of the water afterwards remored from the apparatus, showed more ammonia in the latter than in the former. The conclusion from this second series of experiments also was, therefore, that a considerable quantity of free or uncombined Nitrogen had been assimilated.

\section{II. G. VILLE's experiments in 1851 and 1852, in which the plants were supplied with a current of air washed free from ammonia.}

In 1851, one pot of Sun-flower, from seed, and two pots of 'Tobacco, starting from plants transplanted from good soil, were grown together, under circumstances similar to those of the preceding experiments, with the exception that now the air was deprired of its ammonia by passing orer pumice-stone saturated with sulphuric acid, and also through a solution of bicarbonate of soda, previous to entering the apparatus.

The Sun-flowers gave 95 rudimentary grains; but the Tobaccos did not florrer. Horrever, taking the three experiments together, the dry matter increased nearly 200 -fold, and the Nitrogen increased nearly 40 -fold, during a period of growth of three months. The total gain of Nitrogen in the apparatus was 0.481 gramme.

In 1852, the conditions of the apparatus were the same as in 1851. The selection of plants was as follows:-One pot of Autumn Colzas, starting with young plants; one of Spring Wheat, from seed; one of Sun-flower, from seed; and two of Summer Colzas, from plants.

In every case the dry matter of the produce was many times that of the young plants or seed. In the case of the Sun-flower, it was more than 100 times that of the seed. In each experiment, there was of Nitrogen, also, much more at the conclusion, than at the commencement. In the experiment with Autumn Colzas there were 4.7 times, in that with Spring Wheat 2.2 times, in that with Sun-flower 25.5 times, in one with Summer Colza 3.4 times, and in the other with Summer Colza 6.7 times as much Nitrogen in the total products as in the original plants or seeds. The total amount of Nitrogen gained in the five experiments, was 1.624 gramme, which was 5.3 times as much as was contained in the total original plants and seeds.

To show the degree of luxuriance of growth of the different descriptions of plant, it may be mentioned that the Winter Colzas flowered, but gave no seed; the Sun-flower gave 412 rudimentary grains; and the Wheat seeded completely, giving 47 grains. The Summer Colzas had little tendency to go to seed, but developed a great deal of leaf; and hence it was, it was supposed, that they gained large actual amounts of Nitrogen.

$$
3 \mathrm{R} 2
$$




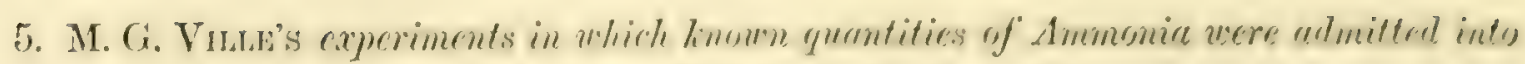
the atmosphere of the cnclosing apparatus.

In each of the three seasons 1850,1851 , and 1852, M. G. Vilide had a duplicate apparatus, enclosing, in each case, similar plants to those in the other, but with this difference in the conditions-that ammonin was supplied to the atmosphere of the second apparatus. As might be expected, the increase, both in dry substance, and in Nitrogen, was much the greater, in relation to the amounts of them contained in the seed or young plants, when ammonia was thus employed. In no case, however, did the plants take up Nitrogen equal in amount, much less exceeding, the whole of that supplied to the air in the combined form, as ammonia. 'The results have not, therefore, so direct a bearing on the question of the assimilation of free or uncombined Nitregen, as to require that we should quote them in any detail. Their chief interest was in showing the influence of ammoniacal supply, not only upon the rigour and luxuriance of growth generally, but upon the order, or course of development, of the plants, according to the stage of growth at which the application was made.

\section{Comparison of M. G. Ville's results with those of M. Boussivanult up to 1853 inclusice.}

It will be remembered that, up to 1853 inclusive, M. Borssivgatut's experimental plants had been grown either in free air-in which case they had fixed, from some source, slightly larger amounts of Nitrogen than were contained in the seed,- or in fixed and limited rolumes of air (carbonic acid being added), in which cases no gain of Nitrogen was observed. The gain of Nitrogen in the free air was, moreover, considered to be too small to indicate, under all the circumstances, any assimilation of free or uncombined Nitrogen. On the other hand, M. G. Virle's experiments up to the same period had indicated an enormous gain of Nitrogen. The Nitrogen in the products, indeed, sometimes amounted to more than forty times that contained in the seed.

Results so strikingly contradictory could hardly fail to excite great attention and interest among Chemists and Vegetable Physiologists. But M. VILLE's plants had been grown in a constant current of renewed air, and not in only a fired and limited rolume of it. This fact, and some other points, were alleged to account for the difference in result. At any rate, on the one hand, M. Boussivgault commenced in 1854, to experiment with a curvent of air; whilst, on the other, a Commission, composed of Members of the Academy of Sciences of France, was appointed to superintend the conduct of a new set of experiments by M. G. Tille. It has already been shown, that M. BorssixGALLT's new experiments in which a current of air was employed, did not indicate any assimilation of free or uncombined Nitrogen, any more than did those in which the plants had grown in limited volumes of air only. 


\section{M. G. VILLE's experiments conducted under the superintendence of a Commission comprising Mim. Dumas, Regaulut, Payen, Decaisne, Peligot, and Chevreul.}

These experiments were conducted at the Muséum d'Histoire Naturelle, Jardin des Plantes, Paris, in the autumn of 1854. M. CloEz was appointed to assist M. VILLE; and M. Crevreul reported on behalf of the Commission, in $1855^{*}$.

In an apparatus similar to that employed in the experiments of M. VILLE which have been already described, three pots of Cress were placed. The soil consisted of ignited brick and sand, to which was added some of the ash of the plant. Carbonic acid was supplied artificially; and the plants were watered with distilled water. The Cress in one of the pots did not thrive well; and, in this case, analysis showed a loss of 2 milligrammes of Nitrogen. In one of the other cases, there was a gain of 0.0492 gramme of Nitrogen, upon 0.0038 gramme supplied in the seed; and in the other, there was a gain of 0.0071 gramme of Nitrogen, upon 0.0039 gramme contained in the seed.

At the suggestion of one of the members of the Commission, a smaller vessel was also attached to the aspirator, in which one pot sown with Cress was placed. 'The soil being duly watered with distilled water, the apparatus was then closed, and not opened (as the other frequently was) until the conclusion of the experiment. In this case also, there was a considcrable gain of Nitrogen indicated, nanely, $0 \cdot 0287$ gramme gain, upon 0.0063 gramme in the seed.

Unfortunately, an element of uncertainty attached to the evidence afforded by these experiments made under the superintendence of the Commission, which is very much to be regretted. A quantity of distilled water taken from the same bulk as that used for watering the experimental plants was saved for analysis. The examination of this water devolved on M. CLoEz; who, unfortunately, was called away for some days, during the evaporation of the water with oxalic acid, with a view to the after-determination of any ammonia it might contain. M. PELIGoT determined the ammonia in the acid residue of the evaporation of this water, as well as in that of the water removed from the cases, after it had served in the experiments. The result was, that there was indicated such an excess of ammonia in the water before being used, orer that in the residual water after removal from the larger case, as more than covered the increase in the Nitrogen of the plants over that in the seeds sown. M. CLOEz found, however, that, in his absence, the craporation of the water had been conducted by the side of ammoniacal emanations from other processes. But when new portions of the original water were eraporated with proper precautions, less ammonia was indicated in it than in the water at the close of the experiment; and then, also, a gain of Nitrogen by the plants in the larger apparatus was indicated.

At any rate, howerer, the result with the single pot, in the small apparatus, showed a considerable gain of Nitrogen, even supposing the first analysis of the supplied water to be correct.

* Compt. Rend. 1855. 
From the result of the whole inquiry, the Commission announced the following con clusion:-

That the experiment made at the Ifusem distoire Naturelle by M. Vinfis, is consistent with the conclusions which he has drawn from his previous labours.

\section{M. G. VILLE's experiments in which the plents were exposed to free air, and Nitrates or Ammonia salts were employed as manure*.}

In 1855 and 1856, M. G. ViLue conducted a series of experiments with the double object, of investigating the action of nitrates upon regetation, and of still further examining into the capability of plants to assimilate the free or uncombined Nitrogen of the atmosphere. The whole of the experiments now in question were made in free air, the plants being only shaded from rain; that is to say, without any enclosing apparatus, or artificial current of air and supply of carbonic acid. 'The soils consisted of calcined sand; ashes of plants such as those to be grown were added; and distilled water was used for watering. Colza and Wheat were the plants experimented upon. Lastly, the special conditions of the experiments were, that nitrate of potash in smaller or in larger quantity, or nitrate of potash and different ammonia salts, in equiralent quantities so far as their Nitrogen was concerned, were employed.

To the prosecution of this scries of experiments, an exact methorl of estimating minute quantities of nitric acid was essential. M. Ville succeeded in derising such a method, which was very favourably reported upon by M. PeLocze, on behalf of a Commission composed of Mis. Balard, Peligot, and Pelotze.

In 1855, two pots, and in 1856 one pot, of Colzas were grown, to each of which 0.5 gramme of nitrate of potash was supplied as manure. By examination of the soil, the point was ascertained when the whole of the nitrate had been dramn from it by the plants. The experiment was then stopped; and analysis showed that the total produce contained almost identically the amount of Nitrogen supplied in the seed and in the nitrate. The dry regetable substance was, howerer, increased about 200 -fold.

Again in 1855, two pots of Colzas were sown, to each of which 1 gramme instead of 0.5 gramme of nitrate was added; and in 1856 tro more, with the same quantity. In each of these cases, the produce (which in dry matter was sereral hundred times that of the sced) contained considerably more nitrogen than had been supplied in the seed and in the nitrate. M. G. VIluE's conclusions were, that the plants had taken up the nitrate and assimilated its Nitrogen, and that when by the larger supply of nitrate the growth had been extended, the free Nitrogen of the atmosphere was also assimilated.

In 1855 an experiment was made with Wheat manured with $1 \cdot 72$ gramme of nitrate of potash. The plants were allowed to mature, and they gare 84 grains. There was more Nitrogen in the regetable produce alone, than in the sced and nitrate, and very much more in the total products, taking into account the residual Nitrogen in the soil. In 1856 , two pots of Wheat were somn, to each of which 1.765 gramme of nitrate were added. The plants of one pot were taken up at the time of flowering, and they contained

* Recherches Expérimentales sur la Végétation, 1857. 
almost identically the same amount of Nitrogen as was provided in the seed and nitrate. Those in the other pot were allowed to go to seed, and 119 grains were formed. In this case, again, the Nitrogen in the produce was much more than had been supplied, and very much more when the residual Nitrogen in the soil and pot was taken into the calculation. Lastly, on this head, two pots of Wheat (also in 1856) were sown without nitrate, and two with 0.792 gramme of nitrate to each. There was a considerable gain of Nitrogen in each of the four cases. 'The actual amount of gain was greater in the cases where the nitrate was employed; but the proportion gained, to that supplied; was greater where no nitrate was used.

To show the comparative efficacy of Nitrogen supplied in different conditions of combination, the following experiments were made during the season of 1856 .

Two pots of Colzas received, each 0.5 gramme of nitrate of potash; and two other pots of Colzas received each an amount of sal-ammoniac equivalent in Nitrogen to the 0.5 gramme of nitrate. 'The two experiments with Nitrate gave equal amounts of Nitrogen in the produce; and the two with sal-ammoniac, also equal amounts. But the two with nitrate gave more than $1 \frac{1}{2}$ time as much Nitrogen in the produce, as the two with sal-ammoniac. In two other experiments, double the quantity of nitrate and sal-ammoniac, respectively, was employed, and the growth was allowed to extend over a longer period. 'The amount of Nitrogen in the produce was, in both these cases, very much greater in proportion to the amount supplied, than in the preceding experiments where the smaller amounts of nitrate and sal-ammoniac were used. It was, moreover, more than three times as much where the nitrate, as where the sal-ammoniac was employed. There was, too, where the nitrate was used, a considerable amount of Nitrogen assimilated beyond that provided, in the combined form, in the seed and manure.

Experiments similar to the above were made with Wheat. Two pots, to each of which nitrate of potash was added, containing $0 \cdot 110$ gramme of Nitrogen, yielded, respectively, in produce, 0.218 and 0.224 gramme of Nitrogen. Two pots of Wheat, each manured with sal-ammoniac, containing also 0.110 gramme of Nitrogen, gave, respectively, in the produce, 0.161 and 0.124 gramme of Nitrogen. In the same way, nitrate of ammonia containing 0.110 gramme of Nitrogen gave 0.118 and 0.142 gramme, and phosphate of ammonia 0.116 and 0.150 gramme of Nitrogen in the matured Wheat plants.

In regard to the experiments of M. VILLE referred to in this Division(S), he remarks, that the point at which the artificially supplied Nitrogen becomes exhausted is indicated by a lightening of the colour of the leaves, and that it is then that the plants begin to assimilate the uncombined Nitrogen of the atmosphere. 'To secure this assimilation, he considers that it is not only necessary that the supply of combined Nitrogen, and the vigour of growth, should reach beyond a certain limit, but that the artificial supply itself should, on the other hand, not exceed a certain limit. Further, the gain of Nitrogen in the experiments conducted on the plan now under consideration was so great, that, bearing in mind preriously obtained results wherein the limit of the effect 


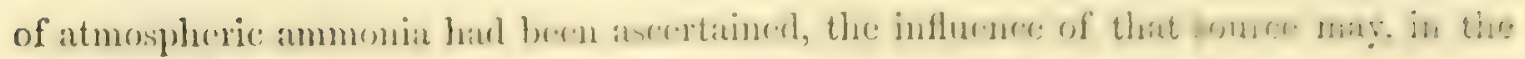
case of these new results, be entircly orerlooked.

The fact that a given amount of Nitrogen in the form of combination of a nitrate was

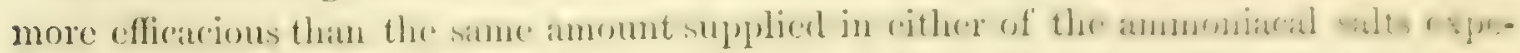
rimented upon, was held to show that the nitrate was taken up by the plants as such, and was not previously transformed into ammonia.

M. VILLE's experiments, as a whole, thus indicated that plants can take up Xitrogen in three forms-namely, as nitric acid, as anmonia, and as free Nitrogen. He enumerates the following conclusions:-

1. By means of nitre we may prove, without the aid of an enclosing apparatus, that plants absorb and assimilate the gaseous Nitrogen of the atmosphere.

2. Nitre acts by its Nitrogen. It is absorbed in the state of nitre.

3. In relation to the amount of Nitrogen, nitre is more active than ammonia-salts.

\section{M. G. VILLE's collateral experiments to control or explain his results".}

MI. VILLE adduces evidence of yet another kind, in support of his view that plants assimilate the free Nitrogen of the air. Air was passed through an otherwise closed apparatus, in which was placed a vessel containing calcined sand, or calcined sand and decomposing organic matter. In no case was nitric acil formed. Nitrification, the result of the combination of the oxygen and nitrogen of the air within the porous suil, was not, therefore, the source of the Nitrogen gained by his experimental plants.

Experiments were made in which a given amount of organic matter (Lupins, Gielatine, \&c.) was mixed with calcined sand, and exposed in an apparatus to a current of air, which carried the gaseous products into acid, to retain 'any ammonia that might be formed. The determination of the Nitrogen remaining in the matrix, and of the ammonia given off and absorbed by the acid, showed i loss of Nitrogen, which could only have passed away in the free gaseous form.

Other vessels of sand were prepared, to which similar known amounts of organic matter were added, and then seeds of Wheat were sown, the organic matter serving as manure. When the growth was stopped at a certain stage, almost exactly the same amount of Nitrogen was found in the Wheat plants and in the sand, \&c., as was originally contained in the seeds sown and in the organic matter added. Assuming that the decomposition of the organic matter had taken the same course as in the other experiments-fice Nitrogen being given off-it was obrious that a corresponding amount of free Nitrogen had been taken up by the plants. In other cases the growth of the Wheat was allowed to continue longer than in the experiments just alluded to; and then the total Nitrogen in the products not only equalled, but considerably exceeded, that in the seed sown and in the organic manure. In this instance, at least, it could not be said that the Nitrogen not reccived by the plant as ammonia had been taken up by it as nascent Nitrogen evolred in the decomposition.

* Recherches Expérimentales sur la Végétation, 1557. 
The general conclusions from this part of the inquiry were as follow:-

1. Organic matters in decomposition lose a part of their Nitrogen as ammonia, and a part as Nitrogen gas.

2. Tegetation does not interfere with the progress of this decomposition.

3. Plants cultivated in a manured soil, give more Nitrogen in their produce than the manure yields as ammonia.

4. The excess of Nitrogen in the produce has been absorbed as free gaseous Nitrogen.

In regard to the explanation of the assimilation of free Nitrogen by plants, M. VILLE calls attention to the fact, that nascent hydrogen is said to gire ammonia, and nascent oxygen nitric acid, with free Nitrogen; and he asks- Why should not the Nitrogen in the juices of the plant combine with the nascent carbon and oxygen in the leaves? He further refers to the supposition of M. DE LvCA, that the Nitrogen of the air combines with the nascent oxygen given off from the leares of plants, and forms nitric acid. Again, the juice of some plants (mushrooms) has been observed to ozonize the oxygen of the air; is it not probable, then, that the Nitrogen dissolved in the juices will submit to the action of the ozonized oxygen with which it is mixed, when we bear in mind that the juices contain alkalies, and penetrate tissues the porosity of which exceeds that of spongy platinum, a body so apt to favour combinations?

Summary Statement of the results and conclusions of M. BoussinguUlT and M. G. VILLE.

II. Boussixgault, when, in his earlier investigations, he grew plants in free air, found only such indications of a gain of Nitrogen as, in his opinion, may be attributed to inaccuracies in the methods of experimenting and analysis at the early date, and to the combined influences of ammonia and organic corpuscles in the atmosphere; and when, more recently, he grew plants only shaded in such a manner as still to allow the free access of air, the gain of Nitrogen observed was not more than he considered might be due to the influences last mentioned. When he grew plants, either in confined and limited rolumes of air, or in a current of air washed free from ammonia and organic corpuscles, the results did not show any appreciable gain of Nitrogen. Lastly, when he supplied either decomposing organic matter, or nitrate, to increase the activity of growth, he did not find such an amount of combined Nitrogen in his products, as to lead him to conclude that there had been any assimilation by the plants of free or uncombined Nitrogen. In these cases, indeed, he generally found a loss of combined Nitrogen during the experiment, supposed to be due to the evolution of free Nitrogen in the decomposition of the matters used as manure.

The results of M: G. VILLE, on the other hand, showed a very considerable gain of Nitrogen during growth, whether the plants were subjected to a current of unwashed air, or of ammonia-free air, - and also when the plants were grown in free air, and their activity of development increased by the use of nitrates, or other nitrogenous matters, as manure. This gain of Nitrogen he considers to be due to the assimilation of free or uncombined Nitrogen. It is remarkable, too, that the proportion of Nitrogen gained, to 
that supplied in the combinerl form, was olserved to be the largest in sone of the cassos where no nitrogenous manure was employed, and where the total amount of combined Nitrogen within the reach of the plants was contined to at few milligrammes only, contained in the original young plants or seeds that were planted. In some such irstances, the amount of combined Nitrogen found in the products was about forty times as much as was supplied. In other cases, the assimilation of free nitrogren only scerned to take place when the activity, and stage of growth, of the plants, had been fored beyond a certain point by the use of considerable amounts of nitrogenous manure.

Results and conclusions so astonishingly conflicting as those of M. BoLsSIYGAULT and MI. G. VILJE, have naturally incited others, either to investigate anew, or to seck, in the conditions provided in their experiments, for some explanation of the discordance. Before entering upon the consideration of our own experiments bearing upon the points in question, it will be desirable to add to the foregoing review a brief notice of the labours, or opinions, of these other experimenters or arbitrators.

\section{C.-M. MEXe's Expernexts*.}

In 1851, M. MiENe made some experiments in reference to the assimilation of Nitrogen by plants. He seems to assume that Boussixgault had concluded from his experiments that the free Nitrogen of the atmosphere was appropriated by plants; and he refers to the experiments of M. G. VILLE as confirmatory of such a view. M. MExe made three sets of experiments in reference to this question.

1. He grew Wheat and Peas, respectively, in powdered glass as soil, allowing them contact with common air, and watering them with pure water. The Wheat increased in Nitrogen in amount equal to one-fourth of that contained in the seed sown; whilst its carbon, hydrogen, and oxygen were double those of the seed. The Pea-plants doubled the carbon, oxygen, and hydrogen of the seed sown, and their Nitrogen was threefold that of the seed.

2. Lentils, Peas, Haricots, Beans, Wheat, Rye, and Oats were grown in a sterile matrix under a bell-glass. They were respectirely supplied with an atmosphere of known composition, and with acetate of ammonia in the soil. The plants increased in Nitrogen, and the ammonia in the soil diminished; but the free Nitrogen of the air was not perceptibly affected.

3. This series of experiments was in every way similar to the second, with the exception that the Nitrogen of the air was replaced by hydrogen. The plants flourished, and took up some of the acetate of ammonia.

M. MÈne concludes that plants do not appropriate the free Nitrogen of the air.

D.-M. Roy's Vietrs ox the subject of the Assmmiation of Nitrogex be Plants

M. Ror gare a paper on this subject in 1854. His supposition was that carbonate of ammonia constituted the chief source of Nitrogen to plants. Leguminous plants, he 
considered, appropriated carbonate of ammonia from the atmosphere by their leaves. Graminaceous crops, on the other hand, he supposed, only took it up in solution by their spongioles. He further supposed that the free Nitrogen of the air was not appropriated by the leaves of plants, but that Nitrogen dissolved in water, and so taken up, by their roots, could be assimilated. He concluded that, in the case of M. Boussix. GAULT's plants grown in limited air, there would be but little passage of solution of Nitrogen by their roots, and evaporation of water from their leaves, and that, hence, the necessary conditions did not exist for the assimilation of free Nitrogen. M. VILLE'S rapid current of air would, on the other hand, cause a considerable amount of solution of Nitrogen to be drawn into the plants.

\section{E.-The Expernaexts of MiI. Cloez and Gratiolet.}

In 1850, MM. Cloez and Gratiolet published the results of some experiments made with Water-plants. 'They found that, carbonic acid and air being both present, the plants gave off oxygen slowly, or very rapidly, according to the condition of the sunlight and the temperature. In water deprived of common air, but containing carbonic acid, the evolution of oxygen rapidly declined, Nitrogen was given off, and the plant contained less Nitrogen than a similar plant in water not deprived of its air. The evolution of Nitrogen diminished as the experiment proceeded. They considered that, in the vegetation of Water-plants, Nitrogen is given off from their nitrogenous constituents and that there must be restoration either from free or combined Nitrogen. And as their experiments showed that ammonia-salts were injurious to the plants, they concluded that they take up free Nitrogen dissolved in water.

In 1855* M. Cloez published the results of some experimental inquiries on nitrification, with a view to the question of the source of the Nitrogen of plants. He made twenty experiments, passing washed air through as many different combinations of porous, earthy, and alkaline matters. The experiments continued from September 1851 to April 1855, when, in some cases, efflorescence was observed. He found nitrates to be formed in notable quantity in calcined brick, or pumice, impregnated with alkaline or earthy carbonates; also, in uncalcined brick similarly impregnated. In chalk, marl, a mixture of kaolin and precipitated carbonate of lime, \&c., only traces of nitrate were formed.

M. CLOEz concluded that nitrates would be formed when a current of air was passed over porous bodies, alkalies being present. He considered, therefore, that the porosity of the pots and brick fragments, the alkalinity of the ashes, the moisture, and the current of air, in M. VILLE's experiments with plants, provided the conditions for the formation of nitric acid. He asks, can such formation take place in limited air?

\section{F.-'The Experiments of M. DE LucA $\uparrow$.}

M. DE LUCA found that, on passing moist ozonous air over potash and potassium, nitrate of potash was formed. He further found that the oxygen given off by plants 
in sunlight was in many casces ozonous. Ile aspirated a large guantity of air, in the neighbourhood of vegetation, through carded cotton, and then through sulphuric acirl, to wash it. 'The washerl air then prassed orer potassium, and through a dilute solution of pure potash, when nitrate of potash was formed. When, on the other barnd, air in the midst of habitations was operater upon in a simila way, the formation of nitric acid was not observed. MI. IE J A ece supposes the air surrounding vergetation, in surnlight, to be ozonous; that by its means the Nitrogen of the air may be converted into nitric acid; and that thus the Nitrogen of the air may be rendered available for assinilation by plants, under the influence of regetation itscle.

\section{G. - The Gixperimexts of M. Harting *}

In 1855, M. Harting published some criticisms, and the results of some experiments, on the question of the assimilation of Nitrogen by plants. He considered that the Nitrogen of the air might contribute indirectly to vegetation. He attributed a formation of ammonia from the decomposing débris of seeds, \&c., and the free Nitrogren of the air, in the case of M. ViLLE's experiments; and also supposed that nitric acid might be formed by the oxidation of the atmospheric Nitrogen. 'The increase of Nitrogen in M. VILLE's plants, and of ammonia in the water of the enclosing apparatus, was taken as proof of such formation of ammonia.

M. Hartiag made two sets of experiments, in one of which the plants grew in a limited volume of air, and in the other in a current of air washed free from ammonia-both arranged with a view to aroid the formation of ammonia. He employed enclosing-apparatus somewhat on the plan of M. Boussingaulit and MI. VILLE; but he used glass rases, instead of porous pots, for his plants. He grew Beans, Buckwheat, and Oats. After the seeds had germinated, and the plants had protruded a little above the surface of the artificial soil, he corered the latter with a mixture of wax and oil, to shut off the access of air. He further enclosed the stems of the plants in caoutchouc tubes; and inserted other caoutchouc tubes through the waxy coating, for the supply of water. Some of the plants were rery vivacious at first; and in the case of the Beans, two began to flower; but then the leares turned yellow, and the experiment was stopped. His apparatus consisted of timed-iron pans, varnished, and surmounted by glass shades of 18 litres capacity. There was an aperture for the admission of carbonic acid, another for that of water, and so on.

The result was that the produced plants yielded no more dry matter than was contained in the seeds. M. Hantisg considered, therefore, that the determination of the Nitrogen was superfluous. 'The growth evidently stopped when the supplies of the seeds were exhausted. M. Hantixg's general conclusions on the subject were as follow:-

1. Plants absorb salts of ammonia, and nitrates, by their roots.

2. The Nitrogen of the air contributes to the formation of ammonia, and nitrates, in the soil.

3. It is not proved that Nitrogen serves directly for the nutrition of plants.

* Compt. Rend. sli. 1855 . 


\section{H.-M. A. Peryilold on the Source of the Nitrogen of Platts *}

In the years 1852 and 1853, M. H. M. Crrlebodarow made some experiments on the subject of the assimilation of Nitrogen by plants, at Dorpat, under the direction of MI. Petzhold, who has reported the results of the inquiry.

M. Petzhold assumes that if plants can appropriate the free Nitrogen of the air, they will not need ammonia; and that if they take Nitrogen from ammonia, the artificial supply of the latter will increase growth.

The experiments were made upon Barley. In 1852, an ignited yellow sand was taken as the soil. To one set of plants, no ammonia was supplied; to a second, carbonate of ammonia was provided in the soil; and to a third, carbonate of ammonia was supplied in the air. Both the crops with an artificial supply of ammonia gave three times as much produce as the crops without such supply. The Nitrogen in the produce was also very much greater, both in percentage, and in actual amount, where the ammonia was used.

In 1853, six sets of experiments were made, and as before, with Barley. 'The soils consisted of an artificial mixture of clay, sand, and felspar, decomposed by heating with lime. The first set of three pots was provided with this soil alone; the second had, in addition, 0.13 per cent. of bone-ash acted upon by sulphuric acid; and the third had 1.33 per cent., or ten times as much, of the same phosphatic manure. 'The three other sets were, respectively, so far like the three just described, but in addition ammonia was artificially supplied to the atmosphere in which the plants grew. The phosphatic manure, whether with or without the ammoniacal supply, much increased the produce of both corn and straw. The Nitrogen of the crops was also very much increased in actual amount (though diminished in percentage in the dry substance) by the aid of the phosphatic manure; and the actual amount of Nitrogen was still further increased by the addition of ammonia to the atmosphere of the plants; and the percentage of Nitrogen in the dry substance was.also greater where the ammonia was supplied, than in the corresponding cases without it. The experiments without ammonia were made in free air. 'The Nitrogen in the produce was about seven times that of the seeds where no phosphates were employed; about twelve times that of the seed witn the smaller quantity of phosphate; and about twenty times that of the seed with the larger amount of phosphate.

M. Petzholdt considered it difficult to account for the fact of M. Boussingault getting little or no increase of Nitrogen when he grew plants in free air, which must have supplied some ammonia, even though rain and dew were excluded. He thinks the error must be on the side of M. Boussingault.

It is seen that the explanations or conclusions of these several arbitrators are nearly as conflicting as those of M. Boussingault and M. G. Ville themselves.

For ourselves we are free to confess that we are unable to discover, either in the

* Journ. für Prakt. Chem. Band lxr. 
differences of plan adopted by M. Boussiscisude and M. G. Vidide, so fur al they have themselves deseribed them, or in the results and explanations of other experinenters, any satisfactory solution of the difference of result arrived at. I priori, there are reasons for concluding, both from the chemical characters of Nitrogen itself, and from what we at present know of the chemistry of vegetation in other respects, that plants would not assimilate Nitrogen offered to them in the free state. On the other hand-to say nothing of the large total amount of combined Nitrogen actually existing - the statistics of Nitrogen-production show that there is an amount of Xitrogen periodically arailable for the regetation of a given area of land, the source of a considerable proportion of which is as yet not satisfactorily explained. 'The question whether or not the assimilation of free Nitrogen by plants may account for all, or a part, of the otherwise unexplained fixation, is seen to be left in a dilemma almost inexplicable, by the conflicting character of the results that have been recorded relating to it. Yet, as has been already said, upon the decision finally come to in regard to this question, must materially depend the degree of importance to be attached to the investigation of the other actual or possible sources of Nitrogen to plants, which we have briefly noticed. Under these circumstances, it seemed desirable that any opinions we might offer or adopt on this subject should have the support of such eridence as might be afforded by renewed experiment. We proceed, then, to follow up our account of the Nitrogen-statistics of regetable production, the consideration of the several possible sources of Xitrogen to phant: and the review of the results and opinions of others on some of the points at issue, by a statement of our own experimental evidence in regard to this important question.

\section{PART SECOND.}

\section{EXPERTMENTAL RESULTS OBTAINED AT ROTHAMSTED DURIYG THE \\ YEARS 1857, 1858, AND 1859.}

\section{Introductory observations.}

In laying this part of the subject before the Fellows of the Royal Society, we shall follow the general order in which the questions involved were presented to ourselves in the investigation. In so doing it will be necessary :-

1. To consider all possible conditions to be fulfilled in order to effect the solution of the main question of the assimilation of free Nitrogen by plants, and to endearour to eliminate all sources of error in our investigation.

2. To examine a number of collateral questions, which have a bearing upon the points at issue, and to endearour so far to solve them as to reduce the general solution to that of a single question to be answered by a final set of experiments.

3. To give the results of the final experiments themselves, and to discuss their bearings upon the question which it is proposed to solre by them. 
We shall dwell more fully upon the conditions involved in the experiments than upon the numerical results which they have afforded, since the value of these results is so wholly dependent on those conditions, that, if the latter are properly arranged and thoroughly considered, any conclusion with regard to the former will be sufficiently apparent from the numerical results themselves.

In studying the conditions, we shall be obliged to touch upon several collateral points, embracing some questions not necessarily involved in the investigation, and which, therefore, we have not attempted to treat with that fulness which, as distinct questions in regetable Physiology, they merit. Yet, we think, it will appear that, in the degree in which we have followed them, their discussion is essential to complete the consideration of the main question of the investigation, and that, in relation to it, they possess an interest quite commensurate with the attention we have deroted to them.

These questions are embraced in the following:-

1. The preparation of the soil or matrix for the reception of the plant, and of the nutriment to be supplied to it.

2. The preparation of the nutriment to be supplied to the plant,--embracing that of mineral constituents (as in the ash), of certain solutions, and of water.

3. The conditions of the atmosphere to be supplied to the plant, together with the means of securing them,-involving a consideration of the circumstances affecting the composition of the atmosphere, and of the apparatus used to supply it.

4. The changes undergone by nitrogenous organic matter during its decomposition, affecting the quantity of combined Nitrogen present, in circumstances more or less analogous to those in which the plants were grown in our experiments upon the assimilation of Nitrogen.

5. The action of agents, as ozone, and the influence of other circumstances which may affect the quantity of combined Nitrogen present in connexion with the plant, and yet independent of the direct action of the vital (growing) process.

In considering these five questions, two important series of conditions must be fulfilled :-

1. Those that relate to the growth of the plant,--which must be so arranged as to include all that is necessary for healthy and vigorous growth, excepting only, in some instances, such conditions as may depend upon the presence of a supply of combined Nitrogen.

2. Those that relate to our means of measuring the quantity of combined Nitrogen present at different periods of growth, -it being essential that we should be able, with the means of investigation afforded in the present state of science, to ascertain the quantity of combined Nitrogen present with the plant at different periods of its growth, with sufficient exactness to detect any changes that may take place, so as to enable us to refer them to their proper source.

If we succeed in fulfilling all these conditions, we shall have at our command all the data requisite for the solution of the question whether plants assimilate free 
Nitrogen. Our preliminary investigations will have enabled us to asoid, or to climinate, all sources of crol due to the incidental circumstances of the reacareh; and the numerical results of a final series of experiments, showing the quantities of conbluned Nitrogen supplied, and those crentually found in commexion with the plant, will afford the necessary data for the solution clesired.

In discussing the conditions involved in the experiments, and the rescarches undertaken to enable us to estimate the value of those conditions, we shall arrange the subs. ject in such order as will most clearly bring out their bearings upon the main question, rather than according to the ofder as to time in which they were made. Several collateral experiments were made, to prove that our conditions of growth, jrovided in sril, atmosphere, and nutriment, were such as we had assumed them to be; for had they not been so, the object of the investigation could not be attained. 'l'he time required for the conduct of these collateral experiments, made it necessary that many of them should be performed simultaneously with the investigations the proper conditions of which they were designed to make known.

We shall first consider the arrangement of the main experiments, and the plan and results of the collateral inquiries with a view to show what the conditions of the former should be, and then show how far the conditions assumed for the first ycar's experiments, and those arranged in the second year, after the results of some of the collateral investigations were known, agree with the conditions indicated by the results of all the collateral investigations taken together.

\section{SECTION I.CONDITIONS REQUIRED, AND PLAN ADOPTED, IN EXPERIJLETS OX} THE QUESTION OF THE ASSIMLATIOY OF FIRE NITROGEY BY PLANTS.

\section{A. - Preparation of the Soil, or matrix, for the reception of the plant, and of the mutriment to be supplied to it.}

In considering the subject of the soil to be used, the remarks made abore on the necessity of combining the conditions of healthy growth with the simplicity of constitution which would allow of a quantitative estimation of the results obtained, acquire a high degree of importance.

So complicated is the constitution of ordinary soils, and so intimately are the nitrogenous compounds existing within them associated with the other matters, that it is impossible either to estimate the Nitrogen with sufficient accuracy for our present purpose, or to extract it from the soil without entirely destroying the other conditions of vegetable growth. We are, moreorer, so entirely ignorant of the character of the organic constituents of soils, of the state in which the principal part of the Nitrogen exists in them, of the changes to which it is subject during regetable gromth and decay, and, more especially, of its relations to regetable gromth, that an ordinary soil could not possibly be used for our purpose.

Our ignorance of the actual constitution of soils, as regards the state of the organic 
matter in them, and its relations to the inorganic substances, entirely preciudes the possibility of our imitating, by artificial means, a natural soil, so as to include all its conditions excepting a supply of combined Nitrogen.

It is erident, therefore, that if all the conditions embraced in an ordinary soil were essential to regetable growth, the solution of the question of the assimilation of free Nitrogen by plants would involve difficulties which our means of inrestigation in the present state of science could not orercome. But the experiments to which attention has been directed in the history of this subject, as well as others, the details of which we shall give further on, show that such is not the case. They show that many of the complicated conditions of an ordinary soil may be entirely dispensed with, so as to bring the examination of it within our means of investigation, and yet to retain all the conditions of healthy growth.

In the experiments of the first year, 1857, two kinds of soil, or matrix, were used.

One was prepared from an ordinary soil, so as more nearly to imitate the usual conditions of regetable growth. The other was prepared from volcanic pumice, with the view to eliminate certain supposed sources of error which the prepared soil might introduce. It was found, however, in the experiments of 1857 , that there was no necessity for this difference of matrix, and hence, in the experiments of 1858 , only prepared soil was used.

The soil selected for the preparation of the matrix was a somewhat heary one (clayey), resting upon chalk, and interspersed with flints. The large stones were removed by picking and sifting; and the clayey lumps were powdered to prevent them from baking into hard nodules during ignition. An attempt to ignite in ordinary clay crucibles was not successful, owing to the reduction of the peroxide of iron to the state of black oxide, and to the formation of sulphides from the reduction of the sulphates present, as indicated by the rapours of sulphurous acid emitted during the ignition, and by the erolution of sulphide of hydrogen on the addition of an acid to the mass after cooling.

The combustion proceeded satisfactorily in a large cast-iron muffle, through which a constant current of air could pass. The ignition was continued until a portion of the soil assumed, on cooling, the red colour due to peroxide of iron, and exhibited no trace of coaly matter. The mass thus prepared was taken from the muffle, and thrown into a large ressel filled with distilled water. The water was rendered highly alkaline by the quantity of caustic lime present. The fluid was decanted, and fresh portions of water added several times during eight or ten days, until all the soluble matter was removed. The residue was then dried, and retained for final ignition before being used. The ferruginous and aluminous character of this soil-matrix pointed to the danger there might be of its acting as a porous body, to promote the formation of nitrogenous compounds independently of vegetable growth, on the one hand, or to absorb and retain the ammonia given to the plant, or that which might be formed from the nitrogenous matter of the seed, on the other.

To ascertain the value of any influence exerted by the soil independently of the plant, MDCCCLXI. 
in the manner just indicated, at pot of soil, prepared exactly as for an experiment with a plant, was submitted to the same conditions of air, temperature, moisture, ENe, ats the prots containing the experimental plants. The result was, that there was no accunulation of combined Nitrogen. The result with the matrix of pumice also showed, compared with that of the soil-matrix, that no error was to be feared from the influence of the latter in absorbing and retaining combined Nitrogen already in connexion with the plant.

For our purpose, pure volcanic pumice was used. It was powdered until the mass was quite fine and the largest pieces were about the size of peas. 'This powder was subjected to long washing in the same manner as the ignited soil. Lastly, it was dried ready for a final ignition before being used.

\section{B.-The Mineral Constituents added to the prepared Soil.}

In most cases the necessary Mineral Constituents were supplied in the form of the ash of the plant of the description to be grown. In a few instances, where this was not practicable, the ash of some other plant was selected. Weak solutions of sulphates and phosphates, as well as ash, were also sometimes used.

In some instances the ash was obtained by burning a quantity of the entire plant when in seed. In other cases, the seed and the rest of the plant being burnt separately, a mixture of the two ashes was made in such proportion as to represent the composition of the ash of the entire plant.

Thus, in the experiments of 1857 , for Wheat a mixture of one part of the grain-ash and six parts of the straw-ash, for the Barley a mixture of one part of the grain-ash and three parts of the straw-ash, and for Beans a mixture of one part of the corn-ash and two parts of the straw-ash was used. In the experiments of 1858, the ash used for these crops was obtained by burning the entire plant. For Clorer, the ash of Clorerhay was employed.

In some instances of Leguminous plants the ash was saturated with sulphuric acid, and then ignited, before being used.

Each ash was burnt in a large shallow platinum dish, heated in a current of air, in a cast-iron muftle. The burning was continued until all coaly matter had disappeared. The ash was then preserved, but was always submitted to a final ignition before being used. Examination failed to detect combined Nitrogen in any of the ashes so prepared.

In order that the roots of the plants should find an abundance of mineral matter at the most active period of growth, it was desirable that the matrix should contain as much of such matter as was consistent with healthy derelopment. A consideration of the chemical constitution of soils suggested a proportion of 0.8 to 1.0 per cent. of ash; and this was the quantity added to the matrix for the experiments of 1557 ; but for those of 1858 only about half as much was employed. 


\section{C.-The Distilled Water.}

The first two-fifths of the distillate from ordinary water was allowed to escape, and the next two-fifths were collected for further treatment. The water so obtained retained traces of ammonia. It was mixed with phosphoric acid, free from nitric acid and ammonia, in such quantity that the amount of acid present exceeded that of the ammonia several thousand times. It was then re-distilled from a copper vessel to which was attached a large Liebig's condenser.

Under these circumstances no ammonia could go over unless it were carried over mechanically, in which case it would be accompanied with several thousand times its own weight of phosphoric acid; and, as no distilled water was used that gave any evidence of the presence of this acid, the amount of ammonia in it, if any, must hare been sereral thousand times less than that to which the term "traces" is applied.

The distilled water was so prepared only a few days prior to being required for use.

All parts of the apparatus, the presence of ammonia in which could possibly affect the result, were, after thorough washing both with ordinary and with common distilled water, finally well rinsed with this pure double-distilled water just before being used.

\section{D.-The Pots used to receive the Soil, Ash, Plant, \&e.}

For the experiments of 1857 common flower-pots were used; their height, and diameter at the top, were each 6 inches, and their diameter at the bottom 3.2 inches; their weight was about $1 \mathrm{lb}$. Small common white glazed earthenware plates were used as the pans.

Subsequent observation suggested, for the experiments of 1858 , the kind of pot, and pan beneath it, represented in Plate XII. figs. 1, 2 \& 3.

The Pot, of which fig. 2, Plate XII., represents the elevation, was made of the same material as ordinary flower-pots. It was, howerer, made as light as possible, and was not baked so hard as the latter generally are. The height, and diameter at the top, were each 5 inches; and the diameter at the bottom was 4 inches. The bottom is perforated with about twenty holes of nearly one-fourth of an inch diameter, as is shown in figs. 1 \& 2. There were also two rows of similar holes $(\mathrm{A}, \mathrm{B}, \mathrm{fig}, 2)$ round the sides at a distance of 0.5 to 1 inch from the bottom.

The Pan, represented with the pot placed in it in fig. 3, Plate XII., is made of hardbaked and well-glazed stone-ware. It is 1.5 inch deep and 5.2 inches in diameter at the bottom. At the top it is curred inwards (A, B, fig. 3 ), so as to adapt its upper rim to the sides of the pot.

These arrangements of pot and pan afford sereral adrantages, for the purposes of the investigation, over those adopted in 1857. The surface for evaporation is less in proportion to the volume of soil. The facilities for the exit of roots, and for the access of air, are, on the other hand, greater. The pan affords room for an abundance of water, 3 т 2 
in which the roots derelope luxuriantly*. Yet this water does not evaporate so frecly as it otherwise would do, owing to the inward curve of the top of the pan, which also serves to protect the roots distributed through the water from the direct action of sunlight. All the conditions of growth are thus attained with a minimum of evaporation from all sources excepting through the plant itself; and a drier atmosphere is maintained. Consequently eraporation through the plant is favoured, and hence the conditions are provided for a constant supply to the plant of all the mineral and gaseous substances in solution in the fluid of the soil and pan.

\section{E.-Final preparation of the Soil, Ash, and Pot, for the Plant.}

The soil and ash, each prepared as described in the foregoing subsections, and the pot, also as described above, were simultaneously heated to redness; and the soil and ash, whilst red-hot, were mixed together in the red-hot pot, which was placed upon a recl-hot brick orer sulphuric acid. The pot and contents were then covered with a large glass shade, and left to cool.

The soil, as in its former preparation, was heated in a cast-iron muffle, from which it was removed with a small iron shovel adapted to the purpose, and heated to redness before being used.

Four or five pots were heated together, one inside the other, the top and bottom ones of which almost invariably broke, either on the application of the heat, or on remoral from the fire; so that only about half of those operated upon were finally arailable for use.

From $2 \frac{1}{2}$ lbs. to $3 \mathrm{lbs}$. of ignited soil were put into each pot; but in the experiments of the second year, 1858, the lower part of the pot was first filled, to the depth of about 1 inch, with very coarsely broken-up red-hot flint. In 1857 , about 14 grammes of ash, and in 1858 about 7 grammes only, were used for each pot. The greater portion of the ash was mixed with the lower layers of the soil ; but some was distributed through the whole of it.

After cooling down sufficiently, the shade was remored, and about 500 cub. centims. of distilled water, prepared as described in subsection $\mathbf{C}$, were added to the soil of each pot, this being as much as it would absorb. Then, after a lapse of ten to twenty hours, the seeds or plants were put in.

\section{F.-The Seeds and Plants taken for experiment.}

In all the experiments recorded, the plants were grown directly from seed sorm in the soils prepared as above described.

In every case, seed of the best quality was taken, which was kindly presented to us for our purpose by the Messrs. Tuoxis Gibbs and Co., of Half-IIoon street. Piceadilly,

* See Table, and general remarks at p. 524; also notes of root-derelopment of Whent No. 6 (1S5i ), p. 553, Wheat No. 1 (1S58), p. 560 , and Wheat No. 9 (1858), p. 569. 
Seedsmen to the Royal Agricultural Society of England, who bestowed much labour and attention upon the selection. From the quantity of each kind received, the largest and the smallest were picked out, as were also any that did not look quite healthy. Given numbers of the remainder were then weighed, and the average weight, per seed, was calculated. A few seeds, each weighing as nearly as possible the mean weight, were then selected for planting.

In order to estimate the quantity of Nitrogen in the seeds sown, in some cases a quantity of seeds equal in weight and number to those sown was submitted to analysis. But the difficulties of grinding, without loss, so small a quantity, and the consideration that one small quantity might differ more in composition from another such quantity, than either would from the average composition of a large number of well-selected seeds, led us generally to estimate the Nitrogen in the seeds sown from the percentage of it found in the mixture of a large number ground up together.

The seeds selected for growing were sown in the pots of soil prepared as already described, to the depth of about 1 inch below the surface. With large seeds, such as Beans, it was necessary that care should be taken so to deposit them that the radicle and plumule should each take its natural direction. If this precaution was neglected, the seed was liable to be raised out of the soil after sprouting, which involved the inconvenience of opening the apparatus in which the plant was enclosed, in order to re-bury the seed.

In some cases, as soon as the seeds were sown the pots were remored from over the sulphuric acid, and placed at once beneath the large glass shades which were to serve as the enclosing apparatus. In other instances, the pots were first placed under other shades, luted by mercury or sulphuric acid, and standing in the laboratory, and then, after a few days, they were removed to their final position.

\section{G.-The Atmosphere supplied to the Plants.}

As regards the essential conditions of growth, and the circumstances associated with it, which must be kept within the control of our means of investigation, the same remarks apply to the atmosphere, though with less force, as have already been made in reference to the soil (subsection A, p. 470).

It is true that the constitution of the atmosphere is less complicated, and that we are much better acquainted with it than we are with that of ordinary soils; yet the extreme mobility of the atmosphere renders the presence in it of exceedingly small quantities of substances calculated to influence vegetable growth much more dangerous in quantitative experiments on vegetation than would be their presence in the soil. Thus the presence of gascous impurities, and of solids mechanically suspended, in the atmosphere cannot be overlooked. And hence, although it is not necessary to submit the natural atmosphere to such radical changes as those to which the natural soil must be subjected, some measures must be taken to exclude the sources of error to which allusion has just been made. 
As in the case of the soil, so in that of the atmosphere, the only essential cronditions to be attained are such as are reguired for healthy growth, and as will at the sarne time cnable us to estimate the amount and the sources of the combined Vituregen coming within the reach of the plant by its means.

In consequence of the mobility of the atmosphere above referred to, it was necessary to exclude the experimental plants from its free access. 'The quantity of ammonia in the air is, lowever, so very small, that, provided the atmosphere of the enclosing apjuaratus were allowed to remain unchanged throughout the period of an experiment, the amount of combined Nitrogen so coming within the reach of the plant might be altogether neglected. Nor, so far as regards the nitrogen and oxygen of the air, is there any necessity for change; but, owing to the peculiar circumstances of temperature and of moisture to which the air of the apparatus is subjected, conditions more closcly allied to those of ordinary regetation are attained by a frequent clange of atmosphere. 'The large quantity of air which thus becomes involved in an experiment precluded the idea of neglecting the consideration of the combined Nitrogen which it contains. It devolved upon us, therefore, either to determine the total amount of combined Nitrogen in the air before and after it came in contact with the plant, or to free the air from combined Nitrogen before admission into the enclosing apparatus. The latter alternative was adopted as the most simple; and the manner in which the object was effected will appear from the following description of the apparatus employed.

H.-The Apparatus used to enclose the Plants, and to supply them with Aiv, Water, Cerbonic Acid, \&e.

Plate XIII. represents the entire apparatus as used for each separate experiment in 1857; and fig. 1, Plate XIV., that used, also for each separate experiment, in 185s, in which, as will be seen, several important modifications of the arrangement adopted in 1857 were made.

The same letters of reference apply to the two so far as the parts are alike; and where there has been any modification in the arrangement in 1558 , as compared with that in 1857 , the same letter's represent the parts of the apparatus used for the same purpose in each, with the exception, that those which apply to the modification of the apparatus in 1858 , are distinguished by a dash, thus '.

A, Plate XIII. (and fig. 1, Plate XIV.), represents a large stone-ware Woulfe's bottle, 18 inches in diameter and 24 inches high.

B, C, and E are glass Woulfe's bottles of 30 ounces capacity.

$\mathrm{F}$ is a large glass shade, the dimensions of which were, in most of the experiments, diameter 9 inches, and height 40 inches; in other cases the dimensions rrere, diameter 16 inches, and leight 28 inches.

$a$ represents the cross section of a leaden pipe $1 \frac{1}{2}$ inch in diameter, which is in connexion with a reservoir of water, not shown. This pipe passes orer all the ressels $A$ (of 
which there is one included in the apparatus for each separate experiment) in a direction at right angles to the plan of the figure. It is connected with each ressel $\mathrm{A}$ by means of a tube $a b$, in which is fixed a stopcock, to open and shut the connexion between the water-supply tube $a$ and the vessel $A$.

c de, Plate XIII., is a leaden exit-tube for air. $c^{\prime} d^{\prime} e^{\prime}$, fig. 1 , Plate XIV., is the corresponding tube in the apparatus of 1858 , which is enlarged at the point $d$ and downwards until it opens into the ressel $A$, thus allowing another, $q^{\prime} r^{\prime} s^{\prime}$, to pass through it and down to the bottom of the vessel $A$, as indicated by the dotted line. This tube $q^{\prime} r^{\prime} s^{\prime}$ is a half-inch safety-tube, opening externally at $q^{\prime}$, and in the apparatus of 1858 replaces the tube $q r s$ shomn in Plate XIII.

The bottles $\mathrm{B}$ and $\mathrm{C}$ are filled to the depth of $2 \frac{1}{2}$ inches with sulphuric acid of sp. gr. 1:85.

The tube D D is about 3 feet long and about 1 inch in diameter, and is filled with fragments of pumice saturated with sulphuric acid. At $f, f$, in this tube, are small indentations to prevent the sulphuric acid from draining against the corks.

The Woulfe's bottle E contains a saturated solution of ignited carbonate of soda.

$g h$ is a bent and caoutchouc-jointed glass tube, connecting the interior of the Woulfe's bottle $\mathrm{E}$ with that of the large glass shade $\mathrm{F}$.

$i k$, better indicated in fig. 2, Plate XIV., is the exit-tube for the air, connecting the interior of the shade $\mathrm{F}$ with an eight-bulbed apparatus $\mathrm{M}$, containing sulphuric acid.

$w w$, Plate XIII., is a block of slate 12 inches square and $3 \frac{1}{4}$ inches thick, in which is a circular groove, half an inch wide and 2 inches deep, adapted to the diameter ( 9 inches) of the glass shade F, the bottom of which rests in it. The groove is filled with quicksilver, which shuts off the communication of the external air with the interior of the shade. It is widened and deepened at four equidistant points, to admit of glass tubes passing underneath the shade. 'Two of these tubes, $g h$ and $n o$, are shown in Plate XIII., and $g h$ also in fig. 1 , Plate XIV., no being there replaced by $n^{\prime} o^{\prime}$. The other two are at right angles to these, and are best seen in the rertical section of the shade and lute, fig. 2, Plate XIV., lettered $u v$ and $i k$ respectively. The tube $u v$ is for the supply of water to the plant; and the tube $i k$ is for the exit of the air, from which it passes outwards throngh the sulphuric acid in the eight-bulb apparatus M. This vertical section of the shade and lute is at right angles to the view of them in fig. 1 ., Plate XIV. ; and from it a judgment may be formed of that of the shade and lute of Plate XIII., as well as of the corresponding tubes to those last described, in the apparatus of 1857.

The tube $n o$, Plate XIII., passing from the outside, beneath the shade, and extending to the surface of the mercury in the groove within the shade, is for the purpose of withdrawing condensed water. In the apparatus for 1858 , the arrangement for this object is rather different. 'Thus O, fig. 1 (and fig. 2), Plate XIV., is a bottle into which passes a tube $n^{\prime} o^{\prime}$, opening into the bottom of the lute $w^{\prime} w^{\prime}$ by means of a hole at $n^{\prime}$, 
seen better in figs. $4 \& 5$, J'late XII., which represent, respectively; the plan and the vertical section of the gla\%ed stone-ware lute-vessel used in 1858. Another glass tube $\left(t^{\prime}\right)$ passes to the bottom of the vessel O (figs. 1 \& 2, Plate XIV.), for the purpose of withdrawing the condensed water which collects in it.

The plan of the stone-ware lute-ressel used in 1858 (fig. 4, Plate XII.) shows the grovere for the mercury, the four widened and deepened points of it for the passagre of the tubes under the shade (of which howerer three only were used), and the hole $u^{\prime}$ at the bottom, for the reception of the tube for carrying off the condensed water. 'This lute-sessel is male of hard-baked and well-glazed stone-ware, and is, in fact, simply a shallow dish with double concentric sides, the space between which latter forms the groore for the reception of the shade and of the mercury luting, and for the passage of the tubes. Figure 5, Plate XII., is a vertical section of the stone-ware lute-ressel, from $A$ to $B$, fig. 4, through two of the widened and deepened portions of the groove, and through the hole $n$. Figure 6, Plate XII., is also a rertical section of the lute-ressel, but from $\mathrm{C}$ to $\mathrm{D}$, fig. 4 .

The Woulfe's bottle 'I', fig. 1, Plate XIII., and 'T', fig. 1, Plate XIV., is for the supply of carbonic acid, and will be referred to, more fully, in the following subsection $\mathrm{I}$.

\section{I.-Use of the Apparatus.}

If the stopcock below $a$ (fig. 1, Plate XIII., and fig. 1, Plate XIV.) is opened, rater flows into the vessel $\mathbf{A}$ from a large reservoir with which the leaden tube $a$ is in connexion. As the pressure increases, the water rises in the safety tube $q r^{\prime} s$, or $q^{\prime} v^{\prime} s^{\prime}$, above the level in the vessel $A$, and at the same time the air begins to escape by the tube $c d e$, or $c^{\prime} d^{\prime} e^{\prime}$, to force its way through the sulphuric acid in the bottles $\mathrm{B}, \mathrm{C}$, then to traverse the tube D D, containing the punice saturated with sulphuric acid, to bubble through the solution of carbonate of soda in $\mathrm{E}$, and finally to enter the shade $\mathrm{F}$ by the bent and jointed tubes $g, h$; and from the shade it passes out through the tube $i k$ and the bulb-apparatus $M$ containing sulphuric acid, into the external air:

The minimum pressure required to produce this passage of air, expressed in the height of a column of mercury which it would sustain, is equal to the sum of the products obtained by multiplying the height of each fluid through which the air has to pass by the sp. gr. of the same, divided by the sp. gr. of mercury, or

$$
[(2 \cdot 5+2 \cdot 5+1 \cdot 0) \times 1 \cdot 85+2 \cdot 5 \times 1 \cdot 2] \frac{1}{13 \cdot 6}=1 \cdot 037 \text { inch, }
$$

in which 1.2 is the sp. gr. of the carbonate-of-soda solution.

The difference between the height of the water in the ressel $A$ and in the safety-tube $q r s$, or $q^{\prime} r^{\prime} s^{\prime}$, must always be equal to the weight of the mercury columm obtained in the manner just indicated, multiplied by the sp. gr. of mercury.

If the difference between the height of the highest points of the tubes $q>s$ and $c d e$, fig. 1, Plate XIII. (that of the former being the higher), be less than the minimum height 
just referred to, then the water must flow out of $A$ through the safety tube $q, r, s$ before it can pass through the tube $c, d, c$, into the bottle B. In accordance with this consideration, the safety-tubes for the apparatus of 1857 were arranged as shown in Plate XIII. $(x, r, s)$; but, owing to occasional leakage of the joints at the top of the ressel $\Lambda$, this principle could not be relied upon; and hence the arrangement shown in fig. 1, Plate XIV. was adopted in the experiments of 1858.

The height from the top of the ressel $\mathrm{A}$ to $r^{\prime}$ (fig. 1, Plate XIV.) was 12 inches, which is sufficient to allow the whole of the air to pass out of the ressel $A$, whilst the great height of $d^{\prime}$, of the tube $c^{\prime}, d^{\prime}, e^{\prime}$, entirely prevented the water from passing orer into the bottle $B$,-an accident which unfortunately happened on a few occasions with the apparatus of 1857 .

When the ressel $A$ was full of water, it was drawn off by a cork-hole at the buttom, air being at the same time admitted by the tube $x$ at the top of the ressel.

The minimum pressure upon the glass shade $\mathrm{F}$ rould be

$$
\frac{1.0 \times 1.85}{13.6}=0.136 \text { inch, }
$$

in which 1.0 is the difference between the height of the lowest and the highest level of the sulphuric acid in the bulb-apparatus M. Experiments showed, howerer, that owing to friction, \&c., the maximum pressure on the inside of the glass shade would be raised to double the above estimated minimum.

The plants were supplied with water, as already said, throngh the tube $u v$, shown best in fig. 2, Plate XIV. At first fresh distilled water was supplied; but as soon as a sufficient quantity of condensed water had run through the tube $n^{\prime} o^{\prime}$ and collected in the bottle $O$, this was drawn off by means of the tube $t^{\prime}$ to water the plant when required. In the experiments of 1857 , the condensed water was dram off from time to time, from the surface of the slate and mercury, by means of the tube $n o$.

All the IVoulfe's bottles were made as air-tight as possible by means of rery good corks. 'Those of the bottles E, Plate XIII., and fig. 1, Plate XIV., and also those of O, fig. 1, Plate XIV., were, however, covered with a cement, composed of eight parts gutta percha, twelve parts common rosin, and one part Venice turpentine, well melted together. 'The glass tube $n^{\prime} o^{\prime}$ was also fixed into the lute-ressel $v w$, at $n^{\prime}$, with this cement.

In the experiments of 1857 , tubes of unvulcanized caoutchouc, made by ourselves from the sheet, were used for the various joints inclicated in the figures; but as these soon became unsound under the influence of the atmospheric changes to which they were exposed, tubes of vulcanized caoutchouc were substituted in 1858. The ends of the glass tubes $o$ and $u$, Plate XIII., and of the tubes $t^{\prime}$ and $u$, fig. 1, Plate XIV., were fitted with pieces of caoutchouc tubing into which pieces of solid glass rod were fixed as stoppers.

In 1857, twelve such sets of apparatus, and in 1858 a larger number, were employed. The whole were arranged sicle by side, on stands of brickwork erected for the purpose, IDCCCLXI. 
in the open air, and were protected from rain, or the too powerful rays of the sun, by a canvas amning which could be drawn down orer them, or withdrawn, at pleasure.

In 1858, in addition to the sets of apparatus above described, two glazed cages, such as were used by M. G. VILLE in his experiments, and which he kindly sent over to us for the purpose, were employed.

\section{J.-The supply of Carbonic Acid to the Plunts.}

Owing to the small proportion of carbonic acid in the atmosphere, and to the fact that a part of it would be alsonber in passing through the apparatus ju-t drecribed, it was necessary to give a supply of it to the plants artificially. It was obtained by the action of chlorhydric acid upon fragments of marble in the vessel $T$, I'lite XIII., or T', fig. 1, Plate XIV.

In regulating the supply of carbonic acid, the points to be observed were, to keep the proportion in the enclosed atmosphere below that in which it would prove injurious to the plants, and at the same time to provide a sufficient quantity for the demands of regetation at the most active periods of growth.

Botssixgatut found * that the air surrounding a plant might, consistently with healthy growth, contain $\delta$ per cent. of carbonic acid. This amount, then, on the one hand, and the rery small quantity in the atmosphere which is sufficient for natural regetation (about 0.04 per cent.), on the other hand, afford us limits between which a wide range is allowed for rariation.

Calculation showed that a minimum quantity of 0.2 per cent. of carbonic acid in the air of the enclosing apparatus would supply 5 cubic inches of the gas within the shade at one time, corresponding to 0.0439 gramme of carbon-a quantity which, maintained daily throughout the sunlight, would be rery much more than was required by the plants.

It is obrious, therefore, that a rariation in the amount of carbonic acid in the atmosphere of the plants between 4.0 per cent. and 0.2 per cent. would be very safely within the limit suggested by the experiment of Botssixgatlit as the maximum, on the one hand, and that indicated by the abore considerations as the minimum desirable in the experiment, on the other.

A question arises as to the influence which the changes in the proportion of carbonic acid in the air, between the assumed limits, may hare upon the plant. In reference to this point, it may be mentioned that our own experiments upon the nature of the gas in plants (some of the results of which will be giren further on) appear to show that the changes in the proportion of the carbonic acid in the air of the cells and intercellular passages, and in that in the fluids of the stem, are much greater, and more rapid than those which can take place in the atmosphere of our apparatus. In addition to this, may be stated the fact that plants derive much of their carbonic acid from aqueous solution absorbed by the roots; and most probably the remainder is absorbed by the fluids of the plant before influencing its growth. These absorptions can take place but

* Iémoires de Chimie Agricole et de Physiologie, 1S51, p. 441. 
slowly; so that somerrhat rapid rariations in the proportion of carbonic acid in the atmosphere surrounding the plant, will be accompanicd by much less rariation in the proportion of carbonic acid within the plant. The latter will, therefore, be a slightly rarying mean between amounts corresponding to the foregoing extremes.

From the above considerations, it appeared probable that there would be no danger in so supplying carbonic acid to the atmosphere of the plants as that its proportion should reach its maximum in a short time, and then, by the passage of air, gradually fall again to the minimum. A few trials, adding different quantities of chlorhydric acid to the ressel 'T, Plate XIII. (or 'T', fig. 1, Plate XIV.), containing marble, enabled us to ascertain the proper quantity to add, to proride about 4 per cent. of carbonic acid in the shade $\mathbf{F}$ when air was not passing. Then passing air, it was found that the proportion of the gas was never reduced below that which we hare above assumed as the proper minimum. In practice a little more chlorhydric acid than the amount so determined was used; and then the passage of the air was commenced simultaneously with the addition of the acid. Repeated analysis of the air in the enclosing apparatus shotred that, operating in this way, our assumed limits for the maximum and minimum proportions, respectively, of carbonic acid were not passed.

The rolume of the air passed through the apparatus daily, was that of the ressel $A$, Plate XIII. and fig. 1, Plate XIV., and was equal to about 2.5 times that of the enclosing shade $\mathrm{F}$.

\section{K.-Adrantages of the Apparatus abore described.}

The adrantages, for the purpose in question, of the plan of apparatus which has been described, over those of sereral of the forms that have been suggested or used by others, may be very briefly stated.

1. When once ready to receire the plant, the use of the apparatus is extremely simple and easy. It is only necessary to place the pot containing the soil, seed, \&c., with its pan, in the stone-wrare lute-ressel, to pour mercury into the groore, to arrange the sereral tubes, and to put on the shade. The plant is then entirely excluded from all external sources of combined Nitrogen; and, in case of its being necessary to open the ressel for any purpose, this can be done with great facility.

2. By means of the arrangement of the bottle $\mathrm{O}$ (fig. 1, Plate XIV.), the water which condenses within the shade is remored from the atmosphere of the plant as soon as it collects. The small pan in which the pot stands (fig. 3, Plate XII.), with its inwardturned sides, allows of a store of water being kept beneath the plant which is at the same time protected from free eraporation. The ressel $\mathrm{O}$ holds as much water as can be eraporated from the plant and soil during sereral days.: The supply of water to the plant is exceedingly easy and simple, it being only necessary to remore that which has collected in the bottle $\mathrm{O}$ by means of the tube $t^{\prime}$, and to pour it in at $u$ (figs. 1 and '2, Plate XIV.). [In the arrangement for the experiments of 1857 the condensed water collected on the surface of the slate, until remored by means of the tube $n$ o.] 
3. A simple glass shade is liable to introduce fewer sources of error than at complicated metallic framework with panes of glass cemented into it. 'The slatede is casice to clean before commencing the experiment, and it is less likely to retain, at the terni. nation of it, any of the combined Nitrogen, cither derived from the plant, or from that which has been supplied during growth. Lastly; the presence of oxidizable metallic sur-

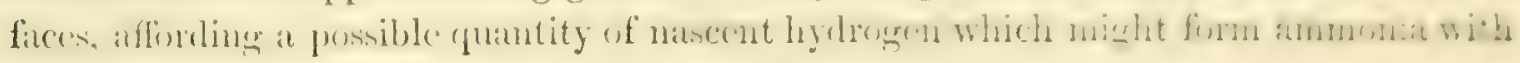
the Nitrogen of the air, is aroided.

4. There is no organic matter present which can affect the result of the cxperiment. 'The only organic matter within the shate is that of a thin coating of the gutta-percha cement which has been described, by which the tube $n^{\prime}$ (fig. 1, Plate XIV.) is fixcd into the hole $n^{\prime}$ (fig. 4, Plate XII.) at the bottom of the stone-ware lute. On analysis this cement was found to contain from 0.10 to 0.15 per cent. of Nitrogen. Hence, if the whole quantity of the cement in contact with the condensed water became decomposed, aud yiclded up its Nitrogen in such a manner as to become a product of the experiment, it would only so yield a few tenths of a milligramme of Nitrogen; but experiment proved that it did not suffer sensible decomposition when subjected, during a whole year, to exposure in the open air.

5. In the passage of the air through the apparatus, the excess of pressure was upon the inside, instead of, as in the experiments of others, upon the outside of the enclosing ressel. In experiments of the kind in question in which the apparatus is exposed to the open air, and so subjected to climatic vicissitudes during a considerable period of time, the ordinary means of securing tightness in the laboratory cannot be depended upon; and an apparatus proved to be tight at one time may, as the result of a variety of causes beyond our control, be subject to lealiage at another. But a leakage from the inside of the apparatus outwards cannot affect the result of our experiment; whilst a leakage in the opposite direction might introduce combined Nitrogen from the cxternal atmosphere. In the arrangement which has been described, the excess of pressure is always on the inside during the passage of the air; and when the air is not passing there cannot be any important amount in the opposite direction due to changes of temperature and barometric condition, for it can never excecd that required to drive the air inwards through the bulb-apparatus MI (Plate XIII., and fig. 1, Plate XIV.), which is altogether insignificant.

6. That part of the apparatus which would be the most liable to leak, and rhich would be the most damaged by pressure, is subjected to the minimum amount of it. The entire pressure required to force the air through the apparatus, independently of that necessary to overcome friction, is

$$
5 \times 1 \cdot 85=9 \cdot 25 \text { inches of water }
$$

to pass through the sulphuric acid in the bottles $\mathrm{B}$ and $\mathrm{C}$ (Plate XIII., and fig. 1, Plate XIV.), and 
to pass through the solution of carbonate of soda in the bottle $\mathrm{E}$, and

$$
1 \times 1.85=1.85 \text { inch of water }
$$

to pass through the sulphuric acid in the bulb-apparatus $\mathrm{M}$, equal a total of $14 \cdot 10$ inches water, or a minimum pressure of about $0.5 \mathrm{lb}$. per square inch. Direct experiment with a manometer showed, however, that the entire pressure, minus that due to the sulphuric acid in the bulb-apparatus $\mathrm{M}$, might, owing to friction, \&c., amount to $0.8 \mathrm{lb}$. per square inch. This would gire a lateral pressure upon the sides of the glass shade of about $900 \mathrm{lbs}$, if the current of air were produced by aspiration instead of forcing- a condition which would be incompatible with the safety of the ressel. In the mode of experimenting adopted, however, the only pressure exerted upon the glass shade was the amount requisite to force the air through the bulb-apparatus M.

It remains to consider the influence upon the air of its contact (in the vessel $A$ ) with the water employed to force it through the apparatus. This can be of three kinds:-

1. The proportions of nitrogen and oxygen may be slightly affected by absorption, under the influence of the slightly increased pressure to which the air is subjected.

2. The air may lose its carbonic acid.

3. It may become more or less saturated with aqueous rapour.

The increase of pressure to which the air is subjected in the ressel $\mathrm{A}$ is so slight, and the time in which it is there in contact with the water is so short, that the total amount of oxygen and nitrogen absorbed by the water must be very small; and, since any change in the constitution of the total amount of air will be dependent on the ratio of the absorption coefficients of oxygen and nitrogen on the one hand, and on the ratio of the quantities of these gases in the air on the other, it will be very much less than in the actual amount of air absorbed; it will in fact be too small to be of any importance.

The whole of the carbonic acid of the air may be absorbed by the water; but as arrangements are made for the artifical supply of it, this is of no consequence.

The amount of water taken up by the air in the ressel A would at first sight appear to be of more importance. But the time during which the air is in contact with the water in the vessel $\mathbf{A}$ is very short, and probably too short for its saturation; it must lose most or all of its acquired water in passing through the sulphuric acid in the bottles $\mathrm{B}$ and $\mathrm{C}$, and orer the pumice saturated with sulphuric acid in the tube DD, whilst the redricel air passes too rapidly through the carbonate of soda solution in the bottle $\mathrm{E}$ for re-saturation; and lastly, as the air in its previous course through the apparatus will be cooler than within the shade, it will not be so near its point of saturation in the latter as it may be before it reaches it.

\section{L.-Adaptation for healthy growth of the conditions of experiment adopted.}

We have thus far discussed the possible sources of error in an experiment on the cutestion of the assmilation of Nitrogen by plants, so far as regards the soil, the inorganic nutriment, and the air, to be provided for the plant, and we have pointed out the means 
adopted to aroid them. From known considerations with regard to the requirements in the soil and inorganic nutriment on the one hand, and in the atmospliere of the plants on the other, and in all combined, we have concluded what are the proper conditions of regetable growth. It remains, however, to appeal to the results of direct experiment, to show that our adopted conditions possess the value which we hare assumed them to have.

$\Lambda$ pot of good garden soil, capable of supporting luxuriant vegetation in the open air, was sown with Wheat, Barley, and Beans, and then placed under one of the experimental shades, and submitted to exactly the same atmospheric conditions as those prorided in the experiments on the assimilation of Nitrogen. 'The result was, exceedingly luxuriant growth (see Records of growth in $\Lambda$ ppendix, Experiment No. 12, of "Plants grown in 1857," fig. 13, Plate XV.; and also lexperiment No. 15, of "Plants grown in 18.58." It was thus prored that the aêrial conditions supplied in our experiments were adapted for healthy growth.

When pots of soil, prepared precisely as has been described abore, were somn with seed and combined Nitrogen artificially supplied, rigorous growth was the result. Hence it was shown that the conditions of soil were properly selected.

\section{SECTIOX II.-OTHER CONDITIONS OF EXPERIMLET, REQUIRITG COLLATERAL INTESTIGATION.}

There remain to be considered sereral conditions which might affect the result of a quantitative experiment on the assimilation of Nitrogen by plants. dependent upon the reciprocal action of the air and the soil, with or without the connexion of the plant.

The following conditions possibly affecting the result of such an experiment. due to the mutual action of the soil. air, and organic matter of the plant. require to be considered :-

1. The influence of ozone, cither within the cells of the plant, or in connexion with it, in promoting the formation of nitrogenous compounds from free Nitrogen. The infuence of ozone in promoting such formation within the soil, either directly. or in connexion with the organic matter of the plant.

2. The decomposition of nitrogenous organic matter, in relation to the question whether there be an erolution of free Nitrogen in the process.

3. The formation of nitrogenous compounds, through the mutual action of nascent hydrogen crolved by decomposing organic matter, and free Nitrogen.

\section{A.-General considerations in regard to the possible influence of Ozone on the supply of combined Nitrogen to growing plants.}

The consicleration of Ozone in comnexion with the plant suggrests the possibility of its presence in tro distinct ways. It may occur within the cells and intercellular passages of the plant, either in the gascous state or in solution. or it may be simply around the plant, without existing within its structures.

With regard to the origin of Ozone in connexion with the plant, it mas be a product 
of the action of the sun's rays, by virtue of which carbonic acid is decomposed, and oxygen erolved. Or, it may result from other causes, to which we shall refer presently.

In order to ascertain how far the presence of Ozone within the plant may have a bearing upon the point at issue, we have attempted to solve, by experiment, the following questions:-

1. Is there, during the growth of plants, Ozone within the cells or intercellular passages?

2. If Ozone be present within the structures of the plant, is it in circumstances in which it would be likely to oxidize free Nitrogen into any of its oxygen compounds?

3. Is Nitric acid present in the living cells of any plant of which it is not a natural product of growth?

In a number of experiments which we have made upon the gases obtained by exhausting plants placed in water freed from air by boiling, no Ozone was perceptible. Another series of experiments upon the oxygen evolved from plants immersed in water saturated with carbonic acid gave similar results.

In the latter series about 1 ounce of the green plant was placed in 500 cub. cents. of carbonated water, and the whole subjected to sunlight. The decomposition of carbonic acid commenced almost immediately, and the evolution of gas was rapid. In this way 100-200 cub. centims. of gas were obtained, which contained sufficient oxygen to inflame a glowing taper; yet no trace of Ozone was manifested on placing test-paper in the gas. That evolved from Wheat, Barley, Oats, Beans, and Clover behaved alike in this respect. Granting that these experiments may not be conclusive for all conditions of the decomposition of carbonic acid by plants, that under certain circumstances Ozone may exist within the vegetable cells and the passages between them, and that it is possible that some of the oxygen of the decomposed carbonic acid may at times appear as Ozone, still, it is difficult to see how it can exert any oxidizing influence upon the free Nitrogen within the plant, under the peculiar circumstances in which it must come in contact with it.

In order to study more fully the circumstances, and to examine, in some detail, the value of the oxidizing and reducing forces operating in the regetable organism, in the different conditions to which it is subjected during growth, a number of experiments hare been made upon plants, under a variety of conditions more or less analogous to those of ordinary growth. As the results of these investigations are too extended in their bearings for full consideration in the present Paper, and are, moreorer, not yet sufficiently complete for publication, we shall give here only such of them as bear upon the point now in question.

It is obvious that the formation of Nitric acid, by the mutual action of Ozone and free Nitrogen within the plant, will be dependent upon the activity of the oxidizing power of the Ozone, and on the intensity of the reducing power of other substances in contact with the Nitrogen to be oxidized. 
The investigations of ScrösBEx and others appear to show that, under cestain circumstances, nitric acid may be formed by the mutual action of Orone and free vitrogen. The question for our consideration here is, whether these circumstances are presented

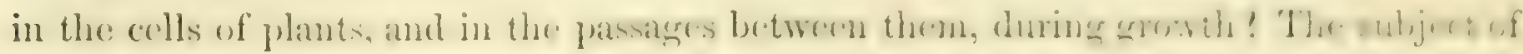
the relation of Ozone to organic matter is obviously too extensive for anything more than a passing consideration here; but we may refer to the well-known intense action

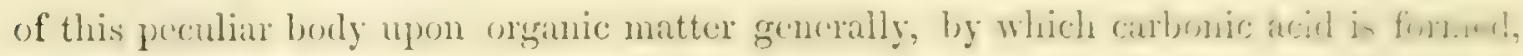
and the Ozone clestroyed. It is well known that Ozone is rapidly destroyed if liept in contact with phosphorus or any other reducing substance. If such conditions for the destruction of Ozone exint within the plint, the probability that it cun there wilum fre. Nitrogen, and so form nitrates, would appear to be exceedingly small. 'The actual conditions within the plant in regard to the points in question may be most efficiently studied by the examination of the gases they contain, under various circumstances. We proceed, therefore, to notice some of the results of such an examination.

\section{B.-Composition of the Gas in Plants.}

\section{Experiments, Series 1.}

Plants, or parts of plants, were put into a flask filled with water that had previonsly been well boiled to remore all air from it. A cork, through which a bent glass tube was passed, was then pressed into the flask, so that the tube was filled with the displaced water. The flask was then placed orer a lamp, the water boiled, and the water and gas driven over collected over mercury, the boiling being continued until the water distilled orer raised that first driven out with the gas to the boiling-point. The rapour thus produced expelled most of the water collected over the mercury. In this way the gas driven out from the plant at the boiling-point mas obtained. The following 'Table (I.) shows the composition of the gas collected under these circumstances. It is seen that Nitrogen and Carbonic acid only were present.

Table I.-Showing the Percentage Composition of the Gas evolved from plants, in water, on continued boiling.

\begin{tabular}{|c|c|c|c|c|c|c|}
\hline \multirow{2}{*}{$\begin{array}{c}\text { Date } \\
(1557) .\end{array}$} & \multicolumn{3}{|c|}{ Description of plant operated upon. } & \multicolumn{3}{|c|}{ Per cent. } \\
\hline & Plant. & Part of plant. & How manured, \&c. & Nitrogen. & Ostgen. & $\begin{array}{l}\text { Carbonic } \\
\text { acid. }\end{array}$ \\
\hline MIay 6 & Wheat. & Whole plant. & Mineral manure .... & $45 \cdot 47$ & $0 \cdot 0$ & $54 \cdot 53$ \\
\hline May 2. & Wheat. & Whole plant. & Mineral manure ... & $46 \cdot 99$ & $0 \cdot 0$ & $53 \cdot 71$ \\
\hline May 2. & Wheat. & Lower part. & Mineral manure .............. & $57 * 00$ & $0 \cdot 0$ & $43 \cdot 00$ \\
\hline MIiy 2. & Wilieat. & Whole plant. & Mineral and Ammoniacal manure...... & $39 \cdot 14$ & $0 \cdot 0$ & 60.56 \\
\hline May 2. & Wheat. & Upper part. & Hineral aud Amuniacal manure...... & $37 \cdot 53$ & $0 \cdot 0$. & $62 \div 7$ \\
\hline Nay 6. & Bean. & Whole plant. & Mineral manure... & $6: 79$ & 0.0 & $37 \cdot 21$ \\
\hline May 6. & Rean. & Whole plant. & Mineral manure ........................... & $63 \cdot 80$ & 0.0 & $36 \div 0$ \\
\hline
\end{tabular}

Other experiments gave similar results, all tending to show that the reclucing power 
of the regetable cells, dependent on the character and conditions of the carbon compounds they contain, was sufficient, under the circumstances specified, to consume all the oxygen (or ozone) that might be present. But the high temperature at which the experiment was conducted must have tended very much to increase this action. In subsequent experiments a different plan of operation was adopted, not open to the same objection.

\section{Experiments, Series 2.}

In these experiments, as in all those subsequently referred to, the plants were put into a tall glass vessel (fig. 7, Plate XII.) 1.75 inch in diameter, and 14 inches in height. The mouth of this ressel is fitted with a long cork, previously well boiled in bees'-wax. Through the cork, two glass tubes, $a$ and $b$, are inserted. The vessel being filled with water well boiled and then cooled without access of air, the plant is put in and well shaken to remove adherent air-bubbles. The cork, with its two tubes, is then forced in, taking care that both the tubes become filled with water and that no air remains in the ressel. As a further security for tightness, a piece of wide and thick caoutchouc tubing may be drawn over the neck of the vessel, projecting upwards a little above the cork, and then the cup thus formed partly filled with melted wax, forming a layer over the cork and its joints. A funnel is then attached to the tube $b$, by means of a caoutchouc tube which can be closed by a strong pinch-cock. Water being admitted through the funnel into the tube $b$, the tube $a$ becomes filled, and it is then brought into connexion, by means of a glass tube and caoutchouc joint fitted with a pinch-cock, with a ressel filled with quicksilver. The connexion being opened, the quicksilver is allowed to flow from the vessel by means of a long tube of more than barometric length fitted into the lower part of it, thus forming a 'orricellian vacuum in the mercury vessel. The gas from the plant passes orer into this racuum, and by a simple arrangement is collected in a eudiometer tube for examination.

The following Table shows the amount and composition of the gas obtained from different plants, in the shade, in the manner above described. 
'IABs: II.-Showing the amount and the composition of the (ias given off by plants, in the slaule, into a 'lorricellian vacuum.

\begin{tabular}{|c|c|c|c|c|c|c|c|}
\hline \multirow{3}{*}{ Distc. } & \multicolumn{2}{|c|}{ Destription. } & \multirow{3}{*}{$\begin{array}{l}\text { Total } \\
\text { rias } \\
\text { collocted, } \\
\text { culs. } \\
\text { ccuty. }\end{array}$} & \multicolumn{4}{|c|}{ S'er ant. } \\
\hline & & & & & & & Uxy \\
\hline & Part of Plant. & Ilow manured, \&c. & & . & Oxysth. & wer-icl. & $\begin{array}{l}\text { Carlmoni } \\
\text { scich }\end{array}$ \\
\hline \multicolumn{8}{|c|}{ Wheat; 1858.} \\
\hline $\begin{array}{l}\text { June } 16 . \\
\text { Juno } 17 . \\
\text { June } 16 . \\
\text { June } 16 . \\
\text { Juve } \mathbf{1 6 .}\end{array}$ & 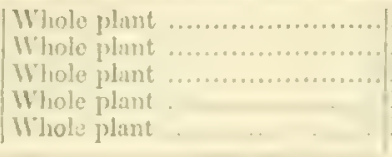 & 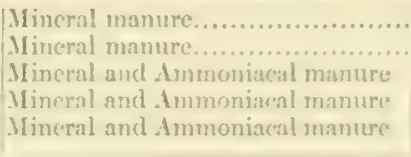 & $\begin{array}{l}57 \cdot 4 \\
53.3 \\
57 \cdot 0 \\
55 \cdot 7 \\
6.57\end{array}$ & $\begin{array}{l}77 \cdot 72 \\
77 \cdot 98 \\
78 \cdot 60 \\
77 \cdot 38 \\
82 \cdot 50\end{array}$ & $\begin{array}{l}2 \cdot 28 \\
3 \cdot 110 \\
1 \cdot 75 \\
3 \cdot 23 \\
0.311\end{array}$ & $\begin{array}{l}2000 \\
17 \cdot(11) \\
19-65 \\
1939 \\
17 \cdot 210\end{array}$ & 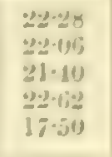 \\
\hline \multicolumn{8}{|c|}{ Barley; 1857.} \\
\hline $\begin{array}{l}\text { June 24. } \\
\text { June 24. }\end{array}$ & 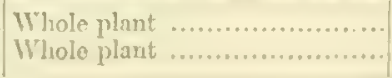 & 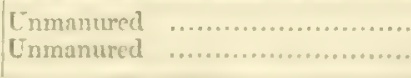 & $\begin{array}{r}8 \cdot 6 \\
20 \cdot 2\end{array}$ & $\begin{array}{l}85 \cdot 12 \\
81 \cdot 18\end{array}$ & $\begin{array}{l}3 \cdot 1 \% 3 \\
\mathrm{j} \cdot 178\end{array}$ & $\begin{array}{l}10-95 \\
16 \cdot 55\end{array}$ & $\begin{array}{l}11.85 \\
18.32\end{array}$ \\
\hline \multicolumn{8}{|c|}{ 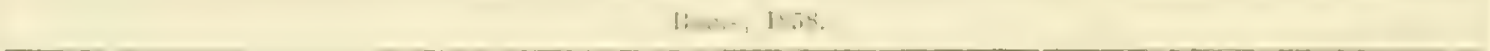 } \\
\hline $\begin{array}{l}\text { June } 17 . \\
\text { June } 17 . \\
\text { June } 17 . \\
\text { June } 17 .\end{array}$ & $\begin{array}{l}\text { Thole plants coming into Flower } \\
\text { Whole plants coning into Flower } \\
\text { Whole plants coming into Flower } \\
\text { Whole plants coming into Flower }\end{array}$ & $\begin{array}{l}\text { Enmanured ............. } \\
\text { Unmanured ............ } \\
\text { dmmoniacal manure.... } \\
\text { Ambioniacal manure .... }\end{array}$ & $\begin{array}{l}513 \\
41 \cdot 5 \\
52 \cdot 5 \\
50 \cdot 4\end{array}$ & $\begin{array}{l}79 \cdot 71 \\
86 \cdot 71 \\
80 \cdot 38 \\
81 \cdot 33\end{array}$ & $\begin{array}{l}5 \cdot 16 \\
4 \cdot 10 \\
4.38 \\
4.36\end{array}$ & $\begin{array}{r}15 \cdot 10 \\
9 \cdot 16 \\
13 \cdot 24 \\
11 \cdot 31\end{array}$ & $\begin{array}{l}20 \cdot 26 \\
13 \cdot 26 \\
15 \cdot 62 \\
15 \cdot 67\end{array}$ \\
\hline \multicolumn{8}{|c|}{ Clorer; 1857.} \\
\hline $\begin{array}{l}\text { Aug. 10.1 } \\
\text { Aug. 10. } \\
\text { Aug. 11. } \\
\text { Aug. 11. }\end{array}$ & $\begin{array}{l}\text { ITeads ................ } \\
\text { Stems and Leares ... } \\
\text { Heads ................ } \\
\text { Stems and Leares ... }\end{array}$ & 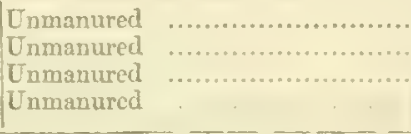 & $\begin{array}{l}47 \cdot 7 \\
59 \cdot 8 \\
91 \cdot 0 \\
42: 3\end{array}$ & $\begin{array}{l}85 \cdot 61 \\
83 \cdot 23 \\
87 \cdot 15 \\
73 \cdot 32\end{array}$ & $\begin{array}{l}6.00 \\
8.33 \\
1 \cdot 89 \\
1.31\end{array}$ & $\begin{array}{r}839 \\
14 \cdot 41 \\
10.96 \\
20 \cdot 37\end{array}$ & $\begin{array}{l}14 \cdot 39 \\
16 \cdot 77 \\
12 \cdot 85 \\
21 \cdot 68\end{array}$ \\
\hline
\end{tabular}

'Ihese experiments also tend to show that the reducing-power of certain of the carbon compounds of the plant was sufficient to convert nearly all the oxygen (or ozone) present into carbonic acid, when in the shade.

The next point is to consider how far the conditions are farourable to the oxidation of Nitrogen in the regetable organism, when the plant is subjected to the action of the direct rays of the sun.

\section{Experiments, Series 3.}

In these experiments, in which over 100 exhaustions were made, the operation was conducted precisely as in the case of the last experiments, with the exception that the plants were exposed during the whole process to the direct rays of the sun. The following Table cxhibits a few of the results obtained, which are sufficient for our present purpose. 
TABLE III.-Showing the amount and composition of the Gas given off into a 'Torricellian vacuum, by plants exposed to sunlight.

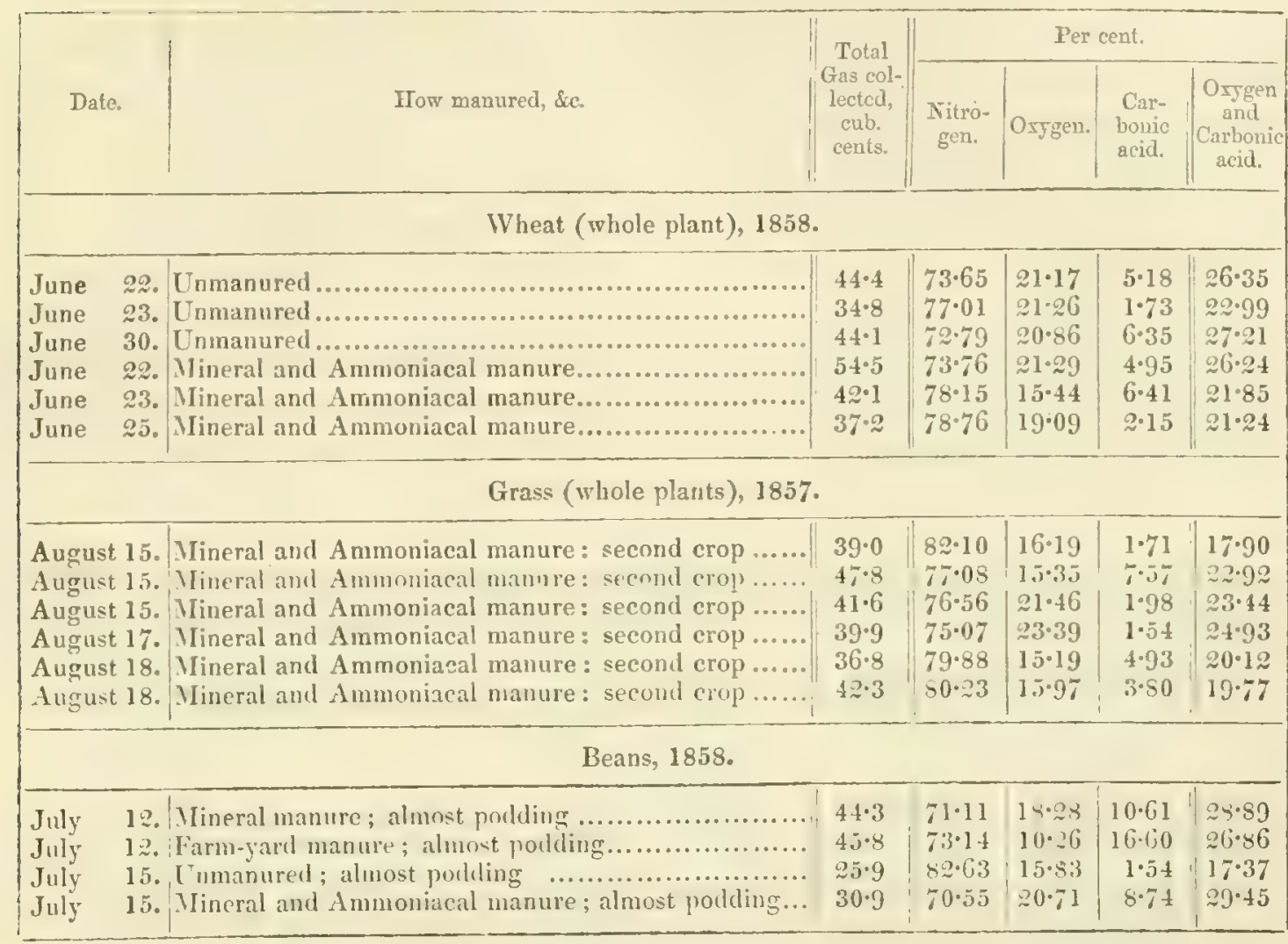

The general accordance in the proportions of Nitrogen found throughont this Series, together with their general approximation to the amounts observed in Series 2 (Table II.), and the consequent similarity in range of the sums of the two remaining gases-carbonic acid and oxygen-point to the character of the change which has taken place, by virtue of which the proportion of carbonic acid is diminished, and that of oxygen increased. The variations in the amounts are, nevertheless, somewhat considerable; and we feel that it would be requisite to exercise considerable caution in attempting to refer them to any other than accidental circumstances beyond our control. There can be no doubt, however, that the carbonic acid, shown to exist in the plants in the shade, has yielded the oxygen evolved when in the sunlight. But the mutual relations of the two gases will be more clearly brought to view by a consideration of the results yet to be adduced.

\section{Experiments, Series 4.}

These experiments, as well as those of the succeeding Series, were arranged to show the influence of the time of action of the sunlight on the plant, upon the relative proportions of carbonic acid and oxygen.

In the Series of experiments now under consideration, duplicate quantities of the $3 \times 2$ 
plant were operated upon at the sane time. Both were preparcel in the shade; an then the vessels containing them were cach entirely exeluded from the light, by sneans of a thick paper covering. In this condition each was attached to a 'lorricellian exhauster*. 'The paper was then removed from one of the vessels so as to expose it, with its contents, to the direct rays of the sun; theother ressel, with its enclosed plant, remaining covered. 'l'he exhaustion of both was then commenced immediately, and the action continued for half an hour.

The following 'Table shows the results obtained in this manner, in sunlight, and in the dark, respectively.

'TABLF IV.-Showing the amount and composition of the gas evolved, during half an hour, into a 'Torricellian vacuum, by duplicate quantities of plant, both kept in the dark for some time before commencing the exhaustion, then one exposed to sunlight, and the other kept in the dark, during the process.

(1858.)

\begin{tabular}{|c|c|c|c|c|c|c|c|}
\hline \multirow[b]{2}{*}{ Date. } & \multirow[b]{2}{*}{$\begin{array}{l}\text { Description } \\
\text { of Plant. }\end{array}$} & \multirow[b]{2}{*}{$\begin{array}{l}\text { Conditions during } \\
\text { Eshaustion. }\end{array}$} & | & \multicolumn{4}{|c|}{ Per cent. } \\
\hline & & & $\begin{array}{l}\text { Total Gas } \\
\text { collected. }\end{array}$ & Nitrogen. & Oxygen. & $\begin{array}{l}\text { Carbonic } \\
\text { acid. }\end{array}$ & $\begin{array}{l}\text { Orygen and } \\
\text { Carbonic } \\
\text { acid. }\end{array}$ \\
\hline & Beans ... & $\left\{\begin{array}{l}\text { In dark.......... } \\
\text { In sunlight ... }\end{array}\right.$ & $\begin{array}{c}\text { cub. cents. } \\
25 \cdot 7 \\
36 \cdot 4\end{array}$ & $\begin{array}{l}66 \cdot 93 \\
69 \cdot 78\end{array}$ & $\begin{array}{l}2 \cdot 33 \\
8 \cdot 24\end{array}$ & $\begin{array}{l}30 \cdot 74 \\
21 \cdot 98\end{array}$ & $\begin{array}{l}33 \cdot 07 \\
30 \cdot 22\end{array}$ \\
\hline July 22. & Oats...... & $\left\{\begin{array}{l}\text { In dark......... } \\
\text { In sunlight ... }\end{array}\right.$ & $\begin{array}{l}28 \cdot 3 \\
25 \cdot 9\end{array}$ & $\begin{array}{l}81 \cdot 63 \\
70 \cdot 27\end{array}$ & $\begin{array}{r}3 \cdot 53 \\
13 \cdot 13\end{array}$ & $\begin{array}{l}14 \cdot 84 \\
16 \cdot 60\end{array}$ & $\begin{array}{l}18 \cdot 37 \\
29 \cdot 73\end{array}$ \\
\hline July 23. & Oats...... & $\left\{\begin{array}{l}\text { In dark......... } \\
\text { In sunlight ... }\end{array}\right.$ & $\begin{array}{l}26 \cdot 4 \\
22 \cdot 7\end{array}$ & $\begin{array}{l}73 \cdot 11 \\
72 \cdot 25\end{array}$ & $\begin{array}{r}8 \cdot 33 \\
16 \cdot 74\end{array}$ & $\begin{array}{l}18 \cdot 56 \\
11 \cdot 01\end{array}$ & $\begin{array}{l}26 \cdot 89 \\
27 \cdot 75\end{array}$ \\
\hline July 23. & Oats..... & $\left\{\begin{array}{l}\text { In dark......... } \\
\text { In sunlight ... }\end{array}\right.$ & $\begin{array}{l}27 \cdot 4 \\
29 \cdot 2\end{array}$ & $\begin{array}{l}68 \cdot 25 \\
67 \cdot 47\end{array}$ & $\begin{array}{r}5 \cdot 11 \\
19 \cdot 86\end{array}$ & $\begin{array}{l}26 \cdot 64 \\
12 \cdot 67\end{array}$ & $\begin{array}{l}31 \cdot 75 \\
32 \cdot 53\end{array}$ \\
\hline July 23. & Oats..... & $\left\{\begin{array}{l}\text { In dark.......... } \\
\text { In suoliglit ... }\end{array}\right.$ & $\begin{array}{l}31 \cdot 4 \\
21 \cdot 7\end{array}$ & $\begin{array}{l}77 \cdot 39 \\
76 \cdot 50\end{array}$ & $\begin{array}{r}6 \cdot 69 \\
16 \cdot 59\end{array}$ & $\begin{array}{r}15 \cdot 92 \\
6 \cdot 91\end{array}$ & $\begin{array}{l}22 \cdot 61 \\
23 \cdot 50\end{array}$ \\
\hline
\end{tabular}

The amounts of carbonic acid and oxygen recorded in the Table, indicate rery clearly the ready transformation of the one into the other-or, rather, the transformation of carbonic acid into a solid carbon compound, and free oxygen. In reference to the question we are considering, these results hare a high importance, as showing the great reducing-force manifested under the influence of the sun's rays, by which the carbonic acid is so suddenly reduced.

* This term, for convenience, we apply to the apparatus which has been described at p.497, by which the plant in the vessel, fig. 7, Plate $\mathrm{III}$, is exhausted. 


\section{Experiments, Series 5.}

This set of experiments was arranged to show how far the reduction of the carbonic acid, with the erolution of oxygen, was due to the action of the sunlight, in conjunction with the fluids of the plant, at the moment of the passage of the gas through the walls of the cells.

If the decomposition of the carbonic acid resulted from a physico-chemical action, in the presence of sunlight, upon this gas only as it passed through the cell-walls, then there might be no oxygen liberated in the growing cell. If, on the contrary, it were decomposed before passing out of the cell, free oxygen would exist within the latter.

To settle this question, a set of experiments was made exactly similar to those the results of which are given in Table IV., with the exception, that now the time of the exhaustion, and of the action of the sunlight, was reduced to four or fire minutes, and the quantity of plant operated upon was increased, so as to give sufficient gas for analysis during this short period. The following Table gives the results obtained.

TABLE V.-Showing the amount and composition of the Gas evolved into a Torricellian racuum, during four or five minutes only, by duplicate quantities of plant, both kept in the dark for some time before commencing the exhaustion, then one still kept in the dark, and the other exposed to sunlight during the short period of the operation.

(1858.)

\begin{tabular}{|c|c|c|c|c|c|c|c|}
\hline \multirow[b]{2}{*}{ Date. } & \multirow[b]{2}{*}{$\begin{array}{l}\text { Description } \\
\text { of Plant. }\end{array}$} & \multirow[b]{2}{*}{$\begin{array}{l}\text { Conditions during } \\
\text { Exhaustion. }\end{array}$} & \multirow[b]{2}{*}{$\begin{array}{l}\text { Total Gas } \\
\text { collected. }\end{array}$} & \multicolumn{4}{|c|}{ Per cent. } \\
\hline & & & & Nitrogen. & Oxygen. & $\begin{array}{c}\text { Carbonic } \\
\text { acid. }\end{array}$ & $\begin{array}{c}\text { Oxygen and } \\
\text { Carbonic } \\
\text { acid. }\end{array}$ \\
\hline July 30. & Oats...... & $\left\{\begin{array}{l}\text { In dark.......... } \\
\text { In sunlight ... }\end{array}\right.$ & $\begin{array}{c}\text { cub. cent. } \\
41 \cdot 7 \\
42 \cdot 5\end{array}$ & $\begin{array}{l}72 \cdot 42 \\
72 \cdot 93\end{array}$ & $\begin{array}{l}3 \cdot 6 \\
4 \cdot 71\end{array}$ & $\begin{array}{l}23 \cdot 98 \\
23 \cdot 06\end{array}$ & $\begin{array}{l}27 \cdot 58 \\
27 \cdot 77\end{array}$ \\
\hline July 30. & Oats... & $\left\{\begin{array}{l}\text { In dark.......... } \\
\text { In sunlight ... }\end{array}\right.$ & $\begin{array}{l}55 \cdot 7 \\
43 \cdot 3\end{array}$ & $\begin{array}{l}71 \cdot 46 \\
69 \cdot 98\end{array}$ & $\begin{array}{l}3 \cdot 23 \\
3 \cdot 23\end{array}$ & $\begin{array}{l}25 \cdot 31 \\
26 \cdot 79\end{array}$ & $\begin{array}{l}28 \cdot 54 \\
30 \cdot 02\end{array}$ \\
\hline July 30. & Oats...... & $\left\{\begin{array}{l}\text { In dark......... } \\
\text { In sunlight ... }\end{array}\right.$ & $\begin{array}{l}37 \cdot 9 \\
38 \cdot 5\end{array}$ & $\begin{array}{l}83 \cdot 11 \\
77 \cdot 14\end{array}$ & $\begin{array}{l}6 \cdot 86 \\
9 \cdot 09\end{array}$ & $\begin{array}{l}10 \cdot 03 \\
13 \cdot 77\end{array}$ & $\begin{array}{l}16 \cdot 89 \\
22 \cdot 86\end{array}$ \\
\hline July 31. & Oats..... & $\left\{\begin{array}{l}\text { In dark........ } \\
\text { In sunlight ... }\end{array}\right.$ & $\begin{array}{l}34 \cdot 4 \\
41 \cdot 8\end{array}$ & $\begin{array}{l}78 \cdot 49 \\
75 \cdot 84\end{array}$ & $\begin{array}{l}7 \cdot 27 \\
7 \cdot 89\end{array}$ & $\begin{array}{l}14 \cdot 24 \\
16 \cdot 27\end{array}$ & $\begin{array}{l}23 \cdot 51 \\
24 \cdot 16\end{array}$ \\
\hline
\end{tabular}

The above results show that the carbonic acid can pass through the cell-wall, in the presence of sunlight, without suffering decomposition. It would hence appear that the free oxygen which a plant yields after it has been for some time under the influence of the direct rays of the sun, existed as such in the cells before the exhaustion. The slight preponderance of oxygen observed in the gas exhausted in sunlight is doubtless due to its action upon the carbonic acid within the cell, during the short period of its operation upon it before it passes out; precisely analogous to the action when the plant is subjected to ordinary atmospheric pressure. 


\section{Erperiments, Series 6.}

In order to bring out more clenly the influence of sunlight before the exhanstion, at scries of experiments were made, in which two vessels, containing the ruplicate guantities of plant, were each kept covered with paper for some time, and then, from twenty to thirty minutes before commencing the exhaustion, the paper was removed from one of them, both being then exhausted, - the process continuing ten, fifteen, or twenty minutes. the following results were obtained.

'AALE VI.-Showing the amount and composition of the Gas evolved into a Torricellian vacuum, by duplicate quantities of plant, both kept in the dark for some time, and then one exposed to sunlight for about twenty minutes, when both were submitted to exhaustion.

\begin{tabular}{|c|c|c|c|c|c|c|c|}
\hline \multirow[b]{2}{*}{ Date. } & \multirow[b]{2}{*}{$\begin{array}{l}\text { Description } \\
\text { of I'lant. }\end{array}$} & \multirow[b]{2}{*}{$\begin{array}{l}\text { Conditions during } \\
\text { Exhaustion. }\end{array}$} & \multirow[b]{2}{*}{$\begin{array}{l}\text { Total Gas } \\
\text { collected. }\end{array}$} & \multicolumn{4}{|c|}{ I'er cent. } \\
\hline & & & & Nitrogen. & Orygen. & $\begin{array}{l}\text { Carbonic } \\
\text { acid. }\end{array}$ & $\begin{array}{l}\text { Orrgen and } \\
\text { Carbonic } \\
\end{array}$ \\
\hline July 31. & Oats & $\left\{\begin{array}{l}\text { In dark..... } \\
\text { In sonlig.. }\end{array}\right.$ & $\begin{array}{l}24 \cdot 0 \\
34 \cdot 5\end{array}$ & $\begin{array}{l}77 \cdot 08 \\
68 \cdot 69\end{array}$ & $\begin{aligned} 3 \cdot 75 \\
24.93\end{aligned}$ & $\begin{array}{l}1, y \cdot 7 \\
1, \cdots 5\end{array}$ & $\begin{array}{l}2 \because \cdot 12 \\
\because 1 \cdot 31\end{array}$ \\
\hline Aug. 2. & Oats & $\left\{\begin{array}{l}\text { In latk..... } \\
\text { In sunlight }\end{array}\right.$ & $\begin{array}{l}18 \cdot 6 \\
39 \cdot 2\end{array}$ & $\begin{array}{l}68 \cdot 28 \\
67 \cdot 86\end{array}$ & 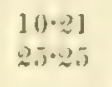 & $\begin{array}{rl}2 & 1 \cdot 31 \\
6 \cdot-9 & =9\end{array}$ & $\begin{array}{l}\because 1 \cdot \div 2 \\
\therefore 2 \cdot 11\end{array}$ \\
\hline Aug. 2. & Oats..... & $\left\{\begin{array}{l}\text { In dark......... } \\
\text { In sualight ... }\end{array}\right.$ & $\begin{array}{l}30 \cdot 7 \\
26 \cdot 5\end{array}$ & $\begin{array}{l}7687 \\
69 \cdot 43\end{array}$ & $\begin{array}{r}8 \cdot 14 \\
27 \cdot 17\end{array}$ & $\begin{array}{r}14 \cdot 99 \\
3 \cdot 40\end{array}$ & $\begin{array}{l}23 \cdot 13 \\
30 \cdot 57\end{array}$ \\
\hline Aug. 2. & Oats...... & $\left\{\begin{array}{l}\text { In dark......... } \\
\text { In sunlight ... }\end{array}\right.$ & $\begin{array}{l}17 \cdot 0 \\
28 \cdot 6\end{array}$ & $\begin{array}{l}79 \cdot 41 \\
76 \cdot 22\end{array}$ & $\begin{array}{r}7 \cdot 65 \\
18 \cdot 53\end{array}$ & $\begin{array}{r}12 \cdot 94 \\
5 \cdot 25\end{array}$ & $\begin{array}{l}20 \cdot 59 \\
23 \cdot \% 8\end{array}$ \\
\hline Aug. 3. & Oats... & $\left\{\begin{array}{l}\text { In dark......... } \\
\text { In sunlight ... }\end{array}\right.$ & $\begin{array}{l}29 \cdot 8 \\
32 \cdot 1\end{array}$ & $\begin{array}{l}81 \cdot 88 \\
66 \cdot 36\end{array}$ & $\begin{array}{r}6 \cdot 38 \\
30-53\end{array}$ & $\begin{array}{r}11 \cdot 74 \\
3 \cdot 11\end{array}$ & $\begin{array}{l}18 \cdot 12 \\
33 \cdot 64\end{array}$ \\
\hline Aug. 3. & Oats... & $\left\{\begin{array}{l}\text { In dark......... } \\
\text { In sunlight ... }\end{array}\right.$ & $\begin{array}{l}11 \cdot 6 \\
23 \cdot 1\end{array}$ & $\begin{array}{l}65 \cdot 52 \\
70 \cdot 56\end{array}$ & $\begin{array}{r}6 \cdot 90 \\
20 \cdot 35\end{array}$ & $\begin{array}{r}27.58 \\
9 \cdot 09\end{array}$ & $\begin{array}{l}34 \cdot 48 \\
\sim 9 \cdot 44\end{array}$ \\
\hline Aug. 3. & Oats. & $\left\{\begin{array}{l}\text { In dark.......... } \\
\text { In sunlight ... }\end{array}\right.$ & $\begin{array}{l}17 \cdot 0 \\
19 \cdot 7\end{array}$ & $\begin{array}{l}80 \cdot 00 \\
73 \cdot 10\end{array}$ & $\begin{array}{r}5 \cdot 88 \\
22 \cdot 33\end{array}$ & $\begin{array}{r}14 \cdot 12 \\
4.57\end{array}$ & $\begin{array}{l}20 \cdot 00 \\
26 \cdot 90\end{array}$ \\
\hline
\end{tabular}

The comparison of the results in this Table with those in Table V., shors that the oxygen must have been liberated from the carbon, and been retained within the cells, until the instant of the exhaustion, as the gas was erolred from all parts of the leaf, and not from the surrounding water, as soon as the pressure was remored.

The conclusions to be drawn from the above sereral Series of experiments are not without an interesting bearing upon our present subject.

1. Carbonic acid, within growing vegetable cells, and intercellular passages, which are penetrated by the sun's rays, suffers decomposition with the erolution of oxygen, the latter remaining in the plant or being erolved from it. This takes place very rapidly after the penetration of the sun's rays. 
2. Living regetable cells, \&c., which are in the dark, or are not penetrated by the direct rays of the sun, consume the oxygen they contained very rapidly after being placed in such circumstances, carbonic acid being formed.

3. There can hence be little or no oxygen in the living cells of plants during the night, or during cloudy days. The presence of oxygen in the cells of thick-leaved plants, or in the deeper layers of fruit, is also very problematical.

4. With every cloud that passes over the sun, the oxygen of the living cell will oscil. late under the influence of the reducing-force of the carbon-matter, forming carbonic acid, on the one hand, and of the reducing-forces of the associated sun's rays, liberating pure oxygen and forming a carbon-compound containing less oxygen than carbonic acid, on the other.

5. The idea is suggested by the above considerations, that there may be in the outer cells, which are penetrated by the sun's rays, a reduction of carbonic acid, and a fixation of carbon, with the evolution of oxygen, at the same time that, in the deeper cells, the converse process of the oxidation of carbon and the formation of carbonic acid is taking place. If such be the case, the oxygen of the outer cells would, according to the laws in conformity with which the diffusion of gases and their passage through tissues are known to take place, be continually penetrating to the deeper cells, and there oxidizing their carbon-matter into carbonic acid; whilst the carbonic acid thus formed would pass in the opposite direction to be decomposed in the sunlight of the outer cells. As the process of cell-formation went forward, and the once outer cells became buried deeper by the still more recent ones above them, they would gradually pass from the state in which the sunlight was the greater reducing-agent, to that in which the carbon-matter of the cell became the greater-from the state in which there was a flow of carbonic acid to them and of oxygen from them, to that in which the reverse action took place. The effect of this action may be the formation of oxidized products-acids, or saccharine matter, \&c.-in the deeper cells, whilst the great reducing-power of the sun's rays may form more highly carbonized substances in the outer cells, which in their turn become subject to oxidation when buried deeper. 'The physical and physiological phenomena of such interchanges are obviously worthy of a closer study; but the subject is too wide for any further development here.

6. The very great reducing-power operating in those parts of the plant where ozone is most likely, if at all, to be evolved, seems unfavourable to the idea of the oxidation of Nitrogen into nitric acid by its means-that is to say, under circumstances where the much more readily oxidizable substance, carbon, is not oxidized, but on the contrary its oxide, carbonic acid, is reduced; whilst, as has been seen, when beyond the influence of the direct rays of the sun, the cells seem to supply an abundance of the more easily oxidized carbon, in a condition of combination readily available for oxidation by free oxygen, or ozone, should it be present. The conclusion that free Nitrogen would not be likely to be oxidated into nitric acid within the structures of the plant, seems to be borne out by the well-known fact, that nitrates are as available a source of Nitrogen 
to plants as ammonia; and lence, if we were to arlmit that Nitrogen can be oxidated into nitric acid in the plant, we must suppose, as in the cuse of carlon, that there are conditions under which the oxygen compound of Nitrogen is reduced within the organism, and that there ane others in which the reverse action, nandy, the rexidation of Nitroren, can take place. In relation to this question, it may be mentioned that several specimens of green Wheat and Grass which had been liberally manured with nitrates were examined for nitric acid, but no trace of it was found in them.

7. 'l'o the foregoing six conclusions, another may be here added relating to this subject, though deduced from the results of experiments on the decomposition of organic matter, which will be referred to more fully presently (p. 509 et ser.). So great is the reducing power of certain carbon-compounds of regetable substances, that when the vital (growing) process has ceased, and all the fiee oxygen in the cells has been consumed, in the formation of carbonic acid, water is decomposed, and hydrogren is evolved. 'This process does not, however, continue long, showing that the cell provides a certain amount of matter more easily oxidized than the remainder, or that the entire cellmatter, after becoming slightly oxidized, loses its energetic reducing-power. 'Lhe former alternative is the more probable one.

'The foregoing consiclerations with regard to the intensity of the reducing action of certain of the carbon-compounds in plants suggest the idea of a possible source of Ozone, very analogous to that by which it is ordinarily ubtained by means of phosphorus. As is well known, the process consists in allowing oxygen to come into incomplete or only instantaneous contact with phosphorus. This substance laving an intense avidity for oxygen, a part of the latter unites with it to form an oxygen-compound of phosplorus, when, if the contact be not too long, another part passes off in the state of Ozone. Certain carbon-compounds of the vegetable cell have also a great affinity for oxygen in the dark (p.488); and the oscillations of the affinities, due to the degree of light (pages 489-492), and to the depth of the cell (p. 493), would afford conditions of molecular action somewhat similar to those under which Ozone is produced in the presence of phosphorus. According to this analogy the Ozone would be due to the action of the carboncompounds of the cell on the common oxygen eliminated from carbonic acid by sunlight, and not to the direct action of the sunlight itself. The Ozone thus formed, if not instantly erolved from the plant, would be destroyed by the easily oxidizable carboncompounds present. It is more probable, however, that the Ozone, stated by DE Lrca and others to be observable in the vicinity of regetation, is due to the intense action of the oxygen of the air upon the minute quantities of volatile hydrocarbons emitted by the plants, and to which they owe their peculiar odours, than to any action going on within the cells. The rapidity of the oxidation in the air of the hydrocarbons, and the rolatile principles of plants generally, goes to farour the rier here suggested; so also does the fact, that Ozone has been observed most readily in the ricinity of such plants as are known to emit frecly essential oils-as, for instance, those of the Labiate family. 
Since it would appear that, under certain circumstances, Ozone is formed in the immediate vicinity of some plants, it remains to consider the possibility of its acting, in an indirect manner, as a source of combined Nitrogen to our experimental plants-that is, through the agency of the materials involved in the experiment-and thus compromising our result in regard to the question of the appropriation, by the plant itself, of free or uncombined Nitrogen. It might so act:-

1. By becoming absorbed by the water that condenses within the vessel enclosing the plant, and then oxidizing the free Nitrogen dissolved in the water.

2. By being absorbed by the soil-either directly from the air of the enclosing apparatus, or from the condensed water returned to the soil-and then, in connexion with it, as a moist, porous, and alkaline body, forming nitrates in the manner referred to by Pelovze and Fresry*, in their remarks upon the experiments of Cloez which we have shortly described at p. 465 of this paper.

3. By passing down in solution in water, or in the gaseous state, to the older and decomposing parts of the roots, and there forming nitric acid by the oxidation either of the free nitrogen contained in the older cells, or of that evolved in decomposition.

These questions have not been so fully investigated as, considered as independent subjects of inquiry and with reference to the results obtained by ScHöNBeIN and others, would be desirable. But so far as they can have a bearing upon the sources of error in our experiments upon the question of the assimilation of free Nitrogen by plants, they have received our careful consideration.

\section{C.-Experiments on the action of Ozonized air on decomposing Organic matter, and porous and alkaline substances.}

Experiments were made to ascertain the influence of Ozone upon organic matter, and certain porous and alkaline bodies, under various 'circumstances. The action of ordinary air upon sticks of phosphorus was had recourse to as the source of the Ozone. The arrangement was as follows:-Three large glass balloons (carboys), each of about 40 litres capacity, were connected together by glass tubes which passed through stone-ware stoppers fitted into their mouths, the joints being made tight with calcined gypsum cement. The bottom of each vessel was covered with water to the depth of about half an inch, so that, when pieces of phosphorus were put in, they were partly covered with the fluid. A tube, which could be opened or closed at pleasure, was fixed through each stopper for the supply of water, and fresh phosphorus, as needed. An Allen and Pepys gasometer, capable of holding about 2 cubic feet of air, was connected by a glass tube with the first of the series of vessels; and by its means, air could be forced in a continuous stream through the three vessels containing the phosphorus. On passing out of the last of them it was led through a wash-bottle, and then into a glass vessel, from which, by means of a number of glass tubes passing from it, it was distributed into bottles containing the substances to be submitted to the action

$$
\text { * Traité de Chimie Générale, tome sixième, p. } 313 \text { (1857). }
$$

MDCCCLXI. 
of the Ozone. 'Thus, all the ozonized air passed the wash-bottle in its course from the balloons to the distributing apparatus.

'The following substances were subjected to the action of the Ozonc-each substance. or mixture, being enclosed in a glass bottle of about 1.5 litre capacity, fitted with an exit-tube in which were framents of punice saturated with sulphuric acid:-

(1) ${ }_{4}^{3} \mathrm{lb}$. of ignited soil, moistened with 100 cub. centims. water, this being just sufficient to make it slightly coherent.

(2) $\frac{3}{4} \mathrm{lb}$. of ignited soil, 300 cub. centims. water, 2.5 ounces boiled starch, and $2 \cdot 5$ ounces dry starch.

(3) $\frac{3}{4} \mathrm{lb}$. of ignited soil, $200 \mathrm{cub}$. cenitms. water, and 2.5 ounces saw-dust.

(4) 2.5 ounces saw-dust, and 100 cub. centims. water.

(5) $\frac{3}{4} \mathrm{lb}$. of igniterl soil, $200 \mathrm{cub}$. centims. water, and 2.5 ounces bean-meal.

(6) $\frac{3}{4} \mathrm{lb}$. of ignited soil, $150 \mathrm{cub}$. centims. mater, and 2.5 ounces bean-meal.

(7) 2.5 ounces bean-meal, and 50 cub. centims. water.

(8) 1 lb. garden-soil.

(9) $\frac{3}{4} \mathrm{lb}$. of slaked lime, and 2.5 ounces bean-meal, made slightly pasty with water.

(10) $\frac{3}{4} \mathrm{lb}$. of slaked lime, some starch, and saw-dust, made slightly pasty with water.

(11) 2.5 ounces of boiled starch, 2.5 ounces fresh starch, and 200 cub. centims. water.

All the bottles were placed before a window where the sum shone directly upon them for a considerable part of the day, as it did also for some hours daily upon the balloons.

Every day, about 9 o'clock in the morning, the cylinder of the gasometer was raised, and a slow current of air passed through the apparatus duxing about two hours. 'This process was generally repeated once or twice more during the day. 'The experiment commenced in April, and continued till the following autumn; that is, through all the warm weather of the summer, when a thermometer in the room frequently stood at $25^{\circ}$ to $29^{\circ} \mathrm{C}$. The amount of Ozone passing through the apparatus was so great, that the vulcanized caoutchoue which connected the tube from the last balloon with that passing into the wash-bottle was cut off with the passage of three or four gasometerfuls of air. The joint was then made by fixing a piece of larger glass tubing orer the point of contact of the smaller connecting tubes, and closing the ends of the larger tube with corks well fitted upon the smaller ones.

Once every three or four days a small piece of phosphorus was dropped into each balloon. In this way the action was sufficiently maintained to produce a distinct odour of Ozone in the room whilst the air was passing.

During the first half of the period of the experiment, a wash-bottle filled with large lumps of pumice, and about half-full of a solution of caustic potash, was used; so that the ozonized air in bubbling rapidly through the solution continually threw it up, by which means the pumice was liept moistened with it.

A careful examination of this liquid, together with the washings of the pumice, failed to detect any nitric acid. About the 1 st of July, the alkaline wash was replaced by a 
bottle containing only pure water. The latter also, at the termination of the experiment, failed to give evidence of even traces of nitric acid.

At the termination of the experiment, the contents of each of the eleven bottles were also examined. A portion was exhausted with water, and the extract concentrated by boiling, after the addition of permanganate of potash to destroy the organic matter. The excess of permanganic acid was removed by carbonate of lead, and the clear solution filtered off from the precipitate. Each solution so obtained was tested for nitric acid; but in no case, excepting that of the garden soil, was there any indication of its presence. An examination of the original garden soil showed that it contained nitric acid before being subjected to the action of the Ozone.

Owing to the negative character of the above results, it is not nccessary to describe the apparatus, and the circumstances of the experiments, in any more detail, which would have been desirable had the results been of a positive kind.

We are, however, by no means prepared to infer, from the eridence just adduced, that under no circumstances in nature is it possible for Ozone to transform nitrogenous compounds of the ammonia class, or the nascent nitrogen evolved during decomposition, into oxides of Nitrogen. We would not say that it may not be possible for Ozone to form such compounds when in connexion with non-nitrogenous bodies or porous substances permeated with gaseous Nitrogen, or even in the atmosphere. Nor are we prepared to maintain that the nitric acid in soils is not in part due to some of these causes. These questions will require much further investigation before they can be satisfactorily settled. 'To some of them we shall refer again presently.

But we wish particularly to call attention to the fact that, in the experiments just referred to, there was a very much larger quantity of Ozone, acting upon organic matter, soil, \&c., in a very wide range of circumstances, and for a much longer period of time, than was involved in our experiments on the question of the assimilation of free Nitrogen by plants. Yet there was no appreciable quantity of nitric acid formed. It may therefore be concluded that there will be no crror introduced into the results of the experiments on the question of the assimilation of free Nitrogen by plants themselves, arising from the action of Ozone upon free Nitrogen under the circumstances of the experiments, and so providing to the plants an unaccounted supply of combined Nitrogen.

\section{Evolution of free Nitrogen in the decomposition of Nitroyenous oryanic comprounds.}

Two obvious methods of investigating the question, whether or not free Nitrogen is given off in the decomposition of nitrogenous organic matter, present themselves.

1. To allow the organic matter to decompose under circumstances in which any free Nitrogen that may be evolved can be collected and estimated.

2. To allow the organic matter to decompose under circumstances in which the total amount of the compounds of Nitrogen formed in the process can be estimated-the loss of Nitrogen then representing the free Nitrogen evolved. 
A number of experinents accorling to the first of these methods has been made by REISET. He submitted nitrogenous animal and vegretable substances to decomprosition under an enclosing vessel in ordinary air, into which he passed oxygen as that of the air was consumed. Ifis result was, that the annount of Nitrogren in the air was gradually increased. He does not appear, however, to have completed the inquiries on this subject which he proposed to undertake.

'The second method has been followed by M. G. ViLit. 'I'he conclusion he anrived at was, that in the decomposition of several nitrogenous regetable substances, about onethird of their total Nitrogen was evolved in the free state.

The losses of Nitrogen which M. Boussingault's experiments on the question of the assimilation of free Nitrogen by plants indicated, when he used nitrogenous organic matter as manure, rendered it desirable to investigate the subject in its bearings upon the conditions provided in our own experiments on that question. The following plan was adopted:-

A given weight of nitrogenous organic matter, the percentage of Nitrogen in which had been previously determined, was mixed with burnt soil, or pumice, prepared as for the experiments on the assimilation of Nitrogen by plants (p. 471), and put into a bottle of about 360 cub. centims. capacity, as shown at B, fig. 8, Plate XII. A proper quantity of water was added; and then the bottle was closed with a cork, through which were tightly fitted two bent glass tubes, which passed externally in opposite directions. One of these tubes was connected with an eight-bulbed apparatus $A$, containing sulphuric acid, for the purpose of washing air drawn through it into the rest of the apparatus. The other tube, passing from B in the opposite direction, was connected with a similar eight-bulbed apparatus C, containing a solution of oxalic acid. From this again passed a tube extending, through a cork, to the bottom of a second bottle D (similar to B), which contained some sulphuric acid. Through the cork of the bottle D another tube $\mathrm{E}$ also passed, but it did not dip into the sulphuric acid. It is obrious that, on drawing the air from $\mathrm{D}$ by means of the tube $\mathrm{E}$, a current of air would pass inwards through the sulphuric acid in $A$, into the bottle $B$, then through the oxalic acid in $C$, and so on. In this way, the air of the vessel $\mathrm{B}$, containing the decomposing organic matter, could be renewed at pleasure by fresh air, washed free from ammonia. At the same time, any ammonia evolved from the decomposing organic matter was dram into the eight-bulbed apparatus $\mathrm{C}$, and there absorbed by the oxalic acid. At the termination of the experiment, the combined Nitrogen remaining in B, and that retained in the form of ammonia in the oxalic acid in $\mathrm{C}$, were determined. The difference between the total amount of combined Nitrogen so found in the products and that originally contained in the organic substance submitted to decomposition, is taken to represent the amount of nitrogen given off, in the free state, during the process. 
SERIES 1.-Experiments on the decomposition of nitrogenous organic matter, made in 1857.

Wheat-meal, Barley-meal, and Bean-meal were the nitrogenous organic substances submitted to decomposition. A quantity of each of these was mixed respectively with burnt soil and with pumice, making in all six separate experiments. About 100 grammes of soil, or about 60 grammes of pumice, were used-these quantities, together with the meal, filling the bottles B to the depth of about 2 inches. Sufficient water was added to bring the mixture into an agglutinated condition. The materials being so prepared, the apparatus was put together according to the arrangement above described. The six sets were then placed in a light room before a large window, so that, during the middle of the day, the sun shone directly upon them.

The experiments commenced on June 10, and terminated on October 8, 1857. Several litres of air were drawn through each apparatus daily, by applying the mouth to the tube E. After the first day the gas possessed a more or less disagreeable taste, and the odour of decomposing organic matter.

The following statement of the condition of the several mixtures, at the termination of the experiment, is condensed from the notes then made:-

1. Theat-meal and ignited Pumice.-The meal slightly mouldy; the odour that of decomposing organic matter; quite moist, so that the particles of pumice adhered together.

2. Wheat-meal and ignited Soil.-A slight mouldy coating on the surface; odour like that of No. 1; the mass moist, but not sufficiently so for the particles of soil to agglutinate.

3. Bariey-meal and ignited Pumice.-No mouldy coating on the surface; odour similar to that of the wheat but more intense, and sour, much like that of fermenting malt; the mass wet and clammy.

4. Barley-meal and ignited Soil.-No mouldy coating on the surface; odour like that of barley No. 3 ; sufficiently moist to agglutinate.

5. Bean-meal and ignited Pumice.-A little mould upon the surface, but not quite so much as with the wheat and soil (No. 2); odour very disagreeable and putrescent; the mass wet and clammy.

6. Bean-meal and ignited Soil. Very similar to the bean-meal and ignited pumice (No 5), but a little more wet and pasty.

In every case, carbonic acid was evolved on the addition of oxalic acid, preparatory to evaporating to dryness. The evolution was the greatest from the bean-meal with soil.

A known proportion, about one-half, of each dried mass, was burnt with soda-lime, and the Nitrogen capable of estimation in that way determined. The remainder was reserved for the determination of nitrates, provided any were present. On examination, however, no nitric acid was detected. To put the validity of the qualitative test for nitric acid beyond doubt, 0.001 gramme of nitric acid was added to the portion of substance which had been already exhausted to test for nitric acid, and had yielded a nega- 
tive result. 'I'he mass was then re-exhausted with water, and the extract subrniterl to precisely the same process as before, when the presence of nitric aciel was made manifest.

In the following Table are given the numerical results of the six experinents:-

'IAbL: VII.-Showing the Numerical results of experiments on the Decomposition of Nitrogenous organic matter, made in 1857.

\begin{tabular}{|c|c|c|c|c|c|c|c|}
\hline & \multicolumn{4}{|c|}{ Substances submitted to experiuent. } & \multicolumn{3}{|c|}{ Xitrowen after Ineromprovition. } \\
\hline & \multirow{2}{*}{$\begin{array}{l}\text { Deseription of } \\
\text { Organic matter. }\end{array}$} & \multirow{2}{*}{ Deseription of Matrix. } & \multirow{2}{*}{$\begin{array}{c}\text { Quintity } \\
\text { of "Meal" } \\
\text { tahen. }\end{array}$} & \multirow{2}{*}{$\begin{array}{l}\text { Quantity } \\
\text { of } \\
\text { Yitrogen. }\end{array}$} & \multirow{2}{*}{$\begin{array}{l}\text { Tolal by } \\
\text { Suda-lime. }\end{array}$} & \multicolumn{2}{|c|}{ Sut recorered. } \\
\hline & & & & & & $\begin{array}{l}\text { Ictual } \\
\text { quisntity. }\end{array}$ & l'er cent. \\
\hline 1. & Whrat-meal... & Ignited pumice $\quad .$. & $\begin{array}{l}\text { Eritumes. } \\
2.0585 \\
0.1089\end{array}$ & grammes. & 0.0338 & $\begin{array}{l}\text { grampues } \\
0.0032\end{array}$ & $\begin{array}{r}8.51 \\
8.5 ?\end{array}$ \\
\hline$\approx$ & Wheat-meal... & Ignited soil .......... & $2 \cdot 1282$ & 0.0383 & 0.0335 & 0.0018 & $12 \cdot 53$ \\
\hline 3. & Barley-meal... & Ignited pumice ... & $\stackrel{2.9495}{2}$ & 0.0380 & 0.0368 & 0.0012 & $3 \cdot 16$ \\
\hline 4. & Barley-Ineal... & - Ignited soil ......... & $2 \cdot 0980$ & 0.0355 & 0.0309 & 0.0046 & $12 \cdot 96$ \\
\hline 5. & Bean-meal ... & - Ignited pumice ... & $2 \cdot 0650$ & 0.0803 & 0.0741 & $0 \cdot 0062$ & $7 \cdot 72$ \\
\hline 6. & Bean-meal ... & . Ignited soil ......... & $\mathscr{g} \cdot 0800$ & $0 \cdot 0809$ & 0.0823 & $(+0.0014)$ & $+(1 \cdot 73)$ \\
\hline
\end{tabular}

The last two columns of this Table, which exhibit respectively the actual amount of Nitrogen not recoverable by the soda-lime process in the substance after decomposition, and the percentage proportion of this loss upon the Nitrogen submitted to experiment, are the most important to consider for our present purpose.

Vith one exception (the gain of Nitrogen in which is quite within the range of the error of analysis), all the experiments point to the fact, that a part of the Nitrogen of decomposing organic matter passes into a state in which it cannot be estimated by the soda-lime process. Neither did it exist as nitric acid. There appears, therefore, to be an evolution of free Nitrogen.

It is not a little remarkable, that although so large a proportion of the total Nitrogen present is lost, doubtless passing off as free Nitrogen, yet scarcely a trace of ammonia was given off from the mass; for the oxalic acid in the bulb-apparatus $C$ was, in each case, separately rendered alkaline with caustic potash and distilled, the distillate being collected and examined quantitatively for ammonia, when, in only one case-that of the Bean-meal and Pumice-was there any ammonia indicated, and then only equal in amount to 0.0002 gramme Nitrogen. This was the case, notwithstanding that the Nitrogen in the mixtures amounted to from 0.03 to 0.08 per cent of their entire quantity.

The questions here arise:-to what extent had the decomposition of the organic substance proceeded? What shall we accept as the measure of the amount of decomposition? what are the intermediate stages through which the substance has passed? what is the character of the organic compounds remaining in the mass? what is the nature of those that have been evolved? and what part does water play in the matter?

The subject of the character of the gradual changes which take place during the 
decomposition of mixtures of nitrogenous and non-nitrogenous substances, in rariable proportions, in connexion with soil and water, involves points so highly complicated, that we cannot pretend satisfactorily to answer all the abore questions.

We may, howerer, ascertain the character of some of the final products of the decomposition, and from a knowledge of these draw conclusions as to the changes of which they are the result under various circumstances.

\section{Series II. - Euperiments on the Decomposition of nitrogenous Organic Matter, made in 1858.}

The following series of experiments was made with a view to embrace a wider range of conditions as to degree of moisture; - to observe the different stages of decomposition as manifested by the odour, \&c.; - to include the circumstances of sprouting, early growth, and subsequent decay of the products of the regetation;- -and to afford material for a more elaborate inquiry into the character of the products of the decomposition.

'The results giren above, in 'Table VII., do not show any difference between soil and pumice as matrix that we can safely refer to other than incidental causes independent of the action of the matrix itself. Yet we continue the use of the two substances, in order to see if, with a larger percentage of organic matter, and a more complete decomposition, the pumice will retain the ammonia formed as well as the soil.

About 175 to 200 grammes of soil, or 120 to 150 grammes of pumice, were used as matrix in each experiment, and the other conditions were as follow:-

( 2.171 secds, weighing $S \cdot() 47 . j$ grammes, 50 c. c, water, with ignited Soil.

Wheat. b. 171 seeds, weighing 8.0715 grammes, 100 c. c. rater, with ignited Pumice.

c. Meal, weighing $9 \cdot 8810$ grammes, 40 c. c. water, with ignited Soil.

Barley. $\left\{\begin{array}{l}\text { a. } 163 \text { seeds, weighing } 8 \cdot(140 \text { grammes, } 50 \text { c. c. water, with ignited Soil. } \\ \text { b. } 163 \text { seeds, weighing } 8 \cdot 1360 \text { grammes, } 100 \text { c. c. water, with ignited Pumice. } \\ \text { c. } \text { Meal, weighing } 8.9670 \text { grammes, } 40 \text { c. c. water, with ignited Soil. }\end{array}\right.$

Bean. $\left\{\begin{array}{c}a .7 \text { seeds, weighing } 6 \cdot 4700 \text { grammes, } 50 \text { c. c. water, with ignited Soil. } \\ \text { b. } 7 \text { seeds, weighing } 5 \cdot 7830 \text { grammes, } 50 \text { c. c. water, with ignited Pumice. } \\ \text { c. } \quad \text { Meal, weighing } 6 \cdot 1750 \text { grammes, } 40 \text { c. c. water, with ignited Soil. }\end{array}\right.$

Those of the mixtures to which about 50 cub. cent. of water were added, were about as moist as soils when in a good condition for vegetable growth. Those with 40 cub. cent. were much drier in appearance, there being no tendency to agglutination of the particles. 'Those with 100 cub. cent. were very wet, there being some free water above the solid matters.

The seeds sown with 50 cub. cent. water showed growth in a few days after being put in, and the vessels (B, fig. 8, Plate XII.) were soon filled with a mass of vegetation. Those sown with double this quantity, or 100 cub. cent. water, showed no indications of sprouting; and in a few days, the odour evolved from them showed that decomposition had set in. The mixtures of meal and soil, also, soon gave odours indicative of 
decomposition, though less foul than those from the whole seed and 100 cub. cerit. water.

'The following Notes, taken at different times during the cxperiments, will indicatce the stages of growth, or decomposition, through which the several organic matters passed.

March 16.

Wheat (a)-Sceds, in Soil with 50 cul.cent.water.-Came up some days later than the corresponding Barley $a$; has not grown so rapidly; las kept green for a longer period; and is yet growing healthily, though much crowded in the small bottle. The air passing from the bottle has not the odour of decomposing organic matter. 'There is a slight mould on the soil due to a few seeds which did not grow.

Wheat (b)-Seeds, in Pumice with 100 cul. cent. water.-'The Pumice in this case mas covered with water to the depth of about one-fourth of an inch, and a few grains floated in the water. In a few days the air drawn through the bottle gave the odour and taste of decomposing organic matter. At the end of about a month the free water on the surface began to disappear rapidly, and in a short time it was all gone, learing a grey mouldy coating of organic matter over the top of the pumice. This disappearance of water was too great to be due to simple evaporation in the air passed through the apparatus. It was doubtless consumed in the process of decomposition-a riew which receives confirmation from our experiments on the nature of the gases evolred during decomposition.

Wheat (c)-Meal, in Soil with 40 cub. cent. water.-Gives little indication of decomposition by the air which passes from it. Compared with Wheat $b$, the difference in this respect is very marked.

Barley $(\alpha)$-Seeds, in Soil with 50 cub. cent. water - Came up soon after being put in, grew rapidly, and in five weeks had grown to the top of the bottle, a height of about 5 inches. By the end of February the bottle was quite filled with green regetable matter, and up to that time no odour of decomposition was distinguishable in the air which was passed through, but from that date the leares became yellor, and decomposition has been manifested both by appearance and the taste of the air.

Barley (b)-Seeds, in Pumice with 100 cub. cent.uater.-Progress almost exactly similar to that of the corresponding Wheat $(b)$ described abore.

Barley (c)-Meal, in Soil with 40 cub. cent. water.-Very like the corresponding Wheat (c) above.

Bean (a)-Seeds, in Soil with $50 \mathrm{cub}$. cent. water.-Came up a week after soming. The sprouts pushed several seeds out of the soil, yet they have continued to grow up to the present time, lying upon the surface. At first there was a natural derelopment of leaf and of roots; but soon the latter took a remarkable course, coming through the surface of the soil and extending through all parts of the bottle, mingling with the 
stems and leaves, and forming a densely crowded mass of vegetable matter. The rootlets from the main branches extending through the mass commenced their growth in all directions indiscriminately, but after growing about one-fourth of an inch they invariably turned downwards.

Bean (b)-Seeds, in Pumice with $50 \mathrm{cub}$. cent. water.-Identical in appearance with the last (Bean $a$ ), excepting a little further dereloped.

Bean (c)-Meal, in Soil with $40 \mathrm{cub}$. cent. water.-Almost exactly like the Wheat $(c)$ and Barley $(c)$ meals, described above.

In no one of the above nine cases was there any Ozone reaction to test-paper.

\section{April 28.}

Wheat (a)-Seeds, in Soil with 50 cub. cent. water. - Twelve to fifteen stems; leaves not umrolled, and scarcely any tendency to expansion. The vegetation not nearly so much crowded as in the case of the corresponding Barley $(\alpha)$; yet most of the shoots show signs of dying. A thin coat of fungoid growth covers the stems to the height of from 1 to 1.5 inch. The stems are from 2 to 2.5 inches high, those of the corresponding Barley being from 3 to 4 and 5 inches high. The air passed through the apparatus is not disagreeable either in taste or odour.

Wheat (b)-Seeds, in Pumice with 100 cub. cent. water.-The Pumice moist, but without visible water, and the surface covered with a grey mouldy coating. The air has had an unpleasant odour ever since March 16, and now it is exceedingly nauseating.

Wheat (c)_Meal, in Soil with 40 cubl. cent. water. - The soil apparently dry, but slightly mouldy, and the air passed over is almost without odour.

Barley (a) -Seeds, in Soil with 50 cub. cent. water.-The bottle full of vegetable matter, all quite yellow at the top where it touches the cork, and yellowish lower down. The plants covered with a coating of greyish fungus. The odour and taste of the air slightly disagreeable. The soil looks quite dry.

Barley (b)-Sceds, in Pumice with $100 \mathrm{cub}$. cent. water.-The soil is moist and mouldy. The mould on the surface appears to be decreasing, and is now less abundant than in the case of the corresponding Wheat $(b)$. The odour of the air is much less disagreeable; indeed there is scarcely any at all.

Barley (c)-Meal, in Soil with 40 cub. cent. water. -The soil mouldy and apparently dry. The air from the vessel tasteless, and inodorous.

Bean (a)-Seeds, in Soil with $50 \mathrm{cub}$. cent. water.-Continued to grow vigorously for a long time, filling the bottle with a confused mass of stems, leaves, and roots, which has commenced to decay rapidly during the last two weeks. The upper portions of the mass are now entirely dead and black; but nearer the soil the stems and leaves are green and long, whilst healthy roots are intermingled with them. The soil is also tolerably filled with roots. The odour of the air is not disagreeable.

MDCCCLXI. 


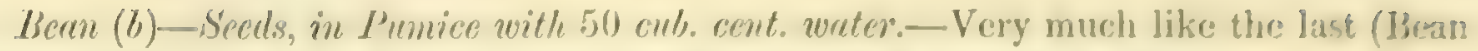
$a$ with soil), excepting that the development of roots is scarcely so great.

Bean (c)-Mecel, in Soil with 40 cub. cent. weeter.-A little mouldy matter on the surface of the soil, which appeats dry.

$$
\text { July } 1 .
$$

Wheat (a)-Seeds, in Soil with $50 \mathrm{cub}$. cent. water.-Plants all dead; the erstire contents of the bottle apparently quite dry. 'The air has a slight musty odour.

Wheat (b)-Seeds, in Pumice with 100 cub. cent. water.-Odour rather more marked than that of the last (Wheat $a$ ); a coating of organic matter on the surface of the pumice.

Wheat (c)-Meal, in Soil with 40 cub. cent. water.-Soil quite dry ; covered with mould; odour of air slight.

Barley (a)-Seeds, in Soil with 50 cub. cent. water.-Plants quite dead and dry; air inodorons.

Barley (b)-Seeds, in Pumice with 100 cut. cent. water.-Soil dry and covered with mould. Air like that of Wheat $b$; more foul than that of any of the others.

Barley $(c)$-Meal, in Soil with 40 cub. cent. water.-Surface dry. 'The air has a slightly musty odour.

Bean (a)-Seeds, in Soil with 50 cub. cent. water.-Plants all dead, and much decomposed; forming a black mouldy mass of organic matter on the surface of the apparently dry soil. 'The air has no perceptible odour.

Bean (b)-Seeds, in Pumice with 50 cub. cent. water.-The same as the last (Bean a).

Bean (c)-Meal, in Soil with 40 cub. cent. water.-Soil dry; slightly mouldy; the air from over it inodorous.

In order to see the effect upon the organic matter of an increased amount of moisture, 100 cub. cent. of water were added to each of the nine bottles of decomposing matter, at this date (July 1).

$$
\text { August } 28 .
$$

Final Report, and termination of the Eaperiment.

Wheat (a)-Seeds, in Soil with 50 cub. cent. water.-Very little odour, and that not unpleasant. On removal from the bottle, it was found that the organic matter was well decomposed, only very indefinite remains of stems and leares being visible in the soil. On the addition of oxalic acid to the mass, to retain the ammonia during the eraporation to dryness, a copious evolution of carbonic acid took place, and the surface of the fluid was constantly corered with a brown froth during the process.

Wheat (b)-Seeds, in Pumice with 100 cub. cent. water.-The mass has a disgusting mouldy odour. The form of the grain is retained, but all the contents are gone, and the 
husk is filled with fluid. On evaporation with oxalic acid, there was evolution of carbonic acid, \&c., as with the last; indeed it was the same with all those which follow.

Wheat (c)-Meal, in Soil with $40 \mathrm{cub}$. cent. water.-In this, as in all the other cases, owing to the water added on the 1 st of July, the mass was covered to the depth of from $\frac{1}{4}$ to $\frac{1}{2}$ an inch with fluid. In both the above cases with Wheat, the supernatant water was colourless, but in this it had a dirty, muddy, yellowish colour. 'The mass emitted a foul disagreeable odour, though not so intense as that of the corresponding Barley.

Barley (a)-Seeds, in Soil with $50 \mathrm{cub}$. cent. water.-The organic matter thoroughly decomposed; stems, roots, and leaves no longer distinguishable in the soil ; other conditions about as those with the corresponding Wheat $a$.

Barley (b)-Seeds, in Punice with $100 \mathrm{cub}$. cent. water.-The pumice covered with a black coating of organic matter; supernatant water clear. The odour of the air above the mixture exceedingly disgusting, resembling that of decaying excrements; traces of sulphide of hydrogen perceptible. The form of the seeds is preserved, but the shell contains only fluid.

Barley (c)_Meal, in Soil with 40 cub. cent. water.-Supernatant water yellowish; odour musty, but not very disagreeable. Decomposition so complete that traces of organic matter are hardly perceptible.

Bean (a)-Seed, in Soil with 50 cub. cent. water.-The organic matter well decomposed. Odour musty.

Bean (b)-Seeds, in Pumice with $50 \mathrm{cub}$. cent. water.-Plants well decomposed; only very indefinite skeletons of stems, leaves, and roots remaining. Odour musty, but not disagreeable.

Bean (c)-Meal, in Soil with $40 \mathrm{cub}$. cent. water.-Supernatant water slightly yellow. Odour musty, but not offensive.

The last description, dated August 28, refers to the state of the respective masses just before being dried for analysis. After drying, any slight remains of organic matter had become brittle; and the substance, in every case excepting where 100 cub. cent. water had been added at the commencement, presented the appearance of clean soil or pumice, without organic matter. In the excepted cases the shell of the grain was still visible. If we take into consideration the amount of growth in several of the cases on April 28, it will be seen how great must have been the subsequent decomposition so entirely to get rid of the organic matter.

It is worthy of remark, that, in a few instances, the sulphuric acid in the bottle $D$, fig. 8, Plate I., became coloured slightly brown, indicating the passage into it, through the oxalic acid, of some carbon-compound more complicated than carbonic acid. In the course of other parts of our investigation, we have observed phenomena indicative of a similar result; but as we have not followed up the subject, we leave it with only this remark as to the fact of what we have observed. 
The following 'lables (VIII. and IX.) show the numerical results of the investigation now under consideration:-

TABL: VIII.-Showing the conditions provided in Experinents on the Decomposition of Nitrogenous Organic Matter; and the amount and proportion of the original Carbon of the substance remaining after the decomposition, or given off during the process.

\begin{tabular}{|c|c|c|c|c|c|c|c|c|c|}
\hline \multicolumn{4}{|c|}{ Substances involved in tho Experiment. } & \multicolumn{2}{|c|}{$\begin{array}{l}\text { Weight of } \\
\text { Organic Matter. }\end{array}$} & \multicolumn{4}{|c|}{ Curton in Organic Jlatter. } \\
\hline \multicolumn{2}{|c|}{ Organic Matter. } & \multirow{2}{*}{ Matrix. } & \multirow{2}{*}{ Water. } & \multirow{2}{*}{ Frcsld. } & \multirow{2}{*}{ Dry. } & \multirow{2}{*}{$\begin{array}{l}\text { Before } \\
\text { Decoun- } \\
\text { pusition. }\end{array}$} & \multirow{2}{*}{$\begin{array}{l}\text { After } \\
\text { Jecom- } \\
\text { position. }\end{array}$} & \multicolumn{2}{|c|}{$\begin{array}{l}\text { Iome in Inerem- } \\
\text { prysition. }\end{array}$} \\
\hline Description. & Condition. & & & & & & & $\begin{array}{l}\text { Actual } \\
\text { quantity. }\end{array}$ & l'cr cent. \\
\hline 1. Wheat. & $\begin{array}{l}\text { a. } 171 \text { seeds } \ldots . . . \\
\text { b. } 171 \text { seods } \ldots . . . \\
\text { c. Mieal ............ }\end{array}$ & $\begin{array}{l}\text { Ignited soil ......... } \\
\text { Ignited pumico ... } \\
\text { I gnited soil ....... }\end{array}$ & $\begin{array}{l}\text { cub. cent. } \\
50 \\
100 \\
40\end{array}$ & $\begin{array}{l}\text { grammes. } \\
80175 \\
8.0715 \\
9.8810\end{array}$ & $\begin{array}{c}\text { grammes. } \\
6.7133 \\
6.7639 \\
8.2803\end{array}$ & $\begin{array}{l}\text { granmes } \\
3.1059 \\
3.1182 \\
3.5172\end{array}$ & $\begin{array}{l}\text { grammes. } \\
0.9 .71 \\
0.9178 \\
1.3199\end{array}$ & $\begin{array}{l}\text { ramines. } \\
2 \cdot 1815 \\
2.2001 \\
2.1973\end{array}$ & $\begin{array}{l}70 \cdot 17 \\
70 \cdot 56 \\
65 \cdot 12\end{array}$ \\
\hline 2. Barlcy. & $\begin{array}{l}\text { a. } 163 \text { sceds } \ldots . . . \\
\text { b. } 163 \text { sceds } . . . . \\
\text { c. Mical ............ }\end{array}$ & $\begin{array}{l}\text { Ignited soil ........ } \\
\text { Ignited pumice... } \\
\text { Ignited soil ...... }\end{array}$ & $\begin{array}{r}50 \\
100 \\
40\end{array}$ & $\begin{array}{l}8.0140 \\
8 \cdot 1360 \\
8 \cdot 9671\end{array}$ & $\begin{array}{l}6 \cdot 71: 37 \\
6.7845 \\
7 \cdot 18: 30\end{array}$ & $\begin{array}{l}3 \cdot 115223 \\
3 \cdot 0872 \\
3 \cdot 1025\end{array}$ & $\begin{array}{l}09595 \\
1.1: 152 \\
1.0995\end{array}$ & $\begin{array}{l}20 y 25 \\
1.8920 \\
2.2020\end{array}$ & $\begin{array}{l}63 \cdot 55 \\
61 \cdot 28 \\
67 \cdot 63\end{array}$ \\
\hline 3. Beans ........ & $\begin{array}{l}\text { a. } 7 \text { sceds } \ldots . . . . \\
\text { b. } 7 \text { sceds } \ldots . . . . \\
\text { c. Ifeal ......... }\end{array}$ & $\begin{array}{l}\text { Ignited soil ........ } \\
\text { Ignited pumico ... } \\
\text { Ignited soil ........ }\end{array}$ & $\begin{array}{l}50 \\
50 \\
40\end{array}$ & $\begin{array}{l}5 \cdot 7830 \\
6 \cdot 4700 \\
6 \cdot 1750\end{array}$ & $\begin{array}{l}4 \cdot 5830 \\
5 \cdot 1275 \\
4 \cdot 8937\end{array}$ & $\begin{array}{l}2 \cdot 2915 \\
2 \cdot 56337 \\
2 \cdot 4468\end{array}$ & $\begin{array}{l}0.8511 \\
0.9778\end{array}$ & $\begin{array}{l}1.1108 \\
1.4630\end{array}$ & $\begin{array}{l}62 \cdot 86 \\
6001\end{array}$ \\
\hline
\end{tabular}

TABLE IX.-Showing the conditions provided in Experiments on the Decomposition of Nitrogenous Organic Matter; the amount and proportion of the original Nitrogen remaining after the decomposition, or given off during the process; together with the amount evolved as Ammonia, or remaining in the products as such.

\begin{tabular}{|c|c|c|c|c|c|c|c|c|c|c|c|}
\hline \multicolumn{4}{|c|}{ Substances involred in the Experiment. } & \multicolumn{4}{|c|}{ Total Nitrogen in Organic Jatter. } & \multicolumn{4}{|c|}{ Nitrogen in the form of Ammonia. } \\
\hline \multicolumn{2}{|c|}{ Organic MIatter. } & \multirow[t]{2}{*}{ Matrix. } & \multirow[t]{2}{*}{ Wrator. } & \multirow{2}{*}{$\begin{array}{l}\text { Before } \\
\text { Decom- } \\
\text { position. }\end{array}$} & \multirow{2}{*}{$\begin{array}{c}\text { After } \\
\text { Decom- } \\
\text { position. }\end{array}$} & \multicolumn{2}{|c|}{ Loss (or Gain). } & \multirow{2}{*}{$\begin{array}{c}\text { Total } \\
\text { quantity. }\end{array}$} & \multirow{2}{*}{$\begin{array}{l}\text { Per } \\
\text { cent. }\end{array}$} & \multicolumn{2}{|c|}{$\begin{array}{c}\text { Absorbed by } \\
\text { Oralic acid } \\
\text { during Decom- } \\
\text { position. }\end{array}$} \\
\hline Description. & Condition. & & & & & $\begin{array}{c}\text { Actual } \\
\text { quantity. }\end{array}$ & $\begin{array}{l}\text { Per } \\
\text { cent. }\end{array}$ & & & $\begin{array}{c}\text { Actual } \\
\text { quantity. }\end{array}$ & $\left|\begin{array}{c}\text { Per } \\
\text { cent. }\end{array}\right|$ \\
\hline 1. Wheat & $\begin{array}{l}\text { a. } 171 \text { seeds } \\
\text { b. } 171 \text { sceds } \\
\text { c. Meal .... }\end{array}$ & $\begin{array}{l}\text { Ignited soil ... } \\
\text { Ignited pumice } \\
\text { Ignited soil ... }\end{array}$ & \begin{tabular}{|c|} 
cub. cent. \\
50 \\
100 \\
40
\end{tabular} & $\begin{array}{l}0 \cdot 1.392 \\
0 \cdot 1396 \\
0 \cdot 1709\end{array}$ & $\begin{array}{l}\text { gramues. } \\
0 \cdot 1348 \\
0 \cdot 1214 \\
0 \cdot 1650\end{array}$ & $\begin{array}{r}+0.0006 \\
0.0182 \\
0.0024\end{array}$ & $\mid \begin{array}{r}0.43 \\
1303 \\
1.74\end{array}$ & $\begin{array}{l}\text { Grammes. } \\
0 \cdot u+29 \\
00373 \\
00197\end{array}$ & $\begin{array}{l}30 \times 83 \\
41 \cdot 010 \\
11 \cdot 49\end{array}$ & 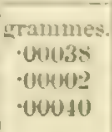 & $\begin{array}{l}1 \cdot .273 \\
110.114 \\
0.2 .21\end{array}$ \\
\hline 2. Barley & $\begin{array}{l}\text { a. } 163 \text { sceds } \\
\text { b. } 163 \text { seeds } \\
\text { c. Meal ..... }\end{array}$ & $\begin{array}{l}\text { Ignited soil ... } \\
\text { Ignited pumice } \\
\text { Ignited soil ... }\end{array}$ & $\begin{array}{r}50 \\
100 \\
40\end{array}$ & $\begin{array}{l}0 \cdot 1217 \\
0 \cdot 1261 \\
0 \cdot 1390\end{array}$ & $\begin{array}{l}0.0746 \\
0.1152 \\
0.1311\end{array}$ & $\begin{array}{l}0.0501 \\
0.02009 \\
0.01079\end{array}$ & $\begin{array}{r}40 \cdot 20 \\
16 \cdot 62 \\
5 \cdot 66\end{array}$ & $\begin{array}{l}00157 \\
0.02314 \\
0.0166\end{array}$ & 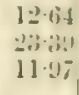 & $\begin{array}{l}.60055 \\
.(6)(10) 2 \\
.00039\end{array}$ & $\begin{array}{l}(1-1111 \\
0-11,6 \\
(1.2 \leq 00\end{array}$ \\
\hline 3. Веачв. & $\begin{array}{l}\text { a. } 7 \text { seerds } \\
\text { 1. } 7 \text { seeds } \\
\text { i. Meal .. }\end{array}$ & $\begin{array}{l}\text { Ignited soil ... } \\
\text { Ignited pumice } \\
\text { Ignited soil ... }\end{array}$ & $\begin{array}{l}511 \\
50 \\
40\end{array}$ & $\begin{array}{l}0.2417 \\
0 \cdot 2704 \\
0 \cdot 2581\end{array}$ & $\begin{array}{l}0.2107 \\
0.2380 \\
0.2267\end{array}$ & $\begin{array}{l}0.0310 \\
0013: \$ \\
0(1 ; 14\end{array}$ & $\begin{array}{l}1: 84 \\
11 \cdot 99 \\
1 \% \cdot 16\end{array}$ & $\begin{array}{l}0.0140 \\
0.1039\end{array}$ & $\begin{array}{r}57.91 \\
40.25\end{array}$ & $\begin{array}{l}\cdot 00311 \\
\cdot 100342 \\
\cdot 00060\end{array}$ & $\begin{array}{l}1 \cdot 1 \cdot 21 \\
11 \leq 15 \\
1 \cdot 232\end{array}$ \\
\hline
\end{tabular}

A comparison of the results in Tables VII. and LX. will show that they are confirmatory of each other as to their more general indications. Both series agree in the entire absence of any tangible relation between the raried circumstances of decomposition, and the products of that decomposition. 
It is quite evident that, whilst in some instances there has been no crolution of $\mathrm{Ni}$ trogen, in others the amount of decomposition involving such evolution has been very great. Indeed, in some cases, the indication of the loss of Nitrogen in this way is so great that we could not have believed such a result possible had it not been attested by repeated analysis. But we have not been able to trace these differences to their ultimate causes.

The amount of decomposition, as indicated by the physical condition of the several substances at the termination of the experiment, as also by the proportion of carbon given off as shown in Table VIII., might lead to the conclusion that the process had gone about equally far, and attained about an equal completeness, in all the cases to which Tables VIII. and IX. refer. But here the equality of effect ceases. 'Thus, from 60 to 70 per cent. of the total carbon in the original organic matter has passed off; but the proportion of the original Nitrogen that is not recovered in the products varies, under the same circumstances, from 0 to 40 per cent. of it. 'The proportion of the Nitrogen of the original substance which was retained in the mass, or absorbed in the oxalic acid in the bulb-apparatus (C) in such form as to be given off as ammonia on distillation from a weak alkaline solution, and which probably existed, therefore, in the products as ammonia, ranged from 12 to 58 per cent. of the total quantity involved in the experiment. And, again, the proportion of the Nitrogen evolved from the mass as ammonia during the decomposition, and which was retained in the oxalic acid solution (C), varied from 0 to about 1.5 per cent. of the original or total Nitrogen.

If we attempt to trace a relation between the loss of carbon, the loss of nitrogen, the formation of ammonia, and the evolution of the small amounts of it during the decomposition, on the one hand, and the circumstances of matrix, moisture, growth, decay, \&c., pointed out in the notes preceding the Tables, we fail to discover any connexion which we may with safety regard as exhibiting cause and consequence.

The most that we can venture to say is that, under a wide range of circumstances, a considerable loss of Nitrogen occurs in the decomposition of nitrogenous organic matter; that under particular, and apparently rather rare circumstances, this loss of Nitrogen does not occur; that the proportion of the Nitrogen taking, under the same circumstances, such form that it may be driven off as ammonia on the distillation of the products with a weak solution of alkali, varied from one-eightl to more than one-half of the total present; and that the amount of the Nitrogen evolved from the mass as ammonia during the process was quite inconsiderable.

These conclusions, though necessarily expressed in very general terms, have nevertheless a very important bearing on certain questions in practical agriculture. Whilst it would appear that there may be a very great loss of Nitrogen-a very important element in manure-under circumstances of decomposition of organic matter, closely allied to those to which, in practice, nitrogenous organic manures are subject, it is at the same time indicated that it is possible for such matters to pass through the process of decomposition without such loss. The importance of further investigation is hence 
suggested, to ascertain the causes of the difference of effect, in order, if prossible, to control them. The results also point to the insignificance of the loss of vitrogen in the form of ammonia, a supposed evil to which the attention of agricultural chemists has specially been directed in order to find means of preventing it, though nothing has as yet been done to avoid the loss, in apparently much larger quantity, of free litrogen. Ihnt as these questions are more appropriate for consideration in a purely agricultural paper, we shall not follow them further in this place.

Other investigations, to which we have to call attention, will throw some light upon the character of the molecular forces by which the decomposition of nitrogenous organic compounds is effected under such circumstances as we have been considering. 'Ihese forces might be one or both of two kinds.

1. They might be of an oxidizing character, analogous to that of the action of chlo. rine upon ammonia by which free Nitrogen is evolved.

2. They might be of a reducing character, similar to that of a great number of substances upon the oxygen-compounds of Nitrogen, by which the oxygen of the latter is appropriated, and free Nitrogen given off.

3. These two actions may operate in succession the one to the other.

It is well known that an oxidizing action may be so intense as to deprive a nitrogrenous organic compound of all its carbon and hydrogen, converting it into oxygen compounds, as is done by permanganic acid. 'The converse action of the transformation of oxygen-compounds of Nitrogen into ammonia is also very well known. An intermediate stage in either of these converse actions may give fiee Nitrogen.

There can be little doubt that the Nitrogen in the organic substances which we have submitted to decomposition existed in them in a condition more analogous to a hydrogen than to an oxygen compound of it. The able researches of Horscas into the nature of compounds formed upon the ammonia type, would lead us to suppose that the Nitrogen compounds upon which we have been operating are of the ammonia class. 'They are more difficult to oxidize into nitric acid than is ammonia; yet their transition into ammonia is so easy, that it is effected in almost all the chemical changes to which they are ordinarily subjected. And, since ammonias yield free Nitrogen under the influence of oxidizing forces, it may be inferred that it has been under the influence of such forces that Nitrogen has been set free in the cases recorded abore. PELouze has remarked* that salts of nitric acid are converted into ammonia, in contact with decomposing organic matter. Experiments of our own have shown that, during the decomposition of organic matters in contact with nitrates, free Nitrogen is not evolved. The erolution of free Nitrogen in the experiments quoted above must, therefore, be referred to the action of oxidizing forces.

The experiments next referred to bear upon these points.

* Comptes Rendus, xliv. p. 118. 


\section{E.-Experiments on the action of the oxidizing and reducing forces, as manifested in the decomposition of organic matters containing Nitrogen.}

Several qualitative experiments showed that when cereal grains and leguminous seeds were placed in water, over mercury, an evolution of gas took place, after about thirty-six to forty-eight hours. This went on rapidly for a week or two, after which all action appeared to cease, no more gas being evolved. The total quantity of gas evolved raried between 20 and 50 cub. cent. from 3 to 4 grammes of the seeds. An examination of the gas proved it to be almost entirely carbonic acid and hydrogen, the quantity of Nitrogen being very small.

To examine this action more thoroughly, about half a pound of a mixture of Wheat, Barley, and Beans was taken, put into a long narrow glass vessel (fig. 7, Plate XII.) of about 500 cub. cent. capacity, which was then filled with well-boiled water, and closed with a cork, through which two glass tubes ( $a$ and $b$ ) passed. The external ends of these tubes were fitted with caoutchouc tubing, for closing with pinch-cocks, or connexion with the Torricellian exhauster as described at p. 487. One of the tubes being so connected with the exhauster, it was allowed so to remain for several hours, in order to remove all the gaseous Nitrogen from the seeds. The ressel was then inverted in mercury, with one of the tubes $(b)$ open under that fluid, and the whole placed in sunlight to farour the decomposition. 'This was done on the 28 th of August, 1858. 'The seeds commenced swelling very soon, and on the 30th of August well-marked decomposition had set in.

On September 13th the vessel was about two-thirds full of gas, the displaced water having passed out through the quicksilver. Part of the seed was now above the water, in the gas, which commenced bubbling out through the tube $(b)$. The arrangement was allowed so to remain until October 5 , when 400 cub. cent. of gas were collected, of which the percentage composition was as follows:-

\begin{tabular}{|c|c|c|c|c|c|}
\hline & 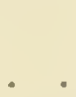 & . & $\begin{array}{c}\text { Carbonic acid. } \\
. \quad 64.87\end{array}$ & $\begin{array}{c}\text { Hydrogen. } \\
34.83\end{array}$ & $\begin{array}{l}\text { Nitrogen. } \\
0.30\end{array}$ \\
\hline Experiment 2 & . & 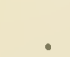 & . $64 \cdot 54$ & $35 \cdot 46$ & traces. \\
\hline
\end{tabular}

The quantity of the gas evolved points to the extent of the decomposition; the amount of carbonic acid and hydrogen shows how great must have been the reducing force exerted; and the small quantity of Nitrogen, which was probably due to accident, indicates that free Nitrogen was not a product of the action.

The vessel was again filled with boiled water, again connected for some time with the 'Torricellian exhauster, and again placed in its former position in the sunlight.

October 9.-A small bubble of gas collected in the top of the vessel.

November 3.- Only a few bubbles of gas at the top of the vessel.

November 17.- The vessel was removed into the laboratory and placed in a room, the temperature of which raried from a few degrees above the freezing-point to about $24^{\circ} \mathrm{C}$.

December 1.-Very little gas evolved.

Decenber 12. - The gas collected without exhaustion measured only 6.1 cub. cent., of 
which 4.6 were absorbed by potash, and the remainder proved to be combustible. Hence, up to this date, there has been no appreciable evolution of frec Vitrogen. In order to see whether the organic mitter present would reduce a nitrate, with the crolution of free Nitrogen, about 5 grammes of saltpetre' were now put into the vessel, and it was replaced in the same room as before.

May 3, 1859.-Several times since December 12, 1858, when the nitrate of potash was put in, the ressel has been warmed up to $30^{\circ} \mathrm{C}$; but up to this date very little gas has been evolved.

May 25, 1859.-Still rery little gas evolved; 4 cub. cent. only collected, one-fourth of which was carbonic acid, and the remainder was combustible. 'The ressel was now placed in the sunlight again, but up to the middle of June no further evolution of gas had taken place. 'The fluid still contained nitrate of potash. 'The ressel was then half filled with oxygen in order to see if this would cause a renewal of the decomposition. After ten days a portion of the gas was examined, when it was found that not one-fourth of the supplied oxygen had been consumed-a result which was quite unexpected. The total gas being remored, the ressel was again nearly filled with oxygen, driving out the greater part of the fluid, and leaving the partly decomposed seeds in an atmosplicre of this gas. The apparatus so arranged was placed in the sunlight, and remained there during some very warm weather.

July 12, 1859.-The gas collected contained in 100 parts$\begin{array}{ccc}\text { Carbonic acid. } & \text { Oxygen. } & \text { Nitrogen. } \\ 20 & 79 & 1\end{array}$

By accident a small quantity of air was admitted into the ressel, so that the analysis can only be taken to show how exceedingly slow was the oxidation of organic matter which had been treated as this had been.

On the remoral of the matters from the ressel, the Beans were found to possess much of their original firmness and solidity. The other seeds, though they retained their form, were softer, and they had evidently undergone a more complete decomposition. They emitted very little odour, which was not umpleasant.

There can be no question as to the absence of any evolution of free Nitrogen during the long period that these three descriptions of seed were under experiment. A rery small proportion of the combined Nitrogen present would, if set free, have been sufficient to fill the vessel with gas. But, as has been seen, only a few bubbles of gas mere erolred during several months.

Several other experiments were made upon the products of the decomposition of organic matter, in the first stages of the process. In Table $\mathbf{X}$., which follows, are given the amounts, and the composition, of the gas obtained from decomposing organic matter in a few out of a number of cases in which we have had occasion to observe themincluding, for comparison, some of the results already referred to. The decomposition took place in water, in vessels similar to that used in the experiments last described (fig. 7, Plate XII.). 
TABLE X.-Showing the products of the action of the reducing forces exercised in the decomposition of Nitrogenous organic matter, as exhibited by the composition of the gases evolved.

\begin{tabular}{|c|c|c|c|c|}
\hline \multirow{2}{*}{$\begin{array}{l}\text { Description of Organic matter subjected } \\
\text { to Decomposition. }\end{array}$} & \multirow{2}{*}{$\begin{array}{l}\text { Total Gas } \\
\text { collected. }\end{array}$} & \multicolumn{3}{|c|}{ Composition of the Gas, Per Cent. } \\
\hline & & Carbonic acid. & Hydrogen. & Nitrogen. \\
\hline & cub. cent. & & & \\
\hline a. Wheat, Barley, and Bean seed ... & 400 & $\begin{array}{l}64 \cdot 87 \\
64 \cdot 54\end{array}$ & $\begin{array}{l}34 \cdot 83 \\
35 \cdot 46\end{array}$ & $\begin{array}{c}0.30 \\
\text { traces. }\end{array}$ \\
\hline b. Turnip plant; root with leaves ... & $166 \cdot 2$ & 76.93 & $22 \cdot 91$ & $0 \cdot 87$ \\
\hline c. Turnip plant; root with leaves ... & $162 \cdot 2$ & 68.83 & $23 \cdot 93$ & $7 \cdot 24$ \\
\hline d. Turnip plant; root with leaves ... & $123 \cdot 6\{$ & $\begin{array}{l}68 \cdot 06 \\
67.50\end{array}$ & $\begin{array}{c}25 \cdot 63 \\
25 \cdot 43\end{array}$ & $6 \cdot 31$ \\
\hline e. Turnip plant; root with leaves ... & $41 \cdot 2^{1}$ & 64.95 & $14 \cdot 66$ & $20 \cdot 39$ \\
\hline
\end{tabular}

The first experiment $(a)$ is that which has been considered above. In all the other cases about two ounces of young Turnip Plant, the root and leaves together, were operated upon. They were cxposed in similar vessels to those used in the other experiments, from August 29 to October 5. At the termination of this period the structure of the plant was almost entirely destroyed; and there remained only a mass of decomposed matter deposited at the bottom of the vessels. The evolution of gas had entirely ceased.

The Turnip plant (b) was exhausted of its gas before exposure; and, as will be seen, there was, under these circumstances, a very small quantity of free Nitrogen found at the termination of the experiment.

All the other Tumip plants were submitted to decomposition without previous exhaustion; and hence the amount of Nitrogen eventually found. In the last experiment $(e)$ there is a much larger percentage of Nitrogen than in the other cases. But the total quantity of gas was much less; and the comparison of this result with the others shows that there was an almost constant actual quantity of Nitrogen in the several cases, doubtless due to that existing within the plant at the commencement of the experiment. Hence it appears that, in the absence of free oxygen, no free Nitrogen is evolved from the nitrogenous compounds of the plant.

At all events the entire cessation of the evolution of gas after the decomposition has gone on for a few days, shows that the presence of free oxygen is essential to the evolution of Nitrogen, as it is conducive to that of carbonic acid. The loss of Nitrogen indicated in Tables VII. and IX. must be considered, therefore, to be the result of an oxidizing process.

We shall have to allude again to the results given in Table $\mathrm{X}$. when we come to discuss the question of the formation of ammonia from the free Nitrogen of the air, and the nascent hydrogen evolved during the decomposition of organic matter.

In order to examine the character of the decomposition of organic matter in oxygen gas, an investigation was undertaken, which, owing to the difficulty of getting the requiMDCCCLXI. 
site apparatus sufficiently air-tight, was not followed up to the cxtent which harl beres intenderl.

The plan proposed was, to plate the organic matter in an atmosphere of pme coxygrn. and to afford a constant supply of the gas as it becane converted into carbonic acid, and was absorbed by a solution of caustic potish.

'The results obtained go to show that, in the presence of free oxygen, Vitrogen gas is erolved. But as the investigation is as yet so incomplete, owing to the circunstince above alluded to, we prefer not to give the results until we can confirm them by a more extended series of experiments under more favourable conditions.

'Iaking together the results of all the experinents which have been made upon the decomposition of nitrogenous organic matters, they obviously point to a scrious difficulty in the way of experiments made upon the question of the assimilation of free Nitrogen by plants. It is not possible to conduct any such experiments without exposing nitrogenous organic matter to conditions more or less analogous to those under which the loss of Nitrogen recorded in 'lables VII. and IX. took place. For although, as boc'sSINGAULT has shown, there may be no loss of Nitrogen during germination, jet, during the entire period of the growth of a plant, certain portions of the regetable substance may be subjected to conditions favourable to the decomposition of its nitrogrenous compounds, and to the evolution of free Nitrogen.

As illustrative of how far these conditions are likely to be operative in the manner indicated, the following results, made with Wheat, Barley, and Oats respectively, are very instructive. Seeds of the three plants were sown, each in precisely the same kind and amount of soil, \&c., as employed in the experiments on the assimilation question. 'The three pots were placed beneath a large glass sliade, 16 inclies in diameter; which fitted into the groore of a stone-ware lute-ressel, into which sulphuric acid was poured to exclude the access of external air. 'The whole stood on a table in the diffused light of the laboratory. The plants were at first supplied with distilled water; but with no carbonic acid beyond that which might be contained in the water. These conditions afforded all that was necessary for germination and growth, with little opportunity for the assimilation of free Nitrogen, even were this possible in the more farourable conditions of sunlight. Yet the conditions were more than ordinarily favourable to the decomposition of nitrogenous compounds, provided this would take place, under certain circumstances, during the growth of the plant. The succulent character of the stems and leaves so grown in the shade, would render the nitrogenous matters more liable to decomposition than in the case of the more firm and hardened stems of plants grown in sunlight.

Eight seeds of each plant were sown; and in a few days all came up, and grew rery rapidly in height, without much tendency to derclopment and expansion of leaf. The plants were all very much alike-tall, slender, delicate, and haring the peculiar palegreen colour common to plants deprived of sufficient sunlight. In sereral other expe- 
riments it was found that plants which had proceeded for some time in this delicate form of growth, immediately ceased this predominant upward tendency when removed into sunlight: then, after remaining stationary for a few days, during which time the extremities of the long delicate leaves lost their vitality, the plants commenced a new order of growth, producing many more leaves, which were much shorter and broader than the earlier ones; the stems also became thicker and more dense than before.

The seeds were put in on May 17 (1858); and on June 10 following, the plants had ceased to grow. Several of the long slender stems were too delicate to support themselves, and began to fall over. All the plants presented much the same appearance, each with a small sheath without any leaf at the base, and three leaves higher up-the two lateral ones being very long, from 8 to 12 inches, and the terminal ones, not unrolled, from 3 to 4 inches long from the axial of the next leaf below, the whole plant being from 7 to 11 or 12 inches high. On removing them from the soil, it was found that the roots were distributed very little through it. They consisted of short fibrils, with divaricated branchlets, extending principally around the seeds, and seldom more than 2 or 3 inches through the soil. The plants were so very much alike, that it was difficult to distinguish the different kinds. Fig. 9, Plate XII., is reduced from a sketch of one of these attenuated plants.

The following Table gives the quantitative particulars of the experiments.

TABLE XI.-Showing the effect of Germination, and Growth without direct Sun-light, or extraneous supply of Carbonic Acid or combined Nitrogen, upon the combined Nitrogen originally provided in the Seed.

Duration of experiment twenty-four days-from May 17 to June 10, 1858.

\begin{tabular}{|c|c|c|c|c|c|c|c|c|c|c|c|}
\hline \multicolumn{5}{|c|}{ Particulars of the seed sown. } & \multicolumn{3}{|c|}{$\begin{array}{l}\text { Dry regetable matter } \\
\text { produced. }\end{array}$} & \multicolumn{4}{|c|}{ Nitrogen. } \\
\hline Description. & No. & $\begin{array}{l}\text { Weight, } \\
\text { fresh. }\end{array}$ & $\begin{array}{c}\text { Weight, } \\
\text { dry. }\end{array}$ & Nitrogen. & Stems. & Roots. & Total. & $\begin{array}{l}\text { In stems } \\
\text { and roota. }\end{array}$ & $\begin{array}{c}\text { In soil } \\
\text { and pot. }\end{array}$ & $\begin{array}{c}\text { In total } \\
\text { products. }\end{array}$ & $\begin{array}{l}\text { Gain or } \\
\text { loss. }\end{array}$ \\
\hline $\begin{array}{l}\text { Wheat ...... } \\
\text { Barley ..... } \\
\text { Oats ........ }\end{array}$ & $\begin{array}{l}8 \\
8 \\
8\end{array}$ & $\begin{array}{c}\text { gramme. } \\
0.4 S 65 \\
0.3875 \\
0.3175\end{array}$ & $\begin{array}{c}\text { gramme. } \\
0.4077 \\
0.3234 \\
0.2900\end{array}$ & $\begin{array}{c}\operatorname{gramme} \\
0.00790 \\
0.00573 \\
0.00640\end{array}$ & $\begin{array}{c}\text { gramme. } \\
0.320 \\
0.290 \\
0.355\end{array}$ & $\begin{array}{c}\text { gramme: } \\
0.140 \\
0.160 \\
0.060\end{array}$ & $\begin{array}{c}\text { gramme. } \\
0.460 \\
0.450 \\
0.415\end{array}$ & $\begin{array}{l}\text { gramme. } \\
0.00697 \\
0.00570 \\
0.00610\end{array}$ & $\begin{array}{c}\text { gramme. } \\
00012 \\
\text { traces } \\
\text { traces }\end{array}$ & $\begin{array}{l}\text { gramme. } \\
0.00817 \\
0.00570 \\
0.00640\end{array}$ & $\begin{array}{l}\text { gramme. } \\
+0.00027 \\
-0.0000 \\
+ \text { traces }\end{array}$ \\
\hline
\end{tabular}

'The weights given for the roots are a little too high, owing to their not having been washed entirely free from soil, the principal object being to ensure a correct result with regard to the Nitrogen which long washing might hare endangered, or at lcast rendered less easy. 'There is, however, evidently a slight gain of dry matter, which, so far as its carbon is concerned, was doubtless due to carbonic acid in the distilled water, of which about 500 cub. cent. were added to each pot at the commencement of the experiment. None was added during the progress of the experiment; but the soil was moist when the plants were taken up.

The rapid growth of the plants, the short period of their contact with the soil, the 4 ^ 2 
very limited distribution of the roots, and the fuct that no water was added duringe growth, which would tend to distribute any soluble or otherwise easily transportable: matters, are conditions all consistent with the almost total absence of Vitrogen in the soil.

Lastly in regard to the results in the 'lable (XI.), the final colunn, showing the gain or loss of Nitrogen, affords us the means of judging how fur the molecular actions by which free Nitrogen. was given off in the cases of the experiments upon the decomposition of nitrogenous organic matter are likely to interfere with the results of our investigations on the question of assimilation of fiee Nitrogen by plants. It is seen that, in the experiments now under consideration, no free Nitrogen was given off during the process of germination and growth. At least, the assumption that fiee Nitrogen was given off implies the still more improbable one, that, under the circumstances detailed, assimilation of free Nitrogen has taken place; whilst the adoption of these two assumptions necessitates the yet more improbable one, that these two independent actions bear a most definite relation to each other-in fact, that the amount of free Nitrogen assimilated is exactly equal to that given off during decomposition.

It would appear, therefore, that we may rest satisfied that our results in regard to the question of assimilation will not be affected by a loss of free Nitrogen as the result of the decomposition of nitrogenous organic matter, so long as that matter is subjected to the ordinary process of germination, and exhaustion to supply materials for growth. Our results in regard to the products of decomposition of nitrogenous organic matter do, indeed, point to the danger of using nitrogenous organic manure in such experiments, and to the error that might occur from seeds decomposing in the soil instead of groming, or from the decomposition of dead leaves, of old roots, or of nitrogenous organic excretions; but they do not afford any evidence of what takes place within the range of the action of the living plant. And, judging from the amount of free Nitrogen evolved when, as in the experiments on decomposition, so large a proportion of the nitrogenous organic matter was decomposed, we may form some idea of the probable extent of such erolution when, as in experiments where vegetable growth is involved, and where the only nitrogenous organic matter supplied is that in the seed sorn, but a small proportion of the total nitrogenous matter undergoes decomposition.

In relation to this question, it should be borne in mind that, in the cases where the large evolution of free Nitrogen took place, the organic substances were subjected to decomposition for a period of about six months, during which time they lost three-fnurths of their carbon. In the experiments on the question of the assimilation of free Nitrogen, however, but a very small proportion of the total organic matter is subjected to decomposing actions apart from those associated with growth, and this for a comparatirely short period of time, at the termination of which the organic form is retained, and therefore but little carbon is lost. It would appear, then, that we need not fear any serious error in our experiments in regard to the latter question, arising from the evolution of free Nitrogen in the decomposition of the nitrogenous organic matters 
involved. On the other hand, the facts adduced afford a probable explanation of any small loss of Nitrogen which may occur when seeds have not grown, or when leaves, or other dead matter, have suffered partial decomposition.

\section{F.-The mutual relations of Gaseous Nitrogen and the Nascent Iydrogen evolved during the decomposition of organic matter.}

The importance attached by MULDER, and others after him, to the action of nascent hydrogen, evolved in the decomposition of organic matter, upon gaseous Nitrogen, as a source of ammonia, is such as to require that we should refer to the subject here, in the course of the discussion of the conditions possibly affecting the supply of combined Nitrogen to our experimental plants. The results given in the last sub-section (pp. 509511 ), leave no doubt of the evolution of hydrogen during the decomposition of organic matter. They suggest, therefore, the possibility that such an evolution may take place in any decomposition of organic matter involved in our experiments on the assimilation of free Nitrogen by plants, and hence prove a source of ammonia to them.

That nascent hydrogen may, under certain circumstances, combine with gaseous Nitrogen, has long been admitted. But the view so prominently put forth by MULDER*, and some others, that those circumstances occur in the evolution of nascent hydrogen accompanying the decomposition of organic matter, requires confirmation.

If only a very small part of the hydrogen evolved in the decomposition of organic matter were to form ammonia with the Nitrogen gas which must always be in most intimate contact with it, the amount of ammonia formed in this way would be enormous. Peat bogs, cesspools, and all stagnant water pregnant with organic matter, as well as many soils, would be constantly so accumulating ammonia. The extensive forests in different parts of the world, which have been annually depositing a coating of leaves upon the surface of the soil for thousands of years, must also have been a very fertile source of ammonia, as the leares have gradually decayed under the influence of moisture and confined air beneath the succeeding layers. And when we contemplate the amount of decomposition that must have corresponded to the very exuberant growth of former geological periods, as manifested in the remains exhibited in our coal beds and limestones, we see a source of ammonia, if formed in the manner now under consideration, which would be incalculable.

The results given in the last subsection (E), upon the decomposition of nitrogenous organic matter, favour the view that the hydrogen evolved in such decomposition does not form ammonia with the Nitrogen of the air. The assumption that it did so, implies that the nascent hydrogen was capable of uniting with free gaseous Nitrogen (forming ammonia) under circumstances in which its affinities were not sufficiently powerful to prevent Nitrogen compounds very similar to ammonias (and which are easily transformed into them) from giving up Nitrogen in the free state. It implies also, that the nascent hydrogen can act upon ordinary Nitrogen, when it cannot do so upon this nascent Nitro-

* Chemistry of Vegetable and Animal Physiology, pp. 111-114, 149-152, \&c. 
gen of the decomposing nitrogenous body. Or, if it alid act upon the latter in preforenere to the former, there would eithex be no firee Nitrogen finally covelved, os, in case of Xitrogen being lost in the free state, it would be obvions that there had heese less mascent Nitrogen converted into ammonia than had becn liberated from its combinations, and hence that, as a resultant, there would be a loss and not a gerin of combined vitropers due to the decomposition.

The fact that, in our experiments upon the gas evolved by veugctable matters in a state of decomposition, both free Nitrogen and free hydrogen were given uff, hears strongly upon this question. 'The Nitrogen evolved las been in most intiuate contact with the lyydrogen given off. It has, indeed, been in the identical cells by the decomposition of the walls or contents of which the hydrogen was set free; yet both ilppear as gas.

From the above considerations it would appear that we need be under little apprehension of error in the results of our experiments on the question of the assinilation of free Nitrogen by plants, arising from an unaccounted supply of ammonia formed under the influence of nascent hydrogen, given off in any decomposition of the organic matter involved in the experiment.

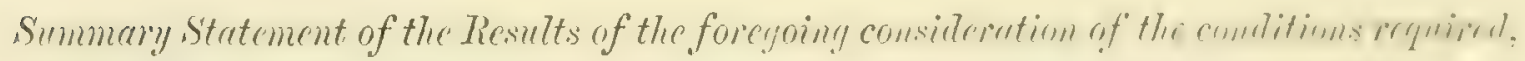
or involved, in Experiments on the question of the assimilation of fiee Nitrogen by Plants.

Before entering upon the discussion of the results of our direct experiments upon the question whether or not plants assimilate free Nitrogen, it will be well, for the sake of perspicuity, to give a very brief enumeration of the results arrived at in the foregoing Sections I. and II. (Part II.), relating to the conditions of experiment required, and to the collateral investigations involved, in the inquiry. They may be stated as follow:-

1. Conditions of soil or matrix which are both adapted for healthy growth and are consistent with the other requirements of the investigation can be attained (Section $I$. Sub-sections A, p. 470, and L, p. 484).

2. The requirements of the experiment in regard to the selection of seeds or plants for growth, to the nutriment to be supplied in the soil, to the water, to the atmosphere, to the carbonic acid, and to other conditions involved, can be satisfactorily met (Section I. Sub-sections B-J, inclusive, pp. 472-48.1; and L, p. 484).

3. The conditions of experiment adopted hare sereral adrantages orer some of those which have been suggested, or adopted, by others (Section I. Sub-section $\mathbf{K}$, pp. 181 483).

4. The mutual actions of the soil, air, organic matter in the soil or in the plant, are not such as to be likely to affect the result of the experiment, by yielding to the plants a quantity of combined Nitrogen not taken into account. The influence of Ozone as a possible element in these actions would be less, in the circumstances of the experiments 
on ssimilation, than in those of experiments the results of which showed no appreciable formation of compounds of Nitrogen (Section II. Sub-sections A-C, pp. 484-497).

5. The fact of the crolution of free Nitrogen during the decomposition of nitrogenous organic matter has been confirmed by experiment; but the circumstances of the decomposition in which the evolution of free Nitrogen was observed, when compared with those involved in an experiment on the question of assimilation, are not such as to lead to the conclusion that there would be a loss of Nitrogen from this source in experiments of the latter kind, unless in certain exceptional cases, in which it might be presupposed (Section II. Sub-section D, pp. $497-508$ ).

6. The forces, by rirtue of which free Nitrogen is eliminated from its compounds in organic matter, are of an oxidizing character; they are not exercised in the absence of oxygen. They are not likely to be operative in comnexion with growing vegetable matter (Section II. Sub-section E, pp. 950, 951).

7. Although it is known that, under certain circumstances, nascent hydrogen may combine with free Nitrogen and form ammonia, it is questionable whether the nascent hydrogen eliminated during the decomposition of vegetable matter will be in the conditions to effect such a combination; nor are the circumstances of our experiments on the question of the assimilation of free Nitrogen by plants such as to lead to the supposition, that an crror in the results can arise from the formation of any ammonia under the influence of the action supposed (Section II. Sub-section F, pp. 515, 516).

SECTION III.-CONDITIONS OF GROWTH UNDER WHICH ASSIMILATION OF FREE NITROGEN BI PLANTS IS MOST LIKELY TO TAKE PLACE; DIRECT EXPERI. MENTS UPON TUE QUESTION UNDER VARIOUS CIRCUMSTANCES OF GROWTH.

\section{A.-General consideration of conditions of growth.}

We have thus far discussed, in some detail, the arrangement adopted in our experiments on the question of the assimilation of free Nitrngen by plants, and the collateral points involved in the relation of gaseous Nitrogen to regetation. In regard to the latter, we have dwelt particularly on those which relate to the sources of available Nitrogen to plants, and which, therefore, may tend to influence the quantitative results which we may obtain by the methods of experimenting followed. It remains to consider what are the circumstances under which it is most probable that free Nitrogen may be assimilated, provided the assimilation can take place at all.

The demonstration of the fact, that the process of cell-development could go on in the presence of free Nitrogen without the latter becoming incorporated into the cell wall, or into the contents of the cell, as a nitrogenous compound, would not carry with it the demonstration that free Nitrogen could, under no conditions of growth, undergo such change. Our aim should be, therefore, to seek the most probable circumstances 
for such change; and if we find that in theme free Nitrogen is assinilaterl, we should then trace up the question through the circumstances in which such assinilation is less likely to take pliace.

If, on the contrary, we find that fiee Nitrogen is not assimilated under the circumstances which appear the most fiwourable for such an action, we maty either gencralize for other conclitions from the negative results so obtained, or we may extend our experiments in order to widen the basis of our generalizations.

In the consideration of what are the cases in which the assimilation of free Vitrogen is most likely to take place, two important classes of conditions present themselves:-

1. 'Those which relate to the supply of combined Nitrogren at the disposal of the plant.

2. 'Those which relate to the activity of growth and stage of derelopment of the plant.

'These two questions, though logically distinct, are physiologically blended; for it may happen that a certain activity of growth, or certain stages of development, can only be attained by a given supply of combined Nitrogen beyond that contained in the seed.

If we examine these conditions a little more closely, we see that they give us the following possible cases for the assimilation of fiee Nitrogen by the plant:-

1. The plant may be able, in the process of cell-formation, to derive the whole of its Nitrogen from that presented to it in the free state.

2. It may be capable of assimilating a part of its Nitrogen from that presented to it in the free state, provided it be supplied with only a part of its required amount in some form of combination.

3. It may assimilate free Nitrogen in the presence of an excess of combined Nitrogen. Again :-

1. It may be capable of assimilating free Nitrogen in the earlier stages of its development.

2. It may be so at the most active period of its growth.

3. It may when near the period of its maturity.

Combinations of these several circumstances present at least nine special cases, in one of which, if at all, an assimilation of free Nitrogen might take place without its doing so in any of the others. The question arises, how are we so to arrange our experiments as to include the greatest number of these cases, and those in which the assimilation of free Nitrogen is the most likely to occur?

The obviously most probable circumstances for the assimilation of free Nitrogen at any stage of development of the plant, are those in which it is brought to that stage in a healthy condition, and then deprired of all sources of combined Nitrogen. It is hardly to be supposed that an assimilation of free Nitrogen would take place if there were an excess of combined Nitrogen at the disposal of the plant; for, if we suppose that the molecular and rital forces are at the same time acting upon Nitrogen supplied by these two sources, in a manner tending to force that from both into the constitution 
of the living organism, it is only consistent with our established notions of force, that the form which yields with the greatest ease will yield first, and that, if its supplies be in sufficient quantity, it only will yield in an appreciable degree to the force applied.

If, on the other hand, the forces involved in regetable growth, tending to form nitrogenous compounds, are capable of appropriating free Nitrogen only in the presence of a certain amount of assimilable combined Nitrogen, then the question of deciding upon the proper proportion of combined Nitrogen to effect the assimilation of that provided in the free state would seem, à priori, to present serious difficulty. For if the plant cannot assimilate free Nitrogen either in the presence of an excess of combined Nitrogen, or without the aid of a certain amount of it, it would, at first sight, appear that there might be some difficulty in so arranging an experiment as to hit the proper medium.

But within a certain range of conditions this supposed difficulty would not occur. If the assimilation of free Nitrogen be possible only as the result of the assimilating forces acting upon it in the presence, or with the aid, of a certain amount of combined Nitrogen, then, when the quantity of combined Nitrogen has become too small, the point must have been passed at which the maximum amount of free Nitrogen would be assimilated in relation to the then existing supply of combined Nitrogen. Hence, the analysis of a.plant at the period at which its growth ceased in consequence of the falling short of the relative supply of Nitrogen in the combined form, would show whether or not an assimilation of free Nitrogen had taken place as the result of either of the conditions referred to in the last paragraph.

If, however, the plant cannot assimilate free Nitrogen under the conditions of the supply of combined Nitrogen just referred to, unless it has attained a certain vigour of growth, or reached a certain stage of its development, and the supply of combined Nitrogen has been insufficient to bring it to the supposed requisite point, then no assimilation of Nitrogen would take place, even though it might do so provided the proper stage of growth had been passed. To the cases here supposed we shall recur further on.

If the assimilation of free Nitrogen can take place at all periods of the growth of the plant, and in the absence of all sources of combined Nitrogen, the solution of our question becomes much more simple than in either of the cases above referred to.

In illustration of the fact that, within a certain range of other conditions, there can be no difficulty in securing in an experiment those involved in the presence of an excess, of a certain limited quantity, or of no combined Nitrogen, attention may be directed to the phenomena of vegetable growth when seeds are grown in a soil and atmosphere free from combined Nitrogen.

Under the circumstances supposed, all the conditions with regard simply to the relative quantity of combined Nitrogen are afforded. Thus, when the seed is first sown, it contains within itself an excess of combined Nitrogen, so far as the demands of the plant at the time are concerned. The rapidity with which the Nitrogen of the seed can MIDCCCLXI. $4 \mathrm{~B}$ 
be used, in the growing process, is seen in the results of the experiment in regard to the question of the decomposition of Nitrogenous matter during growth, as given in lable XI. (p.513); and the extent to which it can carry the growth of the plant is illustrated in that experiment, as well as in others, to which we shall presently refer, relating to the question of assimilation itself. It is obvious that, during a part of the time at the end of which the plant has reached the limit of its supply of combined Vitrogen, it has had at its disposal an excess of combined Nitrogen for its immediate wants. It has then passed through a stage in which the particular relation of combined to free Nitrogen implied in another of our assumed conditions must have existed. It must finally have reached a point at which only free Nitrogen was presented to it.

If an analysis of the plant at the termination of the last-mentioned period showed no increase of Nitrogen, the result would afford conclusive evielenere argainst thr prenibility of the assimilation of free Nitrogen under a wide range of conditions. If, on the contrary, a gain of Nitrogen were indicated, the question would still be open, to which of the several conditions to which the plant had been subjected it owed the increase found. But this question we need not discuss until we have recorded the results of our experiments on the point.

\section{B. - Direct experiments on the question of the ressimitation of firee Vitiongen by pulants.}

We have thus far discussed the methods of experimenting to be adopted, the results of certain collateral inquiries, and the sereral conditions under which the an-imilation of free Nitrogen by plants may be the more or the less likely to take place. We have thus endeavoured to eliminate all known sources of error, and to acquire the means of forming an estimate of the possible influence of certain unknown quantities, and so, as far as practicable, to reduce the solution of our question to that of a single point to be tested by direct experiment. It remains to consider the experimental eridence relating to this last and final point.

An investigation requiring sereral hundred analyses, and a series of observations made at intervals of a few days, through periods of several months, inrolres an amount of recorded detail much too voluminous for full publication. An abstract of the most important portions of the records will, howerer, be given for reference in the Appendix. A statement of the methods of analysis adopted, with illustrations of the limits of accuracy reached, together with a condensed summary of the details of growth of the plants, will there be given.

In the selection of the plants to submit to our adopted conditions of experiment, $\pi$ e have been guided by sereral considerations:-

1. To have such as would be adapted to the conditions of temperature, moisture, \& $\mathbb{C}$., to which they were to be subjected.

2. To have such as were of importance in an agricultural point of riew.

3. To acquire the means of studying any difference, in reference to the point in question, between plants which belong respectively to the two great Natural Orders 
the Graminacere and the Leguminosx, which, in some points of riew, appear to differ so widely in their demands upon combined Nitrogen provided within the soil.

4. 'To take such as had already been experimented upon, with such conflicting results, by M. Boussivgault and M. G. Ville.

We shall first consider the results obtained with plants grown without any other supply of combined Nitrogen than that contained in the seed sown.

\section{I.-Experiments in which the plants had no other supply of combined Nitrogen than that contrined in the seed sown.}

The following Table (XII.) gives, at one view, a summary of the numerical results obtained under this head; see also figs. 1-6, Plate XV., which are reduced from careful drawings taken of six out of the nine Graminacex experimented upon, and illustrate the character and extent of growth attained under the conditions in question.

After the full discussion in the foregoing pages of the circumstances under which the results recorded in the Table just given were obtained, but little need be said in pointing out their bearings upon the question at issue. The column showing the gain or loss in each experiment speaks for itself. In judging of the results of the experiments of 1857, the remarks made in discussing the results of Table XIV. (p. 532), with regard to the slates used as lute-vessels in that year, must be taken into consideration. The source of error referred to being obviated in the experiments of 1858 , the results of 1857 acquire a greater value, as confirming those of the latter year, than, standing alone, they would possess.

The difference between the results obtained with soil and with pumice as matrix, in 1857, are not such as to lead us to attach any importance to them, or to attribute them in any way to the difference of matrix in question. The two experiments may therefore simply be considered as duplicates. Indeed, the character of the results in the one experiment with Wheat, and in the two with Barley, in 1857, was so similar, that the three experiments may be considered as triplicates.

\section{Graminaceous Plants.}

It will be observed that the largest gain of Nitrogen in the three experiments with Graminacex in 1857 was 0.0026 gramme. Keeping in view the probable source of error due to the use of slates in that year, and the difference of result in 1858 when slates were not employed, and, again, considering the fact that so small an amount of Nitrogen had to be determined in such a large amount of soil $(0.003$ gramme or less of Nitrogen in about 1500 grammes of soil), it seems indeed more than questionable whether the gain should not be attributed to the errors of experiment or analysis alluded to. In fact, we can but conclude that, under the circumstances of growth of the Graminaceous plants to which Table XII. relates, there has been no assimilation of free Nitrogen.

It should also be noticed that, even when a gain of Nitrogen in the total products is observed, there is, in no case, more Nitrogen in the plant itself than in the original 


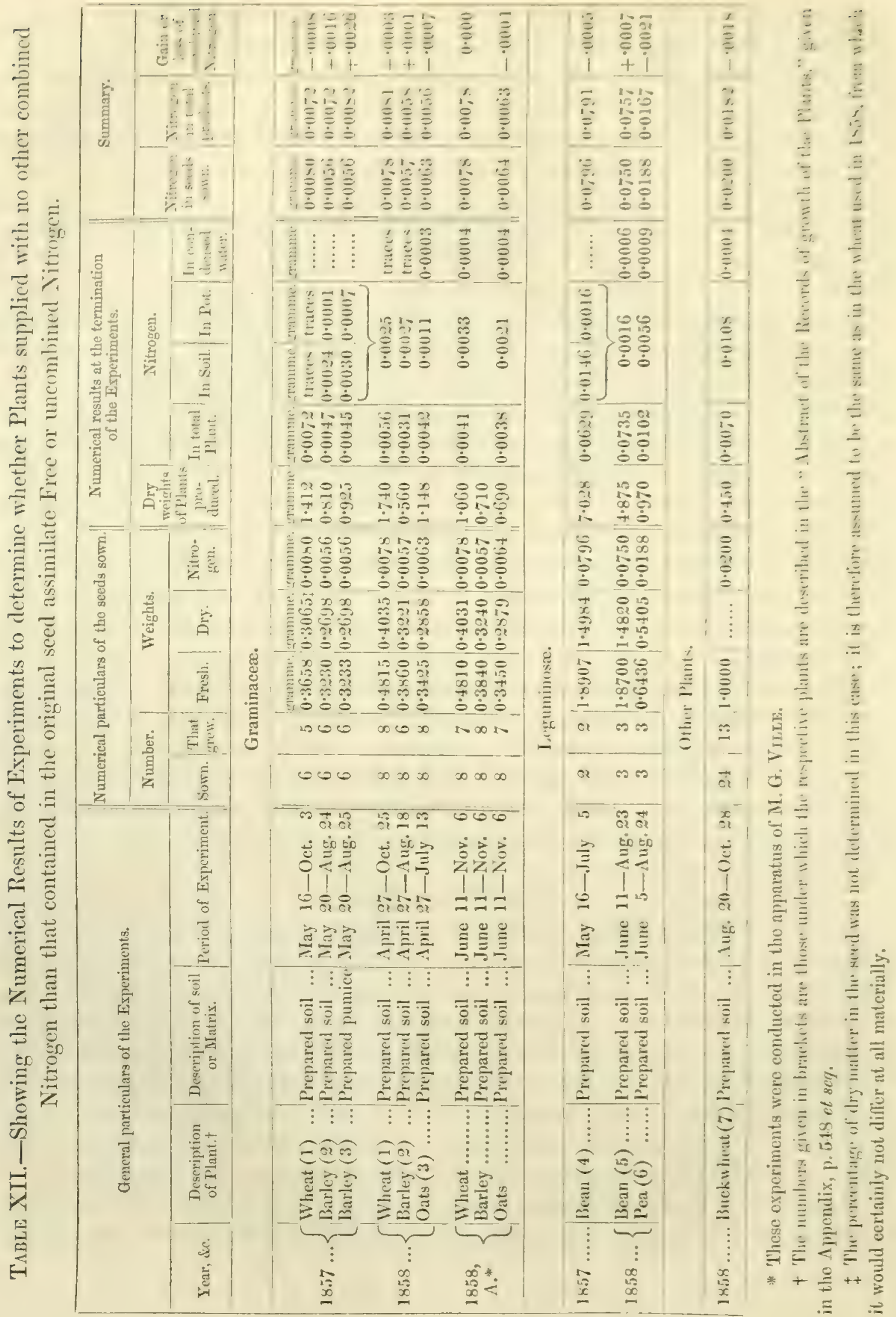


seed,-the gain appearing only when the Nitrogen in the soil and pot is taken into account. It will be remembered that the results of the experiments on the question whether there was an evolution of Nitrogen during germination and growth ('Table XI., p. 513) showed how completely the plants could appropriate the Nitrogen of the seed from which they grew, leaving only traces of it in the soil. Again, the experiments on the decomposition of Nitrogenous organic matter (Tables VIII. and IX., p. 506) have shown how thorough was the decomposition coincident with the passage of any large percentage of the combined Nitrogen of the substance into the soluble state of ammonia. Taking together these facts, we have strong grounds for assuming that at least a part of the Nitrogen found in the soil, in the cases where there was a gain of it in the total products, has never been in actual comnexion with the plant at all. Indeed, in view of the facts just referred to, any gain of Nitrogen in connexion with the plant, without there being a larger quantity of Nitrogen in the plant itself than that provided in the seed, would be very questionable evidence upon which to establish the fact of the assimilation of free Nitrogen.

But the results obtained with Graminaceæ in 1858, when all possible sources of error which the experience of the previous year had suggested had been eliminated, point, without exception, to the fact that, under the circumstances of growth to which the plants were subjected, no assimilation of free Nitrogen has taken place. The regular process of cell-formation has gone on; carbonic acid has been decomposed, and carbon and the elements of water have been transformed into cellulose; the plants have drawn the nitrogenous compounds from the older cells to perform the mysterious office of the formation of new cells (see Notes on growth, Appendix, pp. 559, 561); those parts have been developed which required the smallest amount of Nitrogen; and all the stages of growth have been passed through to the formation of glumes, pales, and awns for the seed. In fact, the plants have performed all the functions that it is possible for a plant to perform when deprived of a sufficient supply of combined Nitrogen. 'They have gone on thus increasing their organic constituents with one constant amount of combined Nitrogen, until the percentage of that element in the vegetable matter is far below the ordinary amount of it - that is, until the composition indicates that further development had ceased for want of a supply of available Nitrogen.

Throughout all these phases, water saturated with free Nitrogen has been passing through the plant; nitrogen dissolved in the fluid of the cells has constantly been in the most intimate contact with the contents of the cells and with the cell-walls. The newly forming cell, stunted in its development for want of assimilable Nitrogen, has nevertheless been surrounded by free Nitrogen. Its delicate membranes have been saturated with water, itself saturated with free Nitrogen; and such are the laws in accordance with which the absorption of gases, and the transmission of liquids through membranes take place, that the instant a part of the Nitrogen of the saturated fluid became assimilated, the equilibrium would be restored, by the penetration into the cell of other saturated liquid, and the re-saturation of that from which Nitrogen had been with- 
drawn. It would hardly be supposed that, under such circumstances, the process of cell-formation could go on without the assimilation of free Nitrogen, provided any forces were exerted in the cell the tendency of which was to fix free Nitrogen in the organism of the plant.

One fact, briefly allucled to above, we wish to call more special attention to, as affording strong evidence of the absence of the power on the part of these cereal plants to appropriate free Nitrogen-namely, the very large development of the root, requiring but little Nitrogen compared with that of other parts. It was observed, in the experiments of 1857 , that several of the cereal plants developed a large proportion of root; but the danger of accident in analysis was such, that we hesitated to double the risk of losing the entire result by analysing the root and the portion of the plant above ground separately. They were, therefore, thoroughly mixed, and the mixture was carefully divided; so that, in case of accident, a duplicate was at our disposal, and in case of all going well, confirmatory evidence was obtained. So very marked, however, was the great development of root in the cereals of 1858 , that, in several cases, it was analysed separately from the other parts of the plant. 'The remarkable result was obtained, that this great root-development was carried on (in two, at least, out of the three instances in question) with a consumption of an almost incredibly small amount of Nitrogen, as the figures given in the following Table will show:-

Table XIII.

\begin{tabular}{|c|c|c|c|c|c|c|c|c|}
\hline \multirow{2}{*}{$\begin{array}{c}\text { Description of Plant. } \\
1858 .\end{array}$} & \multicolumn{3}{|c|}{$\begin{array}{l}\text { Dry Matter in Produce } \\
\text { (at } 100^{\circ} \mathrm{C} \text {.), grammes. }\end{array}$} & \multicolumn{3}{|c|}{ Nitrogen in Produce (grammes). } & \multirow{2}{*}{$\begin{array}{l}\text { Per cent. } \\
\text { of Total } \\
\text { Dry Jatter } \\
\text { in Roots. }\end{array}$} & \multirow{2}{*}{$\begin{array}{l}\text { Per cent. } \\
\text { of Total } \\
\text { Nitrogen } \\
\text { in Roots. }\end{array}$} \\
\hline & $\begin{array}{c}\text { In Stems, } \\
\text { \&c. }\end{array}$ & In Roots. & $\begin{array}{l}\text { In Total } \\
\text { Produce. }\end{array}$ & $\begin{array}{l}\text { In Stems, } \\
\& e^{2}\end{array}$ & In Roots. & $\begin{array}{l}\text { In Total } \\
\text { Produce. }\end{array}$ & & \\
\hline Wheat (1) & $0 \cdot 890$ & 0.850 & $1 \cdot 740$ & 0.0039 & 0.0017 & 0.0056 & $48 \cdot 85$ & $30 \cdot 36$ \\
\hline Barley (2) & $0 \cdot 400$ & $0 \cdot 160$ & $0 \cdot 560$ & $0 \cdot 00: 7$ & $0 \cdot 0004$ & $0 \cdot 00331$ & $2 \pi \cdot 3$ & $1: 10$ \\
\hline Oats (3) ......... & $0 \cdot 798$ & $0 \cdot 350$ & $1 \cdot 148$ & $0 \cdot 0040$ & $0 \cdot 0002$ & 0.0042 & $30 \cdot 49$ & $4 \cdot 76$ \\
\hline
\end{tabular}

The large proportion of root and its small proportion of Xitrogen, as here exhibited, are equally remarkable. Whether this great power of the plant to derelop root be due to the fact that the process of cell-formation in the root requires less of the nitrogenous protoplasmic compound, or to the fact that, floating in water as these roots generally were, that fluid facilitated the withdrawal of the nitrogenous constituents resulting from the decomposition of protoplasma from the old cells, to form new protoplasma for the more active cells, is a question which, though foreign to our present subject, is of considerable interest in a physiological point of riew. The fact that the roots from the base of the stem penetrated the soil, giving off rery few branches into it, but immediately on reaching the water at the bottom of the pot exhibited such a remarkable derelopment (see Notes on taking up the Wheat Plants, Appendix, p. 560), is in farour of the inference that the water afforded the necessary conditions for the character of growth referred to. 
But, apart from the physiological points just referred to, as already said, this great derelopment of a part of the plant requiring a minimum amount of Nitrogen affords strong evidence of its inability to assimilate free Nitrogen within the range of development possible when no combined Nitrogen is provided beyond that contained in the original seed. It exhibits the great tenacity of growth of the plant, and shows the activity of the vital force, long after the demands of the organism had begun to require more available Nitrogen than was at its disposal. When it is considered how great was the length of time during which the growing cells were exposed to the conditions in question, there would seem to be a combination of circumstances favourable to the exercise of any force tending to bring free Nitrogen into the constitution of the plant. But no such effect is manifested in the results.

The Graminacere referred to in the Table (XII.) under the Title of "1858, A.," and which were grown in the enclosing apparatus of M. G. VILLE, as already alluded to, give results quite sinilar in their bearings on the main question to those of 1857 and 1858 already discussed. Being sown later, however, and their period of growth being shorter, they did not manifest such an extraordinary development of root; nor was there so large an amount of vegetable matter produced. Unfortunately the barley grown in M. VILLE's Case without artificial supply of combined Nitrogen, was lost by the giving way of the tube in the combustion for the determination of Nitrogen. In its case, therefore, we can only give the amount of the dry matter of the plants produced. But, comparing this with that of the seed sown, and looking to the proportions of Nitrogen in the produce of barley in the other cases, there is no reason to believe that the result would have formed any exception to that indicated in the other experiments.

In concluding our remarks on the results with the Graminacex grown without any further supply of combined Nitrogen than that contained in the seed sown, we would beg to refer the reader to the foregoing consideration of the conditions possibly farourable to the assimilation of free Nitrogen (p. 517 et seq.).

It will be remembered that, in experimenting with Graminacex, including some of the same description as those experimented upon by ourselves, M. Boussingadlt and M. G. VILLE obtained most unaccountably discordant results. It will be seen that our own results, from nine experiments with such plants, go to confirm those of M. BoussisGAULT. In fact, so far as our labours with these plants bear upon their experiments, they could not have given a more decided result.

For representations of some of the Graminaceæ grown without any supply of combined Nitrogen beyond that contained in the original seed, see figs. 1 to 6 , Plate XV.

\section{Leguminous Plants.}

It still remains to consider the results of our experiments with Leguminous plants grown under similar conditions to those of the Graminaceous ones abore discussed, and to see how far they serve to explain the known characteristics of such plants when grorn in practical agriculture, to which attention has been directed in Part First of this Paper. 
It will be remembered that, under equal circumstances of soil and season, Ioguminous crops yield two, three, or more times as much Nitrogen per acre as Gramiraceous ones. Yet, whilst the latter are very characteristically benefited by the use of direct nitrogenous manures, the former, yielding so much more Nitrogens, are not so. Agrain, the Graminaccous crop, requiring for full produce such direct supply of atvalable Nitrogen within the soil, is very much increased, beyond what it would be if it succeeded a crop of the same description, when it follows a Leguminous crop, in which has been carried off' so much Nitrogen.

Experiments such as those now specially under consideration can obviously bear upon a few only of the circumstances with which may be connected the causes of this difference between the Graminaceous and the Leguminous crops. Without, therefore, pretending adequately to discuss this wide subject, we will consider it only so far as our immediate facts appear to bear upon it; they seem to limit us to the consideration of the following cases:-

1. The difference may be due to the decomposition of nitrogenous compounds during the growth of the Graminaceous plants, and to the evolution of free Nitrogen.

2. The Leguminous plants may assimilate the free Nitrogen of the air, and thus, not only allow the resources of the soil to accumulate, but also leave within it an additional quantity, in roots and other vegetable débris, from that which has been assimilated, as abore supposed.

3. It may be due to the operation of both these causes.

So far as the facts we have already considered go, the difference in question cannot be explained according to the first of the above suppositions; and others, to which we shall have presently to refer, will be seen to afford confirmatory evidence on the point.

With regard to the second supposed explanation, the results we have now to record of our experiments with Leguminous plants are not of themselves sufficient to settle every point which it involves. Reference to the Appendix will show that, in sereral cases, we failed to get healthy growth with Leguminous plants. A doubt might hence be raised, as to the value of those experiments in which we were successful under circumstances so nearly identical with those of our failures that it was not easy to account for the difference of result obtained. In those cases, however, in which we hare succeeded in getting Leguminous plants to grow pretty henlthily for a considerable length of time, the results, so far as they go, confirm those obtained with Graminacex, not showing in their case, any more than with the latter, an assimilation of free Nitrogen.

In 1857, we commenced several experiments with beans, but they grew well in only one of the shades. These, howerer (especially one plant out of the tro in the same pot), progressed remarkably well for a period of 10 weeks, during which time the amount of carbon was increased fire-fold, more than three-fourths of the total Nitrogen of the seed was appropriated, and the plants probably only ceased to grow when the remainder of the latter became so distributed in the soil as not to be arailable to them. 
A reference to Table XII. will show the numerical results of this experiment with beans in 1857 .

The beans and peas of 1858 , the particulars of which are also given in Table XII., did not grow so satisfactorily as the beans of 1857, last noticed. Yet the beans of 1858 gare more than three times as much organic matter in the produce as was contained in the seed, and they appropriated even a much larger proportion of the Nitrogen of the seed than did those of 1857. The result with the peas was not so satisfactory, owing to the less healthy character and the more limited amount of their growth.

From the fact that these Leguminous plants did not go through a complete course of growth to the flowering process, it may be objected that hence they did not pass certain stages of growth in which they might possibly assimilate free Nitrogen. We shall refer to this objection again further on. At present we confine attention to the important fact, that active growth has taken place-that the process of cell-formation, with the accompanying one of the decomposition of carbonic acid and the fixation of carbon, has gone forward with a deficient supply of combined Nitrogen, and in the immediate presence of fiee Nitrogen, and yet none of it has been assimilated. The plants have in fact been subjected to a considerable range of the conditions which were considered, à priori, to be favourable to the assimilation of free Nitrogen; and yet this has not taken place.

It is a fact observed in agriculture, that manures rich in organic matter frequently farour the growth of Leguminous crops. We shall not here discuss the question whether these organic manures, as such, act simply as a source of carbonic acid, or of carbon compounds of a more complicated character. We would, however, call attention to the fact that, in the case of the experiments now under consideration, the vital forces were sufficiently energetic to perform the function of cell-development and multiplication, from carbonic acid as its source of carbon; yet these forces, capable of effecting this result, have been incapable of effecting the appropriation of free Nitrogen.

\section{Buckwheat.}

The evidence afforded by the numerical results in the Table XII. relating to this plant is not of so decisive a character as that with regard to the cereals, or even to the Leguminous plants; for the quantity of dry matter in the produced plants is less than that in the seed sown, whilst the Nitrogen in the plants is little more than one-third that of the seed. But when we come to compare the results of the experiments with Buckwheat grown with and without the supply of ammonia, it will be found that the physiological evidence of the dependence of vegetable growth upon a constant supply of combined Nitrogen is stronger in the case of these plants than in that of the cereals. The small proportion of the total Nitrogen of the seeds which the buckwheat secmed capable of appropriating might lead to the inference that, ceasing to grow with an abundance of combined Nitrogen apparently at its disposal, it had done so for some other reason than the want of available Nitrogen. But this question was set at rest by. the fact that, on the addition of an amount of ammonia very small in its contents of MDCCCLXI. 
Nitrogen compared with the seed, to plants at the time in a precisely similar condition to those now under consideration, the increase in the rapiclity of growth was arat marked.

Most of the huckwheat secel sown came up; but abrut hatf of the: plants liver for only a few days. 'The remainder, which survived, went through all the stages of development to flowering; but the entire amount of growth was on a very limited scale.

licference to the last eolumn of 'lable XII. will show that, under the cronditions of growth above described, the buckwheat, like the plants already discussed, indicated no gain of Nitrogen. In fact there appeared to be a loss in the experiment of nearly 2 milligrammes of Nitrogen; and that the result should be to a small rxtent in this direction may, perhaps, be accounted for by the fact of some of the plants dying early, in conseruence of which there may have been a slight evolution of free Vitrogen due to decomposition.

Beuring of the above results on the question of the ceolution of fice Fitrogen fiom the Nitrogenous Constituents of plants during growth.

We hare thus fax only considered the above results so far as they bear upon the question of the assimilation of free Nitrogen by plants. But from the constancy of the amount of combined Nitrogen maintained in relation to that supplied, throughout the experiments, they afford evidence of an important kind in regard to the converse question of whether plants gire off free Nitrogen during growth. With no less force than they point to the absence of any assimilation of free Nitrogen, do these results show that, under the circumstances of growth involved, there has been no evolution of free Nitrogen from the nitrogenous compounds of the growing plant. At all events, the assumption that an erolution of free Nitrogen has taken place implies, as in the case of the experiments discussed at pl. 513,511 , the still more improbable one, that there has been an exactly compensating amount assimilated. But since the conditions of the experiments now under consideration were arranged with special reference to the question of assimilation, they necessarily do not embrace all the circumstances which, i priori, would be considered the most farourable for the erolution of free Nitrogen during growth.

Various experimenters, from the time of De Sacssche until quite recently, hare entertained the idea of the probability of the decomposition of nitrogenous compounds, and the concomitant evolution of free Nitrogen, during the growth of plants. We are ourselves engaged in following up the subject, by methods better qualified to settle the question than those adopted in regard to the question of assimilation of Nitrogen. We shall therefore not treat of this subject any further here, than to call attention to the incidental bearing upon it of the results now under consideration.

The fact that there has been no decomposition of nitrogenous compounds and loss of Nitrogen as the result of growth, in the particular conditions to which these experimental plants were subjected, affords little evidence that no such decomposition could take 
place under any other circumstances. When supplied with an insufficient quantity of nitrogenous matter, the vegetable organism might not decompose any of that matter; and yet, when an excess of combined Nitrogen was supplied, the decomposition might occur. The results we have given, therefore, afford evidence against the fact of such decomposition only within a rery limited range of circumstances of growth. In discussing the results of the experiments the consideration of which we are now about to enter upon, we shall refer to this question again, in connexion with circumstances of growth which we should suppose would be more farourable to an evolution of free Nitrogen by the plant.

\section{II.-Experiments in which the plants had a known supply of combined Titroyen beyond that contained in the Original seed.}

We have thus far considered the subject of the assimilation of free Nitrogen, by reference to the results of experiments upon plants grown without any supply of combined Nitrogen beyond that contained in the seed sown. We have found that, under these conditions, we have only been able to study the results of growth of a very limited character. The wheat, and barley, and oat plants, grown in 1858, did indeed progress so far as to produce glumes and pales for seed; but they did not afford the opportunity of studying the results of growth during the period of the formation and the ripening of seeds themselves.

It yet remains to consider, therefore, what may take place under circumstances of a more active and vigorous growth, and at a later stage of development of the plant. When considering the conditions apparently the most farourable for the assimilation of free Nitrogen by plants (p. 517 et seq.), we suggested the improbability of such an assimilation taking place in the presence of an abundant supply of combined Nitrogen. If the force of our remarks on this point be admitted, and it be still supposed that an assimilation of free Nitrogen is possible with vigorous growth, only attainable by means of a liberal supply of combined Nitrogen, we seem to be led to the following paradoxical conclusions:-

1. Healthy, active, and rigorous growth are farourable conditions for the assimilation of free Nitrogen by plants.

2. Healthy, active, and vigorous growth can only be attained by keeping within the reach of the plant an excess of combined Nitrogen.

3. Assimilation of free Nitrogen cannot take place in the presence of an excess of combined Nitrogen.

A priori conclusions with regard to the effect of molecular forces, and particularly of those which give rise to vital phenomena, are, however, rery unsafe; and we have not been satisfied to rely upon such eridence only, in reference to the question under investigation, as could be afforded by experimenting with plants grown without an extraneous supply of combined Nitrogen. We have found that active and rigorous growth cannot be attained under the conditions provided, when no more combined Nitrogen than that 
contained in the secd sown is supplied. We have made a series of experiments, in which such growth was attained by means of a supply of combined Nitrogen beyond that constaincd in the seed. It remains to see whether, under these conditions of growth, the assimilation of free Nitrogen can take place, and thus the above paradox be obriated by the proof that the last of the three suppositions is incorrect.

It is true that we have pointed out the improbability of an assimilation of free Nitrogen in the presence of an excess of combined Nitrogen only so far as the vital process of the vergetable cell is concerned. In that intermediate process by which oxygen is taken up and carbonic acid formed in the cell, the results due to an excess of combined Nitrogen might be different.

'Thus, the more active the growth, the greater must be the amount of newly-formed carbon-matter capable of consuming oxygen, when the plant is remored from the influcnce of sunlight into the dark. That is to say, the more vigorous the growth in the sunlight, the greater might be the reducing power of the plant in the dark. The greater the reducing power of the plant, the more nearly will the tendency of its molecular forces approximate to an evolution of hydrogen which, in the presence of free Nitrogen dissolved in the fluids of the cell, may tend to form ammoniacal compounds, to be, on the return of light, appropriated by the plant in the exercise of its growing functions. In connexion with this point, it may be here mentioned that in our investigation of the gases given off by plants under different circumstances, we have had an evolution of oxygen one day as a coincident of growth, and an evolution of hydrogen the next as the result of decomposition.

Our experiments in which the plants have been manured with limited amounts of combined Nitrogen will not only enable us to meet some of the questions abore suggested, but they will also prove whether or not the conditions of soil, atmosphere, temperature, \&c., to which our experimental plants have been subjected were consistent with active and vigorous growth.

The fact of the evolution of Nitrogen in the decomposition of nitrogenous organic matter, illustrated in Sub-section D, p. 497 et seq., indicated the danger of using such matter as a source of supply of Nitrogen. We have therefore used solutions of sulphate of ammonia (see Appendix, p. 542), by means of which we hare been enabled to supply the plants with known quantities of combined Nitrogen at pleasure, as the progress of growth seemed to require.

In the following Table (XIV.) are given the numerical results of the experiments on the question of the assimnilation of free Nitrogen in which the plinuts were supplicel with combined Nitrogen beyond that contained in the seed sown. See also figs. 7, 8, 9, 10, 11, and 12, Plate XV., showing the.character and extent of growth of six Graminaceous plants with extraneous supply of combined Nitrogen, corresponding to the six abore them without such supply. 
THE SOURCES OF THE NITROGEN OF VEGETATION, ETC.

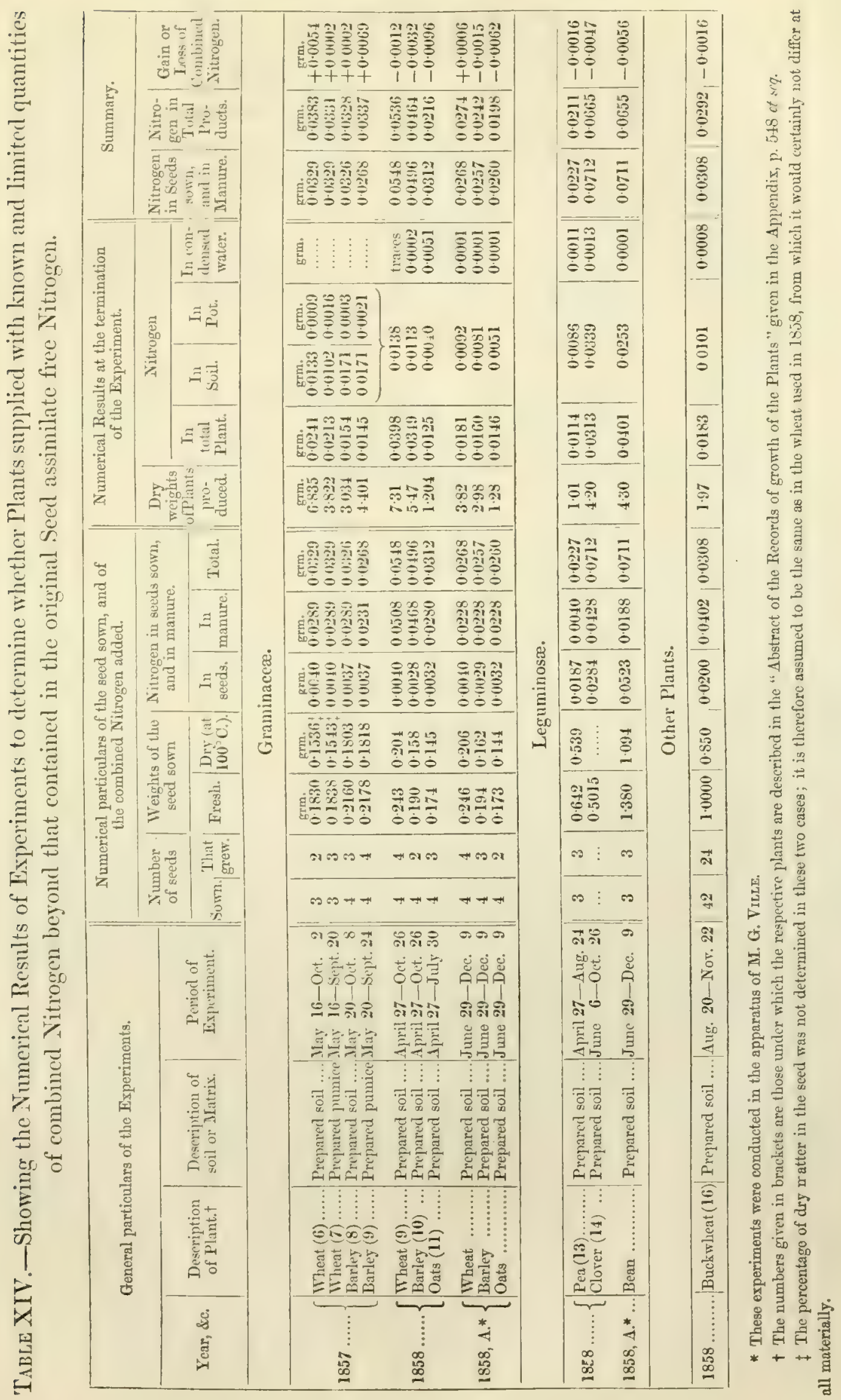


$\Lambda s$ in the case of the experiments already considered, so again with those to which the Table just given relates, it is scen, by reference to the last column, that there was a slight gain of Nitrogen in the experiments of 1857 , but, almost without exception, a loss rather than a gain in those of 1858. Considering that there was a prossible source of gain in 1857 in connexion with the slates used in that year (as explained below), and with the results of 1858 showing generally a loss rather than a gain when slates were not employed, we can interpret the whole in but one way.

In order to bring out fully the evidence afforded by these results of experiments in which the plants were supplied with more or less of combined Nitrogen during the progress of growth, we must consider them in three separate aspects:-

1. As regards the actual gain or loss of Nitrogen, as indicated by the figures giren in the last column of the 'lable (XIV.).

2. As presented in the physiological eridence afforded during growth.

3. As exhibited on comparison with the experiments in which the plants had no other supply of combined Nitrogen than that of the original seed.

\section{The Numerical Results of Table XIV.}

Much that has been said with respect to the plants grown without extraneous supply of combined Nitrogen applies with equal force to those now under consideration; and, so far as the evidence relating to the latter is of a different character, owing to the amount of combined Nitrogen at the disposal of the plants, it still is no more indicatire of an assimilation of free Nitrogen than was that obtained with the plants grown without any artificial supply of combined Nitrogen.

In illustration of the probability that the slates used as lute-ressels were a source of Nitrogen to the plants grown in 1857, some of the obserrations made during growth should be adverted to. It is seen that the barley grown in pumice (1857) gires the largest gain of Nitrogen; and it was observed that, soon after watering with the fluid drawn off from the surface of the slate, the pumice became corered with a slight coating of green matter. And nearly all the slates were found at the end of the experiment to hare a slight coating of similar character beneath the pans in which the pots which contained the plants stood; whilst, in the experiments of 1858 , when glazed earthenrrare lutevessels were employed, no such phenomenon was observed.

The slight loss of Xitrogen exhibited in the experiments of 1858 is casily accounted for on a consideration of the conditions involred. With regard to the peas, clorer, and beans, the physiological circumstances of growth detailed in the Appendix. taken in connexion with the evidence that has been adduced as to the loss of Nitrogen during the decomposition of nitrogenous organic matter, must be supposed to explain the loss in their case, as in some of the experiments in which no extraneous supply of combined Nitrogen was employed.

The loss of Nitrogen indicated in the cases of the wheat, barley, onts, and buck- 
wheat (1858) would not be so easily explained, had not the Nitrogen in the drainwater remaining at the end of the experiment been determined. Our object in doing this was twofold:-

1. To ascertain whether the luting at the bottom of the shade had allowed rain-water to pass, thus affording a source of combined Nitrogen to the plants.

2. To see if the plants growing in soil to which combined Nitrogen was added, had evolved any ammonia.

It was, of course, not possible to accomplish both these purposes. But the fact that ammonia was found in the condensed water only in the cases where there was a loss in the total quantity of combined Nitrogen would lead to the inference that both the presence of ammonia in this water, and the loss of combined Nitrogen in the experiment, were due to the same cause.

The condensed water showing the amount of combined Nitrogen recorded in the Table (XIV.) was that which had been evaporated and condensed during the last four weeks of growth (1858); and during this period the high temperature, and the advanced stage of the plants, were favourable to the eraporation of ammoniacal water. A considerable part would condense on the interior of the shade, owing to its comparatively low temperature; but a certain quantity of that which was in the state of vapour during the passage of the air through the apparatus would be borne forward into the sulphuric acid in the bulb-apparatus $\mathrm{MI}$, and thus occasion a loss in the amount of combined Nitrogen determined in connexion with the plants. The reason why the loss is greater with the oats (as it is in both experiments) than with the other cereals is not perfectly clear; but the circumstances of growth seemed to afford some explanation of the fact. In one case, at least, they ripened at a much warmer period of the season, and they became much drier in stem and leaf, and were therefore more liable to evolve ammonia. On these points, the circumstances of growth detailed in the Appendix should be consulted.

In considering the column of gain or loss of Nitrogen, it is very desirable to take into account the total quantity of Nitrogen at the disposal of the plant, in the different series of experiments. It is also important to consider the amount of growth in the experiments made under the different conditions. The following Tables (XV. and XVI.) bring out the character of the results in these respects more clearly than they can be gathered from Tables XII. and XIV. Table XV. shows, for the plants grown without supply of combined Nitrogen beyond that contained in the seed, and Table XVI. for those grown with such supply, the dry matter, and the Nitrogen, per seed sown,- the dry matter, and the Nitrogen, in the total produce of each seed that grew,-and the per cent. of the total Nitrogen at the disposal of the plant which it appropriated. Finally, the last two columns of Table XVI. show the amounts of dry matter, and of Nitrogen, in the produce grown with the extraneous supply of combined Nitrogen, in relation to those in the produce grown without such supply. 
TABL: XV.

\begin{tabular}{|c|c|c|c|c|c|c|c|c|c|c|c|}
\hline \multicolumn{3}{|c|}{ Gencral particulnas of the Eriw.mimenth } & \multicolumn{2}{|c|}{$\begin{array}{l}\text { Nunsinor of } \\
\text { Hecoln. }\end{array}$} & \multicolumn{3}{|c|}{ Drs Saltu.r. } & \multicolumn{4}{|c|}{ Xitergentr } \\
\hline $\begin{array}{l}\text { Yins, } \\
\text { secen, }\end{array}$ & $\begin{array}{l}\text { D. } \\
\text { of I'lantsions. }\end{array}$ & $\begin{array}{l}\text { Descriplion of } \\
\text { Boil or Mlatrix. }\end{array}$ & Bокn. & $\begin{array}{l}\text { Thine } \\
\text { gre'w: }\end{array}$ & $\begin{array}{l}\text { Pror } \\
\text { nowed } \\
\text { surn. }\end{array}$ & 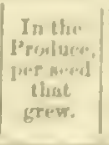 & 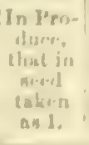 & $\begin{array}{c}\text { Por hoved } \\
\text { townes }\end{array}$ & 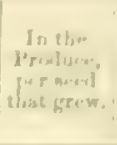 & 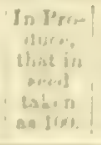 & 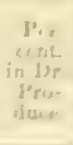 \\
\hline \multicolumn{12}{|c|}{ Gramintm. } \\
\hline 185 & $\begin{array}{l}\text { Whent } \\
\text { Barley } \\
\text { Barley } \\
\text { Bar }\end{array}$ & $\begin{array}{l}\text { Prepared soil ...... } \\
\text { Prepared soil ..... } \\
\text { 'Prepared pumice. }\end{array}$ & $\begin{array}{l}6 \\
6 \\
6\end{array}$ & $\begin{array}{l}5 \\
6 \\
6\end{array}$ & $\left|\begin{array}{l}\text { grom } \\
0(1) 511 \\
001081 \\
0.0149\end{array}\right|$ & $\begin{array}{l}\text { grma } \\
0.2821 \\
0.1350 \\
1) .1522\end{array}$ & $\begin{array}{l}301 \\
3 \cdot 13\end{array}$ & 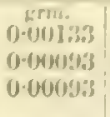 & $\begin{array}{l}0.0(1) 111 \\
0 \cdot(1)(1) 78 \\
0 \cdot 0(0) 75\end{array}$ & $\begin{array}{l}168 \cdot 3+ \\
83.34 \\
80 \cdot 6\end{array}$ & $\begin{array}{l}0.31 \\
0.54 \\
0 \div 48\end{array}$ \\
\hline 1858 & $\begin{array}{l}\text { Wheat } \\
\text { Barley } \\
\text { Oats } \ldots . . . \\
\end{array}$ & $\begin{array}{l}\text { Prepared soil ..... } \\
\text { Prepared soil .... } \\
\text { I'repared soil .... }\end{array}$ & $\begin{array}{l}8 \\
8 \\
8\end{array}$ & $\begin{array}{l}8 \\
6 \\
8\end{array}$ & $\begin{array}{l}00501 \\
00103 \\
0.0357\end{array}$ & $\begin{array}{l}0.2175 \\
0.0733 \\
0.1435\end{array}$ & $\begin{array}{l}4 \cdot 31 \\
2 \cdot 31 \\
4 \cdot 02\end{array}$ & $\begin{array}{l}0-000938 \\
0-000071 \\
0.010050\end{array}$ & $\begin{array}{l}0.00070 \\
0.010052 \\
0.00(5) 525\end{array}$ & $\begin{array}{l}71 \cdot 1 \\
73 \cdot 2 \\
65 \cdot 6\end{array}$ & $\begin{array}{l}0.22 \\
0.51 \\
0.36\end{array}$ \\
\hline $1858, \Lambda$ ** & $\begin{array}{l}\text { Wheat ... } \\
\text { |Tarley ... } \\
\text { Oats ..... }\end{array}$ & $\begin{array}{l}\text { Prepared soil ..... } \\
\text { Prepared soil ...... } \\
\text { Prepared soil ..... }\end{array}$ & $\begin{array}{l}8 \\
8 \\
8\end{array}$ & $\begin{array}{l}7 \\
8 \\
7\end{array}$ & $\begin{array}{l}0.0501 \\
0.0101 \\
00360\end{array}$ & $\mid \begin{array}{l}0 \cdot 151.43 \\
0 \cdot 0888 \\
0.09857\end{array}$ & $\begin{array}{l}3.00 \\
2 \cdot 74\end{array}$ & $\begin{array}{l}0.00098 \\
0.06080\end{array}$ & $\begin{array}{l}0.60058 \\
0.00051\end{array}$ & $\begin{array}{l}59.2 \\
67.5\end{array}$ & $\begin{array}{l}0.38 \\
0.55\end{array}$ \\
\hline \multicolumn{12}{|c|}{ Leguminosx. } \\
\hline 1857 & Bean. & Prepared soil ...... & 2 & 2 & 0.7 .102 & 3.514 & $4 \cdot 69$ & $0 \cdot 03980$ & $0 \cdot 03145$ & $79 \cdot 0$ & $0 \cdot 82$ \\
\hline 1858. & $\begin{array}{l}\text { Bean ... } \\
\text { Pea ... }\end{array}$ & $\begin{array}{l}\text { Prepared soil ...... } \\
\text { Prepared soil ..... }\end{array}$ & $\begin{array}{l}3 \\
3\end{array}$ & $\begin{array}{l}3 \\
3\end{array}$ & $\begin{array}{l}0.4910 \\
0.1802\end{array}$ & $\begin{array}{l}1.6250 \\
0.3233\end{array}$ & $\begin{array}{l}329 \\
1.79\end{array}$ & $\begin{array}{l}0.02500 \\
0 \cdot 00630\end{array}$ & $\begin{array}{l}0.0215 \\
0-0034\end{array}$ & $\begin{array}{l}980 \\
510\end{array}$ & $\begin{array}{l}1 \cdot 51 \\
1.05\end{array}$ \\
\hline \multicolumn{12}{|c|}{ Other Plants. } \\
\hline 1800 & Buckwheat & Prepared soil & 24 & 13 & ...... & $0 \cdot 03461$ & ....... & 0.00083 & 0.00051 & $65 \cdot 1$ & 1.56 \\
\hline
\end{tabular}

\section{Table XVI.}

\begin{tabular}{|c|c|c|c|c|c|c|c|c|c|c|c|c|c|}
\hline \multicolumn{3}{|c|}{ General particulars of the Erperiments. } & \multicolumn{2}{|c|}{$\begin{array}{l}\text { Number of } \\
\text { Seeds. }\end{array}$} & \multicolumn{3}{|c|}{ Dry Matter. } & \multicolumn{4}{|c|}{ Nitrogen. } & \multicolumn{2}{|c|}{$\begin{array}{l}\text { I Ralstimn of Pri- } \\
\text { duce per seed } \\
\text { with Ammonia, } \\
\text { tuthat witivut } \\
\text { it taken as } 1 .\end{array}$} \\
\hline $\begin{array}{l}\text { Year. } \\
\& \text { se. }\end{array}$ & $\begin{array}{l}\text { Description } \\
\text { of Plants. }\end{array}$ & $\begin{array}{l}\text { Deseription of } \\
\text { Soil or Matrix. }\end{array}$ & Sown. & $\begin{array}{l}\text { That } \\
\text { grew. }\end{array}$ & $\begin{array}{c}\text { Per } \\
\text { seed } \\
\text { gокn. }\end{array}$ & $\mid \begin{array}{c}\text { In Pro- } \\
\text { duee, } \\
\text { per seed } \\
\text { that } \\
\text { grew. }\end{array}$ & $\begin{array}{l}\text { In Pro- } \\
\text { dace, } \\
\text { that in } \\
\text { seed } \\
\text { taken } \\
\text { as 1. }\end{array}$ & $\begin{array}{l}\text { Per seed } \\
\text { sown. }\end{array}$ & \begin{tabular}{|} 
In the \\
l'rodace, \\
per seed \\
that grew.
\end{tabular} & $\begin{array}{l}\text { In Pro- } \\
\text { dace, } \\
\text { that in } \\
\text { seed } \\
\text { snd } \\
\text { manure } \\
\text { laken } \\
\text { as } 100 .\end{array}$ & $\begin{array}{l}\text { Per } \\
\text { cuntu. } \\
\text { in Ingy } \\
\text { Pro- } \\
\text { duce. }\end{array}$ & $\begin{array}{c}\text { with Am } \\
\text { tuthut } \\
\text { it take? } \\
\begin{array}{c}\text { Dry } \\
\text { Matter. }\end{array}\end{array}$ & 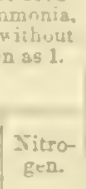 \\
\hline \multicolumn{14}{|c|}{ Graminaeer. } \\
\hline 1857 .. & $\begin{array}{l}\text { Wheat ... } \\
\text { Wheat ... } \\
\text { Barley ... } \\
\text { Barley ... }\end{array}$ & $\begin{array}{l}\text { Prepared soil ...... } \\
\text { Prepared pumice. } \\
\text { Prepared soil ...... } \\
\text { Prepared pumice. }\end{array}$ & $\begin{array}{l}3 \\
3 \\
4 \\
4\end{array}$ & $\begin{array}{l}2 \\
3 \\
3 \\
4\end{array}$ & $\begin{array}{l}\text { grm. } \\
0.0512 \\
0.0514 \\
0.0151 \\
0.0455\end{array}$ & $\begin{array}{l}3.4175 \\
1.2740 \\
1.0113 \\
1 \cdot 1002\end{array}$ & \begin{tabular}{|l|}
$66 \cdot 75$ \\
$21 \cdot 79$ \\
$22 \cdot 12$ \\
$24 \cdot 18$
\end{tabular} & $\begin{array}{l}\text { grm. } \\
0.00133 \\
0.00133 \\
0.00092 \\
0.00092\end{array}$ & $\mid \begin{array}{l}0.070 \\
0.01205 \\
000710 \\
0.00513 \\
0.00362\end{array}$ & $\begin{array}{l}73 \cdot 2 \\
61 \cdot 7 \\
47 \cdot 2 \\
51 \cdot 1\end{array}$ & $\begin{array}{l}0.35 \\
0.55 \\
0.51 \\
0.33\end{array}$ & $\begin{array}{l}12 \cdot 10 \\
4 \cdot 51 \\
7 \cdot 49 \\
7 \cdot 13\end{array}$ & $\begin{array}{l}5 \cdot 36 \\
4 \cdot 33 \\
6.55 \\
4.53\end{array}$ \\
\hline $1858 \ldots\{$ & $\begin{array}{l}\text { Wheat ... } \\
\text { Barley ... } \\
\text { Oats ...... }\end{array}$ & $\begin{array}{l}\text { Prepared soil ...... } \\
\text { Prepared soil ...... } \\
\text { Prepared soil ...... }\end{array}$ & $\begin{array}{l}4 \\
4 \\
4\end{array}$ & $\begin{array}{l}4 \\
2 \\
3\end{array}$ & $\begin{array}{l}0.0510 \\
0 \cdot 0395 \\
0.0362\end{array}$ & $\begin{array}{l}1 \cdot 8275 \\
2 \cdot 7350 \\
0 \cdot 1013\end{array}$ & $\begin{array}{l}35.83 \\
69 \cdot 24 \\
11.08\end{array}$ & $\begin{array}{l}0.00103 \\
0.00070 \\
0.00050\end{array}$ & $\begin{array}{l}0.00995 \\
0.01745 \\
0-00116\end{array}$ & $\begin{array}{l}72 \cdot 8 \\
70 \cdot 5 \\
45-9\end{array}$ & $\begin{array}{l}0 \cdot 54 \\
0 \cdot 64 \\
1 \cdot 04\end{array}$ & $\begin{array}{r}8-40 \\
23 \cdot 31 \\
2 \cdot 50\end{array}$ & $\begin{array}{r}14 \cdot 21 \\
31 \cdot 21 \\
7 \cdot 92\end{array}$ \\
\hline $1858, \Lambda^{*} *$ & $\begin{array}{l}\text { Wheat ... } \\
\text { Barley ... } \\
\text { Oats ...... }\end{array}$ & $\begin{array}{l}\text { Prepared soil ...... } \\
\text { Prepared soil ..... } \\
\text { Prepared soil ..... }\end{array}$ & $\begin{array}{l}4 \\
4 \\
4\end{array}$ & $\begin{array}{l}4 \\
3 \\
2\end{array}$ & $\begin{array}{l}0.0515 \\
0.0105 \\
0.0360\end{array}$ & $\begin{array}{l}0.9550 \\
0.9933 \\
0.6100\end{array}$ & $\begin{array}{l}18.51 \\
24.52 \\
17.78\end{array}$ & $\begin{array}{l}0.00100 \\
0.00072 \\
0.00080\end{array}$ & \begin{tabular}{|c|}
000452 \\
0.005233 \\
0.00730
\end{tabular} & $\begin{array}{l}67 \cdot 5 \\
62 \cdot 2 \\
56 \cdot 1\end{array}$ & $\begin{array}{l}0 \cdot 17 \\
0 \cdot 51 \\
1 \cdot 11\end{array}$ & $\begin{array}{l}6 \cdot 31 \\
6 \cdot 49\end{array}$ & $\begin{array}{l}7 \cdot 79 \\
1352\end{array}$ \\
\hline \multicolumn{14}{|c|}{ Leguminosx. } \\
\hline $1858 \ldots$ & $\left|\begin{array}{l}\text { Pea } \ldots . . . . \\
\text { Clorer .... }\end{array}\right|$ & $\begin{array}{l}\text { Prepared soil ..... } \\
\text { Prepared soil ..... }\end{array}$ & $\begin{array}{r}3 \\
\cdots\end{array}$ & $\begin{array}{c}3 \\
\cdots\end{array}$ & $\left|\begin{array}{c}0 \cdot 1797 \\
\cdots \ldots\end{array}\right|$ & $\mid \begin{array}{c}0.3366 \\
\ldots \ldots\end{array}$ & $\begin{array}{l}1.87 \\
\cdots\end{array}$ & 0.00623 & $\left|\begin{array}{c}0.00350 \\
\cdots \ldots\end{array}\right|$ & $\begin{array}{l}50 \cdot 2 \\
44 \cdot 0\end{array}$ & $1 \cdot 13$ & & \\
\hline $1858, A^{*} *$ & Bean ...... & Prepared soil ... & 3 & 3 & $0 \cdot 3616$ & $|1 \cdot 1333|$ & 3.93 & $0-01743$ & 0.01337 & $56 \cdot 4$ & $0 \cdot 93$ & & \\
\hline \multicolumn{14}{|c|}{ Other Plants. } \\
\hline 1858. & Buckrmlicat & Prepared soil & 42 & 24 & $0 \cdot(1) \geq 0 \div 2$ & 110821 & $4 \cdot 06$ & $0.0101 \%$ & $0 \cdot(14) \div 3$ & $5 ; \cdot 6$ & $(1): 2$ & $2 \because 37$ & $1 \cdot\{1$ \\
\hline
\end{tabular}

* These experiments were conducted in the apparatus of M. G. Tille.

+ There is here eridence that a part of the Nitrogen of the seed that did not grom mas appropriated br the plants groming from the other seeds. 
There are several obrious inferences to be drawn from the figures in these Tables. To some we shall refer further on, in the proper order of the discussion. We here simply call attention to the rery great increase of growth when an extraneous supply of combined Nitrogen was provided, as exhibited in the last two columns of Table XVI.

\section{Consideration of the Physiological Evidence as bearing upon the question of the assimilation of firee Nitrogen.}

Howerer directly the quantitative details given in the Tables may bear upon the question at issue, it is very important to consider them in connexion with the physiological details of the experiments. In order to estimate the value of the eridence afforded in this particular, the indications manifested from the earliest period of growth should be noticed.

Reference to the Notes of the progress of the plants, given in the Appendix, will show that all the plants when they first came up looked green and vigorous, indicative of their being at that period in circumstances embracing all the conditions essential to healthy growth. As already pointed out, they at that time were probably supplied with an excess of combined Nitrogen in relation to their immediate wants. After some days, rarying with the nature of the plants, they began to lose their deep-green colour, and to assume a lighter-green, or pale-yellow tint, indicative of a want of combined Nitrogen. We have already pointed out how farourable, probably, would be the conditions here afforded for the assimilation of free Nitrogen, when the plant was passing from the state in which it had an excess to that in which it had a deficiency of combined Nitrogen for the demands of growth. The vigorous development of the plants grown in garden soil, but under the same conditions as to atmosphere, \&c. as the other experimental plants, indicates that the conditions of atmosphere provided in the experiments were not at fault (see Appendix, Experiments Nos. 12, 1857, and 15, 1858; also fig. 13, Plate XV.). In order to test whether the sum of all the conditions, excepting those connected with a sufficient supply of combined Nitrogen, were appropriate for vigorous growth, we have only to provide some combined Nitrogen when the plants show the declining vigour just described; and if this be all they require, they will resume their healthy green colour. Or if we add the combined Nitrogen before the plants arrive at the period in question, it will prevent them assuming the pale-green or yellow colour. We have had recourse to both of these expedients; and each, so far as the Cereals, buckwheat, and clover are concerned, has yielded a result indicating that all the conditions of the experiments, excepting those comnected with a sufficient supply of combined Nitrogen, were adapted for healthy growth.

The plants to which ammonia was giren in 1857 , were allowed to suffer more before they received it than those of 1858 ; yet in thirty-six hours after the addition of combined Nitrogen to the soil, in amount not exceeding $1 \frac{1}{2}$ milligramme of the element to each plant, they began to manifest an improred appearance. In two or three days the improvement was quite marked; but at the termination of periods rarying from nine to MDCCCLII.

$4 \mathrm{D}$ 
eighteen days, the plants seemed to have consumed all the combined Nitrogen suprylied to them-or rather all of it that had not become inaccessible to them in the soil: 'They then began to manifest the same indications of defective supply as before. Plants so circumstanced must therefore, at a more advanced stage of growth than before they had been supplied with ammonia, have passed from a point at which they had an excess of combined Nitrogen, to that in which they had an insufficiency. 'They' must hence, again, have becn subjected to those conditions which we have assumed to be probably very fivourable to the assimilation of free Nitrogen.

Reference to the details of growth given in the Appendix will show that several times during the progress of the plants the above phenomena were manifested. A new increment of combined Nitrogen caused a new increment of growth, a greener colour, and a more vigorous appearance generally. This was soon followed by the recurrence of the pale colour. In some instances, more ammonia was not supplied until the plants seemed almost past recovery: in a few cases they were quite so. 'The addition of ammonia now (excepting in the few cases just referred to) produced a revirification, to be followed in a short time by the indications of some want, and so on.

A considerable range of conditions of growth was thus provided. Just after each addition of combined Nitrogen the plants must have been supplied with an exeess of this element in an arailable form. The evidence of this was afforded in the obriously increased means of consumption, evinced in the formation of new shoots from the base of the plants, or from their nodes. But these new shoots were too rigorous to allow the plants to go on long without suffering for want of a new supply of combined Nitrogen. In passing to this point, the newly-formed and rigorously-growing portion of the vegetable matter would be in the condition we have assumed to be the most farourable for assimilating free Nitrogen. Instead of doing this, howerer, it soon began to suffer. and continued to do so until a new supply of combined Nitrogen was added, when new vigour succeeded, to be followed again shortly by a cessation of growth. This ç̣cle of conditions, repeated several times during the growth of the same plant, and the experiment similarly conducted with a number of pots of plants of different kinds, with like results in all the cases, affords a wide range of circumstances such as we hare assumed to be farourable to the assimilation of free Nitrogen; but such an assimilation has not taken place.

Without the physiological details, it might not have been clear that the plant had not an excess of combined Nitrogen at its disposal during the greater period of its growth after the addition of the artificial supplies of it, since a considerable proportion of that added remained in the soil at the termination of the experiments, as Tables XIT. and XVI. show. But it is not difficult to imagine that a few milligrammes of ammonia intermingled with 1500 or 1600 grammes of soil (and pot), might become distributed over such an extent of surface, and be so completely absorbed, as that a considerable proportion should remain inaccessible to the plant. The physiological eridence leares no doubt this was the case. 
The Graminaceous plants of the experiments of 1858 were supplied with a considerable quantity of combined Nitrogen at an earlier period of growth than those of 1857 (see Tables showing the dates of addition, Appendix, pp. 542, 543), and they were not allowed to exhibit such marked signs of decline of vigour before receiving their fresh supplies. There is, however, no marked distinction in the proportion of the total supply appropriated by the plants, and left in the soil, respectively, in the two cases.

The Graminaceæ under the title of " 1858 , A " (those grown in M. G. Ville's case) were treated similarly to the others of 1858 , excepting that the combined Nitrogen was given to them at an earlier period of their growth, and they were not allowed to suffer at any time for want of it. We shall notice the difference in result presently.

In addition to the evidence of the physiological phenomena as bearing upon the amount of growth due to the supply of ammonia, attention should be called to the remarkable character of growth which was manifested. 'The evidence afforded on this head, is of interest in considering the question of the character of the conditions most favourable to the assimilation of free Nitrogen; and it also brings to view some remarkable features in regetable physiology.

It will be seen, by reference to the Notes in the Appendix, that, shortly after the addition of ammonia for the first time to the Graminacex (1857 and 1858), the plants began to throw out new shoots at the base of the principal stem. It would thus appear that the plant, being supplied at the commencement of its growth with only the limited quantity of combined Nitrogen contained in its seed, had developed a stem commensurate with that quantity. But when new quantities of combined Nitrogen were placed at the disposal of the plant, forces were thus called into activity which were greater than could operate through the medium of the original stem. Some of the new shoots have come forth close to the surface of the soil, some at the first, and some at the second nodes. The character of growth in this respect can be best studied by reference to the drawings of the plants given in Plate XV.

Another and no less remarkable feature was the formation of roots at the second and third nodes above the ground in the case of most of the Graminaceous plants to which ammonia-salt was added as manure (see Plate XV.). These roots came out around the node, and extended downwards - several of them reaching the soil from heights varying from $\frac{1}{2}$ to $1 \frac{1}{2}$, or even 2 inches, and penetrating it to the bottom of the pot. The most marked instance of this kind of growth was that of the barley represented in fig. 11, Plate XV., and in more detail, with special reference to the points now under consideration, in fig. 16, Plate XV. As will be seen in the figures, roots and new stems come from the same node, making the latter a veritable starting-point, or new axis of growth, like the seed in the first instance. The original stems, below these nodes, did not increase much in size beyond what they had attained before the addition of ammonia; but the stems above the nodes became much larger than the portions below them, as also did those of the new shoots.

Finally, so long as the conditions of growth of the plants were such that an addi4 D 2 


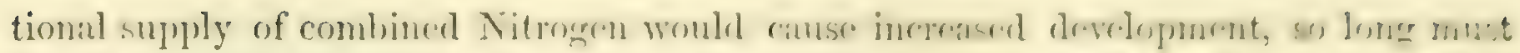

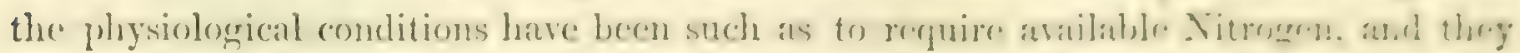
must therefore have been more or less favourable to the assimilation of free Nitrogen, provided such assimilation were possible. Ifence, the fact that this did not take place under the circumstances which have been described, seems to show that, at least in the case of these Graminacea, it is not possible.

Some of the remarks which we hare made with regard to the influence of a supply of combined Nitrogen upon the growth of the Graminacex, apply also, in a greater or less degree, to the other plants experimented upon. We shall not comment here in detail upon the value of each experiment, but simply call attention to the columns of gain or loss of Xitrogen, in the 'Tables, and to the notes in the Aprendix indicating the circumstances of growth of the plants.

With regard to the Leguminosie experimented upon, it is to be observed that the derelopment was by no means so satisfactory as in the case of the Graminacex. Hence the eridence which the results relating to them afford against the fact of a-similation of free Nitrogen must be admitted to apply to a more limited range of conditions of growth, and, therefore, to be less conclusive against the possibility of such assimilation. Still, so far as they go, the results with these plants, and also those with buckwheat, tend to confirm those obtained under the more farourable circumstances of growth with the cereals. It will be remembered, however, that M. Boussivgadut experimented with a great many Leguminous plants, and generally succeeded in getting much more healthy growth than we were able to do in the cases to which the figures in the Tables refer. Yet in no case did he find any such gain of Nitrogen as to lead him to the conclusion that these plants, any more than the Graminacer, assimilated free or uncombined Nitrogen. Our own experiments with Leguminous plants are, howerer, not yet concluded; so that we hope to supply some additional eridence on this subject, on a future occasion.

Relations of the Plants grown with a supply of ammonia to those grown without it.

The hare already called attention to the fact that the physiological phenomena exhibited in the progress of the plants grown under the two different conditions as regards the supply of combined Nitrogen at their disposal, afford satisfactory eridence that the conditions prorided in soil and atmosphere were all that were requisite in experiments for the solution of the question at issue with regard to the Cereals. 'The great derelopment of these plants when ammonia was supplied (which was in fact almost in proportion to the amount supplied), the cessation of growth with the limit of the supply, together with the contrast between the growth with the aid of the ammonia and that without it, all afford evidence in one direction in regard to the question at issue, so far as these plants are concerned.

In Table XIV., relating to the plants to which ammonia was supplied, an experiment with clover is recorded. Reference to the remarks in the Appendix, p. 573, will show 
that we failed to get any growth with clover without the addition of ammonia. Hence, excepting so far as this fact is itself a point for remark, no contrast can be drawn between the growth of this plant with and without an extraneous supply of combined Nitrogen.

From what has already been said, it will be easily understood that the contrast between the beans and peas grown with and without the addition of ammonia is not rery satisfactory. These plants proved to be so sensitive, under the conditions provided in the experiments, that it was obvious that, in many cases, they suffered from other ceuses than a want of combined Nitrogen, which we were not able to control. In but one experiment with such plants, that with the bean "1858, A." (Table XIV.), was the influence of a supply of combined Nitrogen so marked as to indicate that the plants were previously suffering for want of such supply. It will be seen, by reference to the Table, that, in the case here referred to, the seeds sown contained 0.0523 gramme of Nitrogen, and that 0.0188 gramme was added in the form of ammonia-salt—making in all 0.0711 gramme of combined Nitrogen involved in the experiment. Of this the plants appropriated 0.0401 gramme-about one-fifth less, therefore, than was supplied in the seeds alone. Yet, although the numerical results, taken by themselves, thus afford but little evidence of the effect of the 0.0188 gramme of Nitrogen added in the form of ammonia, the increased rigour of growth on the addition did afford such evidence. In contrast with this single result, howerer, attention may be called to the results with the beans grown without any other supply of combined Nitrogen than that contained in the seed sown. The bean plants so grown in 1857, appropriated nearly four-fifths of the Nitrogen of their seed; and those grown in a similar way in 1858, appropriated a considerably larger proportion of the combined Nitrogen so provided to them.

From a review of the whole of the results considered in this Section, it appears, then, that in the case of the Graminaceous plants experimented upon the growth was the most healthy, and such as provided a wide range of conditions for the assimilation of free Nitrogen, provided this were at all possible. The growth of the Leguminous plants was not so healthy, and did not, therefore, provide such a wide range of conditions for the possible assimilation of free Nitrogen. Nor was the growtl of other plants so satisfactory as that of the Graminaceous ones. In all, the growth was more or less increased by the supply of combined Nitrogen beyond that contained in the seed. The effect of such supply was the most marked with the Graminaceous plants-the increase in the produce of dry regetable substance due to extraneous supply of combined Nitrogen being, in their case, eight, twelve, and even nearly thirty-fold, according to the amount of Nitrogen so provided. Yet, with nineteen experiments with Graminaceous plants, six with Leguminous ones, and some with plants of other descriptions-with such great variation in the amount and character of growth in the sereral cases-and with such great rariation in the amount of combined Nitrogen involved in the experiments, in 
no case have the results been such as to lead to the conclusion that there was an assimilation of free, or uncombined, Nitrogen.

The results of the whole inquiry may be very briefly enumerated as follow:-

The yield of Xitrogen in the weretation over a given area of land, within a griwn time, especially in the case of Leguminous crops, is not satisfactorily explained by werferrore

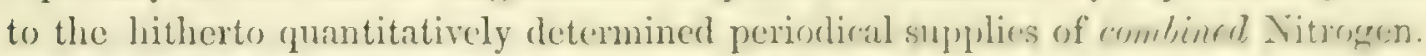

Numerous experiments have been made by M. Botssswatder, from which he concludes that free or uncombined Nitrogen is not a direct source of the Nitrogen of vegretation. M. G. Ville, on the other hand, concludes, from lis results, that free Nitregen may be a source of a considerable proportion of the Nitrogen of growing plants. The views. cor explanations, of other experimenters, on this disputed point, are various, and inconclusive.

It was found that the conditions of growth adopted in our orn experiments, on the question of the assimilation of free Nitrogen by plants, were consistent with the healthy development of rarious (iraminaceous plants, but not so much so for that of the I.cgrminous plants experimented upon.

From the results of various investigations, as well as from other considerations, we think it may be concluded that, under the circumstances of our experiments on the question of the assimilation of free Nitrogen by plants, there would not be any supply to them of an unaccounted quantity of combined Nitrogen, due either to the formation of oxygen-compounds of it under the influence of ozone, or to that of ammonia under the infuence of nascent hydrogen.

We have found that free Nitrogen is given off in the decomposition of nitrogenous organic matter, under certain circumstances. But, considering the circumstances of such evolution, and those to which the nitrogenous organic matter necessarily involved in experiments on the question of the assimilation of free Nitrogen by plants is subjected, it may, we think, be concluded that there would be no loss of combined Nitrogen from this cause in such an experiment, excepting in certain cases, when it might be presupposed.

Our experimental evidence, so far as it goes, does not farour the supposition that there would be any loss of combined Nitrogen in our experiments on the question of assimilation, due to the evolution of free Nitrogen from the nitrogenous constituents of the plants during growth.

In numerous experiments with Graminacenus plants, grown both with, and without a supply of combined Nitrogen beyond that contained in the seed sown, in which there was great rariation in the amount of combined nitrogen involved, and a wide range in the conditions, character, and amount of growth, we hare in no case found ans evidence of an assimilation of free or uncombined Nitrogen.

In our expcriments with Leguminous plants the growth was less satisfactorT; and 
the range of conditions possibly favourable for the assimilation of free Nitrogen was, therefore, more limited. But the results recorded with these plants, so far as they go, do not indicate any assimilation of free Nitrogen. Since, however, in practice, Leguminous crops assimilate, from some source, so very much more Nitrogen than Graminaccons ones, under ostensibly equal circumstances of supply of combined Nitrogen, it is desirable that the evidence of further experiments with these plants, under conditions of more healthy growth, should be obtained.

Results obtained with some other plants are in the same sense as those obtained with Graminacer and Leguminosx, in regard to the question of the assimilation of free Nitrogen.

In view of the evidence afforded of the non-assimilation of free Nitrogen by plants under the wide range of circumstances provided in the experiments, it is desirable that the several actual or possible sources of combined Nitrogen to plants should be more fully investigated, both qualitatively and quantitatively.

If it be established that the processes of vegetation do not bring free Nitrogen into combination, it still remains not very obvious to what actions a large proportion of the existing combined Nitrogen may be attributed. 


\section{APPExprx.}

Receired subsequently to the reading of the paper.

\section{A.-Preparation of solutions for mamuring the Plants, ates of application, and quantities applicd.}

Sulphate-of-Ammonia solution.-Ordinary ammonia-water was di-tiller from a fla-k, the vapour condensed in a receiver containing pure distillerl watcr, and the strensth of the solution detemined by the volumetrie method, by means of dilute sulpluture acid of known strength, the preparation of which is described further on, at p.515. 1 riven volume of the ammoniacal liquid thus prepared was neutralized by fure rlilute sulphurir acid, of which the quantity arded was determined by measurement, and the streneth of the solution calculated accordingly. It was intended that cach cubic contimetres siruld supply about one-tenth of a milligramme of combined nitrogen. The cxact strength ef the sulphate-of-ammonia solutions used in the course of the experinents was as unler:-

\section{TABLE I.}

\begin{tabular}{|c|c|c|}
\hline When used. & $\begin{array}{l}\text { Tolume of the pipette } \\
\text { measure emplojed. }\end{array}$ & $\begin{array}{c}\text { Combined nitrogen in a } \\
\text { pipette measuro of the } \\
\text { eolution. }\end{array}$ \\
\hline 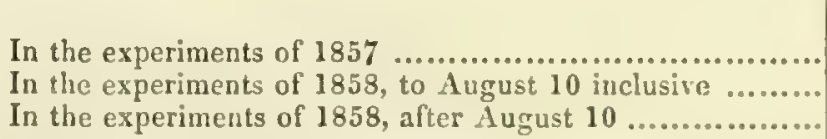 & $\begin{array}{l}\text { Eeptems*. } \\
111.2 \\
100.0 \\
100.0\end{array}$ & $\begin{array}{l}\text { gramme. } \\
0.00578 \\
0.004 \\
0.00359\end{array}$ \\
\hline
\end{tabular}

Tables II. and III. show the dates of the application of the above solutions to the different plants, and the amounts of nitrogen so supplied.

Table II.-Showing the supply of combined Nitrogren, as Sulphate-of-Ammonia solution, to plants grown in 1857 .

\begin{tabular}{|c|c|c|c|c|}
\hline \multirow[b]{2}{*}{ Dates. } & \multicolumn{4}{|c|}{ Nitrogen supplied. } \\
\hline & $\begin{array}{l}\text { Wheat, in pre- } \\
\text { pared soil. }\end{array}$ & $\begin{array}{l}\text { Whest, in pre- } \\
\text { pared pumice. }\end{array}$ & $\begin{array}{l}\text { Barles, in pre- } \\
\text { pared soil. }\end{array}$ & $\begin{array}{l}\text { Barler, in pre- } \\
\text { pared pumice. }\end{array}$ \\
\hline June $10 \ldots .$. & $\begin{array}{l}\text { gramme. } \\
.00578\end{array}$ & $\begin{array}{l}\text { gramme. } \\
.00578\end{array}$ & $\begin{array}{l}\text { gramme. } \\
.00578\end{array}$ & $\begin{array}{l}\text { gramme. } \\
.00578\end{array}$ \\
\hline July $4 \ldots . .$. & .00578 & .00578 & .00578 & .00575 \\
\hline July $11 \ldots . .$. & .00578 & .00578 & .00578 & .00575 \\
\hline July $22 \ldots . .$. & .00578 & .00578 & .00578 & $.005 / 5$ \\
\hline July 29 ...... & .00578 & .00578 & .00578 & \\
\hline Total & $\cdot 0 \approx \$ 90$ & $\cdot 02890$ & $.0 \Omega 590$ & $\cdot 0 \approx 312$ \\
\hline
\end{tabular}

* A septem measure is that of 7 grains ( $=\frac{1}{1000}$ of a pound aroirdupois) of water; that is, rather less than balf a cubic centimetre, which is equal to $15 \cdot 13235$ grains (or 1 gramme) of water. 
TABLE III.-Showing the supply of combined Nitrogen, as Sulphate-of-Ammonia solution, to plants grown in 1858.

\begin{tabular}{|c|c|c|c|c|c|c|c|c|c|c|}
\hline \multirow{2}{*}{ Dates. } & \multicolumn{10}{|c|}{ Nitrogen supplied. } \\
\hline & Wheat. & Barley. & Oats. & Wheat* & Barley* & Oats * & Pea. & Clorer. & Bean*. & $\begin{array}{l}\text { Buck- } \\
\text { wheat. }\end{array}$ \\
\hline May $22 \ldots$ & $\begin{array}{l}\text { grm. } \\
.0040\end{array}$ & $\begin{array}{l}\text { grma. } \\
.0040\end{array}$ & .0040 & grm. & grm. & grm. & grm. & grm. & grm. & grm. \\
\hline June $7 \ldots \ldots . . . .$. & .0040 & .0040 & .0040 & ....... & ...... & ........ & .0040 & $\cdot 0040$ & & \\
\hline June 21 ............... & .0040 & .0040 & .0040 & 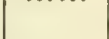 & . & 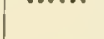 & & & & \\
\hline Jume 26 .............. & .0040 & .0040 & $\cdot 00 \pm 0$ & & & & ....... & $\cdot 0040$ & & \\
\hline July 3 .............. & .0040 & .0040 & .0040 & $\ldots$ & & & $\ldots .$. & .0040 & & \\
\hline$J_{1 i} y^{\prime} \quad 12 \quad \ldots . . . . . . . .$. & .0040 & $\cdot 0040$ & .0040 & & ....... & $\ldots \ldots$ & $\cdots \cdots$ & $\cdot 0040$ & & \\
\hline July $14 \ldots \ldots . . . . .$. & $\cdot 0040$ & $\cdot 0040$ & .0040 & .0040 & .0040 & .0040 & .... & .0040 & .0040 & \\
\hline July $19 \ldots \ldots \ldots$ & .0010 & .0040 & ...... & .0040 & .0040 & .0040 & $\cdots$ & .0040 & .0040 & \\
\hline July 28 ............... & $\ldots .$. & .0040 & $\ldots \ldots$ & .0040 & .0040 & .0040 & ... & $\cdot 0040$ & & \\
\hline July $29 \ldots \ldots \ldots \ldots$ & $\cdot 0040$ & & & & & & & & & \\
\hline August $10 \ldots . . . . . .$. & $\cdot 0040$ & & & & & & ... & $\cdot 0040$ & & \\
\hline August 17 ............ & $\cdot 0036$ & .0036 & ...... & $\cdot 0036$ & $• 0036$ & $\cdot 0036$ & ..... & .0036 & .0036 & \\
\hline August 24 ......... & a.... & $\cdot 0036$ & & & & & & & & \\
\hline & .0036 & & & & & & & & & \\
\hline $\begin{array}{l}\text { September } 7 \quad \ldots . . . . . \\
\text { October } \quad 5 \ldots \ldots . . . . .\end{array}$ & $\begin{array}{r}-0036 \\
\ldots \ldots\end{array}$ & 0036 & $\ldots . .$. & .0036 & .0036 & .0036 & $\cdots \cdots$ & .0036 & $\cdot 0036$ & $\begin{array}{l}.0036 \\
.0036\end{array}$ \\
\hline October $24 \ldots . . . . .$. & $\ldots \ldots$ & $\ldots . .$. & ...... & .0036 & .0036 & .0036 & $\cdots \cdots$ & $\ldots . .$. & $\cdot 0036$ & .0036 \\
\hline Total ... & .0508 & $\cdot 0468$ & .0280 & •0228 & .0228 & .0228 & .0040 & $\cdot 0428$ & .0188 & .0108 \\
\hline
\end{tabular}

Phosphate-of-Soda solution.-The strength of a dilute solution of phosphoric acid was determined by means of a titrated alkali-solution (for the preparation of which see page 545); and it was then neutralized by carbonate of soda. Each pipette measure of this solution given to the plants supplied about 01 gramme phosphate of soda. It was only employed in the experiments of 1858. In the records of growth of the plants, it is stated whenever they were manured with this solution.

Sulphuric-Acid solution.-The strength of some very dilute pure sulphuric acid was determined in the same manner as was that of the phosphoric acid, as stated above. It was then so far reduced, that the pipette measure by which it was applied to the plants contained exactly as much $\mathrm{SO}_{3}$ as the pipette of sulphate-of-ammonia solution then in use, namely, 0114 gramme $\mathrm{SO}_{3}$, corresponding to $\cdot 004$ gramme N. For the application of this solution see the records of growth of the plants.

The value of each of the above solutions was determined by analysis, to ensure that it was such as was supposed.

\section{B.-Taking up the Plants, preparation for analysis, methods of analysis, \&c.}

At the termination of growth the glass shade was washed outside, quicksilver was poured into the groove to displace from it the condensed water not removable by the arrangement of apparatus of 1857 , or already collected in the drain-water bottle adopted in that of 1858 , as the case might be, and the shade was then remored. The

* These plants were grorn in M. G. VILLE's case.

$\operatorname{MDCcct} L \mathrm{I}$. 
previonsly corered portions of the slate or stone-ware lute were then washed with jume distilled water, and the: wash-water was added to the condensmel or drain-water. In the experiments of 1858 this fluid was analysed separately, but in those of 1857 it was mixed and dried down with the soil.

The pot, with the soil and plants, was removed to a clean table covered with white paper, the plants measured in all their parts and then cut off at the surface of the soil; the roots were removed, slightly washed from soil, and observed. The plants were then put into a small wide-mouthed bottle, generally stem and root together, funt sonetimes they were put into separate bottles. In the experiments of 1857 the contents of the bottles were dried in a water-bath, with a current of air, previously washed through sulphuric acid, passing through the bottle and thence through a srilution of a known quantity of pure oxalic acid. But it was found that no appreciable amount of ammonia was thus accumulated. Hence, in 1858, a little oxalic acid (in solution) was added to the vegetable matter, and the whole dried in the water-bath without the above precaution.

When dry, the regetable matter was cut small by means of a pair of clean long scissors, reaching to the bottom of the bottle. In this way the substance was reduced to a considerable degree of fineness, and it was still further ground up in the mortar when mixed with soda-lime for analysis. When duplicate analyses were to be made, the matter was carefully dirided so as to ensure equal proportions of stem, fine leafy matter, \&c., in each half. IIence, if both analyses were successfully conducted, the results were mutually confirmatory; or if one portion were lost, the other still represented a proportionate amount of the whole material.

The soil was removed from the pot to a porcelain dish, and a sufficient amount of a solution of oxalic acid added to keep it acid. The mixture was then heated on a sandbath (stirring constantly) until most of the water was expelled, more fully dried in a watcr-bath, and then preserved in well-corked bottles for analysis. The pots were pounded up; those of 1857 being preserved and analysed separately, and those of 1858 mixed with the soil before it was dried with oxalic acid. The pieces of flint at the bottom of the pot were also pounded and mixed with the soil.

For analysis, 150 to 200 grammes of the soil, pot, or mixture, were mixed with about half the volume of soda-lime, the whole put into a large combustion-tube, some sodalime put in advance of the mixture, and then asbestos, as usual. The combustions were made in charcoal furnaces, and the ammonia collected in titrated sulphuric acid, of which the strength, and the amounts employed, are described at pp. 545,546. When very small quantities of nitrogen were involved, the ammonia from two or three tubes of substance was sometimes collected in the same quantity of acid, so as to diminish the error of titration. It was found, however, to be better to use very small quantities of acid, and to estimate the product of each combustion separately; for, by the former method, if any accident occurred in the second or third combustion, it inrolred the loss of the determination of the products previously collected. 


\section{Preparation of the titrated solutions.}

A weighed quantity of pure, dry carbonate of soda was dissolved in water, and to the solution water added to a given volume. As a preliminary step, the strength of some dilute sulphuric acid was tested against a given volume of the carbonate-of-soda solution; and from the data thus obtained, by further dilution a large quantity of acid was made of about the strength desired. The exact value of this acid was then ascertained by repeated trials with the standard carbonate-of-soda solution. To accomplish this, a given volume of the soda-solution was put into a beaker, a little litmus added, and the mixture heated over a spirit-lamp. The acid to be tested was then allowed to flow from a burette until a wine-red colour (indicating that the carbonate is converted into sulphate and bicarbonate with carbonic acid in solution) was produced. On boiling, the blue colour is restored; acid is added until red; the boiling is repeated, till the blue returns; acid again added, and so on, until the solution remains red on the addition of the last drop. The point at which the permanent change takes place in the first trial being known, the experiment is easily repeated so as to ensure great accuracy.

Thus, 50 septems of a solution of carbonate of soda, of which 1000 septems contained 6.652 grammes of the salt, required, for neutralization as above, the following number of septems of the dilute acid, in six different trials-

\section{Hence-}

$$
58 \cdot 3,58 \cdot 2,58 \cdot 3,58 \cdot 3,58 \cdot 2,58 \cdot 2 \text {; mean } 58 \cdot 25 \text {. }
$$

$$
\frac{6 \cdot 652}{1000} \times \frac{50}{58 \cdot 25} \times \frac{\mathrm{N}}{\mathrm{NaO}, \mathrm{CO}_{2}}=\frac{6 \cdot 652}{1000} \times \frac{50}{58 \cdot 25} \times \frac{14}{52.98}=0.001508 \text { gramme N. }
$$

The mean of six experiments with a solution of carbonate of soda of another strength gave in the same way 0.0015008 gramme $\mathrm{N}$; and we adopted the mean, or 0.001504 gramme, as the amount corresponding to one septem of the titrated acid.

It remained to prepare an alkaline solution to test against this standard acid. At first a solution of sugar-lime was employed; but this being found to be liable to constant change, due doubtless to fermentation, a solution of caustic soda was had recourse to. This solution was prepared of such dilution that the extreme error possible in reading off a unit of volume on the burette should be much less than would be admissible as the maximum error of analysis. The burette was of small enough diameter to allow of one-tenth of a septem being read off on it; and the alkali-solution was so dilute that it required about three septems of it to ncutralize one septem of the titrated acid. Hence one septem of the alkali-solution corresponded to only about one-half of a milligramme of nitrogen, and the probable error of reading would therefore amount to only about one-twentieth of a milligramme.

In the case of the sugar-lime solution, it was found necessary to test its strength against that of the acid every day that it was employed. But the soda-solution, if properly prepared, and well preserved, remained for months unchanged; so that, when its value was once established against that of the standard acid, it could be expressed $4 \mathrm{E} 2$ 
by a number of four or five digits, which, multiplied by the number of septems

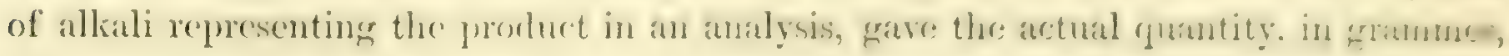
of the nitrogen to be estimated.

\section{Amount, and measurement, of the titrated acid used in Nitrogen determinations.}

It was desirable that at least three times as much acid should be used as would be neutralized by the ammonia formed. 'The acid being more concentrated than the alkali, it required a more exact methor of measurement than was afforded by the burctte used for the latter. Pipettes, of which the diameter at the point of reading off is comparatively small, and which henec admit of a higher degree of accuracy, were threfefore employed. In the construction of those to be used, care was taken to maintain the same relation of the diameter of the neck at the point of reading to the entire volume in instruments of different sizes- $a$ condition seldom observed by makers of pipettes. When the quantity of nitrogen involved in an analysis was very small - as in the case of the soils and pots in the experiments without nitrogenous manure-only about six septems of the titrated acid, measured in a small pipette with a very narrow neck, were used. The exact volume of the pipette-ful of acid was not a matter of any consequence. It was only essential to ascertain its exact ralue expressed in septems of the titrated alkalisolution. When the amount of nitrogen involved was larger, and more under controlas for example when grains were to be analysed-care was taken to operate on such a quantity of nitrogenous material that the number of septems of the alkali representing its nitrogen should be sufficiently large to render the constant errors of titrating, reading, \&c., inappreciable. This end was attained whon the substance experimented upon contained 5 to 8 milligrammes, or more, of nitrogen.

\section{Combustion-tubes, bulbs, \&e.}

The combustion-tubes used in the determinations of nitrogen in the soils, pots, \&c., were about 3 feet long and about 1 inch in diameter. The bulb-apparatus was capable of holding two-and-a-half to three times as much fluid as that usually employed; but the central and lowest bulb, and particularly its tubular connexions with the other bulbs, were very small, so that a small quantity of liquid could close the passage. This arrangement was necessary orving to the small quantity of acid frequently used, and the large amount of water driven off in the combustion from the large quantities of soil and sodalime. For the combustion of the experimentally grown plants smaller tubes were employed; and for seeds, \&c., ordinary combustion-tubing was used.

\section{The Soda-lime.}

Before use, the soda-lime was ignited with 2 per cent. of pure sugar, in order to ensure its freedom from ammonia-yielding matter. It was then slaked with pure distilled water, dried, and kept in well-corked bottles. 


\section{Accuracy of the method for the determination of nitrogen by combustion with soda-lime, \&c.}

In order to ascertain the accuracy of the method before relying upon it for the purposes of the inrestigation, a few preliminary experiments were made upon the determination of small and known quantities of nitrogen, mixed with large quantities of soil, which had been previously freed from combined nitrogen as in the preparation of the soils for the plant-experiments. The nitrogenous substance taken for the purpose was the powdered crystals of purified quadroxalate of ammonia, $\left\{\begin{array}{c}\mathrm{N} \mathrm{H}_{3} \\ \mathrm{H}\end{array}\right\} \mathrm{O},\left(\mathrm{C}_{2} \mathrm{O}_{3}\right)_{4}+7 \mathrm{HO}$. The results were as follow-

Experiment 1.-50 grammes of the prepared soil were mixed with quadroxalate containing by calculation 0.0024 gramme nitrogen; and on burning with soda-lime, and determining as above described, 0.0027 gramme nitrogen was found.

Experiment 2.-100 grammes of the soil mixed with quadroxalate equal, by calcula. tion, to 0.0035 gramme nitrogen, gave on combustion 0.0037 gramme nitrogen.

The error of analysis was, therefore, three-tenths of a milligramme of nitrogen with the 50 grammes, and two-tenths with the 100 grammes of soil. These results were obtained at the commencement of the inquiry, with comparatively large quantities of titrated acid, and therefore before experience had suggested the precautions to be adopted to reduce the errors of determination to the minimum. They may hence be taken as examples of the maximum crrors of analysis, but they are less than would affect the bearing of the results in the investigation on the question of assimilation.

\section{Testing for Nitric acid.}

The indigo test, as recently refined by Boussivgaul *, and the protosulphate-of-iron test, were both employed. When nitric acid was sought for and not found, if practicable the negatire result was always confirmed by the addition to some of the substance under examination of a quantity of nitric acid (in the form of nitrate) less than could affect any conclusions to be drawn from the fact of its presence or absence in the substance in question. In all the cases of such addition the re-examination showed the presence of nitric acid.

The method of Boussingault was much more delicate than the protosulphate-of-iron test; but, on the other hand, the latter was much less liable to give deceptive indications, dependent on other circumstances than the presence of nitric acid. In using the protosulphate test, the aqueous extract of the substance under examination was evaporated to a small volume with excess of fixed alkali, then transferred to a test-tube, and further evaporated till only a few drops remained. A considerable excess of concentrated sulphuric acid was then added, and on the surface of the liquid a concentrated solution of protosulphate of iron was carefully poured without agitation, by means of a small pipette with a mouth of almost capillary fineness. The characteristic brown tinge indicated the presence of nitric acid.

* Ann. de Chim. et de Phys., rol. slviï. (1856) p. 153 et seg. 


\section{C.-Abstract of the Recorns of Gromtin of the Plants.}

\section{I.-P'PANTS GROWN IN $1857^{*}$.}

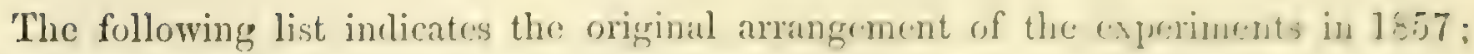
but, as the records will show, beans sown and resown under shades Nos. 5, 10, and 11 died before they had attained any matrial amount of growth; and henere the loweducts in these cases were not submitted to analysis.

Series 1. With no other combined nitrogen than that contained in the seed:-

1. Wheat; in prepared soil.

2. Barley; in prepared soil.

3. Barley; in prepared pumice.

4. Beans; in prepared soil.

5. Beans; in prepared pumice.

Series 2. With a supply of linown quantities of combined nitrogen beyond that contained in the seed:-

6. Wheat; in prepared soil.

7. Wheat; in prepared pumice.

8. Barley; in prepared soil.

9. Barley; in prepared pumice.

10. Beans; in prepared soil.

11. Beans; in prepared pumice.

And also-

12. Wheat, Barley, and Beans, together; in rich garden soil.

Reconds of Sowing, and Early Stages of Grottit, of all the Playts coleectimly.

May 12.-The weighed seeds of wheat (Nos. 1, 6, \& 7), of barley (Nos. 2, 3, 8, \& 9), and of beans (Nos. 4, 5, 10, \& 11) were respectively put into small bottles, a few septems of pure distilled water added to soak them, and then corked up.

May 16.-The wheats (Nos. 1, 6, \& 7), and the beans (Nos. 4, 5, 10, \& 11), were sown, and the pots removed to their places on the stand, and corered with the shades; seeds all swelled; some sprouting.

May 20.-The barleys (Nos. 2, 3, 8, \& 9), freshly weighed seeds (the soaked ones being abandoned), were set, and the pots remored to their position under the shades.

May 27. - Nearly all show shoots above the surface, all of which look green and healthy.

June 2.-Wheat and barley plants two or three leares each, healthy, but pale green. No. 4 beans (soil) healthy and vigorous. No. 5 beans (pumice) one plant up, with three leaves speckled with black spots; the other plant blackened and apparently dead. Beans No. 10 (soil) and No. 11 (pumice) slightly speckled with black spots.

June 3.-Commenced the daily passage of mashed air orer the plants, in quantity

* The figures (Plate XV.) of the plants grown in 1557 are reduced from dramings taken, for the most part, about the middle of August. 
equal to about $2 \frac{1}{2}$ times the volume of the shade. Carbonic acid also daily supplied, in amount as described at pp. $480,481$.

June 6.-Graminaceous plants (Nos. 1, 2, 3, 6, 7, 8, \& 9) all healthy, though with a tendency to turn yellow at the tips of the leaves. Of the Leguminous plants, Nos. 5, 10 , and 11 give indications of dying.

June 8. - Some of the wheat and barley plants tuming yellow. Beans Nos. 5, 10, and 11 obriously dying; probably injured by the causticity of the ash added to the soil, as No. 4 beans, the seeds and roots of which happen to be washed when water is supplied, are healthy and vigorous.

\section{RECORDS FOR EACI EXPERLIENT GIVEN SEPARATELY.}

No. 1.-Wheat (1857); six seeds; prepared soil; without nitrogenous manure.

(See Plate XV. fig. 1.)

June 9.-Five plants up; one quite small, the others 2 to 4 inches high, with two leaves developed and a third appearing; yellowish at the tips of some of the leaves.

June 15.-Five healthy plants, each with three fully developed leaves; tips of the lower leaves slightly yellow.

June 24.-Plants 5 inches high; lower leaves dead and dry, upper pale green; with some of the tips yellow, but general appearance of the upper leares healthy.

July 4.-Plants 6 to 7 inches high; 5 leaves on each; upper ones pale green, lower ones yellow.

[Note-Drops of water condense rapidly on the tips of the leaves of all the Cereals, but not of the Leguminous plants; they also form and run down the inner surface of all the shades, casting focal rays apparently injurious to the plants when not shaded from direct sunlight.]

July 11:-Same number of leaves; very little further growth; lower leaves more dried up.

July 22.-Very little improvement.

July 29.-Very little growth, though upper leaves continue green; but little tendency to form stem.

[Note.-Shade opened a few seconds to substitute a tube for one accidentally broken.] August 10.-Green colour maintained, but no apparent increase in size.

August 24.-Five plants, 6 to 9 inches high, with eight or nine leaves each, all dried up but the two upper ones, which are green and healthy, one expanded, the other folded in the axis of growth. The healthy appearance of the upper leaves has been maintained several weeks, with otherwise almost total cessation of growth.

October 3.-Plants taken up:-

The plants have been almost stationary since the last report; termination of the ascending axis keeps green; no indication of heading. (See Plate XV. fig. 1.)

Soil moist, soft, and spongy.

Roots not distributed generally throughout the soil; a few isolated ramifications 
extended to the lower part of the pot; but the great mass renained uear the lane of the: stem. 'Total quantity of root very small compared with that of wheat No. 6 manured with ammonia-salts. For greneral character of root-dexelopment, sed Plate: XV. fir. 15.

For method of further treatment see pp. $543,544$.

No. 2.-Barley (1857); six seeds; mepared soil; without nitrogenous manure.

(See Plate XV. fig. 2.)

June 9.-Six plants; 2 to 3 inches high, with two fully developed leaves; tips of some of the leares slightly yellow.

June 15.-Three plants with three leaves, and three with two leares each; tips of lower leaves slightly yellow, but general appearance healthy.

June 24.-Plants 4 to 6 inches high, with three or four leaves each; much the same condition as wheat No. 1 at this date.

July 4.-6 to 7 inches high, with four or five leaves; paler than wheat No. 1; looking sickly. Drops of water on tips of leares and inner surface of shade: see Yote thereon to wheat No. 1, same date.

July 11.-Lower leaves drying up; upper ones growing a little, apparently at cxpense of the lower. Stems of these and the other barley plants reddish, and hare been so since the formation of true stems with nodes. The barleys form stem more readily than the wheats, which are more leafy.

July 22.-Not much improvement.

July 29.-Only two small leares at the top green; the amount green at one time does not increase; lower leaves dry up as new ones form.

August 10.-Very little change, except that one stem shows slight indications of heading.

August 24.-Plants taken up:-

Six plants, 5 to 17 inches high, with six to nine leaves on each plant. Two indicate slight tendency to heading, the sheath being swollen; but growth obriously censed. the two upper leaves having at last lost colour and dried up. On opening, one head shorred a rachis 2 inches long. The plant was very dry, so no fresh weight taken.

Prepared and analysed as described at pp. 543, 544.

No. 3.-Barley (1857); six seeds; prepared pumice; without nitrogenous manure.

(See Plate XV. fig. 3.)

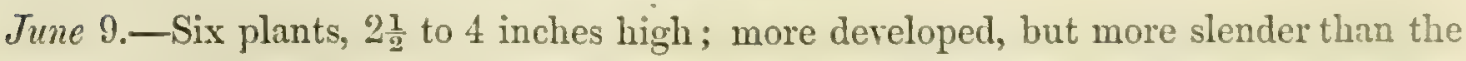
barleys in soil (Nos. $2 \& 8$ ). Leares turning yellow at the tips.

June 15.-Six plants, 6 inches high, each with three fully developed leares; tips of lower leaves dried up; middle leaves hare yellow tips; upper ones pale green but healthy. Plants appear to have almost done growing.

June 24.-Height about the same; three or four leares each plant; lorrest dried up, next drying, and upper ones green. 
July 4.-Plants 6 to 7 inches high; five or six leares each; upper leaves only pale green.

[Drops of water collect as described in reference to No. 1 Wheat at this date.]

July 11.-Plants 6 to 8 inches high; five or six leaves each; upper ones green and growing a little as the lower ones dry up; general aspect stationary.

July 22.-Very little growth.

July 29.-Plants 8 to 10 inclies high, very slender, like mere threads; all lower leares dried up; upper ones 1 to 2 inches long and pale yellow. The six plants show twenty nodes. Slight tendency to form very small heads.

August 10.-Plants quite dried up.

August 25.-Plants taken up:-

Six very slender plants, mere filaments, 8 to 20 inches long; with four to sis nodes, and six to eight leaves each. Stems zigzag at the nodes; leaves dried up and brown. The top sheath of five of the plants indicates an excessively small head with zigzag rachis, at the upper part of which is a well-defined husk but no seed; the lower parts have beards and small rudimentary husks.

Preparation and analysis as described at pp. 543, 544.

No. 4.-Beans (1857); two seeds; prepared soil; without nitrogenous manure.

June 9.-Two plants up; one 6 inches high, four leaves with two leaflets each and two large stipules; the other smaller; both healthy and vigorous.

June 15.-One plant $7 \frac{1}{2}$ inches high, with five leaves, each with two or three leaflets and two stipules; the other 31 inches high, with four leaves and corresponding stipules. Tips of some of the lower leares slightly speckled, but the upper ones green, and both plants healthy and vigorous.

June 24.-One plant 15 inches high, with seven leares, each with two or three leaflets and two stipules; lower leaves yellow, with dark specks at the edge, upper leares and stem light green; the other plant 9 inches high, four or five leares with two to three leaflets, \&c., each; lower leaves as on the other plant, but upper ones greener. Plants appear to hare nearly done growing.

July 4.-One plant 19 inches high; five leaves fallen off within two days, three upper ones remain, these green, appear to live on nutriment drawn from the lower ones. The other plant 12 inches high, seven leares, and a small sprout just at the surface of the soil; lower leares dead, upper ones nearly done growing.

July 5.-Plants tatien up*:-

Preparation and analysis as described at pp. 543, 544.

* After removal of the beans, a barley plant from the field was potted with its orn soil which was comparatively dry, and placed under the shade without being watered, in order to see whether water was given off and condensed within the glass as freely as in the case of the experimental plants. It mas so ; and hence it was concluded that the experimental soils were not too wet.

MDCCCLI. 


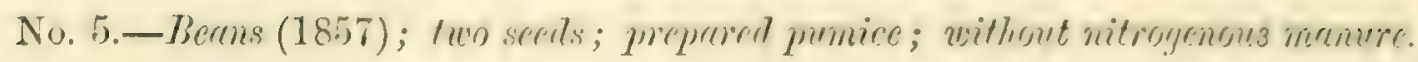

June 9.-One plant $1 \frac{1}{3}$ inch high, blackened, and dying; the other smaller and already dead.

As will be seen by the records (1. 557), Beans Nos. 10 \& 11 showed erqually unhealthy growth; all were therefore removed and re-planted. It was obvious that the failure was too early to be due to want of available nitrogen; especially, as No. 4 Beans with a similar amount of nitrogen lived. The result was considered to be due to the causticity of the ash, as beans set in ash-free soil and pumice flourished much longrer, and in the case of No. 4 the seeds happened to be so placed as to be washed when water was applied.

It was found on examination that all showed signs of recommencement of growth; new roots and stems were forming. The sects, \&c. were removed; a little sulphuric acid arded to the soil (or pumice) to neutralize the ash, and it was then ignited as originally, put into fresh red-hot pots, and cooled and moistened orer sulphuric acid. Before putting in fresh seeds, holes were made for them in the soil, and water poured in to remore soluble matter from the neighbourhood of the young rootlets. The experiments were then continued as before.

\section{Report of No. 5 Beans contimued.}

Jine 24.-One plant just up.

July 1.-An accident occurred to this experiment. A fresh pot of soil, prepared precisely as abore, was planted with beans that had been set in small glass tubes ready for any contingency, and the experiment continued.

July 4.-One plant, leares just opening.

July 11.-Still only one plant up, and it looks very unhealthy.

July 22,-One plant, obviously dying.

July 29.-Dead.

No. 6.-Wheat (1857); three seeds; prepared soil; with nitrogenous mamure.

(See Plate XV. fig. 7.)

June 9.-Two plants up; one $2 \frac{1}{2}$, the other $4 \frac{1}{2}$ inches high; three leares each. Tips of leaves slightly yellower than those of Wheat No. 1.

June 10. A pipette-ful of the solution of sulphate of ammonia (=.00578 gramme X.) added to the soil.

June 15.-Two plants; green and rigorous; marked improrement since the addition of ammonia-salt; the leares wider and of a deeper green. Three leares each plant.

June 24.-Two plants; 7 inches high ; four or fire leares each; lower ones dried up, upper ones deeper green than Wheats No. 1.

July 4.-Two plants; 9 inches high; six learcs each; lower ones yellow, upper ones broad, long, and of a healthy deep green; but the rigour due to the first addition of 
ammonia appears to hare ceased. Second pipette-ful of ammonia-solution (same quantity) added.

July 11.-Two plants, 10 inches high; seven leaves each; upper ones deep green, broad, and vigorous. Third pipette-ful of the ammonia-solution added.

July 22.-Growth rigorous; shooting out at the base of the stems. Fourth pipette-ful of the ammonia-solution alded.

July 29.-Much greater tendency to form leaf than stem. One plant with four, and the other with two subdivisions. 12 to 16 inches high, the height greatly due to the length of the leaves. Not a single node clear of the sheath of the one below it; thus essentially different from the barleys, which have great tendency to form nodes and stem. Fifth pipette-ful of the ammonia-solution added.

August 10.-Green and flourishing.

August 24.-Plants 17 to 20 inches high; ten to twelve leaves on each; upper ones long, broad, and green; lower ones dried up. But little tendency to form stem; leares larger than on plants in the field; some 12 inches long and $\frac{1}{2}$ inch wide; no nodes clear ; the leaves spring out so close together as to appear almost opposite. Five stems from the two seeds.

October 2.-Plants taken up:-

One seed has given three strong and one small stem; another one stem; the third did not grow. Leaves very numerous and close together, giving several thicknesses. of sheath around the stem, and hiding all the nodes; lower leaves dried up; upper leaves and central axis of growth green. Condition nearly stationary for the last two or three weeks. Average height of plants about 18 inches.

Soil quite moist throughout; also soft, and spongy, rather more so than the pumice soils; a little water remained in the plate below the pot.

Roots much, but rery irregularly distributed-a large bunch around the base of the stem; small, long, isolated roots extended to the bottom and up the sides of the pot; quite a mass of ramified roots over the bottom, and somewhat up the sides of the pot; and a greater mass in the dish under the pot, forming a circular web the size of the bottom of the pot. A crack in the bottom of the pot was penetrated with roots throughout, showing, perhaps, that more openings than the one hole at the bottom might be advantageous. For representation of the root-development, see Plate XV. fig. 14.

Preparation and analysis as described at pp. $543,544$.

No. 7.-Wheat (1857); three seeds; prepared pumice; with nitrogenous manure.

June 9.-Three plants up, 3 to 4 inches high; each with three leaves completely formed, of which the tips are slightly yellower than those of Nos. 1 and 6 , but no appearance of diseased condition in any of the wheats.

June 10. A pipette-ful of the ammonia-solution (=.00578 gramme N.) added to the soil.

June 15.-Plants 5 to 6 inches high, with four leaves each; the tips of the lower $4 \mathrm{~F} 2$ 
ones yellow; the newer and upper leaves green, healthy, and rigorous; marked improvement since ndeling the ammonia-solution on June 10 , the effect of which was manifest within two days after the addition.

June 24.-Plants 5 to 7 inches high, with four leaves each; lower leares driced up, but upper ones green and vigorous; obviously improving; forming stem with nodes.

July 4.-Plants 7 to 8 inches high, with five to seven leaves each; the newer ones broad, well developed, and of a deep green colour; upon the whole vigorous. Second pipette-ful of the ammonia-solution added.

[Drops of water accumulate as described in reference to No. 1 of this date.]

July 11.-Plants 8 to 9 inches high, with six or seren leaves each; lower ones pale yellow, upper ones green and vigorous. One of the stems semding out a sheret at its hase. Third pipette-ful of ammonia-solution added.

July 22.-Growing very well; tillering very much. Fourth pipette-ful of the ammoniasolution added.

July 29.-Plants 12 to 16 inches high; one with six shoots 4 to 8 inches long; one with one shoot 3 inches long; and the other with two shoots just forming; shoots, and upper leares, green. The ammonia seems to induce multiplication of shoots instead of upward growth; no nodes clear of the sheath. Fifth pipette-ful of the ammoniasolution added.

August 10.-Green and flourishing.

August 24.-Very similar to Wheat No. 6 at this date.

September 20.-Plants taken up:-

The lower leaves begin to lose colour considerably, no increase of growth apparent for some days, nor any tendency to form seed; hence, the season being far adranced, the plants taken up.

Great derelopment of root; the plate under the pot corered with a dense network ramified from a few fibres extended to the bottom of the pot; a similar network at the bottom and partially up the sides within the pot; comparatively little in the centre of the soil.

Preparation and analysis as described at pp. $543,544$.

No. 8.-Barley (1857); four seeds; prepared soil; with nitrogenons manure.

(See Plate XV. fig. 8.)

June 9.-Three plants up; two $1 \frac{1}{2}$ inch and one $3 \frac{1}{2}$ inches high; colour pale.

June 10.-A pipettc-ful of ammonia-solution (=.0057S gramme $\mathrm{X}$.) added to the soil.

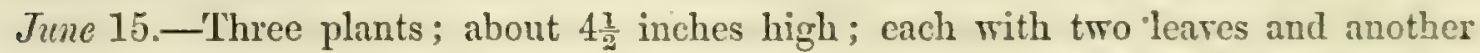
forming. Improred by the ammonia added June 10, but not so much as the Theat No. 6.

June 19-20.-During thenight the shade was cracked, from the bottom in the quicksilver, 9 inches upwards. 'The pot with its contents was remored and put under a shade over sulphuric acid. After four days it was returned to its place, and corered with the 
shade of Experiment No. 12 (with plants in garden soil), the latter being replaced by the damaged shade after the crack had been mended with strips of bladder cemented with albumen and lime-rater. All the circumstances of this accident were carefully considered, and it was concluded that no appreciable error could arise from it.

June 24.-Three plants, 3 to 5 inches high; three or four leaves each; lower ones dried up, upper ones pale green; plants slender, but improved since the addition of the ammonia-solution.

July 4.-Plants 6 to 7 inches high ; five leaves each; the most delicate and slender of the plants that have had ammonia-solution; upper leaves darker green than those without ammonia; lower leares yellow. Second pipette-ful of ammonia-solution added.

[The same remarks apply here, as were made to No. 1 at this date, in reference to condensation of drops of water.]

July 11. - Plants 7 to 9 inches high; six or seren leaves each; stem reddish; upper leares healthy and deep green. Third pipette-ful of ammonia-solution added.

July 22.-Growing vigorously. Fourth pipette-ful of ammonia-solution added.

July 29.-Four plants, 16 to 20 inches high. Since the last two additions of ammonia-solution, two of the plants have sent out at the base two new shoots, 6 to 8 inches high; one, two new shoots 2 to 4 inches high; and the other, one shoot. All these shoots are deep green and growing rigorously. A great tendency to develope new foliage; and though some of the stems were just begiming to swell, indicative of heading, and one showed a beard, yet this growth was arrested, and the energies of the plant directed to the new growths at the base. In all, serenteen nodes clear of the sheaths. Fifth pipette-ful of the ammonia-solution added.

Aunust 10.--Since the last three additions of ammonia the old stems ceased to derelope, but some of the new ones are on the point of heading.

August 24.-Eight plants from the three seeds. One seed has given one plant 24 inches high, with seren nodes clear, and nine leares, of which the seven lower ones are dried up; the plant terminated by a well-formed head. Another seed has four stems, 16 to 20 inches high; one dried up just as it was heading; the three others green and healthy, and two just commencing to head; each stem four to six nodes, and six to ten leares. The third seed has three stems 12 to 24 inches high, each with three to fire nodes and five to ten leaves; one stem dried up.

\section{October 8.-Plants taken up:-}

Eight stems from three seeds, as under:-

(a) Seed with one stem; 18 to 20 inches high; seven nodes. This was the first plant that headed; all ripe and dry; six glumes, containing only rudimentary or undeveloped seeds.

(b) Seed with three stems. One 17 inches high; head ripe, and rather decaying. Another 25 inches high; grown sereral inches, and formed head, since August 24; head green, with fire soft milky unripe grains. The third stem green at top, and upper sheath swollen with the head. 
(c) Seed with four stems:-(1) 22 to 23 inches high, with groen head and six unrigr: rrains; leaves dry and ripe; (2) stem 15 inches high, dried up, hrad-sheath fonmed; (i) 19 inches high; yellowish-erreen hear, with nine glumes, ind undereloped secels; (4) about 15 inches high; rather green, sheath swollen, and beard appearing.

During the last three weeks some heads came out more, and indications of others developed; otherwise not much change. From the low trmperature and lituram of the scason, it was thought the plants would not mature further.

Preparation and analysis as described at pp. $543,544$.

No. 9.-Barley (1857); four seeds; prepured pumice; with nitrogenous manure. (See Plate XV. fig. 9.)

June 9.-Four plants; one quite small; the others 3 to 4 inches high. These more grown than the Barley plants Nos. 2. S \& 8; but the leaves, particulirly the lower one. yellower at the ends.

June 10. - $\mathrm{d}$ pipette-ful of ammonia-solution $(=.00578$ gramme N.) added to the soil.

June 15.-Four plants; 5 to 6 inches high; four leares each; lower ones losing vitality. Lower leaves were too far gone, but a most marked improrement in the upper ones since the ammonia-salt was added; it was manifest in two to three doys after the addition.

June 24.-Four plants; height 6 to 8 inches; improved very much by the addition of the ammonia-solution.

July 4.-Plants 8 to 13 inches high; six or seven leaves each; stems rery slender, but show well-formed nodes. Second pipette-ful of ammonia-solution added.

[Drops of water accumulate as described in reference to No. 1 of this date.]

July 11.-Plants 9 to 14 inches high; seven or eight leares each; upper ones deep green; lower ones yellow; stems red. Third pipette-ful of ammonia-solution added.

July 22.-Growing rery well; showing indications of heading. Fourth pipette-ful of ammonia-solution added.

July 29.-The four plants all out in head; about 30 inches high; each stem six nodes; two of the plants have shoots 5 inches high. The ammonia seems to tend more to new growth than to the development of the old.

August 10.-Heads well dereloped.

August 24.-The plants appear to be ripening; heads turning brown; but one ner stem is still green and growing.

September 24.-Plants taken up:-

Seven plants; five 2 to $2 \frac{1}{2}$ feet high, one green; one $1 \frac{1}{2}$ foot high, green head; ono 14 inches high, green. Six with heads, four ripe and two green; the shortest plant with green leares and without head. Heads 1. inch long; glumes all along the rachis, but only some with grains. 
Roots by no means so abundant as those of Wheat with ammonia-salt; only a few fibres extended through the hole at the bottom, or to the sides of the pot.

Preparation and analysis as described at pp. 543, 544.

No. 10.-Beans (1857); two seeds; prepared soil; intended to have nitrogenous manure.

June 9.-Only one plant up; 2 inches high; turning black and obriously dying.

For particulars of taking up, setting fresh seeds and recommencement of the experiment, see remarks made on June 9 to Bean No. 5, p. 552.

June 15.-Not yet up.

June 24.-Two plants just appearing.

July 4.-Two plants well up and growing; leaves just opening.

July 11.-Tiro plants; 6 to 8 inches high; leares deep green.

July 22.-Green, healthy, and rigorous.

July 29.-Nearly as at last date, but somewhat declining.

August 10.-Obviously dying.

August 24,-Dead.

The season too far adranced to repeat this experiment.

No. 11.-Beans (1857); two seeds; prepared pumice; intended to have nitrogenous manure.

June 9.-One up; slender; black spots on the leares; obviously unhealthy. Taken up, and the experiment recommenced; for particulars of resetting, \&c., see remarks to Bean No. 5 of this date, p. 552.

June 15.-Not yet up.

June 24. -Two plants just up.

July 11.-Apparently not going to grow.

July 22.-Dead; the season too far advanced to repeat this experiment.

No. 12.-Theat, Barley, and Beans (1857); Wheat and Barley three seeds each, Beans two seeds; in rich Garden soil. (See Plate XV. fig. 13.)

MIay 18.- -Seeds of wheat, barley, and beans, all sown together in a single pot of good garden soì, and placed under a shade (No. 12), to be supplied with washed air, \&c., just as in the other experiments. The seeds germinated well.

May 28-29.-During the night, owing to a leakage of water from the reserroir into the ressel A (see description at p. 476 et seq., and Plate XIII.), it passed over into the sulphuric acid and carbonate of soda wash-bottles, and the mixed liquid passed into the shade to the depth of some inches, and destroyed the experiment.

JI ry 30.-Plants from seeds which had been set at the same date as the foregoing, were transplanted into a fresh pot of garden soil, which was placed under the shade, and the experiment recommenced. The wheat and barley plants were about 5 inches, and the beans about 4 inches high.

June 15.-Healthy, and growing rigorously.

June 24.-Three wheats, three barleys, and two beans. Wheat 14 inches, barley 
13 inches, and beans 11 inches high. Wheat and barley much branched at the base, giving fourtcen stems from the six seeds; all a deep green colour. Beans deep greecin, and growing well, excepting that one has a few black specks on the lower leaves. Sin much growth that the plants are considerably crowded in the shade.

July 4.-Much crowded. Graminacexe 20 inches, Leguminose 15 inches high. The former growing as well as in the open air. 'The latter appear to suffer from crowding; their lower leaves dying.

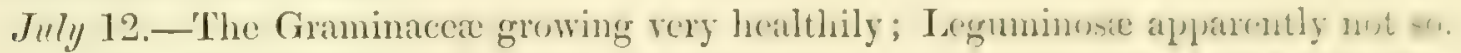

July 22.-The (iraminacex growing vigorously; Leguminese revived, and al:on sor,wing vigorously at the top. During the last few days they have becn protected from the direct sun by a sheet of paper tied round the shade.

July 29.-Four barleys in head; wheat not so advanced, but nearly as high; the beans had again suffered, but one is recovering. 'Too much crowded.

August 10.-About as at last date.

August 24.-About as at last date; barley slowly ripening.

The object of the experiment being attained, which was to determine whether the conditions of atmosphere were suited to healthy growth, provided the soil supplied sufficient nutriment, no further records of growth were made.

\section{Plants grown in 1858*.}

As in the experiments of 1857 , so in those of 1858 , the plants grown may be dirided into two Series, as under:-

Series 1. With no other combined Nitrogen than that containcd in the seed sown.

Series 2. With a supply of known quantities of combined Nitrogen beyond that contained in the seed.

The notes of growth of the plants grown without any extraneous supply of combined nitrogen are given first, and then those of the plants grown with such supply. As before, in several experiments instituted with Leguminous plants they died before attaining a sufficient amount of growth to render it of any use to analyse the products. The records of their progress, such as it was, are, nevertheless, shortly giren.

No. 1.-Wheat (IS5S); eight seeds; prepared soil; without nitrogenous manure. (See Plate XV. fig. 4.)

April 27.-Seeds set, and the pot placed under a shade orer sulphuric acid.

May 7.-All the plants up; the pot removed to its shade on the stand.

IIay 20.-Eight plants; all of a healthy green colour; seren 4 inches high, one just abore the soil.

* The figures (Plate $\mathrm{XV}$.) of the plants grown in $185 \mathrm{~S}$ are reduced from dramings talen, in most cases, not many days before the plants were taken up. 
May 22.-A pipette-ful of the sulphuric-acid solution added.

May 29.-Eight plants, 4 to 6 inches high; each avith four leaves, the two lower yellow, the two upper green and healthy. A drop of water appears on the tip of the upper leaves in the morning, but it disappears before midday, as the air is passed through the shade. A pipette-ful of the phosphate-solution added.

June 7.-A pipette-ful of the phosphate-solution, and a pipette-ful of the sulphuricacid solution added.

June 19.-Plants 5 to 7 inches high; two lowest leaves on each dried up; upper ones yellowish green.

Jine 26.-Eight plants, 6 to 7 inches high; six leares each, three lower ones dried up, next two pale green, only upper central one green and healthy. Apparently at limit of growth without more combined nitrogen; very much as last year without nitrogenous manure.

July 3.-A pipette-ful of the phosphate-solution, and a pipette-ful of the sulphuricacid solution added.

July 14.-Plants 6 to 8 inches high, with six or seven leaves each; only the two upper ones yellowish green; apparent stagnation of growth.

July 29.-Much as last; two upper leaves seem to sustain life at the expense of the rest.

August 17.-After long inactivity several plants show tendency to grow in stem. In this, somewhat more like the barley than wheat of last year. Some disposition to heading.

September 7.-Still developing stem; nodes and internodes distinctly marked. Plant (a) 13 inches high, ten leaves, three nodes bare, slightly swelled at top as if heading; new stem-leaves, only 2 to 3 inches long. Plants $\left(b\right.$ and $c$ ) $9 \frac{1}{2}$ inches high, nine leares, two or three bare nodes; slight indication of heading. Plants $(d, e$, and $f) 7 \frac{1}{2}$ inches high, trro bare nodes; stems shorter, leaves eight or nine, a little longer than above. Plant $(g)$ two branches; the first short, and dried up; a new one formed from its base, green, but only $4 \frac{1}{2}$ inches high, with four green leares. Plant $(h)$, dried up stem with three long leaves; but a new green shoot with two leaves, though little growth. General remark:-all lower and first-formed leaves dried up, the next yellowish, and only the two upper ones green. Drops of water collect at the tips, and axils, of the green leaves. The later growth obviously at the expense of the earlier.

October 5.-Little change, except riper. Plant $(a) 14$ inches high, eleven leares, nearly all dricd up, four bare nodes, a head with indications of seeding: $(b) 10 \frac{1}{2}$ inches high, eleven leaves, all ripe but the uppermost, three bare nodes, and indication of heading: $(c) 91$ inches high, nine leaves, three nodes: $\left(d\right.$ and $e$ ) $81 \frac{1}{2}$ inches high, eleven leaves each: ( $f$ and $g$ ) 4 to 7 inches high, dead stems with eight to ten leares each, but green shoots at the base: (h) 7 inches high and seven leaves, dead ripe.

October 24.-Weather much warmer again lately, and slight renewal of growth; drops of water again appear on the green top leares. The chicf growth is further dereMDCCCLXI. 
lopment of the rudimentary head; a definite rachis formed, with joints and rudinu ntary husks, but no indication of secd.

October 25.-P'lants taken up:-

Soil quite wet, loose, and open, to the bottom; roots pass through the pot at nearly all the bottom holes, and at some of the side ones; long roots distributed among the flints; very few roots come to the sides of the pot (see Plate XV. fig. 17)。

Plant 1. Dead ripe, 7 inches high, seven long leaves, one dead shoot; roots long, apparently going to the bottom, very little distributed.

Plant 2. Seven inches high; two stems; one with six leaves, dead ripe; the other with three leaves, one still slightly green; no nodes visible; each, a moderate annount of root.

Plant 3. Eight inches high; ten leaves, lower long and dead, two upper green; no nodes visible. Many roots at the base, some extending downwards. Revots of this and all the plants have short forked branches, $\frac{3}{4}$ to $\frac{1}{2}$ inch long, blunt and thick, and generally forked at the end; strikingly different from the roots among the Inowe flints at the bottom, and those under the pot.

Plant 4. Height 101 inches; thirteen leares; six risible norles; slight swclling at the head. Fewer roots branched and distributed in the soil near the base of the stem; mont go to the bottom, or even under the pot, thus taking nutriment from the water in the dish rather than from the soil;--perhaps associated with this the superior growth orer plants 1, 2, and 3 .

Plant 5. Very similar to No. 4.

Plant 6. Very similar to Nos. 4 and 5; but the head rather more dereloped, and risible through the transparent sheath, and the roots with rather more the character of pot or soil roots.

Plant 7. Eleven inches high; twelve leaves; five nodes visible; head with chaff without grain, and beard $\frac{3}{4}$ inch long; rachis 1 inch long. Roots but little branched, going down and developed more at the bottom and in the dish than in the soil.

Plant 8. The largest and most developed plant. Fourteen inches high; twelre leares; lower ones long and crowded, upper ones shorter and further apart (as in all); four nodes; head with rachis $1 \frac{1}{4}$ inch long, with glumes and pales. Roots very similar to No. 7 , forming under the pot a thick matted mass, running round the dish, some of which, when untangled, are 3 to 4 feet long; white, transparent, and with many small thread-like branches; the whole somewhat resembling a mass of white thread.

Preparation and analysis as described at pp. $543,544$.

No. 2.-Barley (1858); eight seeds; prepared soil; without nitrogenous manure. (See Plate XV. fig. 5.)

April 27.-Seeds set, and the pot placed under a shade orer sulphuric acid.

May 7.-Pot removed to its shade on the stand.

IFay 20.-Fire plants 4 inches high, and one 1 inch. Were at first quite green and healthy, but the last few days turning yellowish green. 
May 22.-A pipette-ful of the sulphuric-acid solution added.

May 29.-Five plants 4 to 5 inches high, with three or four leaves each; lower ones yellow and dried up; upper pale yellowish green. A sixth plant, smaller. A pipette-ful of the phosphate-solution added.

June 7.-A pipette-ful of the phosphate-solution, and a pipette-ful of the sulphuricacid solution added.

June 19.-One plant dead; two about 4 inches high with shoots at the base; other two about 8 inches high.

June 26.-Plant (a) dead; cause not obvious. Plant (b) 10 inches high; as last year, forming stem well. Plant $(c) 8$ inches high. Plant $(d)$ a main stem which is dead, and a new shoot which is green (each 3 to 4 inches high). Plant $(c)$ a good denl like $(d)$.

July 3.-A pipette-ful of the phosphate-solution, and a pipette-ful of the sulphuricacid solution added.

July 14.-Plant (b) 9 to 10 inches high; six dried up, and two green leaves; swelling apparently for heading. Plant $(c)$ about 7 inches high; seven dried up and two green leaves. Plant $(d)$ two stems 4 to 6 inches high; six dried up and two green leaves. Plant $(e)$ two stems 4 to 6 inches high, with five dead and two green leaves.

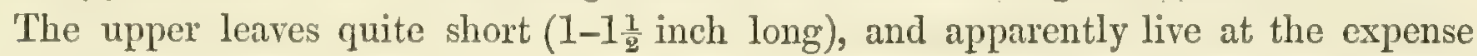
of the lower.

July 29.-Plant ( $\alpha$ ) dead; six leaves, becoming brown-yellow; a black mildew has attacked the leaves and stem; and a white gossamer-like fungus has attached itself in places to the stem and leaves. Leaves $3 \frac{1}{4}$ to 4 inches long; the upper thread-like and drooping. Plant (b) the most flourishing; 14 inches high; but very spindly; six nodes, which, with portions of the adjoining culm, especially the upper part, are dark purplish ; eight leaves; lower ones yellow, and the lowest two, which are.in contact with plant (a), affected with the mildew; all but the uppermost leaf 2 to $2 \frac{1}{2}$ inches long; the upper one $1 \frac{1}{2}$ inch long, pale green, and quite erect, apparently the last effort of the plant, no new leaves forming. Plant $(c)$, divided just beneath the soil into three shoots; two apparently suckers from the other, each 3 inches high, and dead. The main plant 6 inches high; has seven leaves; the four lower dead, and the three upper, making up half the plant, pale green; the uppermost only $\frac{1}{2}$ an inch long, in the fold of the second. Only one node risible; the culm, where seen, is purplish. The white fungus occurs, but no mildew. Plant $(d)$ much like the main plant $(c)$; evidence of early effort to put out shoots at the base. Twelve leaves; ten lower ones dead; two upper ones living; all 2 to $2 \frac{1}{2}$ inches long. Plant $(e)$ the second in size. Eleven inches high; ten leaves; eight lower ones dead, two upper ones living; all erect but the lowest two; each 2 to 3 inches long.

August 18.-Plants taken up:-

Evidently done growing; four stems swelled for head; all leaves except the uppermost dried up. Roots not much distributed; general characters much like those of barley without nitrogenous manure last year (1857). Soil moist, loose, and open.

Preparation and analysis as described at pp. 543, 544 . 
No. 3.-Oats (1858); cight secels; prepared soil; without nitroyenous menure.

(Sec Plate XV. fig. 6.)

April 27.-Sceds set, and the pot placed under a shade over sulphuric acid.

MIay 7.-Whe pot removed to its shade on the stand.

May 22.-A pipette-ful of the sulphuric-acid solution added.

May 29.-Eight plants, 4 to 6 inches high; four or five leaves each; lorrer ones yellow, upper ones green and growing. These Oats growing rather lecttex than cither No. 1 Wheat, or No. 2 Barley. $\Lambda$ pipette-ful of the phosphate-solution added.

June 7. $-\Lambda$ pipette-ful of the phosphate-solution, and a pipette-ful of the sulphuricacid solution added.

June 19.-Eight plants, 6 to 9 inches high; five or six leaves cach, lower yellow and dead, upper green. 'Tips of some of the leaves injured by action of direct sun-rays.

[General note.-White paper had been tied over all the shades to screen from the direct rays of the sun; but in this case not quite high enough.]

June 26.-Eight plants; five 10 to 11 inches high, and in head; threc 8 to 9 inches high; no appearance of heading, and two of them a green shoot at the base. Six or seren lenves on each plant. The rachis of the seeding plants long and crooked, with one or two seeds at top, without signs of seed below. All the plants apparently at termination of growth; remain only to see how far they will ripen.

July 3.-A pipette-ful of the plosphate-solution, and a pipette-ful of the sulphuricacid solution added.

\section{July 13.-Plants taken up:-}

Eight plants, quite dead ripe for some days, having had a hot sun.

Plant (1) $13 \frac{1}{2}$ inches high; five leares; rachis $1 \frac{1}{2}$ inch long, with one seed. Plant (2) $11 \frac{1}{2}$ inches high; five leaves; rachis $1 \frac{1}{2}$ inch. Plant (3) 12 linches high; fivelcaves; rachis

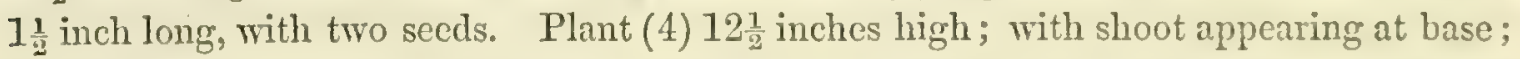
rachis $1 \frac{1}{2}$ inch long, with two seeds. Plant (5) $11 \frac{1}{2}$ inches high; fire leares; with shoot appearing at base. Plant (6) 9 inches high; five leaves; and shoot at the base, 4 inches long. Plant (7) 10 inches high; five leaves; and shoot at the base 4 inches long. Plant (8) $10 \frac{1}{2}$ inches high; five leares; rachis $1 \frac{1}{2}$ inch long, two seeds. Roots only extended about 2 inches deep in the pot. Soil wet and soft; the lower part firm, but not hard.

Preparation and analysis as described at pp. 543, 544.

No. 4.-Beans (1858); three seeds; prepared soil; without nitrogenous manure.

April 27.-Seeds set, and the pot placed under a shade over sulphuric acid.

May 20.-Pot removed to its shade on the stand. Three plants up, $2 \frac{1}{2}$ inches high; three leaves on cach; dark green and healthy.

May 22.-A pipette-ful of the sulphuric-acid solution added.

May 29.-Plants 3 to 4 inches high; one looks to be dying; the others have specks on their leaves. A pipette-ful of the phosphate-solution added.

June 7.-A pipette-ful of the phosphate-solution, and a pipette-ful of the sulphuricacid solution added to the soil. 
Tune 19.-One plant dead; another looling unhealthy; the third 4 to 5 inches high, with five leaves, growing pretty well.

June 26.-Two plants dead; the other growing, 7 to 8 inches high, with nine leaves, ench with two stipules.

July 3.- $\Lambda$ pipette-ful of the phosphate-solution, and a pipette-ful of the sulphuricacid solution added.

July 14.-The third or only surviving plant has ten leares, but looks unhealthy.

July 29.-The two dead plants fallen, moulded, and dried up. The other blackened and mouldy at the base of the stem, and thence to the top yellow; three top leares partly yellow, but the remainder black.

August 17.-All three entirely dead. Pot removed, but products not analysed, as there had not been sufficient healthy growth. It is difficult to account for this failure; but it is possibly due to the very hot weather.

No. 5.-Beans (1858); three seeds; prepared soil; without (but intended to have) nitrogenous manure.

June 11.-Seeds set in prepared soil, with ash that had been neutralized with sulphuric acid, and gently re-ignited; and the pot placed orer sulphuric acid and covered with a glass shade.

June 21. - The pot removed to its place on the stand.

June 26.-Three plants up; green and healthy; four leaves, each with two leaflets, and trro stipules. Plants delicate, but healthy green colour; one shows air-roots.

July 3.-A pipette-ful of the phosphate-solution, and a pipette-ful of the sulphuricacid solution added.

July 14.-Three plants, healthy and vigorous; 8 to 12 inches high; eight leaves on cach; a few black specks on some of the leares, otherwise healthy. The weather has been comparatively cool since planting till now; but now hotter with bright sun. A few air-roots at the base of the stems.

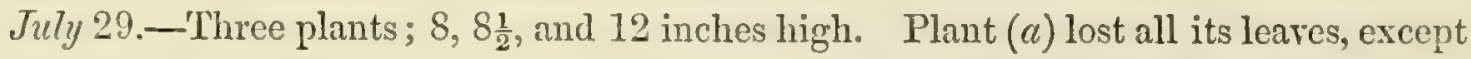
rudimentary ones at the top. A shoot 2 inches long with four small leaves about an inch from the base, more growing than the parent plant; another shoot appearing about an inch above. Plant $(b)$ very unhealthy; lost all leaves but six small and partly black ones at the top; a vigorous shoot 5 inches long, springing an inch from the base, seems to exhaust its strength; another small shoot 1 inch long, about 2 inches higher up. Plant $(c)$, most of the leares dropped; but sereral of the petioles remain, and are green; some small withering leares at the top; two shoots starting near the base.

August 17.-Three plants; the main stem of each lost nearly all the leaves. Each plant has living shoots with several leaves each near the base.

\section{August 23.-Plants taken up:-}

There has been scarcely perceptible growth for two or three weeks; leaves nearly all off. Soil moist. Roots extend only a little way, and consist of a thick mat around the 
base, much divided; none reacherd the flint; the uppere ones dead, the lower living; 1.e. root than last year.

Preparation and analysis ns described at pp. 543, 544.

No. 6.-Pea (1858); three secds; prepared soil; without nitrogenous manure.

June 5.-Three peas previously set died. 'Three more set to-day in prepared soil, with ash that laad been neutralized with sulphuric acid, and gently re-ignited; and the frot placed over sulphuric acid and corered with a glass shade.

June 7.-A pipette-ful of the phosphate-solution, and a pipette-ful of the sulphuricacid solution added.

June 19.-Pot remored to its place on the stand.

June 26.-Three plants, 6 to 7 inches high, with four leares each; not growing well.

July 3.-A pipette-ful of the phosphate-solution, and a pipette-ful of the sulphuricacid solution added.

July 14.-Three plants; doubtful whether they will live.

July 29.-Three plants; two 6 inches, and one 7 inches high; apparently dead some days, yellow, and a few spots of mould.

August 24.-Plants taken up:-

All dead for some time past; probably owing to the heat. Products submitteci to analysis, but the results can only be of confirmatory ralue.

No. 7.-Buckwhent (1858); sech, 1 gramme; prepaied spil; without nitroyenous manure.

August 20.-Seed sown, and the pot placed orer sulphuric acid, and corered with a glass shade.

August 24.-Remored to its shade on the stand. Sereral plants up.

September 7.-Growing well.

October 5.-Sixteen plants, 2 to 4 inches high, four to six leares each.

October 24.-Eighteen plants, 3 to 4 inches high, with four to six leares each; leares

$\frac{1}{3}$ to $\frac{3}{4}$ inch wide, but hare begun to look yellow and curl up; some plants dead. The plants appear to have attained their maximum growth without nitrogenous manure.

October 28.-Plants taken up:-

Eighteen plants with four to six leares each, including the scminal opposite ones; 2 to 3 inches high ; obriously done growing; only five or six with green leares remaining. Roots only 2 to 3 inches long, slim, delicate, and rery little distributed. Soil quite loose, porous, and friable.

Preparation and analysis as described at pp. 543, 544.

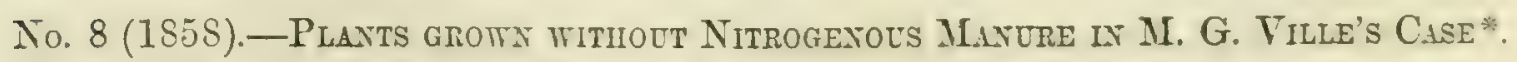

II. VILle kindly forwarded porous pots, and glazed white pans to set them in, such

* The experiments conducted in MI. G. TILLE's cases mere commenced later in the season than those with the shades, as we waited some time in the hope that MI. VILLE might be able to come orer and superintend the arrangement himself. 
as he used in his experiments; but as too many were broken in transit to use these entirely, it was decided to use pots and pans the same as for our other experiments in 1858. The soil, ash, \&c., were also prepared in the same way as for the other experiments of 18j8-the ash, however, being saturated with sulphuric acid and re-ignited before being used, as in a few only of the other cases; for description, see pp. 470-4i2.

Pot 1-Wheat; eight seeds.

Pot 2-Barley; eight seeds.

Pot 3-Oats; eight seeds.

Pot 4-Beans; three seeds.

June 11.-Wheat, Barley, and Oats; seeds set, and the pots placed orer sulphuric acid, and covered with a shade.

June 12. - The three pots removed to M. VilLE's Case.

June 19.-Wheat, Barley, and Oats all up, and looking green and healthy.

June 25.-Cereals all about the same size, with three leaves each; wheat quite pale, barley and onts green at the top, and lower leares dead.

The Case ras opened, and the pot of three beans put in.

July 1.-Wheat pale and blanched; barley and oats, lower leaves dead, upper ones green and growing.

July 3.-All the Cereals getting quite pale; beans healthy.

July 14.-Bean, three plants up; two cotyledons and two leaves on each, healthy. Wheat, seven plants; 4 to 6 inches high; four leaves on each, upper green, lower dead: Oats, seven plants; very like the wheat; but little more disposition to form stem. Barley, eight plants; much like the oats.

August 2.-Beans, 4 inches high; lower leaves dead, and show a white mould; small stems putting out languidly. Barley, eight plants; 4 to 5 inches high; lower leares yellow and dead; upper blades green; stems appear mouldy. Oats, seven plants about o inches high; lower leares deal and mouldy; upper part of stem green, and slightly swelled as if going to head. Wheat, very much like the barley.

August 17.-Cereals appear to have nearly done growing; beans dying.

September 7.-Beans dead. Wheat green at the tops, but dead below; 4 to 6 inches high; about ten leaves each. Oats nearly dead. Barley nearly dead.

October 24.-Wheat still green at the top; oats and barley dead. Beans dead (not analysed).

November 6.-Plants taken up. Notes as under:-

Wheat. Seven plants; 4 to 5 inches high; no nodes visible; little tendency to form stem; lowrer leares dead; top leaf green, and on some the next greenish yellow. Soil moist. Very little root.

Oats. Seven plants, 4 to 6 inches high; about sir leaves each; generally four nodes visible; most forming head. Roots but little distributed; very little below $1 \frac{1}{2}$ inch; ferwer and more slender than those of the wheat. All the plants dead or ripe, but not decomposed; the stems firm and elastic.

Barley. Eight plants, 4 to $0 \frac{1}{2}$ inches high; two to four nodes risible in all; six or 
seren leares on each; most have a leaf-like heading stretching upward; l, wer lea:e

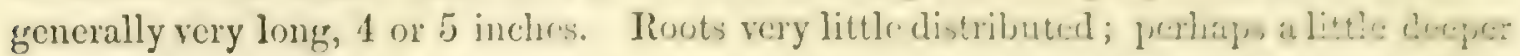
than the oats; but few deeper than $1 \frac{1}{2}$ to 2 inches. Soil dry, loose, and porous; flints quite open.

Wheat, Oats, and Barley prepared and analysed as described at pp. $5.13,5.14$.

Plants grown in 1858, with a supply of combined Nitrogen beyoun that contringed in the seed sown.

No. 9.-Theat (1858); four seeds; prepared soil; with nitrogenous manure.

(See Plate XV. fig. 10.)

April 27. Seeds set, and the pot placed over sulphuric acid, and covered with a glass shade.

Ifay 20.-Four plants up; healthy, green, and groming; about 4 inches high; very similar to Wheats No. 1 of this date.

IIay 22.-A pipette-ful of the sulphate-of-ammonia solution (=0.00.1 gramm: X.) added to the soil.

Mray 29.-Four plants, from 4 to 6 inches high. Greener and fresher since the addition of the ammonia-solution; new shoots appearing; only the lowest leaf on cach yellow. A pipette-ful of the phosphate-solution added.

June 7.-Second pipette-ful of the sulphate-of-ammonia solution added; and a pipette-ful of the phosphate-solution.

June 19.-Four plants; one with four shoots or stems, and two others with tro stems each; in all nine stems or plants; 5 to 7 inches high; leares more healthy; green and vigorous.

June 21.-Third pipette-ful of ammonia-solution added. Plants had begrun to show the want of available nitrogen.

June 26.-Fourtl pipette-ful of the ammonia-solution added. As intimated Mar 24: the ammonia tends much to new shoots from the base. The four seeds hare girenNo. 1, one stem, with seven leaves: No. 2, two stems, each with sir leares: No. 3, three stems, each with five or six leaves: No. 4, four stems, with four, five, or six leaves each: in all ten stems. The two lowest leaves dead, the others green and rigorous. More regetable matter from these four seeds, with ammonia, than from the eight (No. 1 Wheat) without it. Plants 8 to 11 inches high, and improve with each addition of ammonia.

July 1. - The shade slightly cracked at the bottom during the night, but still sufi:ciently air-tight for changes of temperature to affect the level of the sulpluuric acid in tine bulb-apparatus. Shade replaced by a small one temporarily. An inmaterial amount of condensed water lost. Many roots found to be distributed through the bottim of the pot, and growing in the dish beneath it.

July 3.-Fifth pipette-ful of ammonia-solution added. [It is intended that none of the plants shall suffer so much for want of combined nitrogen, as in 1857.] Also a pipette-ful of the phosphate-solution added.

July 12.-Sixth pipette-ful of ammonia-solution added. 
July 14.-Serenth pipette-ful of ammonia-solution added. Details of growth from the four seeds as follow:-

No. 1, one stem only, 8 to 10 inches high; three upper leaves green and vigorous; four lower yellow. No.2, three stems: (a) 3 to 4 inches high, two yellow and two green leaves; ( $b$ ) 4 to 6 inches high, two yellow and two green leaves; $(c) 12$ to 14 inches high, three yellow and three green leares. No. 3, three stems: (a) 4 to 6 inches high, two yellow and two green leaves; (b) 8 to 10 inches high, two yellow and three green leares; (c) 13 to 15 inches high, two yellow and three green leaves. No. 4, four stems, 8 to 10 inches high, three yellow and three green leaves each.

The "yellow" leares are small ones at the base, developed before ammonia was added, and are dead. The ammonia strikingly developes the new shoots, and their leares are much larger. As last year, much more tendency to form leaf than run to stem. The height given abore includes that of the erect leares extending abore the ascending axis.

July 19.-Eighth pipette-ful of ammonia-solution added.

July 29.-Ninth pipette-ful of ammonia-solution added. The following details will show how dependent is the development upon the proximity to the mouth of the tube by which the ammonia-solution is applied.

No. 1 (furthest from the tube), one stem strong and rigorous at the base, and 13 inches high. No. 2 (third from the tube), three stems; one 12 to 13 inches high, the others smaller. No. 3 (second from the tube), five stems; three 12 to 13 inches high, and two new ones 1 to 2 inches high. No. 4 (nearest the tube), seven stems; four 8 to 13 inches high, and three new ones 1 to 3 inches high.

All upper leaves green and vigorous, most of the lower yellow and dead; some of the shoots entirely green.

August 10.-Tenth pipette-ful of ammonia-solution added.

August 17.-Eleventh pipette-ful of ammonia-solution added (a new solution, the pipettc-ful $=0.00359$ gramme N.).

Recently, much more disposition to form stem; several plants from 18 to 30 inches high; nodes clear of the sheaths. Comparing with the Wheat without ammonia, which also tends more to stem of late, it appears that the amount of growth is due to the supply of combined nitrogen, and its character (stemmy) more to the season.

August 26.-Twelfth pipette-ful of ammonia-solution added.

September 7.-Thirteenth pipette-ful of ammonia-solution (the last application; in all, 0.0508 gramme N.) added. Growth from each seed as under:-

No. 1 (furthest from the ammonia-solution tube), one stem 23 inches high; twelre leares; tro nodes clear; slight indication of heading.

No. 2 (third from the tube), one main stem growing, and two shoots dead; main stem 23 inches high; three upper leaves green, six lower ones yellowish; not heading yet.

No. 3 (second from the tube), three stems; two like "No. 2"; the third 12 to 14 inches high; little tendency to form stem, but long leaves from the axis.

No. 4 (nearest the tube, some of the roots washed when the solution, or water, is MIDCCCLXI.

4 II 
added), two stems and five small shoots:-( $\alpha$ ) highest leaf touches the trop of thre shrer? and 3 inches of it lie aratinst the wot grass, by which it is injured ; ten leaves ; threes fare nodes; (b) $2: 3$ inches high; nine laves, three npler green, others yrollowish; rordea not clear of the sheath; not hrading yet; $(r)$ three small stems from the baer, fo to 8 inchess high, ceased to grow, and apparently dying; (d) two small rudimeritary shesets; creaned to grow, and dying.

Main stems-lower leaves yellow or dearl; those startiner a frow inches from the sril numerous, and 12 to 16 inches long; those higher up, 4 to 6 inches long, green, and healthy; apparently incapable of supporting all the shoots started.

October 5.-1'lants principally increasing in height of stem; three touch the top of the shade; upper leaves green. Shaded from the direct sun to prevent injury from the little aqueous lenses formed on the interior of the shade; yet sun apparently wanted for ripening.

October 24.-Shade cntirely full of vegetable matter, some stems touching the top, and leaves touching on all sides. Season for growth about orer; plants secmed stationary during some recent cold weather, but, the last few days being warmer, they have revived again. [This remark applies to all the Cereals.]

October 26.-Plants taken up; produce from each seed as under:-

No. 1 (furthest from the ammonia-solution tube), a mass of tufted leares at the base; five leaves higher up below any visible node, formed before the plants began to run up stem (it was the same with the other plants, and with the leafy growth last year); higher up five more leaves, four visible nodes, and a head; total height 30 inches; rachis $1 \frac{1}{2}$ inch; three barren joints, and six with unripe seeds.

No. 2 (third from the tube), two dead shoots at the base, with sereral leares each; twelve leaves higher up on the main stem, lower ones 6 to 9 inches long, upper ones shorter; four nodes visible; total height 28 inches; rachis $1 \frac{1}{2}$ inch long, three barren joints, and six with glumes and pales, but still green.

No. 3 (second from the tube), three stems: $(a) 6$ inches high; ten long narrow leaves; stem dead. (b) 24 inches high; fourteen leaves below the first node, and three higher up; two nodes visible; plant still growing and vigorous. (c) Height 31 inches; twelve leaves below the first node, and three above it; swelled at the top with a head not yet out.

No. 4 (nearest the tube), seven plants-five being small shoots 2 to $S$ inches high, and two main stems. As mentioned in respect to No. 1, and applicable pretty generally to the Cereals with ammonia, a dense matted mass of leaves below the first node near the base, 8,12 , and 15 inches long, with thick sheaths forming a dense coat at the base of the stem. These plants are individually as follow:-(a) 28 inches high; three nodes; rachis two inches long, with five barren joints, and scren with glumes and pales, and seeds forming, green. (b) 35 inches high; four visible nodes; rachis $2 \frac{1}{2}$ inches long, with five barren joints and seven with glumes and pales, and shrivelled seeds turning yellow:

The soil wet, soft, and loose, and not filling up the interstices among the flints. 
The roots tolerably distributed throughout the whole pot, though not extending much to the sides, but passing through all the holes at the bottom, and some at the sides, of the pot, and forming a dense matted mass underneath it in the pan. Those of the plants nearest to the watering and manuring tube have sent by far the most roots domnwards into the pan,- - those furthest from it having their roots proportionally much more confined in the soil near the base of the plant, where they are much matted, with divaricate branches and short branchlets-these characters being more nearly those of the Cereals grown without nitrogenous manure.

Preparation and analysis as described at pp. 543, 544 .

No. 10.-Barley (1858); four seeds; prepared soil; with nitrogenous manure. (See Plate XV. fig. 11.)

April 27.-Seeds set, and the pot placed over sulphuric acid, and covered with a glass shade.

MTay 7.-The pot removed to its shade on the stand.

May 20.-Two plants up.

Mary 22. - A pipette-ful of the sulphate-of-ammonia solution (=0.004 gramme N.) added to the soil.

May 29.-Two plants; 4 to 6 inches high; five leaves on each, the lowest dead, the others green; improved since the addition of ammonia, more active growth and colour deeper green. A pipette-ful of the phosphate-solution added.

June 7.-Second pipette-ful of the sulphate-of-ammonia solution added; also a pipette-ful of the phosphate-solution.

June 19.-Two plants; 10 to 12 inches high, forming stem well; each plant seven leaves; one stem has a small shoot forming at its base.

June 21.-Third pipette-ful of the sulphate-of-ammonia solution added.

June 26.-Fourth pipette-ful of the sulphate-of-ammonia solution added. Two plants; 16 to 18 inches high, healthy and vigorous; eight leaves each; also each a vigorously growing shoot 4 to 5 inches long.

July 3.-Fifth pipette-ful of the sulphate-of-ammonia solution added; also a pipette-ful of the phosphate-solution.

July 12.-Sixth pipette-ful of the sulphate-of-ammonia solution added.

July 14.-Seventh pipette-ful of the sulphate-of-ammonia solution added. Two plants, namely, -

No. 1. (a) Main stem, 26 inches high; lower leaves ripe or dead, and yellow, upper ones green and growing; beard just appearing at the head. (b) Shoot, 18 inches high ; three ripe or dead leaves, and three green.

No. 2. (a) Main stem, 28 inches high; lower leaves ripe or dead, four upper ones green; air-roots developing. (b) Shoot, 12 to 14 inches high; one dead, and four green leaves. (c) Shoot, 4 to 6 inches high; one dead, and three green leaves.

July 19.-Eighth pipettc-ful of the sulphate-of-ammonia solution added. 
July 28.-Ninth pipette-ful of the sulphate-of-ammonia solution added.

July 29.-Only two of the seeds germinated; plants as follow:-

No. 1. (a) Main stem, out of the ground single, and then gives off $(b)$ and $(c)$; is 22 inches high; lower leaves dearl, and lowest shows a fungous growth; six air-arot. (two still growing) from first joint or print of sepruation; five nodes, early giving at leaf. conly the top one green; head bursting forth. (b) 28 inches high; five nodes, with leaves, upper two only growing; stem slim below and thicker higher up; awns of head appearing. $(c) 5$ inches high; two leares; fresh and green.

No. 2. More vigorous than No. 1, and livelier colour; leares the ground single; half an inch up divides, and also gives off roots which go into the soil; three-quarters of an inch higher a second shoot, and more roots given off; one reaches the sril, two grrowing downwards, and several withered; lowest leaves dead and show fungous errowth, particularly where they lie on the soil.

Angust 17. -Tenth pipette-ful of the ammonia-solution added (new solution $=0.00359 \mathrm{~N}$ ). Plants growing rigorously under the influence of the ammonia; nearly at the top of the shade; several heads appearing.

August 24.-Eleventh pipette-ful of the ammonia-solution added.

September 7.--Twelfth pipette-ful of the ammonia-solution added.

October 5.-Plants ripening; seven stems with heads; lower leaves of each dead or ripe, and two or three upper ones of each green. Some new shoots appearing at the base.

October 24.-Three heads green, the others ripe.

October 26.-Plants taken up:-

Only two seeds grew, and gave plants as follow:-

No. 1. Stem divided a little above the surface of the soil, giving plant $(a)$, and an inch higher up divides again, giving $(b)$ and $(c)$; below the first point of separation the stem scarcely thicker than a pin, hard and solid. (a) 34 inches high; six risible nodes; stem below the lowest rery thin and hard, but larger, soft and succulent higher up; head 3 inches long, having sixtcen joints, with glumes and pales, and awns 4 to 6 inches long; two ripe plump seeds, and others shrivelled up. (b) 28 inches high ; fire nodes; below the lowest stem hard, firm, dry, and almost solid, and but little thicker than a pin; stem higher up larger, but still quite delicate; head $1 \frac{1}{2}$ inch long, with three joints barren, and seren with glumes, pales, and long awns, but no seed. (c) 30 inches high; five nodes; lower part of stem not quite so thick as $(a)$ and $(b)$; head ripe; rachis $2 \frac{1}{2}$ inches long, with two joints barren, and thirteen with glumes, pales, and awns; also some shrivelled seeds.

No. 2. Stem to $1 \frac{1}{2}$ inch abore the soil little thicker than a pin, quite solid, and firm; then a thick and bunchy node and six stems. Stem $(a) 18$ inches high to rachis; four nodes; four leares; crooked rachis $1_{4}^{1}$ inch long, with three joints barren, and seren with glumes, pales, and awns. (b) 21 inches high to head; rachis $2 \frac{1}{2}$ inches long, with three joints barren, and thirteen with glumes, pales, and long awns; four nodes; five 
leaves. (c) green; $2 \frac{1}{2}$ inches high, and still growing. $(d),(e)$, and $(f)$ about 25 inches high to rachis; each with four or five nodes; rachis $1 \frac{1}{2}$ inch long, with three or four joints barren, and nine or ten with glumes, pales, and some green seeds.

The Root-development of these Barley plants was rery extraordinary. Plant No. 1 has about ten roots coming from the first node or point of separation, extending dcep into the soil, and some even through the bottom of the pot; roots also come out from the next joint above, on each of the separate stems, but these do not reach the soil. Plant No. 2, from the first joint, whence spring the six stems, throws out more than a dozen small roots, five of which reach the soil and ramify in it, some of the ramifications going down into the pan. The roots starting within the soil not so much matted near the base of the stem as those of the Wheat; a good many go down and ramify amongst the flints, or go through into the pan; they are finer, and not so much blunted and divaricated as the Wheat roots. For illustration of the curious root-development of the barley plant, see Plates XV. fig. 16.

Soil dry, loose, and porous.

Preparation and analysis as described at pp. 543, 544.

No. 11.-Oats (1858); four seeds; prepared soil; with nitrogenous manure. (See Plate XV. fig. 12.)

April 27.-Seeds set, and pot placed over sulphuric acid, and covered with a glass shade.

May 7.-The pot remored to its place on the stand.

May 20.-Three plants up; 4 to $4 \frac{1}{2}$ inches high; two leares each; green and healthy.

May 22. - A pipette-ful of the sulphate-of-ammonia solution added ( $=0.004 \mathrm{grm}$. N.).

May 29.-'Three plants; 5 to 7 inches high; four or five leaves each; two lowest dead, three uppermost green and growing. These plants have increased the most of any since the addition of ammonia. A pipette-ful of the phosphate-solution added.

June 7.-Second pipette-ful of the sulphate-of-ammonia solution added; also a pipette-ful of the phosphate-solution.

June 19.-Three plants; 10 to 14 inches high; six leaves each; apparently somewhat injured by hot sun the last few days.

June 21.-Third pipette-ful of the sulphate-of-ammonia solution added.

June 26.-Fourth pipette-ful of the sulphate-of-ammonia solution added. Three plants, 12 to 14 inches high. No. 1, head dereloped and obviously seeds forming; one shoot 1 inch, and one 4 inches long from the base. No. 2, head forming; two shoots from the base 4 to 5 inches long. No. 3, much like No. 2. Growth of main stems apparently checked and that of shoots increased by some recent hot weather; in all, six shoots; green, healthy, and promising further growth.

July 3.-Fifth pipette-ful of the sulphate-of-ammonia solution, also a pipette-ful of the phosphate-solution added.

July 12.-Sixth pipette-ful of the sulphate-of-ammonia solution added. 
July 14.-Serenth pipette-ful of the sulphatrof-ammonia solution addecl. Plarts as follow:-

No. 1. 'Two stems; one ripe, with two or three seeds; six leaves, lowest dead ripe, and five green. 'The other stem 12 to 14 inches high; green; forming head.

No. 2. Three stems, from 12 to 15 inches high. One stem swelled at the top with a

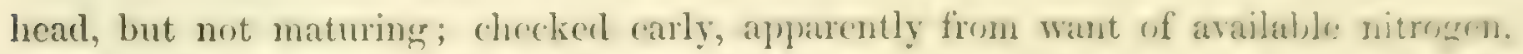
after which the ammonia aded developed the two shosts, whose stems are gren, with one dead and four green leaves, and heads forming.

No. 3. 'Two stems; one 8 to 10 inches high, dead or ripe; the other 14 to 15 inches high, green and healthy.

July 30.-The plants taken up:-

The experiment stopped rather prematurely, the shade getting slightly cracked. Thr plants had manifested three orders of growth, as follow:-

(1) The first growth, which was forming head when a fresh supply of ammonia rare: rise to shoots at the base. (2) The abore shoots gare three headed stems: one with three full and two imperfect seeds; one with two full and one imperfect seed; and one with one full and two imperfect sects. (3) New shoots from the base on the further addition of ammonia; green and healthy at the close, but promising to go to seed.

The roots were very little more distributed than those of the Oats without nitrogenous manure in No. 3 shade, and only extenderl about half the depth of the pot. The soil was wet and soft.

Preparation and analysis as described at pp. 543, 544.

No. 12.-Beans (1S58); three seeds; prepared soil; with nitrogenous manure.

April 27.- Sceds set, and the pot placed over sulphuric acid, and covered with a glas shade.

May 20.-Pot removed to its shade on the stand. Three plants up; 21을 inches high; three leares on each, colour dark green; healthy.

May 22.-A pipette-ful of the sulphuric-acid solution added.

MFay 29.-Three plants; one dead, one much specked, the third improring. A pipetteful of the phosphate-solution added.

June 7.-A pipette-ful of the sulphate-of-ammonia solution added; also a pipetteful of the phosphate-solution.

June 19.-All apparently dying; leares much specked with black.

June 21.-Plants all obviously past recorery; removed but not analysed.

No. 13.-Peas (1858); three seeds; prepared soil; with nitrogenous manure.

April 27.-Seeds set, and the pot placed orer sulphuric acid, and corered with a glass shade.

May 20.-Pot remored to its shade on the stand. Three plants up, groming exceedingly well; $3,2 \frac{1}{2}$, and 1 inch high; three, two, and two leares, respectirely. 
May 22.-A pipette-ful of the sulphuric acid solution added.

May 29.-One plant dead; another sickly; the third has given off shoots 3 to 4 inches high, which appear healthy. A pipette-ful of the phosphate-solution added.

June 7.-A pipette-ful of the sulphate-of-ammonia solution ( $=0.004$ gramme $\mathrm{N}$.) added; also a pipette-ful of the phosphate-solution.

June 1.9. - Two plants dead; the third has two green shoots, 3 and 5 inches high, but delicate.

June 26.-The two shoots growing languidly; seven leaves each; also some leaflets.

July 3.-A pipette-ful of the phosphate-solution added.

July 14.-Main shoot 12 to 13 inches high; four lower leaves dead, four upper green; two shoots at the base dead, and one green and thriving.

July 29. -The two dead plants entirely prostrate, and near one a pale.green moss formed on the surface of the soil. The third plant has three dead branches, and one about 6 inches high with green leaves at the top.

August 17.-All the plants dead.

August 24.-Plants taken up, and submitted to analysis, although the growth so unsatisfactory. Of course, of themselres, the results can have little weight in reference to the question at issue.

No. 14.-Clover (1858); 226 seeds; prepared soil; with nitrogenous manure.

Two pots of Clover had been sown at the same time as the other plants, one to be without, and the other with nitrogenous manure. They came up well, but very soon died; and on June 6 two more pots were sown in the same manner as before, excepting that the ash was neutralized with sulphuric acid, and re-ignited before being mixed with the soil ; both also had a pipette-ful of the phosphate-solution, and the one that was to have nitrogenous manure a pipette-ful of the ammonia-solution, at the time of sowing the seed. The one sown without the ammonia-solution failed so soon that the experiment was abandoned early; the other (with the ammonia) forms the subject of the following record.

Jine 6.-Seeds set as abore, in soil with neutralized ash, and both phosphate and sulphate-of-ammonia solution added*

June 19.-A good deal up; actively and healthily growing.

June 21.-Second pipette-ful of the sulphate-of-ammonia solution added*.

June 26. - Third pipette-ful of the sulphate-of-ammonia solution added. Plants quite green and healthy.

July 3.-Fourth pipette-ful of the sulphate-of-ammonia solution added; also a pipetteful of the phosphate-solution.

July 12.-Fifth pipette-ful of the sulphate-of-ammonia solution added.

July 14.-Sixth pipette-ful of the sulphate-of-ammonia solution added. Surface of

* It is not quite certain that the ammonia-solution was added at this date; and in the Table of the results (XIV.p. 531) it is assumed that it was not. 
the soil covered with plants, growing well; 3 to 4 incless high, with two or these thifolinte leaves cach.

July 19.-Serenth pipette-ful of the sulphate-of-ammonia solution added.

July 28.--Lighth pipette-ful of the sulphate-of-ammonia solution added.

July 29.-The plints growing, but not vigorously; some black and drarl, and woms: withering leaves; some petioles more than 4 inches long.

August 10.-Ninth pipette-ful of the sulphate-of-ammonia solution added.

August 17.-'T'enth pipette-ful of the sulphate-of-ammonia solution added (now solletion $=0.00359$ gramme N.). Green and growing well; twenty to twenty-five stems 1 to 6 inches high; a good many roots abore ground.

September 7.-Eleventh pipette-ful of the sulphate-of-ammonia solution arlderl. Large strong roots visible; numerous leaves from the base; not much derelopment of stem; length of petioles 3 to 5 inches.

October 5.-Twelfth pipette-ful of the sulphate-of-ammonia solution added. Not growing much, yet not dying; stems becoming bushy.

October 24.-Many of the lower petioles and leaves dead, and some a little mouldy; from the base of the dead petioles generally spring a number of green leares, and petioles 2 to 4 inches long bearing green leaves; which look healthy; but almost stationary from day to day.

October 26.-Planits taken up:-

Twenty-one plants; much as at last date.

Roots somewhat matted at the base, and throughout the surface of the soil; extending 2 to 3 inches through the soil, and some to the inner sides of the pot; none among the flints, or in the pan under the pot.

Soil rather wet, loose, and porous.

Preparation and analysis as described at pp. 543, 544 .

No. 15 (1858).-Wheat, Barley, Oats, Beans, Peas, and Clorer, in a pot of Gurlen soil.

May 20.-Some of the plants just coming up.

Mlay 29.-Wheat, Barley, and Oats, 6 to 8 inches high; Beans 4 to 6 inches high, with some specks on the leares; Clorer up and growing. The condensed water yellowish, and gires a yellowish-green deposit.

June 19.-The pot full of green herbage. Wheat, Barley, Oats, and Beans, all healthy and growing well; Peas 3 to 4 inches high; Clorer 2 to 3 inches, with three leaflets.

June 26.-Wheat and Barlcy touch the top of the shade, and the plants crowded; Clover 3 to 4 inches high.

July 14. - Shade full of growing matter. Wheat and Barley just heading.

Angust 2.-The Oat heading, with two grains; Wheat growing, but the ends of some of the leares dying. The two Beans quite black and dead. Several kinds of weed come up; two in bloom. 
August 17.-Shade full of vegetable matter. Wheat, Barley, Oats, and weeds growing; but Leguminous plants dead.

September 7.-A good deal of growth yet.

October 5.-A good deal of grass and weeds growing. Cereals ripening.

October 24.-Shade full; experiment stopped. Wheat not quite ripe. Barley and Oats dead ripe; Beans and Peas all dead; a little Clover still living; some grass, and other wceds, green, and some seeded. The whole soil filled with roots, many distributed through the flints, and a large quantity growing in the pan under the pot.

\section{No.16.-Buckwheat (1858); forty-two seeds (1 gramme); prepared soil; with nitrogenous manure.}

August 20.- Seed sown, and the pot placed over sulphuric acid, and covered with a glass shade.

August 24.-Pot removed to its shade on the stand. Several plants up.

September 7.-A pipette-ful of the sulphate-of-ammonia solution added $(=0.00359$ gramme N.). Plants growing well.

October 5.-Second pipette-ful of the sulphate-of-ammonia solution added. Much more vigorous than the Buckwheat without ammonia (No. 7); about twenty plants; 5 to 7 inches high; four to six leaves on each.

October 24.-Third pipette-ful of the sulphate-of-ammonia solution added. Growing well; 5 to 7 inches high; six plants in bloom. Comparing with No. 7, the influence of ammonia here is very marked, as shown in size, vigour, and maturation.

November 22.-Plants taken up:-

Twenty-four plants; 4 to 7 inches high; five to seven leaves on each; six stems have flowered; bloom gone off and rudimentary seed formed; would probably have grown more but for frost.

Roots less in proportion to upward growth than with Buckwheat without ammonia; none deeper in the soil than $1 \frac{1}{2}$ to 2 inches; slim, delicate, and but little distributed.

Soil loose and porous.

Preparation and analysis as described at pp. 543, 544.

No. 17 (1858). - Plants arown with Nitrogenous Manure in M. G. Ville's Case.

The same descriptions of pot, pan, soil, ash, \&c., were used for these experiments as for the others, as explained at page 565. Plants as under:-

Wheat, four seeds; Barley, four seeds; Oats, four seeds; Beans, three seeds.

June 29. - Seeds set, and the pots placed over sulphuric acid, and covered with a glass shade.

July 5.-Pots removed to M. VILLE's Case.

July 14.-A pipette-ful of the sulphate-of-ammonia solution given to each pot ( $=0.004$ gramme N.). Wheat, four plants just appearing; Barley, three plants $1 \frac{1}{2}$ inch MDCCCLXI. 
high; Oats, two plants just appearing; lyeans, one plant 4 inches high, two rethero just appearing.

July 19.-Second pipette-ful of the sulphate-of-ammonia solution tre sarth prot.

July 28.-Third pipette-ful of the sulphate-of-ammonia solution to each jrot ef (ereals.

August 2.-Wheat, four plants; 7 inches high; extremities of some of the leaves dying. Barley, three plants; two 9 inches, and one 7 inches high; two lower leaves of each yellow, remainder green. Oats, two plants; 10 inches high; the lowcr leaf of each dead, and the tips of some of the others turning yellow. Beans, two plants up; one 8 , and the other 6 inches high.

August 17.-Fourth pipette-ful of the sulphate-of-ammonia solution ardad (new srilution, $=0.00359$ gramme N.). All the plants growing luxuriantly. Wheat, abuut 14 inches high; Barley and Oats, 8 to 12 inches high; Beans, 9 and 12 inches high.

September 7.-Fifth pipette-ful of the sulphate-of-ammonia solution added.

Wheat, four plants; (a) 14 inches high with ten leaves; (b) 13 inches high with nine leaves; (c) 15 inches high with ten leaves; (d) 11 inches high with ten leaves.

Barley, three plants; (a) 23 inches high with eleven leaves; (b) 14 inches high with ten leaves; $(c) 25$ inches high with eleven leaves.

Oats, two plants; ( $a$ ) 26 inches high with seren leares; ( 6$) 29$ inches high, nine leares.

Beans, two plants; main stems dead, but new shoots growing.

October 5.-Wheat, four healthy and vigorous plants; (a) 14 inches high; two green and eight dead leaves; $(b) 14$ inches high; two green and seren dead leares; (c) 15 inches high; two green and eight dead leares; (d) 11 inches high; three green and eight dead leaves.

Barley, three plants; two healthy and vigorous, and one less so; (a) 24 inches high; three green and eight dead leaves; (b) 18 inches high; three green and seren dead leaves; (c) 28 inches high; three green and eight dead leares.

Oats, two healthy and vigorous plants, in ear; (a) 30 inches high; two green and five dead leaves; (b) 30 inches high; two green and seven dead leares.

Beans, two plants; (a) 9 inches high with three branches; (b) 14 inches high with three branches.

October 24.-Wheat, four plants, erect and firm; much as on October 5, but larger; no nodes visible; but little tendency to form stem. Barley, much as on October 5. Oats, much as on October 5. Beans, apparently ceased to grow.

Sixth pipette-ful of the sulphate-of-ammonia solution added. Wheat, four plants, 14 to 18 inches high; stems stout and erect, but without visible nodes; very leafy. Barley, four plants, just coming to car. Oats, two plants, main stems touching the top of the Case; $(a)$ has a shoot 22 inches long springing from the first node 2 inches from the soil, and coming into head; $(b)$ has three small shoots, one $\frac{1}{2}$ inch and one $1 \frac{1}{2}$ inch long, springing from the base, and one 3 inches long from the furst node. Beans, slightly revired since the last report. 


\section{Notes on taking up the Plants.}

Wheat taken up December 9.-The four plants all about the same size; strong, healthy, and vigorous; ten to twelve long dead leaves each, 8, 10, or 12 inches long, closely compacted one abore another at their base, and two or three green flourishing leaves each at the top. Roots very thick and matted at the base, extending immediately around in all directions, with short rootlets covered with divaricated branches, filling the upper layers of soil; not many extend more than $2 \frac{1}{2}$ inches down, very few go through the bottom of the pot into the pan, and none ramify there. Soil loose, porous, and moist; and some water in the pan.

Barley taken up December 9. -Three plants; (a) 29 inches high, with a small shoot (second growth) 1 inch long, from the base; fifteen leaves, two top ones green and growing; swelled at the top with a head forming; (b) 20 inches high; thirteen leaves, upper ones green and growing; and indications of head forming; $(c)$ much like $(a)$ in height, leares, and shoot; a short air-root from the first node. Roots the same character in all; branched, considerably matted at the base, finely divided with numerous little divaricate branchlets; only a few extend down into the pan, and they do not ramify in it. Soil loose, open, porous, and moist; some water in the pan.

Oats taken up December 9.-Two plants:-(a) with two stems; one 32 inches high, eleven imperfect seeds, and seven leares; the other 26 inches high, coming from the second node 2 inches up the main stem, with twelve seeds; six or eight air-roots 1 to 2 inches long, coming from the base node; a shoot an inch long from the lowest node, and another lower down at the base. (b) A main stem with two long branched ones; main stem 32 inches long, with five leaves and teh undeveloped seeds without solid nucleus; one branched stem, from the third node, 3 inches up the main stem, 14 inches long, with three leaves, still green and growing; the other branch from the base of the main stem 10 inches long, green and growing; some air-roots 1 to 2 inches long come from the base of the largest branch, also several from the next node below, one or two of which extend to the soil and ramify in it. There is also another small branch 2 to 3 inches long coming from the base of the plant and still green and growing. Roots much alike in both; considerably matted at the base, little distributed, extending 3 or 4 inches in the upper parts of the soil, with many small divaricate branches; no roots in the pan. Soil loose, porous, and moist; and some water in the pan.

Beans taken up December 9. - Two plants, with eight or ten leaves each; one 9 inches, the other 14 inches high; both dead. The roots of both very much branched at the base of the stem, but not extending deep into the pot, none going down to the flints.

The Wheat, Barley, Oats, and Beans, prepared and analysed as described at pp. $543,544$. 


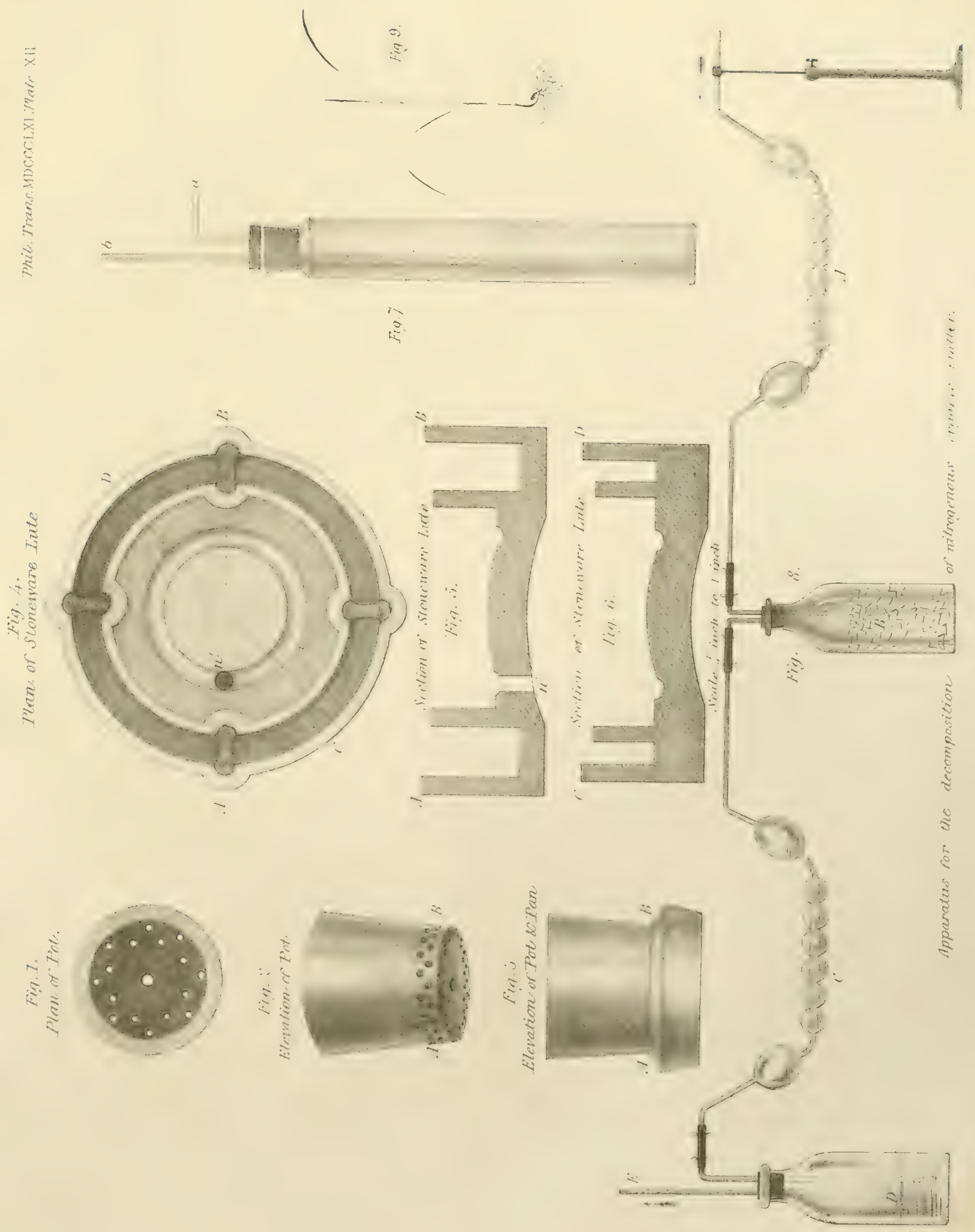



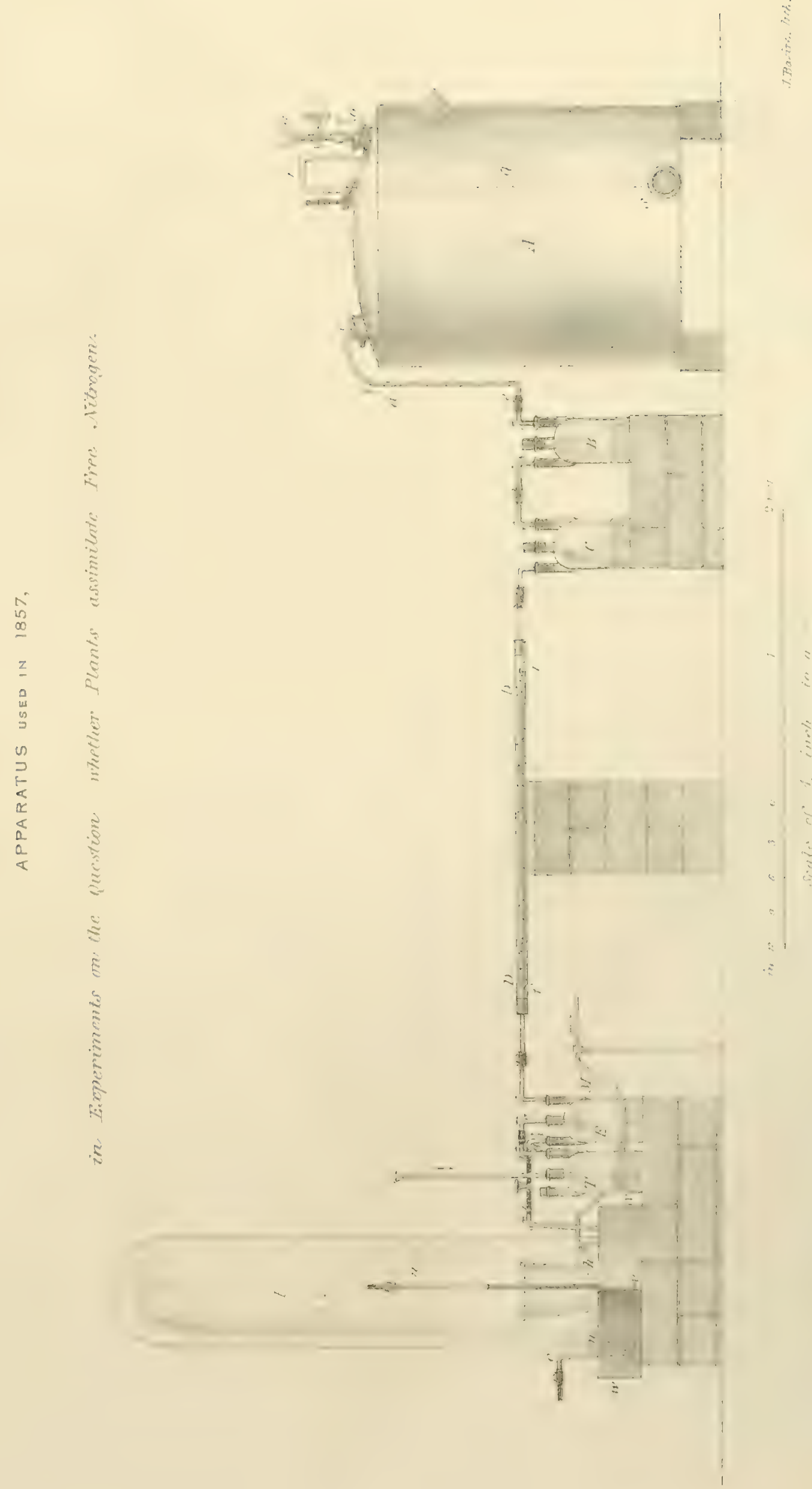



ऐ)

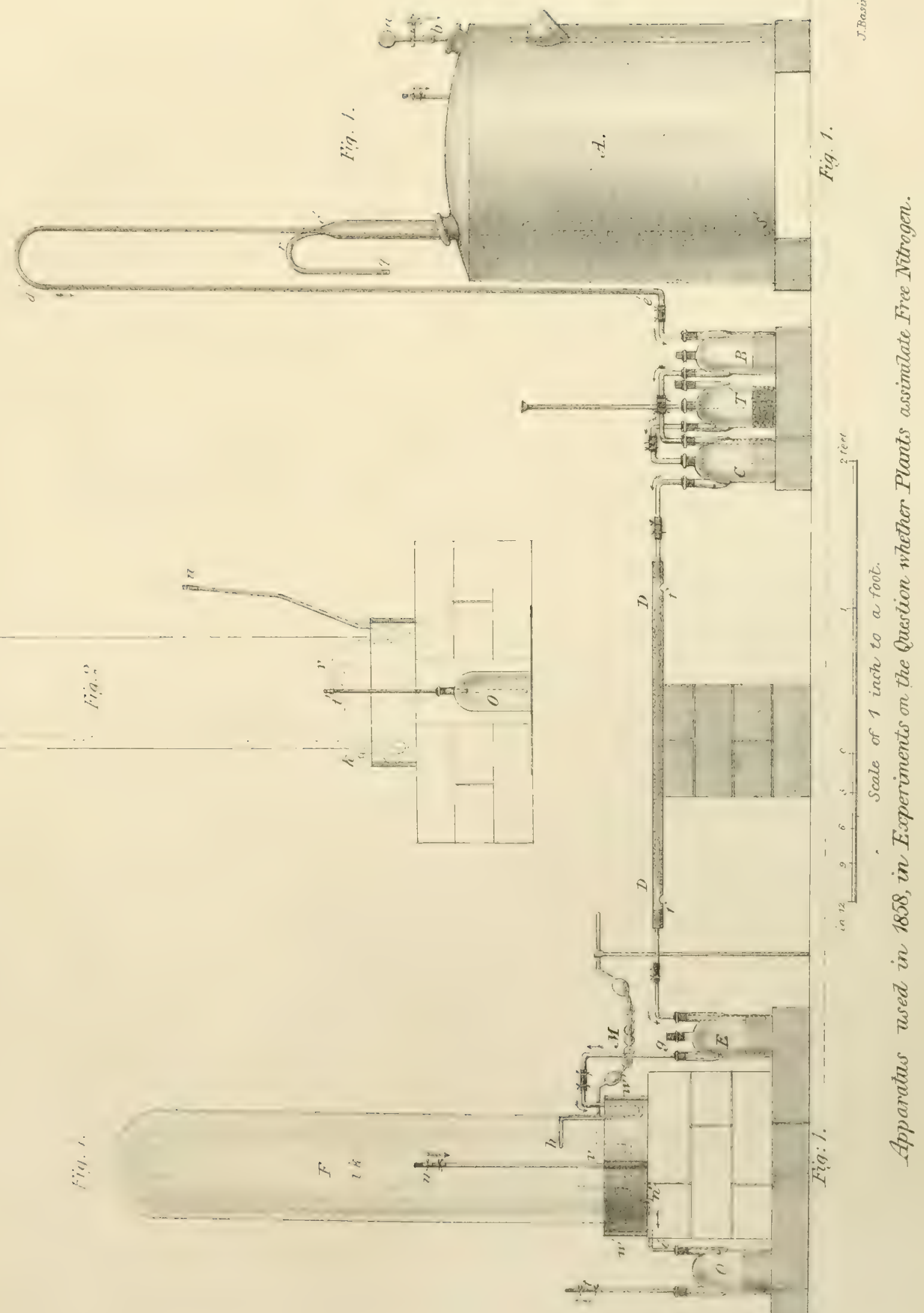





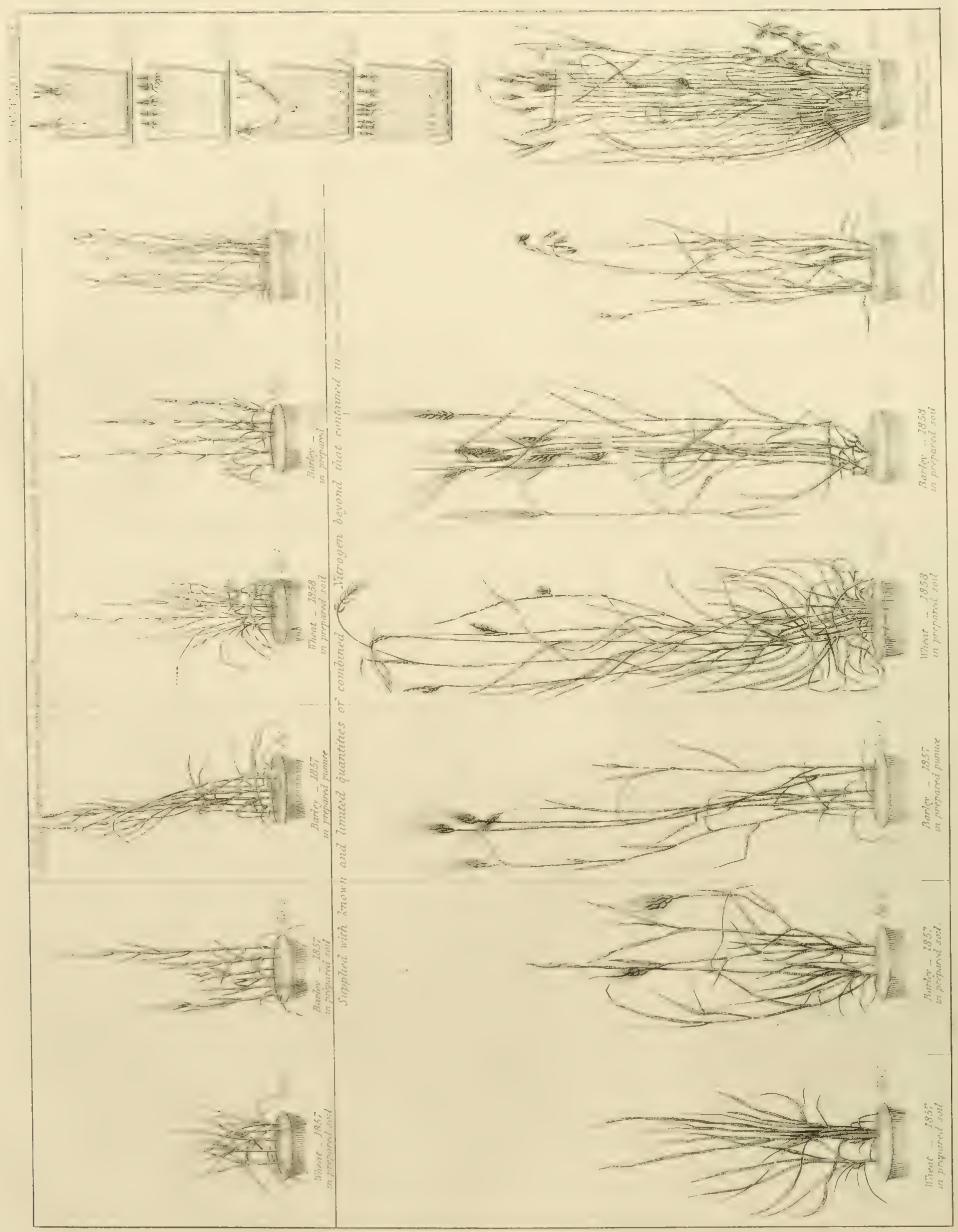








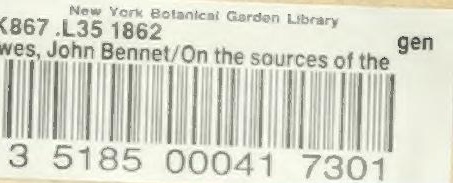


